\title{
MODULAR AND ARCHITECTURAL INNOVATION IN LOOSELY COUPLED NETWORKS
}

Matching customer requirements, product architecture, and supplier networks

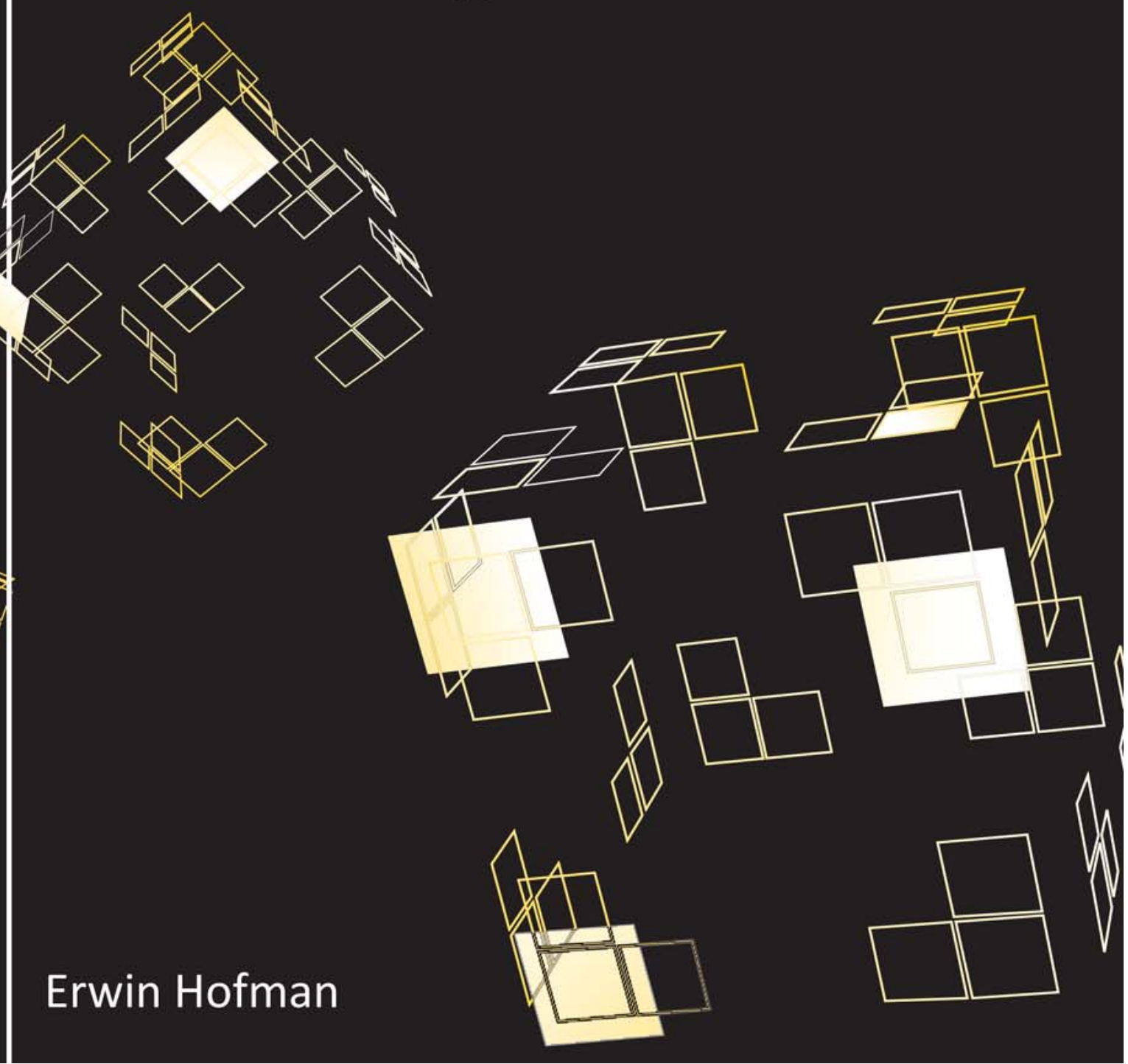




\section{MODULAR AND ARCHITECTURAL INNOVATION IN LOOSELY COUPLED NETWORKS}

Matching customer requirements, product architecture, and supplier networks

Erwin Hofman 


\section{Promotion committee}

Chair/secretary prof. dr. F. Eising

Promotor

prof. dr. ir. J.I.M. Halman

prof. dr. M. Song

Member dr. J.T. Voordijk

prof. dr. ir. P.C. de Weerd-Nederhof prof. dr. ir. J. Lichtenberg

prof. dr. H.J. Hultink
University of Twente

University of Twente

University of Twente and

Missouri - Kansas City

University of Twente

University of Twente

Eindhoven University of Technology

Delft University of Technology 


\section{MODULAR AND ARCHITECTURAL INNOVATION IN LOOSELY COUPLED NETWORKS}

Matching customer requirements, product architecture, and supplier networks

DISSERTATION

to obtain the doctor's degree

at the University of Twente, under the authority of

the rector magnificus, prof. dr. H. Brinksma,

on account of the decision of the graduation committee,

to be publicly defended

on Friday the $12^{\text {th }}$ of November 2010 at $15.00 \mathrm{hrs}$

by

Erwin Hofman

born on the $29^{\text {th }}$ of February 1980

in Utrecht, the Netherlands 


\section{This dissertation has been approved by:}

Prof. dr. ir. J.I.M. Halman Promotor

Prof. dr. M. Song Promotor

ISBN 978-90-365-3101-6

Copyright (c) 2010 by Erwin Hofman

All rights reserved. No part of this publication may be reproduced or transmitted in any form or by any means electronic or mechanical, including photocopying, recording, or by any information storage and retrieval system, without permission in writing from the author.

Printed by Gildeprint, Enschede, the Netherlands.

The work contained in this thesis has been conducted within the scope of PSIBouw. Financial support of PSIBouw is gratefully acknowledged 


\section{ACKNOWLEDGEMENT}

'Have you ever thought about becoming a PhD?' Joop Halman asked me by the time I was finishing my master thesis. Several people, including my brother, explained the joy this can bring, and not long after that I decided to seize the opportunity. Every PhD learns that to become one it requires curiosity, endurance, and the ability to focus. Curiosity seems to be the natural duality of focus; endurance is required in the process of balancing the influence of both requisites. In this, I would not have succeeded without the support of many people, some I would like to thank in particular. I appreciate the help of Joop Halman and Michael Song who challenged me to narrow down the great number of thoughts and variables I initially used to develop my (middle range) theories. This really helped me to focus my research. I would also like to thank all my colleagues from the departments of Construction Management and Engineering and the department of Operations Organization and Human Resources for their constructive feedback, the nice conferences (sometimes even at exotic places such as the Grand Bahama Island), and the many, sometimes hilarious discussions we had about research and much broader subjects as well. Of course, I would also like to thank all the people from my sounding board and the many companies I visited during my study. This helped me to study questions that were not only interesting from a theoretical perspective but also from a practical, business point of view. Besides my two supervisors, I am also grateful to the promotion committee for this dissertation; Hans Voordijk, Petra de Weerd-Nederhof, Erik Jan Hultink and Jos Lichtenberg, thank you very much for your fast feedback. Last but not least, I would like to thank my family, friends and my spouse, Francine Brink; thank you for the many small sacrifices you made that enabled me to pursue my PhD degree!

Enschede, November 12, 2010

Erwin Hofman 


\section{TABLE OF CONTENT}

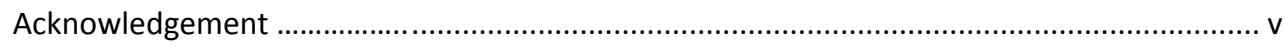

Chapter 1: General introduction

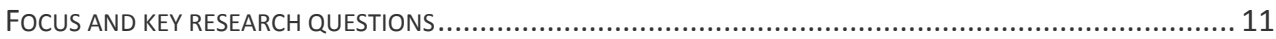

CHALLENGES FOR THE DEVELOPMENT OF MODULAR SYSTEMS IN LOOSE INNOVATION NETWORKS .................. 13

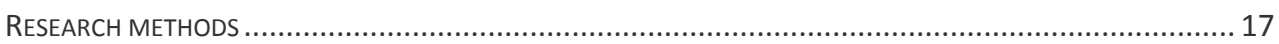

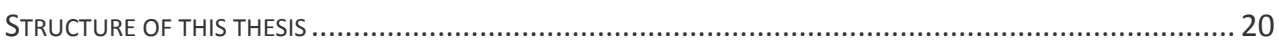

Chapter 2: Variation in housing design identifying customer preferences

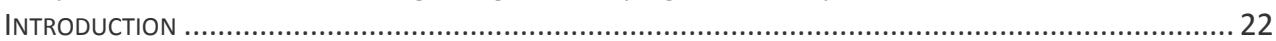

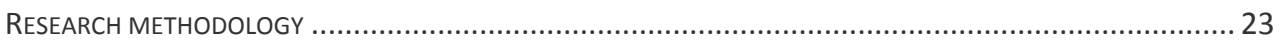

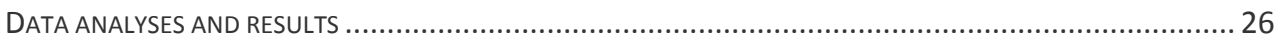

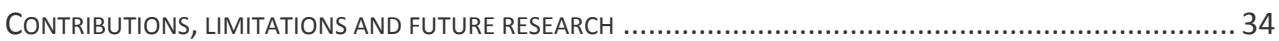

Chapter 3: Matching supply networks to a modular product architecture in the housebuilding industry

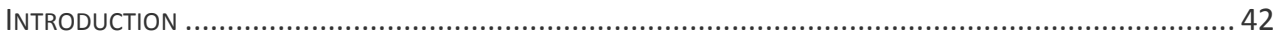

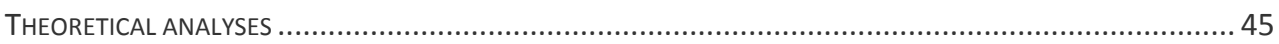

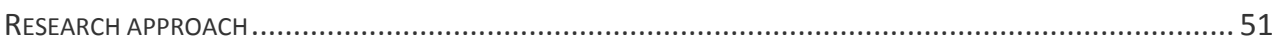

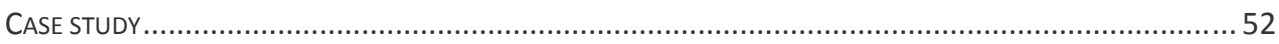

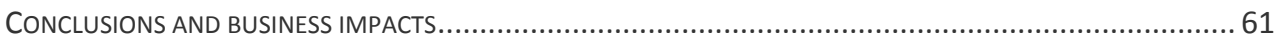

CHAPTER 4: ARCHITECTURAL INNOVATION IN LOOSELY COUPLED NETWORKS, HOW TO COMPENSATE FOR LOOSE COUPLING AND INERTIA.

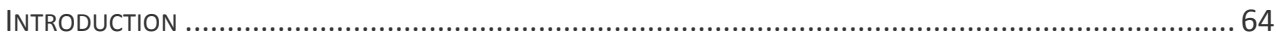

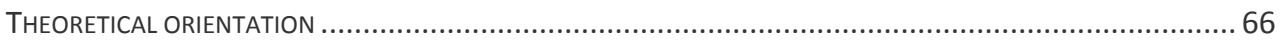

ARCHITECTURAL INNOVATION IN LOOSELY COUPLED NETWORKS: CONCEPTUAL BACKGROUND ........................ 70

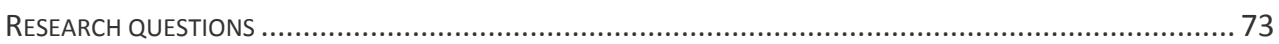

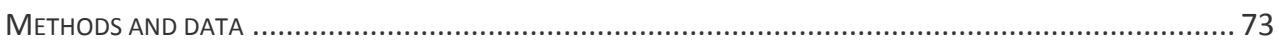

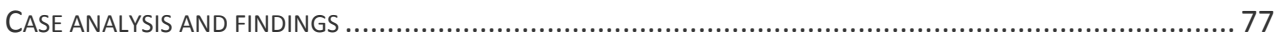

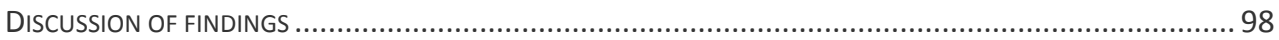

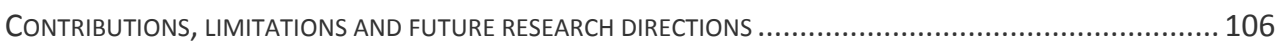

CHAPTER 5: THE STRENGTH OF LOOSELY COUPLED NETWORKS FOR INNOVATION? EMPIRICAL EVIDENCE

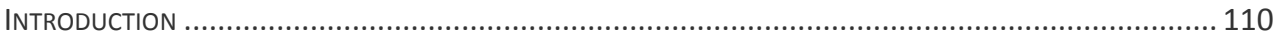

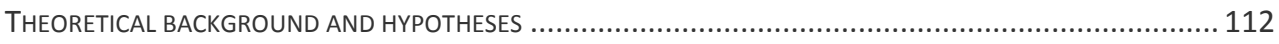

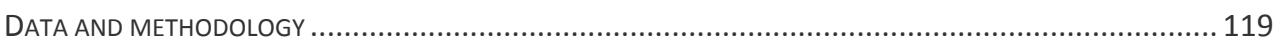

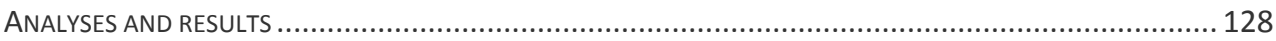

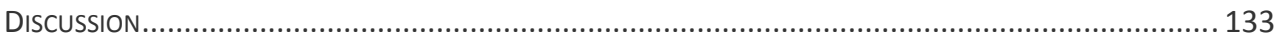

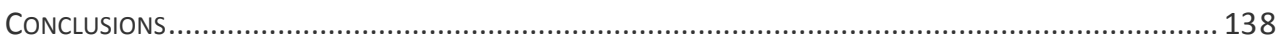


CHAPTER 6: PRODUCT DESIGN RULES, DO DESIGN RULES COMPENSATE OR COMPLICATE INNOVATION?

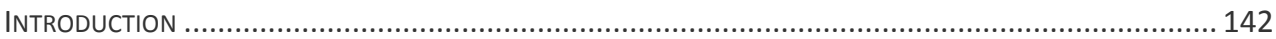

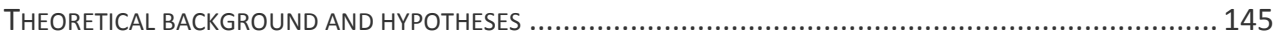

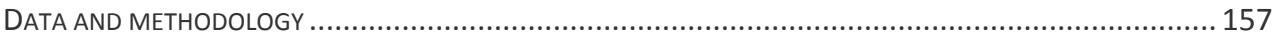

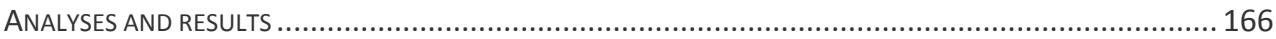

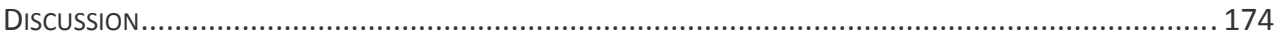

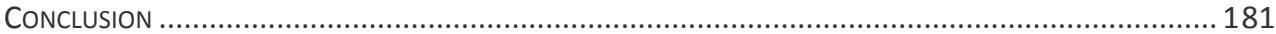

Chapter 7: General discussion, limitations and conclusion

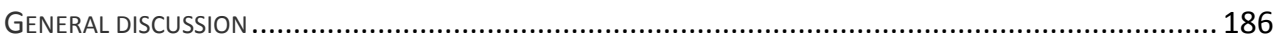

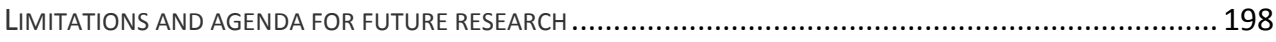

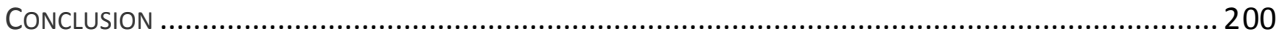

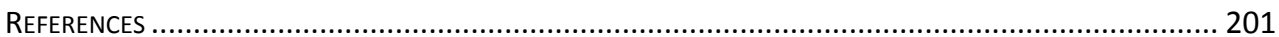

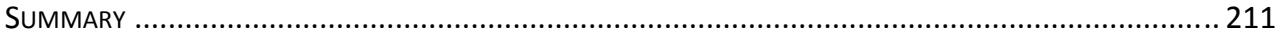

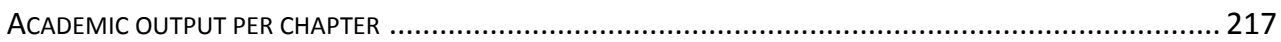

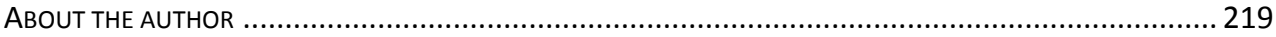




\section{CHAPTER 1}

\section{General introduction}

Today's competitive landscape is characterized by systemic technologies with shortening product life cycles due to rapid technological change and fast changing customer demands (Garud \& Kumaraswamy, 1995; Langlois \& Robertson, 1992). To cope with these dynamics, companies have become increasingly interested in modularizing their products, production processes, and organizational structures (Baldwin \& Clark, 2000; Salvador, Forza, \& Rungtusanatham, 2002; Schilling, 2000).

The concept of modularity is seen as a key success factor in many markets because it allows a family of differentiated products to be quickly developed and produced at a decreased cost (Ro, Liker, \& Fixson, 2007; Ulrich, 1995). Products composed of modules with standard interfaces allow producers to customize products at low cost and allow customers to reap the benefits of customized products at relatively low prices. Success stories of modular product platforms include for example Black \& Decker power tools (Meyer \& Utterback, 1993), Hewlett Packard's Deskjet printers (Meyer \& Lehnerd, 1997) and Microsoft's Windows (Schilling, 2000). But not only companies from high-tech manufacturing industries like the computer industry are challenged to more efficiently serve their dynamic markets. Also traditional industries like the house-building industry, that were supposed to be stable, are challenged to cross the chasm between what their loosely coupled, vertically specialized industry can produce and what the changing environment demands (Cacciatori \& Jacobides, 2005). 
However, relatively little attention has been paid to product modularization in an industrial context of loosely coupled business networks like the construction industry (Krishnan \& Ulrich, 2001; Sosa, Eppinger, \& Rowles, 2004; Staudenmayer et al., 2005). In a loosely coupled network, unlike in a tightly coupled, centralized business network, no single company has sufficient architectural knowledge about components and their interactions (Langlois \& Robertson, 1992; Sanchez \& Mahoney, 1996), or sufficient control, to take the lead in developing a full set of modular design rules. The result is that many construction companies struggle in developing and adopting modular housing systems.

This research contributes to both the field of management science as to the specific field of construction management. It starts with a focus on the Dutch house-building industry and the challenges construction companies face in their struggle to develop modern, modular methods of housing construction. Some of the challenges that are specific to the housebuilding industry are outlined in box 1 .

Calculations of the Ministry of Housing, Spatial Planning and the Environment (VROM) in 2002 indicated a shortage of 170,000 homes; this number approximates $2.5 \%$ of the total national housing stock. Governmental policy was focused on reducing this number in 2010 to $1.5 \%$. However, these goals have not been met. Still, the current annual production volume equals the annual population growth; therefore, to catch up, yearly housing production must increase (VROM, 2005).Governmental policy is not only focused on increasing production speed, enlarging the voice of the customer in house-building projects is the second objective. From 2005, one-third of all newly build homes had to be customer driven produced (Remkes \& Pronk, 2000). This corresponds to developments taking place internationally. The approach to take into account the customers' perspective and requirements concerning customization are relatively new to most building companies that have been used to mass-producing standard houses with little customer influence for many years.

Box 1.1: drivers towards modular house-building 


\section{FOCUS AND KEY RESEARCH QUESTIONS}

In their review of research in product development, Krishnan and Ulrich (2001) outlined the need to validate the relations between customer requirements - product architecture designs and product architecture designs - supply chain structure. Our research also builds around these three core variables: customer requirements, the product architecture, and the supply chain structure and we specifically focus on the relationships between these three variables.

The first critical relationship in product modularization that we study is that between customer requirements and the product architecture design. The modular systems theory proposes that heterogeneity in demand is a key driver towards the adoption of modular systems (Schilling, 2000). For developing modular systems, engineering design for variety methods require explicit knowledge about customer variety needs (Martin \& Ishii, 2002; Robertson \& Ulrich, 1998). However, although knowledge on customer needs forms primary input in the modular product development process, this knowledge is currently not available for most companies developing modular housing systems.

The second critical relationship in product modularization that we study is that between product architecture design and supply chain structure. Very little is known about the organizational design implications, both within the firm and across the supply chain, when companies move toward more modular product architecture (Ro et al., 2007). Some modularity studies focused on modularization of products and processes within the boundaries of a single firm (Baldwin \& Clark, 1997, 2000; Brusoni, Prencipe, \& Pavitt, 2001; Jacobides, 2005). Their main conclusion is, that once established, modular design rules often lead towards loosely coupled, specialized organizational forms. However, when modular product architectures get out of date, re-modularization is than to be organized in a loose innovation context. To date, no researcher has studied the relationship between architectural innovations and loosely coupled supplier networks. We depict these core relationships in our conceptual model shown in Figure 1.1. In this study we develop models to map (1) the relation between customer requirements and product architecture designs and; (2) the relation between product architecture design and supply chain structure. We contribute to the literature of construction management by developing and validating the 
indicated models within the specific setting of the house-building industry. In addition we test whether our findings can be generalized to other industries, including the computer and software industries, machinery and equipment industries; and household appliances industries.

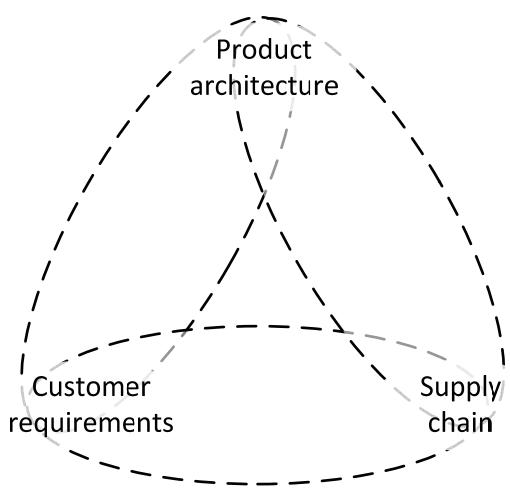

Figure 1.1. conceptual model

On a higher level of abstraction, the objective of this research is to enrich our understanding of architectural and modular innovation in loosely coupled innovation networks. The general research problem is formulated as:

How to create modular product design rules in the context of loosely coupled organizational networks?

Within this overall aim, this thesis focuses on a number of challenges for companies that are motivated by fast changing customer demands and quick technological turnover to develop modular, platform-based products. In answering this question, we address challenges related to the links between: customer variety needs and product modularization, and a company's ability to develop and exploit modular products and the configuration of their supply chain structure. More specifically this thesis focuses attention to five pressing issues within this research domain. The challenges are addressed in five chapters that form the cornerstones of this thesis. 


\section{Challenges for the DeVElopment OF MOdULAR SYSTEMS IN LOOSE INNOVATION NETWORKS}

This thesis is a bundle of five coherent chapters that each addresses a specific challenge related to the development of modular systems in loose innovation networks. Chapter 2 focuses on the voice of the customer in housing design and its link with product modularization. The link between a company's ability to develop and exploit modular products and the supply chain structure is elaborated on in Chapter 3. A case study on inertial factors that impede architectural innovation in loose innovation networks and on compensation mechanisms that can be used to overcome these obstacles is presented in Chapter 4 . The relationship between different innovation network configurations and the performance of modular and architectural innovations is discussed in Chapter 5 . The impact of modular product design rules on the performance of modular and architectural innovations in loose and tightly coupled innovation networks is discussed in Chapter 6 . The thesis concludes with a discussion of the key findings including the implications for management and theory and directions for future research. We will now clarify the research questions addressed in the successive chapters.

Chapter 2. How do potential new home buyers in the Netherlands prioritize the different elements in a house design from the perspective of obtaining a variety of alternative solutions from which to select? And. What is the willingness-to-pay extra for a customized housing proposition? The first topic is related to the identification of customer variety needs. Construction companies are being forced to respond to the growing individualization of demand. Previous studies have suggested that if companies want to meet customers' needs better than their competitors, they should offer a large variety of products (Dertouzos, 1989; Halman et al., 2003; Kahn, 1998; MacDuffie et al., 1996; Stalk \& Hout, 1990). From the modularity literature it follows that for parts with a great variety, several alternative solutions could be created in advance while parts with a low variety can be produced as standard solutions for all homes, thereby taking advantage of economies of scale. However, although people generally prefer to have the opportunity to select from options, they will be less inclined to do so if this option also means a considerable increase in price. Therefore, this study also examines the trade-off relationship between the value customers place on variety and the maximum price that can be asked for a customized housing proposition. The 
chapter concludes with implications of the study's findings for evaluating trade-off decisions between standardization and customization resulting in modular housing systems.

Chapter 3. What types of supplier relationships are needed to develop and produce a modular housing system successfully? The various buyer-supplier strategies available to manage suppliers are well known in manufacturing. Their applicability in the construction industry, however, is still less well-understood (Barlow et al., 2003; Barlow and Ozaki, 2003, 2005). Currently, opportunities to capitalize on economies of scale are often lost on individual projects. For developing and exploiting modular platform-based products and services in construction, arm's-length transactions could be replaced by relationships based on partnering and integrated working; approaches that stimulate cooperation, adaptation and joint development between buyers and suppliers (Dubois and Gadde, 2002; Storer et al 2003) (Axelrod, 1984). Although such relationships have been investigated in other industries, limited research has so far been conducted in the specific setting of the housebuilding industry that links development of new modules and components for modular houses to the selection and level of cooperation among potential suppliers.

Chapter 4. Why is architectural innovation difficult in loosely coupled innovation networks? And how do companies compensate for loose coupling and inertia? While previous research has examined the concept of architectural innovation by developing new and overturning old design rules, most of it has focused on the modularization of products or processes within the boundaries of a single company or within a tightly coupled, centralized business network (Baldwin \& Clark, 2000; Brusoni \& Prencipe, 2006; Langlois, 2002; Schilling, 2000). However, relatively little attention has been paid to architectural innovation in the increasingly common industrial context of 'loosely coupled' decentralized innovation networks (Krishnan \& Ulrich, 2001; Sosa et al., 2004; Staudenmayer et al., 2005). In a loosely coupled context like the construction industry, no single company has sufficient architectural knowledge about all modules and their interactions (Brusoni et al., 2001; Langlois \& Robertson, 1992; Sanchez \& Mahoney, 1996) nor sufficient control to take the lead as a systems architect and architecturally innovate since loose coupling erodes architectural control (Langlois and Robertson, 1992). Therefore this context imposes added complexity for companies trying to coordinate architectural innovations beyond the boundaries of their own organization (Langlois \& Robertson, 1992). 
Chapter 5. Do companies benefit more from tight organizational coupling for architectural innovation than they do for modular innovation? This study of collaborative innovation projects examines the impact of different innovation network configurations on innovation performance. Although the tradeoff between the potential benefits and drawbacks of loose and tight organizational couplings are discussed in the social network literature, their impact on the performance of modular and architectural innovations have not so far been studied. The existing empirical evidence shows that the more radical or systemic that innovations are, the more likely it is that companies select partners with whom they share tight organizational links (Hoetker, 2006; Li, Eden, Hitt, \& Ireland, 2008). However, social network theories present opposed predictions about the potential impact of different degrees of organizational coupling on innovation performance.

Chapter 6. Do product design rules compensate or complicate collaborative innovation? And, is this relationship contingent upon the type of innovation (i.e. modular or architectural innovation) and on the degree of organizational coupling among partners in the innovation network? Each collaborative innovation project is embedded in a unique innovation context that can be defined by the availability of product design rules and the degree of organizational coupling among the innovation network partners. However, ambiguity exists about how different innovation contexts influence collaborative innovation performance. The theoretical model developed and tested in this final chapter depicts the innovation network configuration as directly related to collaborative product innovation performance and shows that this relationship is contingent upon the availability of product design rules and the type of innovation. A new typology is developed that definitely answers our question.

The five challenges and related research questions that are addressed in this thesis are summarized in Table 1.1 
Table 1.1. Challenges addressed in this thesis and associated research questions

\begin{tabular}{|c|c|c|}
\hline Challenges & Research Questions & Chapter \\
\hline $\begin{array}{l}\text { In considering the implementation of product } \\
\text { variety, housing suppliers are challenged to } \\
\text { create this variety at acceptable cost. This } \\
\text { requires in-depth knowledge about how } \\
\text { potential new home buyers in the Netherlands } \\
\text { prioritize the different elements in a house } \\
\text { design from the perspective of obtaining a } \\
\text { variety of alternative solutions from which to } \\
\text { select. }\end{array}$ & $\begin{array}{l}\text { How do potential new home buyers in the } \\
\text { Netherlands prioritize the different elements in } \\
\text { a house design from the perspective of } \\
\text { obtaining a variety of alternative solutions } \\
\text { from which to select? And, what is the } \\
\text { willingness-to-pay extra for a customized } \\
\text { housing proposition? }\end{array}$ & 2 \\
\hline $\begin{array}{l}\text { Many companies experience difficulties in } \\
\text { developing and adopting modular housing } \\
\text { systems that allow them to produce customer } \\
\text { variety efficiently. The research goal is to } \\
\text { reveal how contractor-supplier relationships } \\
\text { are moderated by both demand and supply } \\
\text { aspects and may be established to develop and } \\
\text { produce industrial, modular houses } \\
\text { successfully. }\end{array}$ & $\begin{array}{l}\text { What types of supplier relationships are } \\
\text { needed to develop and produce a modular } \\
\text { housing system successfully? }\end{array}$ & 3 \\
\hline $\begin{array}{l}\text { Many problems and challenges facing } \\
\text { architectural innovation stem from } \\
\text { organizational loose coupling and inertia. } \\
\text { Companies would benefit from increased } \\
\text { insights in potential compensation } \\
\text { mechanisms to overcome these issues. }\end{array}$ & $\begin{array}{l}\text { How can companies compensate for } \\
\text { organizational loose coupling and inertia } \\
\text { during collaborative architectural innovation? }\end{array}$ & 4 \\
\hline $\begin{array}{l}\text { The available social network and innovation } \\
\text { theories present opposed predictions about } \\
\text { the impact of loose coupling on collaborative } \\
\text { innovation performance. }\end{array}$ & $\begin{array}{l}\text { Do companies benefit more from tight } \\
\text { organizational coupling for architectural } \\
\text { innovation than they do for modular } \\
\text { innovation? }\end{array}$ & 5 \\
\hline $\begin{array}{l}\text { Each innovation project is embedded in a } \\
\text { specific innovation context defined by the } \\
\text { availability of product design rules and the } \\
\text { degree of organizational coupling among } \\
\text { innovation partners. Ambiguity about the } \\
\text { interactions between innovation contexts and } \\
\text { the performance of modular and architectural } \\
\text { innovation complicates collaborative } \\
\text { innovation management. }\end{array}$ & $\begin{array}{l}\text { Do existing design rules compensate or } \\
\text { complicate collaborative innovation? And, is } \\
\text { this relationship contingent upon the type of } \\
\text { innovation (i.e. modular or architectural } \\
\text { innovation) and on the degree of } \\
\text { organizational coupling among partners in the } \\
\text { innovation network? }\end{array}$ & 6 \\
\hline
\end{tabular}




\section{RESEARCH METHODS}

This research is theoretical and empirical alike and combines qualitative and quantitative methods to obtain answers to the research questions. The method followed can best be described as triangulation (Jick, 1979). Using both case study and survey research methods helped in capturing a more complete portrayal of the phenomenon under study. However, triangulation was not only used to examine the same phenomenon from multiple perspectives and uncover shared variance to increase generalizability. Each method also uncovered unique variance and insights about the phenomenon that would not have been captured by relying on a single method (Jick, 1979). For example, qualitative case studies provided a rich and holistic understanding of why loose coupling among innovation partners adds complexity for companies trying to coordinate architectural innovations beyond the boundaries of their own organization (Langlois \& Robertson, 1992). Quantitative research methods are commonly used to contribute to greater confidence in the generalizability of results. Because we focused on interactions between this study's key constructs this has resulted in a richer and more fine-grained understanding of collaborative innovation contexts than is currently available in the literature. The typology that we developed using survey research provides support for a configuration perspective on collaborative product innovation. This theory could not have been developed without rigorous quantitative empirical testing (Doty, Glick, \& Huber, 1993). We will now give a brief overview of the research methods used per chapter.

Chapter 2. Because design customization can be seen as a complex decision-making situation, a vignette-based questionnaire was preferred to study the price-value trade off of different degrees of customization (Govers, 1993; Rossi \& Anderson, 1982; Wason et al., 2002). On a vignette, a situation, in our case a product proposition, is represented by some short descriptions. In this way vignettes approximate real-life decision-making situations and therefore they are superior to direct-question-based studies (Wason et al., 2002). In the questionnaire design process, the steps suggested by Govers (1993) were followed: identification of relevant characteristics, creation of vignettes and collection and statistical analysis of data. To determine the price-value trade-off in customized housing propositions we used regression analysis. 
Chapter 3. The goal of this study is firstly to illustrate how to modularize a housing design from a product architecture point of view and secondly to advance our understanding of the types of supplier relationships that are needed to successfully develop and produce a modular housing system. To this end we conducted an in-depth case study at a Dutch house building company that is developing an 'industrialized' modular housing system in collaboration with several specialized suppliers. The case studied was selected because initial interviews revealed sufficient variance in the degrees of supplier integration and prior research indicates that we could expect sufficient variance in the degrees of customer variety needs by including different building modules (Hofman, Halman, \& Ion, 2006). The study was conducted in two steps: the first step involved a literature study and, in the second part, qualitative case study findings were used to explore how different strategies for involving suppliers can be followed to develop and produce the various component families of a modular house. We use a full ego-network design (Marsden, 1990; Sobrero \& Roberts, 2001) to collect data on 10 dyadic contractor - supplier relationships to show that the degree of customer variety needs per product module, dependence on supplier knowledge, relation specific investments and intentions relating to learning or efficiency are important predictors of the degree of supplier integration.

Chapter 4. To better understand the implications of the loosely coupled business networks contexts for architectural innovation, an exploratory case study involving twentysix firms was conducted. A significant event such as our case, involving a major, identifiable attempt to shift toward increased product modularity, offered a natural experiment in which inertial forces and compensatory mechanisms could be examined in detail (Schilling and Steensma, 2001). Our research setting, concerning housing supply in the Netherlands, consisted of a network of firms linked to an architectural innovation in housing systems, named 'Mind Building'. These firms provided different value adding activities within the housing supply chain and included professional clients, general contractors, specialized trade subcontractors, architects, engineers, and suppliers of various building elements. All firms that were involved in this architectural innovation, as well as all the firms that decided not to join or to leave the development team, agreed to engage in this study. In addition to the interview data we examined secondary sources including industry reports, annual reports, the firms' websites, and technical documents including 17 patents that were publicly 
available through the European Patent Office. The study has an embedded design: companies that were involved in a large architectural innovation form our unit of analysis. The firms involved come from the Netherlands, Belgium, and Germany. Firm level analysis was used to draw conclusions related to the dynamics at the firm, as well as at the network level. The firms were treated as a series of experiments, each serving to confirm or reject the inferences drawn from the previous ones (Eisenhardt, 1989b; Yin, 1984). We developed 'formally stated observations', which would be the basis for our tentative propositions (Eisenhardt, 1989a; Glaser \& Strauss, 1967; Yin, 2003).

Chapter 5. This chapter examines two conflicting social network theories about the impact of loose and tight organizational coupling between innovation partners on collaborative innovation performance. We collected data related to collaborative product innovation networks in four different industries in the United States. Companies were selected from the construction industries, computer and software industries, machinery and equipment industries, and household appliances industries. In total, we received responses from 664 companies. Confirmatory factors analysis was used to assess the psychometric properties of our measures. To test our hypotheses, we used hierarchical moderated multiple regression analysis to verify the individual effects on collaborative innovation performance of loose coupling and the type of innovation, and determine any interaction effects.

Chapter 6. The theoretical model developed and tested in this final chapter depicts the innovation network configuration as directly related to collaborative product innovation performance and shows that this relationship is contingent upon the availability of product design rules and the type of innovation. Our study of social network theories (Burt, 1992; Coleman, 1988), theory of loosely coupled systems (Orton \& Weick, 1990) and modular systems theory (Baldwin \& Clark, 2000; Schilling, 2000) complemented our case study findings and helped in developing testable hypotheses. The study uses data collected on 664 different collaborative product innovation networks in four different industries in the United States. Confirmatory factors analysis was used to assess the psychometric properties of our measures. To test our hypotheses, we used hierarchical moderated multiple regression analysis to verify the individual effects on collaborative innovation performance of loose coupling and the type of innovation, and determine up to three-way interaction effects. The 
results challenge the conventional wisdom and are used to develop a new typology of innovation contexts. We also provide suggestions for future research on collaborative innovation.

Finally, to improve understanding of our empirical findings, during the PhD research we presented the research findings to a sounding board that included representatives of eight companies from the house-building industry.

\section{STRUCTURE OF THIS THESIS}

In the next five chapters we elaborate on each of the five challenges posited in this chapter. Next we discuss the key findings per chapter including the implications for management and theory. We conclude with some general limitations and the implications of our research for directions for future research. 


\section{Chapter 2}

\section{Variation in housing design, identifying customer preferences ${ }^{1}$}

House builders in different countries are exploring ways to deliver higher levels of customization in housing design. To create such variety at acceptable cost, it is important to know how potential buyers of new houses prioritize the different elements such as bathroom, kitchen and roof type of a house design. For parts with a great variety, several alternative solutions could be created in advance while parts with a low variety can be produced as standard solutions for all homes, thereby taking advantage of economies of scale. This paper presents the findings of a vignette-based survey about the requirements for customization among potential buyers of new houses in the Netherlands. Based on the survey, a list of priority housing attributes is derived. This priority listing is of great importance for building developers who offer (or are considering offering) customized housing. Although people generally prefer to have the opportunity to select from options, they will be less inclined to do so if this option also means a considerable increase in price. Therefore, this study also examines the trade-off relationship between the value customers place on variety and the maximum price that can be asked for a customized housing proposition. The paper concludes with implications of the study's findings for evaluating trade-off decisions between standardization and customization.

\footnotetext{
${ }^{1}$ Published as: Hofman, E., Halman, J. I. M., \& Ion, R. A. 2006. Variation in housing design: Identifying customer preferences. Housing Studies, 21: 929-943.
} 


\section{INTRODUCTION}

Companies are being forced to respond to the growing individualization of demand. Previous studies have suggested that if companies want to meet customers' needs better than their competitors, they should offer a large variety of products (Dertouzos, Lester, \& Solow, 1989; Halman, Hofer, \& van Vuuren, 2003; Kahn, 1998; MacDuffie, Sethuraman, \& Fisher, 1996). More variety will make it more likely that customers find exactly the options they prefer. In considering the implementation of product variety, companies are also challenged to create this variety at acceptable cost. For elements with a great variety, several alternative solutions could be created in advance. Potential buyers will successively choose the elements that best fit their own requirements. However, elements with a low need for variety can still be produced as standard solutions for all homes, thereby retaining economies of scale. Thus, making enterprises more customer-centric has become a priority in most industries (Tseng \& Piller, 2003).

In the housing industry there is an increasing customer demand for variety. Recent research about construction firms in countries such as Japan (Barlow et al., 2003a; Gann, 1996; Noguchi, 2003), the USA (Kendall \& Teicher, 2000), Great Britain (Ball, 1999; Ozaki, 2003) and the Netherlands (Van den Thillart, 2004) shows that several firms are exploring ways of delivering higher levels of customization in housing design. The aim is to keep the price at an acceptable level without losing the advantages of serial, project-based production (Wolters, 2001). To produce this required variety at acceptable cost, it is important to know how customers prioritize the different elements such as bathroom, kitchen and roof type of a house design. However, there is still a lack of knowledge when it comes to the way in which house buyers make choices and what customer priorities are in a mass customization environment (Dellaert, 2005). More specifically, while interest in mass customized housing solutions has become more widespread (e.g. Barlow, 1999; Barlow et al., 2003; Noguchi, 2003), the prioritization of housing attributes in house design customization still remains unknown by house builders. Therefore, this study focuses on investigating how potential new home buyers in the Netherlands prioritize the different elements in a house design from the perspective of obtaining a variety of alternative solutions from which to select. 
The structure of the rest of this paper is as follows. The research methodology section explains the successive steps that have been followed in conducting a vignette-based survey among potential new home buyers in the Netherlands. This is followed by an analysis of the vignettes using Saaty's clustering method (1982). In addition to the vignettes, respondents also had to prioritize 35 housing attributes in terms of the level of importance in achieving customized solutions. In the data analysis section the housing attributes are presented and sorted according to the relative importance of expressed customization needs. This section also presents the relationship that has been found between the price offered for specific housing propositions and on the degree to which they are valued by potential buyers of new houses. The final section elaborates on the contributions and limitations of this research and suggests future directions for research.

\section{RESEARCH METHODOLOGY}

This study is based on empirical evidence drawn from a mail survey conducted in the Netherlands. A preliminary phase was spent defining the research objectives, conducting a literature review as well as interviewing experts in the field of mass customized house building. After analyzing current developments in mass customization in house building, the current research focused on exploring customers' priorities for variety needs in housing design. The literature on Open Building revealed five levels of intervention. These levels cover both urban and housing design dimensions (Habraken \& Teicher, 1998; Kendall \& Teicher, 2000). Comparison of option lists offered by several housing developers showed that, in total, variation was offered in 35 housing attributes. Based on the literature review, the field research and discussion with experts, five dimensions of housing attributes were derived. These are the dimensions customers have in mind when they think of variation in housing design. These dimensions are: (1) technical systems; (2) interior finish; (3) floor plan; (4) house volume and exterior; and (5) environment. These dimensions and the 35 attributes were used for structuring the draft version of our questionnaire. 


\section{Questionnaire design}

Sometimes it is straightforward to measure priority judgments about a product or service. One can just ask the interviewee to select between two quality criteria. However, in complex decision-making situations in which multiple options are to be evaluated by customers, a vignette-based questionnaire is preferred (Govers, 1993; Rossi \& Nock, 1982; Wason, Polonsky, \& Hyman, 2002). On a vignette, a personal or social situation is represented by some short descriptions. The descriptions comprehend the most important factors in the priority decision-making process and each description contains a well-defined stimulus component. Vignette-based studies are superior to direct-question-based studies because vignettes better approximate real-life decision-making situations (Wason et al., 2002). In the questionnaire design process, the steps suggested by Govers (1993) were followed: identification of relevant characteristics, creation of vignettes and collection and analyses of data. In the present study, the relevant characteristics consist of the five dimensions of housing attributes as pointed out earlier. Choice alternatives at each of these dimensions increase customer value to some extent. The purpose of this study has been to elicit the relative weights of these choice alternatives. Vignettes are used to describe hypothetical housing propositions. These propositions are represented by the five dimensions of housing attributes. Potential buyers of new houses had to score several vignettes with respect to the level they valued this proposition. Table 2.1 outlines the dimensions of housing attributes and the values linked with these dimensions (stimuli).

Table 2.1. Description of vignette characteristics

\begin{tabular}{ll}
\hline Dimension of housing attributes & Value \\
\hline$A$ Technical systems & 1 Choice \\
& 2 No choice \\
$B$ Interior finish & 1 Choice \\
& 2 No choice \\
& 1 Choice \\
& 2 No choice \\
$D$ House volume \& exterior & 1 Choice \\
& 2 No choice \\
$E$ Environment & 1 Choice \\
& 2 No choice \\
\hline
\end{tabular}


The respondents also had to score each hypothetical situation under different price conditions. This ensures that the price constraint is built into the choice experiment. A six point semi-labeled rating scale was used for scoring the criteria (see Appendix 1); this is a socalled forced-choice response scale. Such a scale forces the respondents to decide whether they lean more towards the 'very good' or 'very poor' end of the scale for each vignette. Figure 2.1 presents an example of a first-order vignette. A first-order vignette defines one negative statement and four positive statements. A second-order vignette defines two negative statements and three positive statements, and so on. The number of vignettes to be evaluated by respondents is limited by a respondent's time and concentration. Therefore, it was decided to present to each respondent random sets of 10 vignettes. Respondents evaluated a total of 15 vignettes. In addition to the vignettes, 35 attributes were included in the questionnaire. These attributes are related to the five dimensions of housing attributes. For each attribute, respondents were asked to score the relative importance to be involved in the housing design process.

Vignette no. 1: Imagine the following housing proposition:

Participation in designing your future home demands a lot of time, money and effort from the customer as well as from the professionals such as the housing developer, architect and the construction company. Therefore: the more variation is demanded, the higher the costs in general will become. A standard home is a home that's offered without any variation.

+ You will have a say about technical systems (such as the type of heating (wall or floor) and the number and location of the sockets, switches and water taps).

- You will have no say about the interior finish (such as the type of kitchen, washbasins and toilet, the floor - and wall finish and the door hardware (locks and latches).

- You will have no say about the floor plan (such as position and size of the living-, bed- and toilet rooms, kitchen and doorways).

- You will have no say about the volume of the home and the exterior finish (such as the size of the home, the type of roofing and the façade design).

- You will have no say about the environment (such as plot layout, parking lots and pavement of the neighbourhood).

$1=\mid$ evaluate this housing proposition as very good, $6=\mid$ evaluate this housing proposition as very poor

Figure 2.1. Example of a first-order vignette 


\section{Data collection}

After constructing the questionnaire a pilot was tested within a group of four experts and 10 non-experts. The group evaluated each question for clarity, specificity and representativeness. After small improvements, the questionnaire was made ready to be sent out. The sampling frame consisted of 304 potential buyers of new houses. Their addresses were obtained with the help of a large Dutch real estate office. First, a letter was sent to all 304 potential customers. The letter explained the purpose of the research, and the respondent was notified about a confirmation call a week later, to ask whether or not the respondent was willing to participate. Second, phone calls were made to each potential respondent. About 110 customers were reached, giving opportunities to clarify the purpose of the research. They were also informed that the survey would be anonymous; 86 agreed to participate while 24 refused. The sampling frame consisted of 304 potential buyers of new houses minus the 24 persons who refused to participate. This resulted in 82 respondents, giving a return rate of 27 per cent, which is about average for a postal survey.

The sample population represents the group of potential buyers of new single-family homes in the province of Utrecht in the Netherlands. Buyers of other types of home, such as apartments, were not included within the sample population. To test the research for nonresponse biases, 20 non-respondents were interviewed briefly. The 'interest hypothesis' (Armstrong \& Overton, 1977), involves the assumption that respondents who are less interested in the subject of the questionnaire, variation in housing design, are also less willing to participate. If so, the survey results would be biased. However, none of the 20 nonrespondents indicated disinterest as a cause for non-participating. Therefore, no significant consequences of non-response were assumed for the survey estimates. The survey results approximate the true population's mean with a confidence level of 0.95 and a confidence interval of 0.1 .

\section{DATA ANALYSES AND RESULTS}

After data collection, three types of data analysis were performed. First, for the five dimensions of housing attributes it was determined how customers prioritize these dimensions in terms of influencing the design decision-making process. The relative weights 
were calculated by using Saaty's clustering method (Saaty \& Vargas, 1982) for the respective vignettes. In a next step, the relative importance of expressed customization needs for the 35 housing attributes were determined that were included in this study. Finally, a regression analysis was performed to determine the trade-off between the potential price that can be asked for specific customized housing propositions and their effect on the way in which potential buyers evaluate or re-evaluate such propositions.

\section{Allocation of weights}

To calculate the relative weights assigned by customers to the five dimensions of housing attributes, as explained earlier, Saaty's clustering method was applied (Saaty \& Vargas, 1982). Clustering is a way to improve the consistency of estimates where respondents have to evaluate many or complex options. In addition, clustering can dramatically decrease the number of estimations needed. The following procedure was followed (see also Table2.2):

- $\quad \mathrm{i}=\mathrm{a}, \mathrm{b} . . . e$, this is the first-order vignette with a variance of attribute $\mathrm{i}$;

- $\quad \mathrm{ij}=($ a..e $)($ a..e) this is the second-order vignette with a variance of attributes $\mathrm{i}$ and $\mathrm{j}$;

- In Table 2.2 the varied attributes are indicated by a + sign.

Step 0: The mean score of the first order vignettes $S_{i}$ and second order vignettes $S_{i j}$ are derived from the individual customer scores.

Step 1: The normalized mean score $S_{i}$ and $S_{i j}$ is calculated by $S_{i} /\left(\sum S_{i}+\sum S_{i j}\right)$ and $S_{i j} /\left(\sum S_{i}+\sum S_{i j}\right)$. The normalized scores are denoted by respectively $\hat{S}_{i}$ and $\hat{S}_{i j}$.

Step 2: The normalized attribute-scores $\hat{S}_{i}$ are multiplied by the matching normalized attribute-scores $\hat{S}_{i j}$ for the scores with corresponding $i=a, b, . ., e$.

Step 3: The weights $w_{i}$ are calculated by $w_{i}=\sum_{j=a}^{e} \hat{S}_{i} \hat{S}_{i j} / n$ for $i=a, b, . ., e$. The final priority vector $w$ is calculated by normalization of $w_{i}: w=w_{i} / \sum_{i=1}^{n} w_{i}$ 


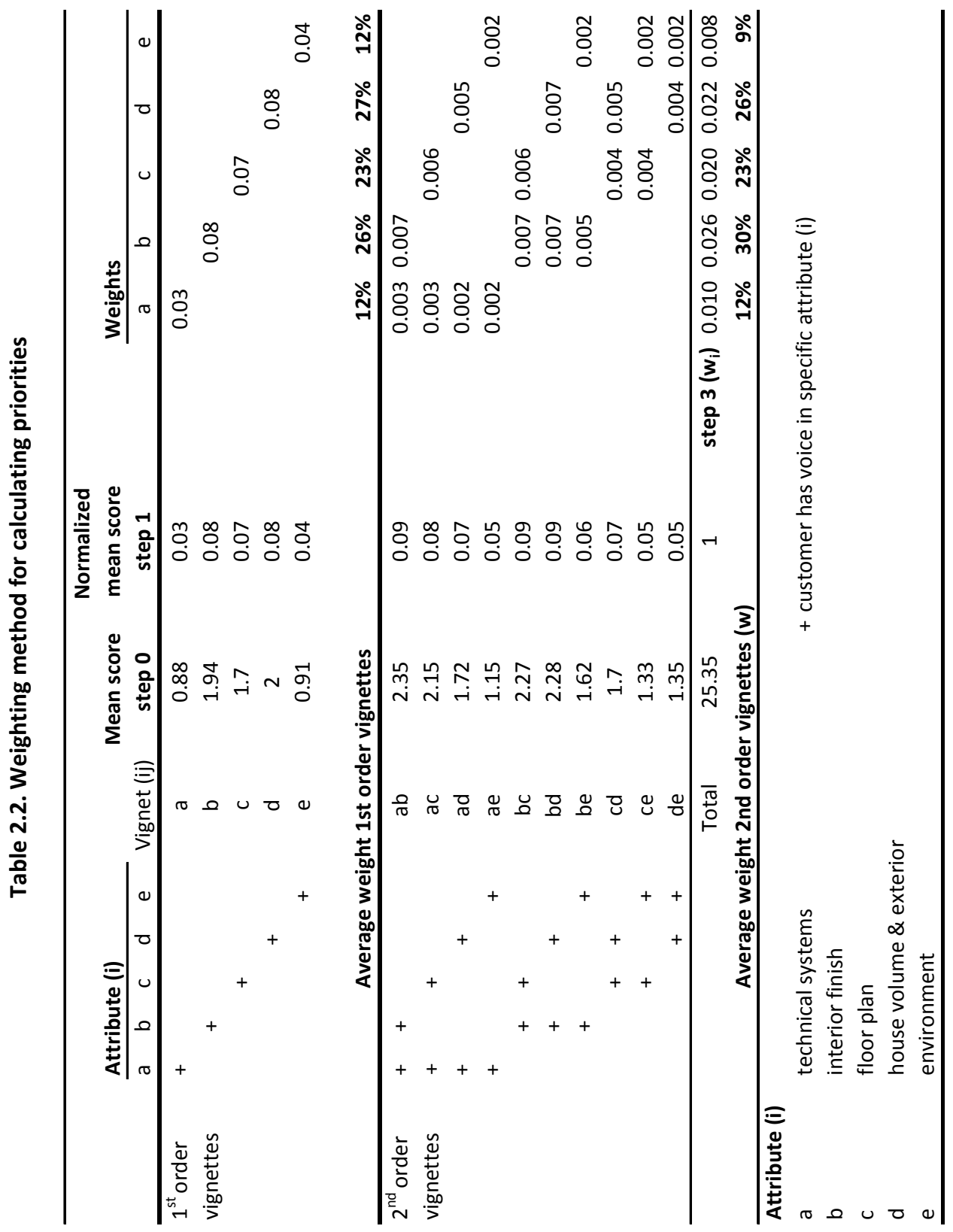




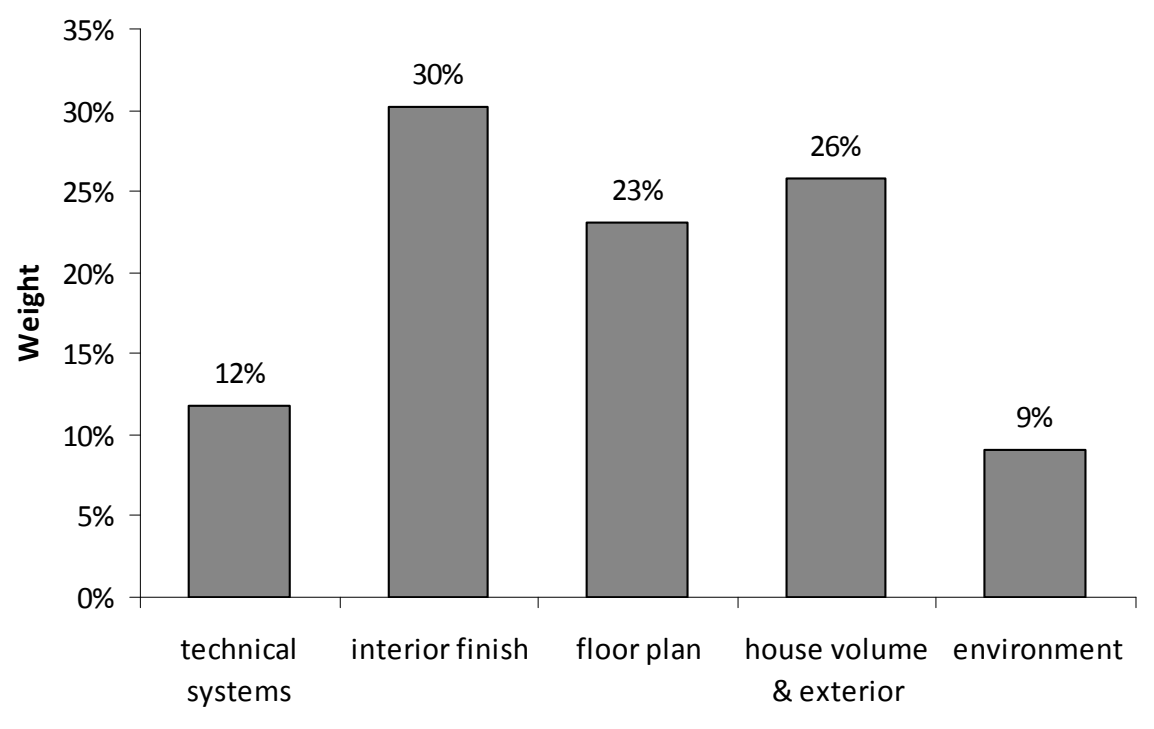

Dimension of housing attributes

Figure 2.2. Customer priorities in dimensions of housing attributes

The customers' weights from Table 2.2 are shown in Figure 2.2. As can be seen in this Figure, customers evaluate the interior finish as the most important dimension of housing attributes; it has a weight of 30 per cent. The floor plan and the volume \& exterior of the home have weights of 23 per cent and 26 per cent respectively. The direct environment of the home and technical systems are regarded as the least important dimensions with weights of respectively 9 per cent and 12 per cent. The homogeneity of the dimensions has been measured using Cronbach's alpha (0.79). Cronbach's alpha is sufficient to confirm the five dimensions of housing attributes as a subscale of the dimensions customers have in mind when they think of variation in housing design.

\section{Relative importance of housing attributes}

A characteristic of a hierarchy is that it consists of levels. The five dimensions of housing attributes together form the highest hierarchy in this study. These dimensions were further broken down into 35 housing attributes. As well as evaluating the proposed vignettes, 
respondents were also asked to score the relative importance of each housing attribute on their value of offering a customized solution. Figure 2.3 shows the 35 attributes, sorted according to the relative importance expressed by potential buyers of new homes for achieving customized solutions. The attributes with the highest relative importance appear to be part of the interior finish dimension of housing attributes while the five least important attributes except for the roof finish attribute, belong to the environment dimension.

\section{Trade-off between price and perceived value of a customized solution.}

Respondents were also asked to score each hypothetical housing proposition under different price conditions. The prices ranged from $€ 0-40000$. This made it possible to estimate the trade-off between the price asked for a housing proposition and the perceived added value to the potential buyer. Figure 2.4 illustrates this price-value elasticity for the five identified dimensions of housing attributes. The curves in Figure 2.4 were determined by interpolation of the data. Using regression analysis, it was found that the relevant equations (see Table 2.3) all show great resemblance. Therefore, it is assumed that the perceived trade-off between price and customer-value is similar for the dimensions of interior finish, floor plan and house volume and exterior. The technical systems and environment levels also have comparable equations. The $R^{2}$ ranges from 0.34 to 0.59 , so price explains a considerable part of the total variance. The remaining variance is caused by, for example, heterogeneity of customer needs. To further study this relationship, analysis of variance or a conjoint type of research should be performed. 
Relative importance

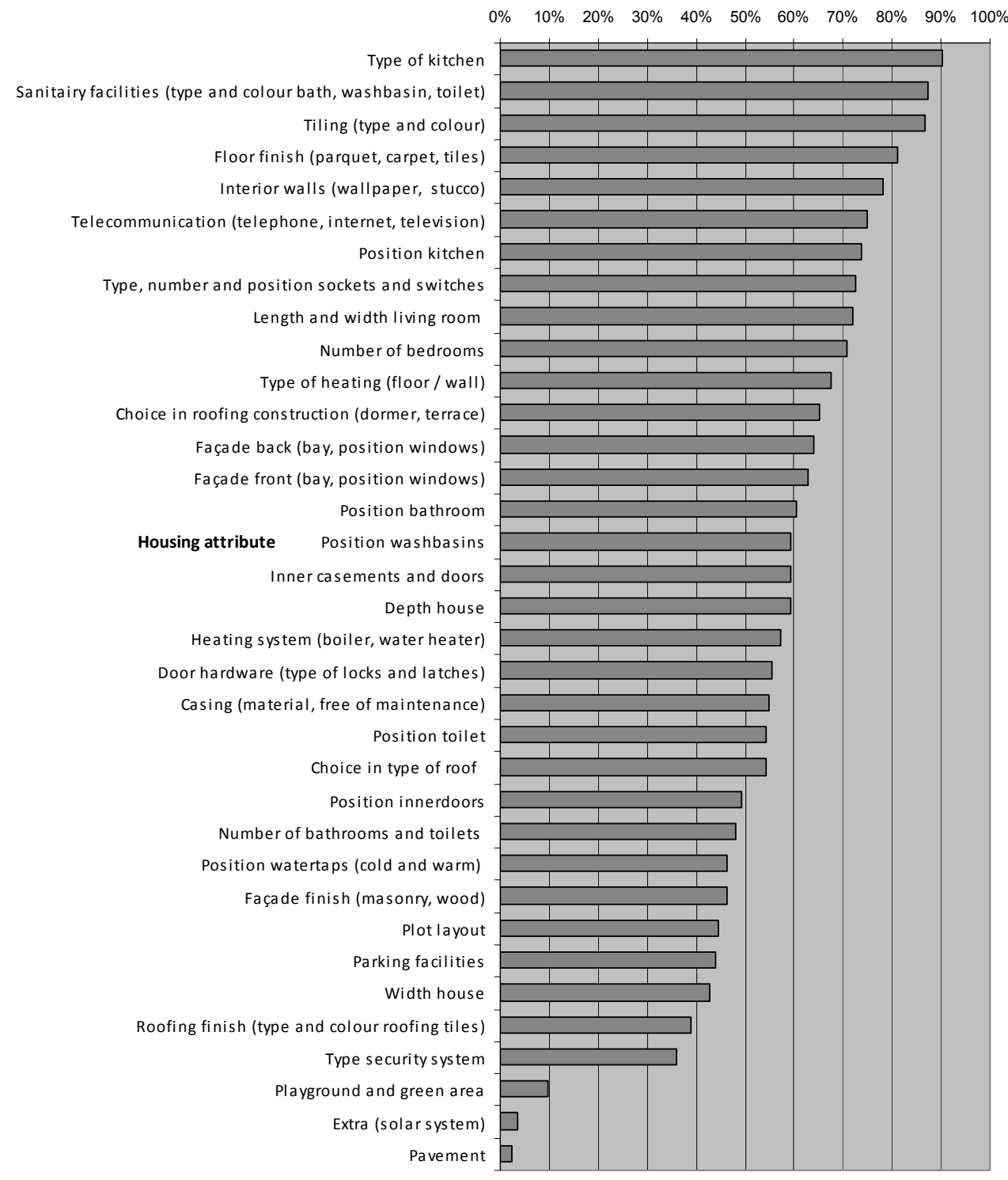

Figure 2.3. Housing attributes: relative importance for potential buyers 


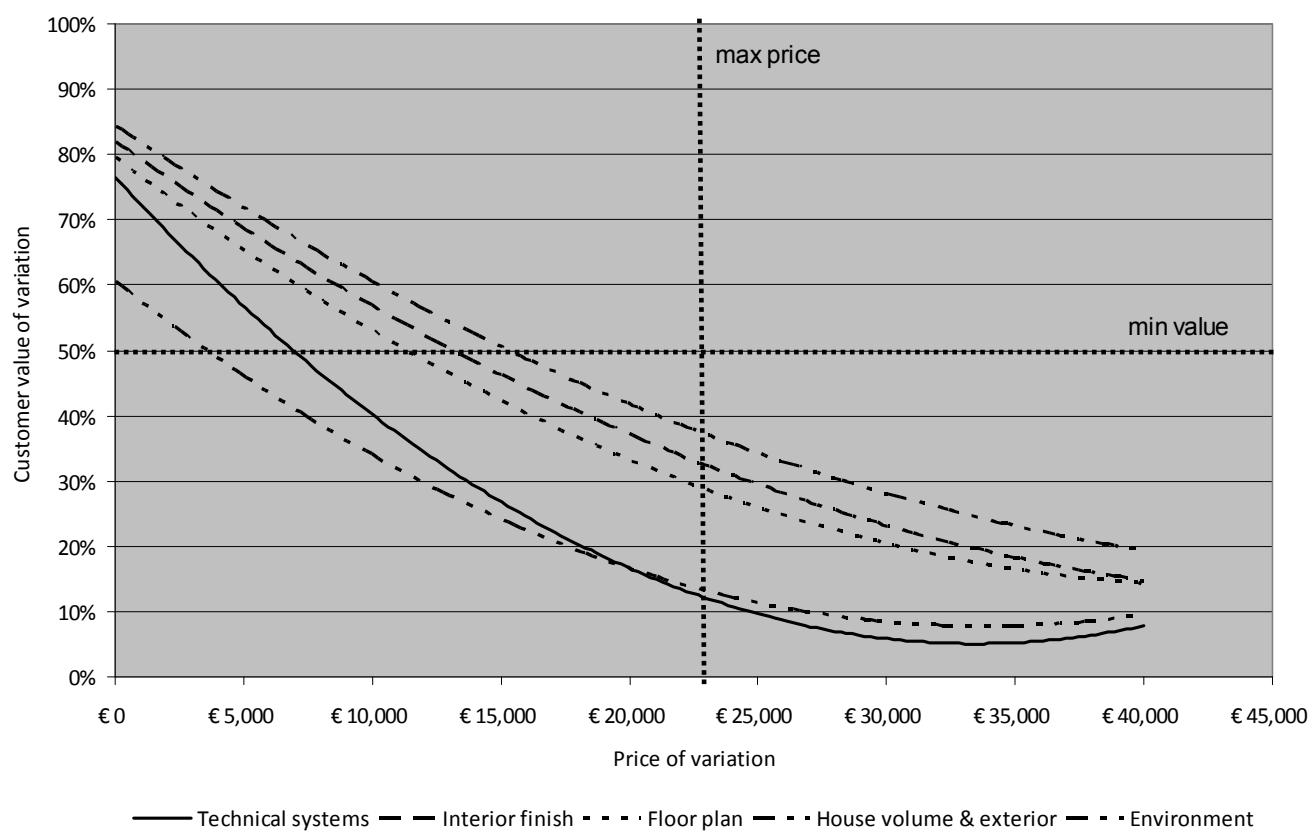

Figure 2.4. A price-value trade-off in customized housing propositions

The questionnaire also asked for the maximum amount of money a customer was willing to pay for the housing proposition that would best fit his or her needs. The one-way ANOVA technique was employed to determine the significance of group differences for this maximum amount. This analysis was applied for the categories: $€ 100$ 000-199 000; $€ 200$ 000-299 000; $€ 300$ 000-399 000; and $€ 400$ 000-500 000. Figure 2.5 shows that for the distinguished categories the willingness to pay extra approximates to 10 per cent of the preferred maximum house price. The results show that, on average, a customer is willing to pay $€ 23333$ extra for the 'perfect package' compared to a house in which no variation is offered. This amount is represented by the vertical axis in Figure 2.4. Customers also indicated on a six-point scale their perceived value of each of the hypothetical housing propositions. In Figure 2.4, the points of intersection between the price-value curves of the respective housing propositions and the minimum value limit of 50 per cent indicate the maximum price for which each proposition remains acceptable in terms of price. The difference between a package price and the maximum sum a customer is willing to pay for 
his or her 'perfect package' forms the sales opportunity for the supplier. The supplier can add priced options to the package up to the maximum price that the customer is willing to pay.

Table 2.3. Regression model of price-customer value trade-off

\begin{tabular}{lll}
\hline Dimension of housing attribute & Equation trend lines & $R$-squared \\
\hline Technical systems & $\mathrm{y}=6 \mathrm{E}-10 \times 2-4 \mathrm{E}-05 \mathrm{x}+0,7654$ & $R^{2}=0.58$ \\
Interior finish & $\mathrm{y}=3 \mathrm{E}-10 \times 2-3 \mathrm{E}-05 \mathrm{x}+0,8199$ & $R^{2}=0.43$ \\
Floor plan & $\mathrm{y}=3 \mathrm{E}-10 \times 2-3 \mathrm{E}-05 \mathrm{x}+0,7951$ & $R^{2}=0.39$ \\
House volume and exterior & $\mathrm{y}=3 \mathrm{E}-10 \times 2-3 \mathrm{E}-05 \mathrm{x}+0,8438$ & $R^{2}=0.39$ \\
Environment & $\mathrm{y}=5 \mathrm{E}-10 \times 2-3 \mathrm{E}-05 \mathrm{x}+0,6054$ & $R^{2}=0.34$ \\
\hline
\end{tabular}

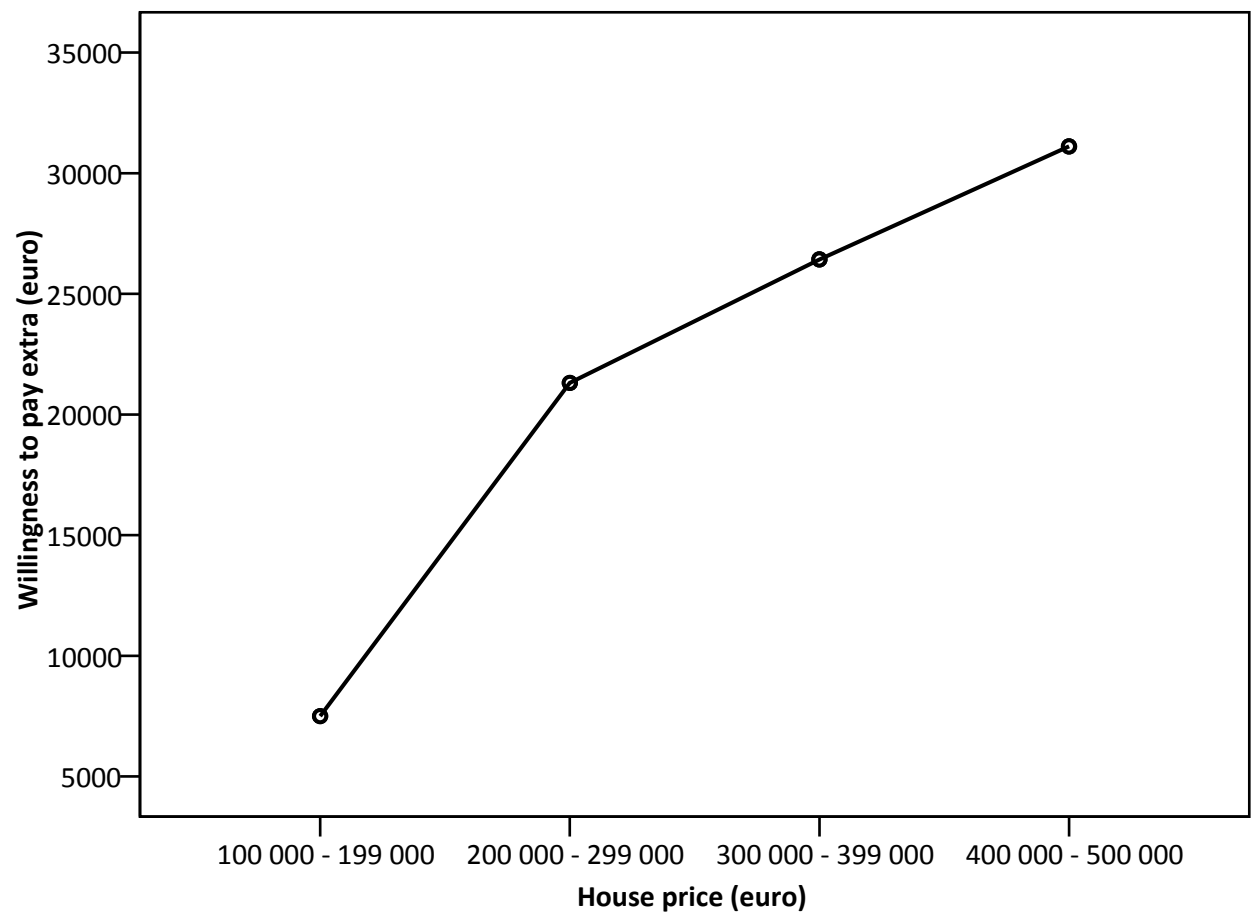

Figure 2.5. Willingness to pay extra for housing propositions 


\section{CONTRIBUTIONS, LIMITATIONS AND FUTURE RESEARCH}

The objective of this study has been to explore how potential new home buyers prioritize the different parts and elements in a house design from the perspective of achieving a customized versus a standard solution. Based on the findings of this study, the contributions and limitations of this study will be discussed and some directions for future research will be suggested.

One main outcome of this study is the priority listing of housing attributes as shown in Figure 2.3. This priority listing is of great importance for all building companies who offer or are considering offering customized housing. Building developers may see from this listing what potential buyers regard as being the most important housing attributes within customized solutions. This priority listing will help building developers in their decision making about the right balance between the variety (such as different types of bathrooms, kitchens and roof types) to be offered versus the need to standardize and produce at acceptable cost.

Using the example of Japan's factory-based housing industry, Barlow et al. (2003) argue that the trade-off decision between the levels of standardization versus customization also implies the use of different supply-chain models. This argument is supported by research conducted by Novak \& Eppinger (2001) in which they claim that sourcing decisions require careful evaluation of the trade-offs between product architecture differentiation and vertical integration. Recently, methods have been developed for evaluating trade-off decisions between standardization and customization (Martin \& Ishii, 2002). The derived priority listing can be considered as a fundamental input for applying these methods in the case of customized housing in the Netherlands.

The outcome of this study was presented to the largest housing developer in the Netherlands. The corporate new product development unit decided to use the priority listing to evaluate the options offered in its existing line of housing projects. The assessment showed that, for several higher prioritized attributes, no variation was offered and for lower prioritized attributes it was. The company decided to adapt its future offerings of variation according to the outcome of this study. 
Although people in general prefer to have the opportunity to select from options, they will be less interested if such options also mean an increased price. A second principal contribution of this study has been the discovery of the trade-off relationships between customer value and the price of the distinguished dimensions of housing attributes. The difference between perceived customer value and price could be used as a measure of the incentive for the customer to buy. To outperform competitors, it is proposed that house builders follow a strategy of maximizing this difference. Based on this research, also some limitations are determined. First, this study was conducted in the Netherlands. One might question to what extent the results will also be applicable in other countries. Repeating this research outside the Netherlands would reveal to what extent potential buyers of new houses in other countries differ in prioritizing attributes in house design. A second limitation in the research concerns a lack of insight into the perceived customer value of packages of options under different price conditions. In practice, a house builder offers several packages of variation at the different dimensions of housing attributes at the same time. Such a strategy maximizes customer value and minimizes the matching price. To offer the optimum package, it is necessary to improve insights into the way in which customers value possible packages of variation as a function of the corresponding package-prices.

An important consequence of the need to offer various elements is that building companies will have to become capable of modularizing their product portfolio. However, although methods have been developed recently for evaluating the applicability of modules and product platforms in different industries (e.g. Martin \& Ishii, 2002), so far no systemic methods have been applied and tested in the house building industry. Therefore, it is suggested that research should be initiated that would provide insight into successful methods to define and implement modularization concepts in the house building industry, and also investigate the implications of such concepts for the building supply chain. Filling the aforementioned gaps in knowledge would be an important contribution, both from an academic as well as from a business point of view. 


\section{Appendix 2.1: Questionnaire customized housing}

Customer oriented house building is nothing more than building what the customer asks for. The customer may participate in for instance the design of:

- Environment; examples are paving, parking lots and playing fields.

- Volume and exterior finish; examples are the volume of the dwelling and choice of type of masonry.

- Layout: examples are position of bedrooms and the number of bedrooms.

- Interior finish and materialization; examples are tiling and the finish of interior partitions.

- Technical systems; examples are electro technical systems and type of heating system.

Housing developers and construction companies want to effectively act upon customers' needs. We would be glad to hear your opinion about variation in design.

We thank you for your co-operation!

\section{General questions}

If you would buy a new house, which price category would the house be part of? (amount of money in $€$ )

$\begin{array}{lllll}\text { Up to } 100000 & 100000-199 \quad 200000-299000 \quad 300000-399000 \quad 400000 \text { or more } \\ & 000\end{array}$

[ ] [ ] $\left[\begin{array}{llll} & \text { [ ] }\end{array}\right.$

Have you ever bought a newly built house before?

Yes No

[ ] [ ]

What house would like to buy?

$\begin{array}{llll}\text { Detached } & \text { Semi-detached } & \text { Corner house } & \text { Row house } \\ \text { [ ] } & {[]} & {[]} & {[]}\end{array}$

What is your age category?
$0-25$ years
25-35 years
35-45 years
45-55 years
55-65 years
$65+$
[]
[]
[ ]
[]
[ ]
[ ]

What is your family type?

Single family

Pair without children

Pair with children

Single-parent

[ ]

[ ]

[ ]

family

[ ]

What is your income category?

Up to $€ 10000 \quad € 10$ to $20000 \quad € 20$ to 30000

[ ]

[ ]

[]

More than $€ 30000$

[ ]

\section{Example of vignette related questions}

For each proposition please indicate how you judge these fictive situations: $1=\mathrm{I}$ mark this situation as very good; $6=1$ mark this situation as very poor.

(Sums of money are in $€$.) 
Vignette no. 2: Imagine the following housing proposition:

Participation in designing your future home demands a lot of time, money and effort from the customer as well as from the professionals such as the housing developer, architect and the construction company. Therefore: the more variation is demanded, the higher the costs in general will become. A standard home is a home that's offered without any variation.

- You will have no say about technical systems (such as the type of heating (wall or floor) and the number and location of the sockets, switches and water taps).

+ You will have no say about the interior finish (such as the type of kitchen, washbasins and toilet, the floor - and wall finish and the door hardware (locks and latches).

- You will have no say about the floor plan (such as position and size of the living-, bed-and toilet rooms, kitchen and doorways).

- You will have no say about the volume of the home and the exterior finish (such as the size of the home, the type of roofing and the façade design).

- You will have no say about the environment (such as plot layout, parking lots and pavement of the neighbourhood).

$1=\mid$ evaluate this housing proposition as very good, $\quad 6=1$ evaluate this housing proposition as very poor How do you evaluate this housing proposition with $1=$ very good, $6=$ very poor respect to the offered participation, if you pay:

40000 more than for a standard home?

$[1] \quad[2] \quad[3] \quad[4] \quad[5] \quad[6]$

30000 more than for a standard home?

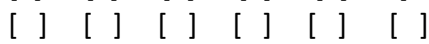

20000 more than for a standard home?

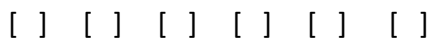

10000 more than for a standard home?

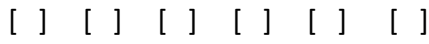

5000 more than for a standard home?

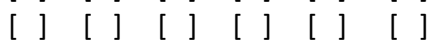

0 more than for a standard home?

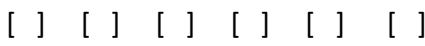

In total respondents were presented 15 vignettes consisting of five first-order vignettes and 10 second-order vignettes.

\section{Additional questions}

Please read the following list and indicate how important variation in the different attributes is for you. Score each attribute and mark it with a cross.

Explanation score, pay attention!

$1=I$ think participation in this option is very important;

$3=$ I think participation in this option has a neutral importance;

$5=I$ think participation in this option is absolutely not important.

How important is participation to you?

$1=$ very important, $5=$ not important

Code Name
A. Environment
a.1 Plot layout
a.2 Parking facilities
a.3 Pavement

$\begin{array}{lllll}1 & 2 & 3 & 4 & 5\end{array}$

[] [] [ [ ] [ ] []

[] [] [] [] []

[ ] [ ] [ ] [ ] [ ] 

a.4 Playground
B. Volume and exterior finish
b.1 Width dwelling
b.2 Depth dwelling
b.3 Choice in type of roof
b.4 Choice in roofing construction (e.g. dormer window)
b.5 Façade front (bay, glass, position windows)
b.6 Façade back (bay, glass, position windows)
b.7 Façade finish (masonry, wood, other)
b.8 Casements (material)
b.9 Roofing finish (type and color roofing tiles)
C. Layout house
c.1 Length and width living room
c.2 Position kitchen
c.3 Position bathroom
c.4 Position toilet
c.5 Position inner doors
c.6 Number of bedrooms
c.7 Number of bathrooms and toilets

$\begin{array}{ccccc}{[]} & {[]} & {[]} & {[]} & {[]} \\ 1 & 2 & 3 & 4 & 5 \\ {[]} & {[]} & {[]} & {[]} & {[]} \\ {[]} & {[]} & {[]} & {[]} & {[]} \\ {[]} & {[]} & {[]} & {[]} & {[]} \\ {[]} & {[]} & {[]} & {[]} & {[]} \\ {[]} & {[]} & {[]} & {[]} & {[]} \\ {[]} & {[]} & {[]} & {[]} & {[]} \\ {[]} & {[]} & {[]} & {[]} & {[]} \\ {[]} & {[]} & {[]} & {[]} & {[]} \\ {[]} & {[]} & {[]} & {[]} & {[]} \\ 1 & 2 & 3 & 4 & 5 \\ {[]} & {[]} & {[]} & {[]} & {[]} \\ {[]} & {[]} & {[]} & {[]} & {[]} \\ {[]} & {[]} & {[]} & {[]} & {[]} \\ {[]} & {[]} & {[]} & {[]} & {[]} \\ {[]} & {[]} & {[]} & {[]} & {[]} \\ {[]} & {[]} & {[]} & {[]} & {[]} \\ {[]} & {[]} & {[]} & {[]} & {[]}\end{array}$

How important is participation to you?

$1=$ very important, $5=$ not important

$\begin{array}{ccccc}1 & 2 & 3 & 4 & 5 \\ {[]} & {[]} & {[]} & {[]} & {[]} \\ {[]} & {[]} & {[]} & {[]} & {[]} \\ {[]} & {[]} & {[]} & {[]} & {[]} \\ {[]} & {[]} & {[]} & {[]} & {[]} \\ {[]} & {[]} & {[]} & {[]} & {[]} \\ {[]} & {[]} & {[]} & {[]} & {[]} \\ {[]} & {[]} & {[]} & {[]} & {[]} \\ {[]} & {[]} & {[]} & {[]} & {[]} \\ 1 & 2 & 3 & 4 & 5 \\ {[]} & {[]} & {[]} & {[]} & {[]} \\ {[]} & {[]} & {[]} & {[]} & {[]} \\ {[]} & {[]} & {[]} & {[]} & {[]} \\ {[]} & {[]} & {[]} & {[]} & {[]} \\ {[]} & {[]} & {[]} & {[]} & {[]} \\ {[]} & {[]} & {[]} & {[]} & {[]} \\ {[]} & {[]} & {[]} & {[]} & {[]}\end{array}$


Vignette no. 2: Imagine the following housing proposition:

Participation in designing your future home demands a lot of time, money and effort from the customer as well as from the professionals such as the housing developer, architect and the construction company. Therefore: the more variation is demanded, the higher the costs in general will become. A standard home is a home that's offered without any variation.

+ You will have a say about technical systems (such as the type of heating (wall or floor) and the number and location of the sockets, switches and water taps).

- You will have no say about the interior finish (such as the type of kitchen, washbasins and toilet, the floor - and wall finish and the door hardware (locks and latches).

- You will have no say about the floor plan (such as position and size of the living-, bed-and toilet rooms, kitchen and doorways).

- You will have no say about the volume of the home and the exterior finish (such as the size of the home, the type of roofing and the façade design).

- You will have no say about the environment (such as plot layout, parking lots and pavement of the neighbourhood).

$1=1$ evaluate this housing proposition as very good, $6=1$ evaluate this housing proposition as very poor

Example of a first-order vignette. 


\section{CHAPTER 3}

\section{Matching supply networks to a modular product architecture in the house-building industry ${ }^{2}$}

Notions of aligning modular product architectures and buyer-supplier relationships, which have spread widely through other industrial and retail sectors, have largely bypassed the house-building industry. The major question posed in this study is: what types of contractorsupplier relationships are needed to develop and produce a modular housing system successfully? An in-depth case study examines a Dutch house-building company that is developing an 'industrialized' modular housing system in collaboration with several specialized suppliers. Based on the analysis of the ten dyadic contractor-supplier relationships, it is shown that contractor-supplier relationships in modular house-building are moderated by both demand and supply aspects. The alignment between product modules and contractor-supplier relationships is found to be contingent on four drivers: the degree of variety in customer demand, the extent of the required supplier investment, the extent of dependence on supplier knowledge, and the intentions of both the supplier and the buyer in a relationship.

\footnotetext{
${ }^{2}$ Published as: Hofman, E., Voordijk, H., \& Halman, J. 2009. Matching supply networks to a modular product architecture in the house-building industry. Building Research and Information, 37: 31-42.
} 


\section{INTRODUCTION}

During the 1960s and 1970s, housing manufacturers primarily focused on the mass production of their products (Barlow et al., 2003a; Craig \& Roy, 2004; Gann, 1996; Ozaki, 2003; Van den Thillart, 2004). Today's consumers, however, are no longer satisfied with monotonous, uniform products, even though the products themselves are reliable in terms of product quality. Therefore, the housing industry is looking for ways to accommodate and increase the influence of the customer on the design of their future house, but without increasing the price too much and losing the advantages of serial, project-based production (Wolters, 2001). To produce variety efficiently, housing suppliers are increasingly adopting modern construction methods that are based on modularity in design and production. The key for combining efficiency and variety is the sharing of a common platform and modules across products and projects. This approach makes it possible to reduce process complexity, increase flexibility and variety in product design (Halman et al., 2003; Muffato \& Roveda, 2000; Sanderson \& Uzumeri, 1995), increase speed in product development (Meyer, Tertzakian, \& Utterback, 1997), reduce product development costs and increase product reliability (Muffato \& Roveda, 2000).

In a module-based product family, product family members are created by adding, substituting and/or removing one or more functional modules from the platform (Simpson, Siddique, \& Jiao, 2006). In this way, modularization allows the overall product to be differentiated to a high degree and thus meet the varied customer requirements while development and production costs are minimized by the reuse of the modules at the multiproject level. In this way, the architecture of the product can be related to manufacturing firm performance (Ulrich, 1995).

While recent studies have focused on customer demands for variety, and design methods to utilize the platform potential of housing designs e.g. Hofman et al. (2006) and Veenstra et al. (2006), the implications for the supply chain structure have not been wellresearched (Voordijk, Meijboom, \& De Haan, 2006). Analysis of these implications can be related to different streams of construction supply chain research that have been identified by London and Kenley In the context of the present study, the strategic perspective on the supply chain concept as developed by Porter (1985) seems to be most appropriate. In terms 
of Porter (1985), a firm can position itself competitively by developing collaborative relationships with certain buyers and suppliers in the value chain (London \& Kenley, 2001). Most construction firms, however, continue to approach building projects as one-off efforts. Buyer-supplier relationships in this traditional construction setting can be characterized as a typical market exchange relationship, where, according to Bensaou: 'information exchange between two firms takes place mainly during bidding and contract negotiations. Suppliers do not get involved in the design of the component and usually manufacture to the buyer's specifications' (1999) (p. 41). It has been argued, for example, by Dubois and Gadde, (2000) that this lack of continuous relationships between firms is the main reason for the construction industry's failure to increase in efficiency and innovation. This leads to difficulties in accumulating and disseminating corporate learning among projects: the project-based, customized design and execution process fails to capture the benefits of standardized work processes. Opportunities to capitalize on economies of scale are lost on individual projects. The various buyer-supplier strategies available to manage suppliers are well known in manufacturing. Their applicability in the construction industry, however, is still less well-understood (Barlow et al., 2003a; Barlow \& Ozaki, 2003, 2005). For certain products and services in construction, arm's-length transactions could be replaced by relationships based on partnering and integrated working; approaches that stimulate adaptation and joint development between buyers and suppliers (Dubois \& Gadde, 2002; Storer, Holmen, \& Pedersen, 2003).

Previous research in other industries such as the photolithography (Henderson \& Clark, 1990), aircraft (Brusoni et al., 2001) and computer industries (Baldwin \& Clark, 2000) has found that product architecture and supply chain structure designs are complementary and that alignment leads to better performance. Novak and Eppinger (2001) for instance, found that integral product architectures (products consisting of a large number of components that are highly interdependent) matched with more integrated supply chain structures. Several academics have investigated this relationship and found that a modular architecture, with standardized interfaces between the modules, enables the firms supplying the modules to specialize. Fully specified interfaces, codified in design rules, define the input and output requirements for the various modules and allow the firms to carry out their development, production, and marketing tasks autonomously and concurrently (Sanchez, 2000). Analogous 
to modular product designs, in modular business networks, activities in specialized groups or firms tend to remain integrated and based on tacit linkages, while the linkages between these groups are achieved by the transfer of codified information (Sturgeon, 2002). In this way, building a house by integrating modules from different suppliers should require less conscious managerial effort since it can be achieved just by respecting the technological and organizational interfaces defined by the modular architecture (Brusoni et al., 2001).

Although such relationships have been investigated in other industries, limited research has so far been conducted in the specific setting of the house-building industry that links development of new modules and components for modular houses to the selection and level of cooperation among potential suppliers. In developing and implementing modular product architectures, both demand- and supply-side issues have to be resolved and balanced with the product architecture. Former research in house-building focused on generic supply chain concepts supporting customized house-building in Japan Barlow et al. (2003a) or United Kingdom (Barlow et al., 2003b; Ozaki, 2003). The present study contributes to this research by relating modular design aspects of a customized housing concept to contractor-supplier relationships in this industry. The research goal is to reveal how contractor- supplier relationships are moderated by both demand and supply aspects and may be established to develop and produce industrial, modular houses successfully. The authors did not take the project as the unit of analysis but made a study of a network of firms that developed a modular housing system that required new forms of multi-project collaboration.

In this respect, the following research question was formulated. What types of supplier relationships are needed to develop and produce a modular housing system successfully? 


\section{THEORETICAL ANALYSES}

This section will first present the theoretical background to two of the basic concepts of the study: product architecture and supplier relationships. Next, the case study in which these two concepts are explored further is discussed. The section shows how new design rules are introduced and then the development and implementation of these rules are linked to various matching supplier involvement strategies.

\section{Product architecture}

A product architecture can be distinguished by the extent to which its components are tightly coupled or loosely coupled. Ulrich (1995) makes a distinction between the two extremes of product architecture, namely modular and integral approaches. A modular architecture includes a one-to-one mapping from functional elements in the function structure to the physical components of the product, and specifies interfaces between components. An integral product architecture involves a complex (rather than a one-to-one) mapping between functional elements and physical components and/or coupled interfaces between components. In integral product architectures, a change made to one component requires a change to the other components in order for the total product to function correctly. When modules, for instance, exchange information, energy or loads, such interdependencies may have a large potential impact on the functioning of the interfacing modules when one of the modules is changed, and design changes may therefore require tight coordination between the module suppliers (Pimmler \& Eppinger, 1994; Sosa, Eppinger, \& Rowles, 2003; Sosa et al., 2004). In contrast, with a modular product architecture, components are interchangeable, autonomous, loosely coupled, and individually upgradeable since the interfaces are standardized.

Modularity is a strategy for organizing complex products and processes efficiently. A modular system, in general, is composed of modules that are designed independently but function as an integrated whole (Baldwin \& Clark, 1997). System integration needs are defined by the final product architecture. Essentially, there are three aspects to modularity that are interrelated and have to be balanced: modularity in use, modularity in production, and modularity in design (Baldwin \& Clark, 1997): 
- Modularity in use is related to offering variety: it allows customers to mix and match elements according to their own demands and tastes. The costs of offering customer variety can be reduced by using modular product designs since less design effort is needed than with fully customized, unique solutions.

- Modularity in production is achieved through the partitioning of the production and development process into manageable tasks that can be performed independently of each other.

- Modularity in design is achieved by partitioning information into visible design rules and hidden design parameters:

- Design rules fall into three categories: the architecture defines what modules form part of the system, and what their functions will be; the interfaces describe how the modules interact, including how they fit together; and standards guide the conformity of the modules.

- Hidden design parameters enable design freedom within the boundaries of a module, and are essentially managed by the module supplier.

Figure 3.1 illustrates how design rules apply to the different component families in a housing design; component families are, for instance, the wall and floor modules and supporting columns. Each module has a clear function and the interfaces between those modules that are physically connected are standardized. The interface specifications define how the modules are connected, for instance what amount of loads and energy they exchange, how the physical coupling is designed, and how tight the modules' tolerances should be. In this way, the modules are 'loosely coupled' and can easily be mixed and matched to produce a large range of customized designs (Baldwin \& Clark, 2000). The functional specifications can be defined by the component buyer, while the detailed engineering specifications can be left to the module supplier.

These design rules enable a designer to modify one part of a system without needing to communicate with and involve designers of other parts. Modular products can therefore lead to modular organizations, as product design rules define both the technological and the organizational architecture of the firms e.g. (Brusoni \& Prencipe, 2006; Langlois, 2003; Sanchez \& Mahoney, 1996; Sturgeon, 2002). Several authors have explained how modular 
innovation may lead to, and can be performed within, a loosely coupled network of firms (Langlois \& Robertson, 1992; Sanchez \& Mahoney, 1996).

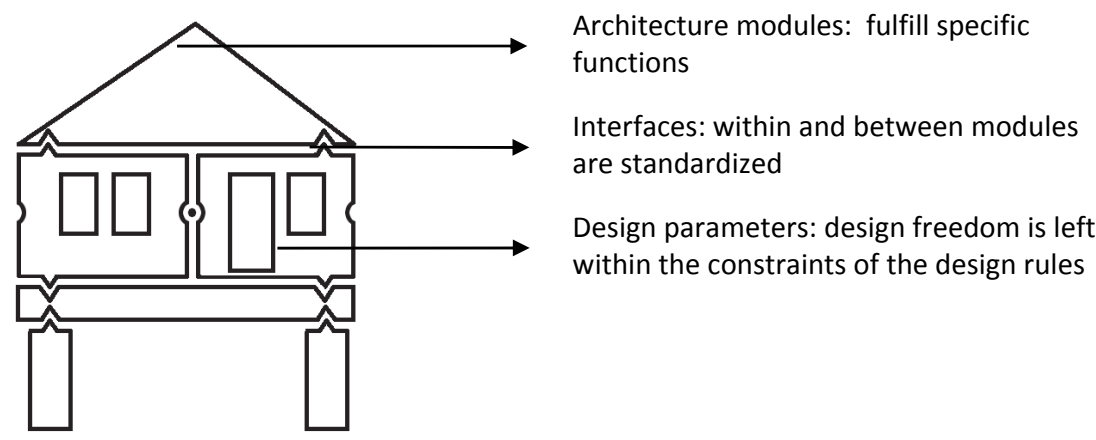

Figure 3.1. Design rules

When an existing modular product architecture is redesigned rather than upgraded, one should speak of an 'architectural innovation' since this overturns the old product architecture and interface designs, and requires a new combination and integration of complementary capabilities that hopefully exist within a set of firms (Henderson \& Clark, 1990). In such a situation, system integration is required and firms have to reconnect their complementary capabilities. Firms are able to achieve this integrative task when they have architectural knowledge at the system level, that is when 'they know more than they produce' (Brusoni et al., 2001). Although more concentrated, integrated relationships are found to be less efficient in the short run, they do provide more opportunities for learning (Sobrero \& Roberts, 2001). Since organizational design and product architecture development are interrelated and complementary, they both have to be realigned if either of them undergoes a radical change.

Empirical studies in various industries and at different levels of analysis (i.e. transactions, organizations and value chains) have already shown that if architectures of products or organizations do change autonomously, that both become realigned over time. Examples can be found in the microcomputer, stereo components (Langlois \& Robertson, 1992), tyre manufacturing (Brusoni \& Prencipe, 2006) and hard disk drive (Chesbrough \& Kusunoki, 1999) industries. These studies report architectural changes in products and supply chains and the way the two are interrelated. However, this relationship has hardly been 
investigated in the construction industry, a notable exception being (Cacciatori \& Jacobides, 2005) who studied the gap between what a vertically specialized construction industry can produce, and what a changing environment demands. They showed how this gap set a process of experimentation with integrated service provision in motion and how firms strategized to change their institutional environment including the boundaries of their firm and supplier relationships, helping to create new all-in-one, integrated markets.

Two widely acknowledged drivers of product modularization are large variety needs from the customer perspective, and a high innovation speed from the supplier perspective (Langlois \& Robertson, 1992; Muffato \& Roveda, 2000; Salvador et al., 2002). Randall and Ulrich (2001) found that matching the degree of product variety to the supply chain structure leads to enhanced performance. For example, in the computer industry, the innovation speed of microprocessors is greater than that of disk drives. If the two subsystems were tightly coupled, a lot of redesign effort would be necessary each time a new microprocessor was introduced, and therefore a looser coupling is more efficient. Also from a demand-side perspective, decoupled, modular interfaces are preferable if customers ask for customized products. If demand heterogeneity is high, decoupled subsystems decrease development time and costs, and provide a solution that offers customized designs at acceptable prices, a combination that determines customer satisfaction (Hofman et al., 2006). A risk associated with introducing new design rules is that firms can become isolated if their design rules are not accepted by their partners in the business network. The success of design rules depends on the extent to which they are accepted by upstream and downstream firms and final customers.

If a housing company adopts a modularization strategy, it can choose between two substrategies. Firstly, it could compete as a systems architect and integrator (Ulrich, 1995), defining the product architecture and creating the design rules for a product made up of modules, and then communicate this to its suppliers. Alternatively, it can compete as a module supplier that produces goods that conform to the design rules laid down by the systems architect (Baldwin \& Clark, 1997). Modularity in design, and variety in housing designs, can then be achieved in two ways: by varying the parts that belong to a modular platform that is leveraged for several projects, or by varying the parts that are included at the project level. System-level parts are designed and produced for repeated use in several 
projects and product families. Project-level parts can easily be purchased on the market, or they can be designed and produced specifically for a project. The case study explores the way these two roles are fulfilled by different network participants in the development and production of houses that conform to the new design rules.

\section{Construction networks and supplier relationships}

In specialized, non-integrated business networks, two forms of networks can be identified: centralized and decentralized (Langlois \& Robertson, 1992). Centralized networks are those in which suppliers are tied to a 'lead' firm (as in the Japanese automobile industry), the design rules (standards of compatibility) are laid down by the lead manufacturer, and they may differ from one lead firm to another. The lead manufacturer fulfils the role of systems architect. In decentralized networks, however, suppliers have to meet the demands of diverse customers, and the standards are determined jointly by component producers, assemblers, and users through market processes or negotiation. Nobody in the network has total control, and anyone who attempts to standardize in a decentralized network risks isolation if other producers and users do not follow their lead. Most construction companies operate in such a decentralized network of suppliers and customers, and draw on the production capacity of various external suppliers. In such networks, it is hard to function as a lead firm, a systems architect, and introduce design rules for standardized product modules. This is also due to the project-based nature of the construction industry and the often unique site conditions. The options to standardize are often limited to the project level: construction projects can be seen as temporary organizations between and within organizations, and therefore standardization at the multi-project level is difficult as project teams and product designs change from project to project.

Essentially, in product development and production, companies can opt to develop and produce parts in-house or they can buy development and production capacity on the market. Between the extremes of vertical integration and vertical specialization are options of vertical, and horizontal, networks of producers, also known as quasi-vertical integrated networks (Karlsson, Nellore, \& Soderquist, 1998). Quasi-vertical integration combines the benefits of vertical integration with the benefits of vertical specialization, and can be a viable option enabling companies in decentralized networks to modularize systems and subsystems. 
As discussed above, in non-integrated or specialized supply chain structures, the systems architect decides whether to outsource only production tasks or to outsource both design and production tasks. There are four options in dividing design and production tasks between supply chain partners. One can: internalize development and production; internalize development and outsource production; outsource development and internalize production; or outsource both development and production (Ulrich \& Ellison, 2005). In a non-integrated or specialized supply chain structure, both development and production tasks are outsourced to external suppliers. In a nonintegrated or specialized supply chain structure, both development and production tasks are outsourced to external suppliers. A change in product architectures and design rules can be seen as a motive for either outsourcing or internalizing activities. When a series of companies in a supply chain is considered, one tends to characterize the supply chain structure by the extent to which a company is integrated with the upstream and downstream firms in the chain. Following the definitions of (Zollo, Reuer, \& Singh, 2002), we define traditional project-based relationships are defined as non-stable, non-integrated relationships; and cooperative agreements of any form at the multiproject level aimed at the development, manufacture and/or distribution of new products are defined as quasi-integrated relationships. In a situation where an upstream firm supplies a specific component exclusively to a single downstream firm - in other words both firms neither sell this specific component to, or buy it from, other firms, and firms collaborate at the multi-project level - one speaks of a fully integrated supply chain structure (Harrigan, 1986). Furthermore, as contractor-supplier relationships can be distinguished on the base of its scope (Sobrero \& Roberts, 2001), a contractor can internalize design and production tasks or outsource these tasks to partners (Ulrich \& Ellison, 2005). 


\section{RESEARCH APPROACH}

The goal of this study is firstly to illustrate how to modularize a housing design from a product architecture point of view, and secondly to advance an understanding of the types of supplier relationships that are needed to develop and produce a modular housing system successfully. To this end, an in-depth case study was conducted at a Dutch house-building company that is developing an 'industrialized' modular housing system in collaboration with several specialized suppliers. A full ego-network design was used (Marsden, 1990; Sobrero \& Roberts, 2001) to collect data on ten dyadic contractor-supplier relationships within a modular housing construction network in the Dutch construction industry to show that the degree of customer variety needs per product module, a dependence on supplier knowledge, relation-specific investments, and intentions relating to learning or efficiency are important predictors of the degree of supplier integration. In-depth interviews with six employees of the construction firm that were closely involved in the development of the modular housing systems were used. The set of interviews was started by interviewing the systems architect of this architectural innovation project. He initiated and launched the project and experienced all nearby firms. Besides the interview data, secondary sources such as industry reports, annual reports, the firm's websites and the data of 17 patents related to the innovation that were publicly available through the European Patent Office were examined. Finally, two pilot projects were visited: the first home built near the construction firm and the second pilot home that was part of a larger traditional housing project. These documents and site visits offered a way to cross-check the interviews and to control for retrospective bias.

The case studied was selected because initial interviews revealed sufficient variance in the degrees of supplier integration and prior research indicates that one could expect sufficient variance in the degrees of customer variety needs by including different building modules (Hofman et al., 2006). The case shows the importance of aligning supplier relationships with the changing nature of the product: from an integral to a modular form of product architecture. A mid-sized construction firm was selected because its production scale is limited and therefore it is unlikely that it would be able to develop and produce an innovative modular product completely independent of suppliers and customers. 
Furthermore, the company operates in a decentralized business network where a large number of organizations have influence over different parts of the housing system. Aligning supplier relationships with the new product architecture in such a context might well be crucial to success since new standards or design rules can lead to isolation if other suppliers or customers do not follow (Langlois \& Robertson, 1992). Therefore, it was expected that this case would enable one to isolate the central concepts that pertain to the research question from each other. The study was conducted in two steps: the first involved a literature study and, in the second, qualitative case study findings were used to explore how different strategies for involving suppliers can be followed to develop and produce the various component families of a modular house. For data analysis purposes the contractorsupplier relationships were arranged according to variables under research and we looked at within-group similarities and inter-group differences. A case study approach, and more specifically an ego-network analysis, was chosen because this method is especially appropriate for explorative research with a focus on 'how' and 'why' questions (Eisenhardt, 1989a; Yin, 1984). A major limitation of this research is that it cannot be statistically generalized beyond the sample of firms observed. However, a significant event as this involving a major, identifiable attempt to shift toward increasing product modularity offered a natural experiment by which the ensemble of supplier relationships and predictor variables could be examined in detail (Schilling \& Steensma, 2001). The following section presents the case study findings.

\section{CASE STUdY}

A new concept by a Dutch housing company was used as a case study. Vos Construction, part of the Vos Group, is a building development company operating in the north, east and central parts of The Netherlands. The company employs around 550 people, and has revenues of about E140 million per year. An important criterion in selecting this firm for study was its past performance in developing and offering customized housing concepts. To address the differentiation in demand, Plegt-Vos Living, a department within Vos construction, in 2003 started to develop a model from which several distinctive house types could be derived. Each house type starts with minimum standard dimensions. The platform 
potential of this design concept has been analyzed in a case study by Veenstra et al. (2006). To take customization and industrialization to a higher level than possible with the current concept, Vos Construction and the architect Jan Wind are now developing a new type of house with a modular product architecture. The design rules and supplier relationships that are part of this modular product architecture are discussed below.

\section{Product architecture}

The product architecture of the new system is modular and has been designed in such a way that industrial offsite production is possible for a number of component families. The assembly of the subsystems will still be completed onsite. To investigate the options in modularizing the product architecture, the Design for Variety method was used (Veenstra et al., 2006). This method is a detailed step-by-step approach to aid design teams in developing a product architecture that incorporates standardization and modularization which aims to reduce future design costs and efforts. A simplified illustration of the system is given in Figure 3.2. System-level parts can be repeatedly used at the multi-project level, and projectlevel parts used at the project level for several houses, with other parts being tailored to unique customer demands and applied at the project level. In this case study, the product architecture was as follows:

- Subsystems, used at the multi-project level, are essentially modules that form part of the structure:

- There are three component families: floor parts (structural and system), exterior walls and columns. The functional specifications of these component families, as well as the engineering specifications and interfaces, are clearly defined. The structural floor parts have standard sizes $(900 * 900 \mathrm{~mm} ; 900 * 600 \mathrm{~mm}$ and $900 * 300 \mathrm{~mm}$ ) and have standard steel couplings. Variety (layout and surface) is achieved by mixing and matching these components. Interfaces between the component families are standard steel connections, specifically designed for this system.

- Technical installations: mechanical systems for heating and ventilation form part of the system floor. Above the structural floor, the pipes and wiring can be freely 
located. Further, above this structural floor, a decoupled system will be placed combining the heating (floor and air) and ventilation systems.

- Subsystems or components used at the project level such as: staircase, exterior finish (cladding), roof, windows, and project-specific infill. If necessary, the interface specifications of the parts are communicated to the suppliers. Interface specifications for the exterior finish are also clearly defined to ensure that the cladding can be easily attached to the standardized concrete exterior walls which are part of the system level. Variety at the project level is achieved by decoupling the exterior finish (cladding and windows) from the pre-cast concrete exterior walls. Since the structure allows significant design freedom within it, infill systems can differ from project to project and are more or less unique at the project level.

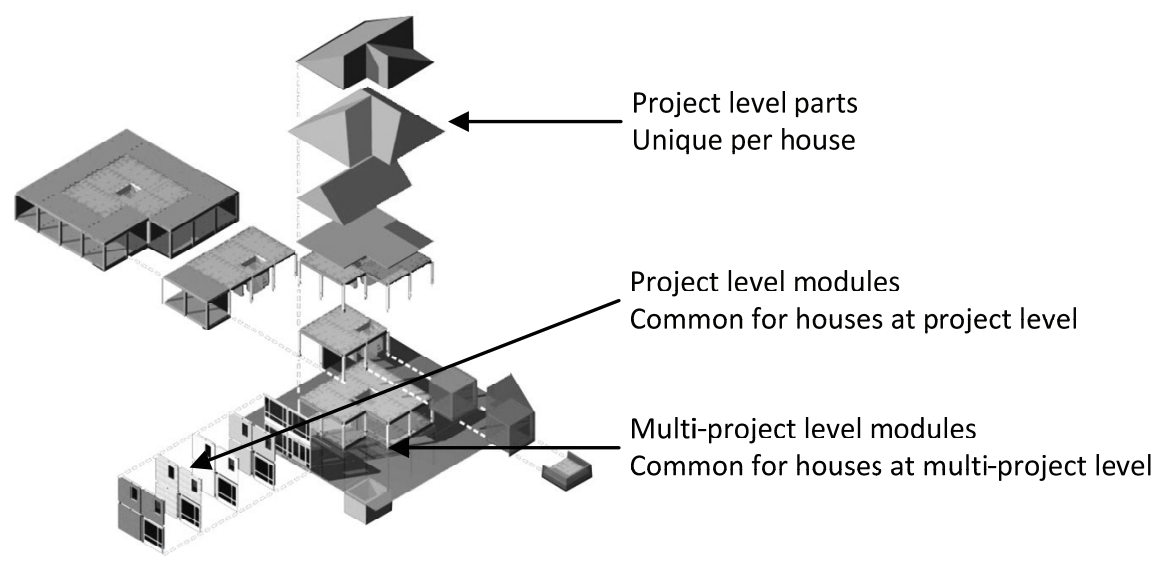

Figure 3.2. Breakdown of the new housing system. Drawing courtesy Jan Wind

\section{Supplier relationships}

In developing the system multi-project level modules, such as floor parts (structural and system), exterior walls, columns and their interfaces, Vos Construction together with Wind fulfilled the role of systems architect. They set the design rules for the new products (functions and interfaces) and they restructured and aligned the supply chain to achieve the desired product modularization. Vos Construction and Wind did not own the resources 
(materials and money) or the competencies (knowledge) which are required to develop and produce these modules. For instance, one of the intentions is to produce the pre-cast multiproject level parts offsite and then to assemble them onsite, but Vos Construction, as a traditional construction company, does not own factories and has no extensive experience with industrial production systems. Therefore, Vos Construction has to rely on external suppliers and outsource production and in so doing gain access to essential resources and knowledge.

During meetings with several suppliers, it became clear that the suppliers were initially reluctant to invest in setting up new product lines to produce the new modules or to invest in, for instance, the special moulds needed to produce the structural floor parts. This is typical of a decentralized business network: parties do not have sufficient bargaining power to force partners to adopt new design rules, even when it is expected that the new design rules are better than the old ones in terms of increased efficiency and speed in product development. Several reasons were uncovered why the suppliers were unwilling to work to the new design rules. These are summarized below:

- New standards: new design rules require adapted working routines and production lines; suppliers are reluctant to adopt new standards.

- Design for manufacturing and material knowledge: initial module designs did not align with manufacturing practice and could have been improved if the supplier had been involved in module development.

- Scale: traditional project-based procurement leads to relatively small production batches from a supplier point of view; and thus their willingness to make relation-specific investments is limited by previous experience.

- Knowledge: suppliers were unfamiliar with the new design rules and also with co-maker relationships, supplier willingness increased during discussions on these issues.

- Capacity: the current construction market is buoyant and suppliers have little or no surplus capacity; thus new work that requires conforming to the design rules of external customers has little attraction. 
This case study has illustrated that, in a traditional, decentralized construction network, it can be hard to introduce and force adoption of new design rules. To overcome the problems, that are the forces that worked against the adoption of new design rules, Vos Construction as system architect decided to restructure the supply chain by committing a few supplier of building elements to collaborate. The modular network that appeared to be appropriate for developing and implementing the new design rules is illustrated in Figure 3.3. Based on the analysis of the ten dyadic contractor-supplier relationships, three types of relationships could be distinguished in this network: integrated, quasi-integrated, and non-integrated. The parties within the inner circle are part of the development team and are fully integrated suppliers; the parts they develop conform to the new design rules and are supplied exclusively within this relationship. he parties within the second circle offer production capacity and are quasi-integrated suppliers; the outer circle suppliers offer products that are non-integrated and therefore traditionally procured.

The supply chain structure thus was matched with the requirements of the new design rules. For different parts of the system, namely the multi-project modules and the project-level parts, distinct strategies were followed. Vos Construction, together with a Wind, fulfilled the role of systems architect and started by defining the functional and engineering specifications of the modules and their interfaces. As the systems architect, Vos Construction and Wind are part of the development team, and they will also use this system in future housing projects to substitute and diversify their traditional building system. The other bodies that form part of the development team are Vos's Engineering Office, some specialist consultants, and some specialist suppliers.

The supply chain management (SCM) office is a new legal entity - owned by Vos Construction and Wind - that will monitor the functionality of the modules and the integration of these modules into a system; they will also evaluate changing system requirements and update the design rules if necessary. They will also monitor supplier relationships and will consider future supplier integration or segregation. The Engineering Office is the second new function in this network and has extensive knowledge on how to fit project-specific designs by external architects into the new system; their primary task is to coordinate the project-specific design aspects of future projects. 


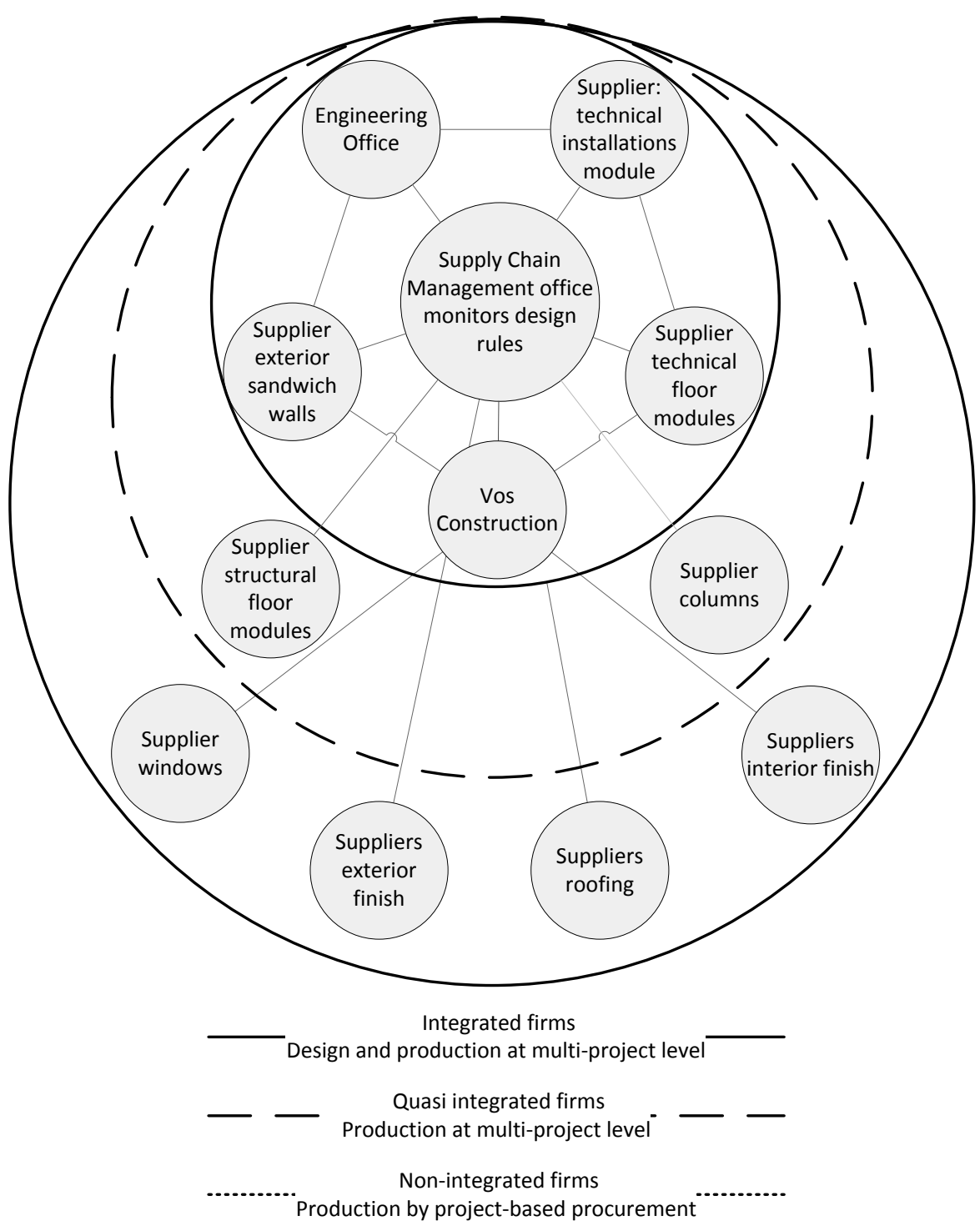

Figure 3.3. Modular network structure that matches the new design rules

Table 3.1 summarizes the matched pairs of product modules and supplier relationships within the case study. It further details the drivers of these specific matches; drivers are the degree of customer variety needs, the degree of dependence on supplier knowledge, the degree of supplier investments, and specific intentions within the respective supplier relationships. The first three drivers are typified as either 'high', 'moderate', or 'low'. The 
intentions within the supplier-buyer relationship indicate whether the supplier relationship is aimed at efficient development and production, at learning and transferring knowledge between firms, or wishing to remain flexible.

Table 3.1. Framework of differentiated supplier relationships and drivers for differentiation

\begin{tabular}{|c|c|c|c|c|c|}
\hline \multicolumn{2}{|c|}{$\begin{array}{l}\text { Matched pairs of module } \\
\text { and supplier relationships }\end{array}$} & \multirow[b]{2}{*}{$\begin{array}{l}\text { Degree of } \\
\text { customer } \\
\text { variety }\end{array}$} & \multicolumn{3}{|c|}{ Drivers that lead to supplier differentiation } \\
\hline Module & $\begin{array}{l}\text { Supplier } \\
\text { relationship }\end{array}$ & & $\begin{array}{l}\text { Degree of } \\
\text { dependence } \\
\text { on supplier } \\
\text { knowledge }\end{array}$ & $\begin{array}{l}\text { Degree of } \\
\text { relation- } \\
\text { specific } \\
\text { supplier } \\
\text { investments }\end{array}$ & $\begin{array}{l}\text { Intentions within } \\
\text { supplier/buyer } \\
\text { relationship }\end{array}$ \\
\hline $\begin{array}{l}\text { Couplings } \\
\text { between } \\
\text { modules }\end{array}$ & Integrated & Low & Moderate & Moderate & $\begin{array}{l}\text { Owning property rights of } \\
\text { interface designs }\end{array}$ \\
\hline $\begin{array}{l}\text { Technical floor } \\
\text { modules }\end{array}$ & Integrated & Low & High & High & $\begin{array}{l}\text { Learning and long-term } \\
\text { efficiency }\end{array}$ \\
\hline $\begin{array}{l}\text { Exterior } \\
\text { sandwich wall }\end{array}$ & Integrated & Moderate & High & Moderate & $\begin{array}{l}\text { Exploitation of supplier's } \\
\text { unique capabilities which } \\
\text { the supplier is reluctant to } \\
\text { share (no focus on } \\
\text { learning) }\end{array}$ \\
\hline $\begin{array}{l}\text { Installations } \\
\text { module }\end{array}$ & Integrated & Low & High & Low & $\begin{array}{l}\text { Learning and long-term } \\
\text { efficiency }\end{array}$ \\
\hline $\begin{array}{l}\text { Structural floor } \\
\text { modules }\end{array}$ & $\begin{array}{l}\text { Quasi- } \\
\text { integrated }\end{array}$ & Low & Moderate & Moderate & $\begin{array}{l}\text { Learning and long-term } \\
\text { efficiency }\end{array}$ \\
\hline Columns & $\begin{array}{l}\text { Quasi- } \\
\text { integrated }\end{array}$ & Low & Low & Moderate & Long-term efficiency \\
\hline Windows & $\begin{array}{l}\text { Non- } \\
\text { integrated }\end{array}$ & Moderate & Low & Low & $\begin{array}{l}\text { Short-term efficiency and } \\
\text { flexibility }\end{array}$ \\
\hline Exterior finish & $\begin{array}{l}\text { Non- } \\
\text { integrated }\end{array}$ & High & Low & Low & $\begin{array}{l}\text { Short-term efficiency and } \\
\text { flexibility }\end{array}$ \\
\hline Roofing & $\begin{array}{l}\text { Non- } \\
\text { integrated }\end{array}$ & High & Moderate & Low & $\begin{array}{l}\text { Short-term efficiency and } \\
\text { flexibility }\end{array}$ \\
\hline $\begin{array}{l}\text { Interior finish } \\
\text { (type of } \\
\text { kitchen, type } \\
\text { of tiling, etc.) }\end{array}$ & $\begin{array}{l}\text { Non- } \\
\text { integrated }\end{array}$ & High & Low & Low & $\begin{array}{l}\text { Short-term efficiency and } \\
\text { flexibility }\end{array}$ \\
\hline
\end{tabular}




\section{Degree of customer variety and degree of dependence on supplier investment}

Supplier involvement involves the supplier, the buyer or both investing, and it can only be justified where the benefits exceed the costs (Gadde \& Snehota, 2000). Developing a modular platform should only be considered when there are clear possibilities for the construction firm and its suppliers of reusing it in future products. The main risks to consider are the uncertainties in forecasting future consumer demands, the integration of existing elements, and the major impact of any mistakes made early in the development phase (Halman et al., 2003).

In the case study company, the costs are closely related to the necessary financial investments in development and production, and the risks related to knowledge sharing. The decision to invest depends on the likelihood of investments being recovered from future sales. Table 3.1 shows that a decrease in the extent of customer variety demands combined with an increase in the required relationship-specific supplier investments results in an increase in supplier integration. The authors believe the explanation for this relationship is as follows. A positive return on an investment is dependent on the size of the investment and the reuse potential of modules related to that investment. Reuse potential is high when customer variety needs are low and, conversely, reuse potential is low when customer variety needs are high leading to partly standardized designs being unacceptable. Therefore, certain potential suppliers were not allowed to invest in the modular housing system because of the expected limited reuse potential.

It is therefore argued that the demand for variety coupled with the extent of the investment jointly determine the extent of supplier integration. Components that have extensive variety in customer demands are better suited to non-integrated relationships and project-based procurement. Elements with low customer demand for variety where large supplier investments are required are more appropriately delivered through integrated supplier relationships since stable multi-project (i.e., long-term) production is necessary to convince suppliers that the investments are justified.

In this case study, integrated, or quasi-integrated, supplier relationships were achieved through mutual agreements on the allocation of future production orders to those suppliers who took part in module development. In this way, the suppliers willing to invest in both development and production could foresee adequate production to deliver an acceptable 
return on their investment. To overcome the reluctance of suppliers to make relationshipspecific investments in development and in new production facilities, Vos Construction thus switched from project-based procurement to stable, multi-project, supplier relationships and integrated the supplier into the process.

\section{Degree of dependence on supplier knowledge and supplier/buyer intentions}

The findings from this case study further suggest that a significant dependence on a supplier's knowledge base also leads to closer supplier integration. For example, during the development of the technical floor modules and the exterior sandwich wall, it became clear to Vos Construction that it lacked the necessary knowledge about material properties and production techniques. Especially for these two aspects, it required the suppliers' expertise, which would improve the module designs and the related manufacturability, product performance and production costs. Inputs of supplier knowledge in the development phase improved the quality of the design rules, which led directly to an increased adoption of these rules by the suppliers. This approach to integrating suppliers in the development phase and the development team was focused more on learning and long-term benefits than on shortterm efficiency. This integration of suppliers in product development and production resolved the problem of Vos Construction's lack of specific knowledge and competences. The proposed supplier of the exterior walls also had specialized production capabilities which they were reluctant to share, since no suppliers were available with similar knowledge, their bargaining power increased. In order to access and exploit their capabilities, Vos Construction decided to integrate with this supplier. More specifically, the supplier was able to keep its production techniques hidden; the interface designs are owned by the SCM bureau and the product module will only be traded within this unique buyer-supplier relationship.

In developing those parts for which Vos Construction did not rely on the specialized knowledge of suppliers, the focus was on short-term efficiency rather than learning. For example, to develop the structural floor modules, interior walls and columns, Vos Construction did not need specialized supplier knowledge and the development of these parts was therefore completed in-house. To ensure that suppliers would accept the new design rules and be willing to invest in new production lines, moulds and adapting routines, 
the traditional project-based relationships have been transformed into stable multi-project ones. The preferred suppliers now produce parts on the multi-project level. The difference between suppliers in the development team and quasi-integrated suppliers is that the latter do not fulfill development tasks; development is done by the development team. Furthermore, quasi-integrated suppliers do not own property rights of the modules and will compete with one or two other suppliers in a pool of 'preferred' suppliers.

Other modules including roofing and interior finish parts such as kitchens and tiling continue to be traditionally procured at the project level. These commodity items are bought on the open market through traditional procurement methods, with both functional and detail design being handled by the supplier.

As described above, aligning the degree of supplier integration with the various modules seems to be key to effective modularization. Parts with limited variety and which require supplier investment and supplier knowledge seem suited to cooperation at the multiproject level with full integration. For parts with a moderate to low demand for variety, and for which moderate supplier investments are needed but no specialized supplier knowledge required, quasi-vertical integration is sufficient. For parts for which it is hard to limit oneself to standard units at the multi-project level, one can still standardize to some extent for houses within a certain project and offer options per house. Conversely, for parts with a high demand for variety, such as type of kitchen, or type and color of tiling, housing suppliers can best leave the choice to the buyer and procure these parts on a project-by-project basis. Overall, it is concluded that when new design rules are introduced for developing and producing a rage of component families, various strategies to involve suppliers will be necessary.

\section{CONCLUSIONS AND BUSINESS IMPACTS}

This research sought to reveal how contractor-supplier relationships are moderated by both demand and supply aspects and may be established to develop and produce industrial, modular houses successfully. To this end, an in-depth case study was conducted of a network of firms that developed a modular housing system that required new forms of multi-project collaboration. Based on the analysis of the ten dyadic contractor-supplier 
relationships, different supplier relationships could be distinguished for different product modules: integrated, quasi-integrated, and non-integrated relationships.

The alignment between product modules and supplier relationships were found to be contingent on four drivers: the degree of variety in customer demand, the extent of required supplier investment, the extent of dependence on supplier knowledge, and the intentions of both the supplier and the buyer in a relationship. A significant dependence on a supplier's investments and knowledge base combined with a moderate to low demand for variety lead to closer supplier integration. Modules characterized by a high demand for variety and no dependence on a supplier's investments and knowledge base can best be procured on a non-integrated traditional project-by-project basis.

This study supports and complements the existing literature on how the development and production of modular housing can be realized by different contractor- supplier relationships. Realizing multi-project modular housing in decentralized networks depends in particular on the likelihood of a supplier's investments being recovered from future sales and the risks related to knowledge sharing. Further research is needed to test the significance of the found relationships and the costs and risks of different contractorsupplier relationships. 


\section{CHAPTER 4}

\section{Architectural innovation in loosely coupled networks, how to compensate for loose coupling and inertia ${ }^{3}$}

Why is architectural innovation so difficult in loosely coupled business networks? We have investigated the problems and opportunities for modularization (i.e. architectural innovation) that arise from a loosely coupled business context. Our study of an architectural innovation process provides rich details that highlight the multitude of inertial factors that form barriers that inhibit innovation and the necessity for managers to apply compensation mechanisms to overcome these inertial forces. We developed a better understanding of the problems and challenges facing architectural innovation that stem from loose coupling and inertia. Secondly we study the compensation mechanisms that are available to managers to overcome these issues.

\footnotetext{
${ }^{3}$ Accepted and presented at $15^{\text {th }}$ EIASM international product development management conference (2008). This chapter has been submitted to an international refereed journal.
} 


\section{INTRODUCTION}

Over recent decades, firms have become increasingly interested in modularizing their products, production processes, and organizational structures. The concept of modularity is seen as a key success factor in many markets as it allows a family of differentiated products to be quickly developed and produced at a decreased cost.

While previous research has examined the concept of modularity, most of it has focused on the modularization of products or processes within the boundaries of a single firm or within a centralized business network (Baldwin \& Clark, 2000; Brusoni \& Prencipe, 2006; Langlois, 2002; Schilling, 2000). Relatively little attention has been paid to modular product development in the increasingly common industrial context of 'loosely coupled' business networks (Krishnan \& Ulrich, 2001; Sosa et al., 2004; Staudenmayer et al., 2005).

In a loosely coupled context - unlike in a tightly coupled centralized business network no single company has sufficient architectural knowledge about modules and their interactions (Brusoni et al., 2001; Langlois \& Robertson, 1992; Sanchez \& Mahoney, 1996) or sufficient control to take the lead in developing modular design rules (Langlois and Robertson, 1992). This context therefore imposes added complexity for firms trying to coordinate modularization beyond the boundaries of their own organization (Langlois \& Robertson, 1992). Not only do these type of firms need to overcome the drawbacks of 'loose coupling' but also the strong inertial forces that impede technological change (Anderson \& Tushman, 1990). Factors creating inertia include for example design standards that shape companies' routines that are misaligned with the new technology and prove to be difficult to change (Hannan \& Freeman, 1984; Tushman \& Anderson, 1986).

We have investigated the problems and opportunities for modularization (i.e. architectural innovation) that arise from a loosely coupled business context. The purpose of this chapter is twofold. First we develop a better understanding of the problems and challenges facing architectural innovation that stem from loose coupling and inertia. Secondly we study the compensation mechanisms that are available to managers to overcome these issues.

For this, we draw on the theories of modular and loosely coupled systems (Orton \& Weick, 1990; Schilling, 2000), inertia (Hannan \& Freeman, 1984; Tushman \& Anderson, 1986), 
and the concept of design rules (Baldwin and Clark, 2000). These theories provide us with complementary views on innovation and change. One view is that incumbent firms have large inertia such as routines and rigid strategic beliefs towards change (Hannan \& Freeman, 1984; Tushman \& Anderson, 1986). The second view is that 'loose coupling' erodes architectural power which complicates architectural innovation that depends on the collective actions of many firms, and on these actions being aligned (Langlois \& Robertson, 1992; Orton \& Weick, 1990; Schilling, 2000). A third view explains how compensation mechanisms such as enhanced leadership, or what others call transformative leadership (Howell \& Avolio, 1993) by 'heavyweight' product managers (Clark \& Fujimoto, 1990), create shared values and aligned strategic beliefs among firms which help to overcome the problems of loose coupling and inertia (Orton \& Weick, 1990). In this study, we provide a synthesized account of compensation mechanisms that can overcome the drawbacks of loose-coupling and inertia that prevent architectural innovation.

Using data from an in-depth field-based study of an architectural innovation involving twenty-six firms - concerning the development of a module-based housing system named 'Mind Building' - we have deepened our understanding of what types of inertial factors are prevalent, and what compensation mechanisms are appropriate for overcoming these challenges in order to achieve architectural innovation.

This chapter is organized as follows. The next section reviews and links the factors that affect architectural innovation in loosely coupled business networks. Following this, the research methodology is introduced, and the case data discussed. Based on an analysis and discussion of the findings, a conceptual model for understanding and managing architectural innovation in decentralized business networks is developed. From this analysis and conceptual model, propositions are offered for future research. The chapter concludes by discussing the contributions made to the study of architectural innovations, the research limitations, and the potential business impacts. 


\section{THEORETICAL ORIENTATION}

Developing modular products requires explicit knowledge and information about their structure. In the process of creating modular products, the development team needs to determine the standards of compatibility which comprise the following categories of design rules: the product architecture, the interfaces, and the standards for evaluation that will be used (Baldwin and Clark, 2000). The product architecture comprises the specification of the modules that constitute the platform, their functions, the physical elements by which each module will fulfill its intended function and the layout of the modules. The interface specifications describe how modules will interact with other modules including how they are physically connected, how power or material is transferred and how they communicate (Sanchez, 2000). Modular interfaces are decoupled meaning that, within certain limits, a module does not have to change when other modules to which it is connected are changed (Ulrich, 1995). Finally, testing standards easy the evaluation of the modules' relative performances and allow a designer to verify whether a module conforms to the design rules and make sure it will function in the end-system. Finally, design rules include standards for testing the relative performances of modules, and these standards allow a designer to verify that a module conforms to the design rules and will function in the system.

\section{Architectural innovations and the locus of innovation}

A negative implication of modular products, and the accompanying organizational specialization and 'loose coupling', is that this potentially creates barriers to architectural innovation since specialization can lead to a loss in market power and, more importantly, architectural control (Schilling and Steensma, 2001). Modular innovation takes place through changes within modules that do not affect connecting modules (Sanchez \& Mahoney, 1996). Henderson and Clark (1990) adopted the notion of architectural innovation and framed this in a single-firm context. They defined architectural innovation as innovation that: "change[s] the way in which components are linked together, while leaving the core design concepts (and the basic knowledge underlying the components) ... untouched".

Where modularization has resulted in specialized business networks, two basic network forms have been identified: centralized and decentralized networks (Langlois and Robertson, 
1992). Further, dominant design rules may or may not be present. In centralized networks, suppliers are tied to a 'lead' firm that fulfills the role of systems architect and controls the system's architecture. Design rules (standards of compatibility) can be laid down by the lead firm and may differ from one lead firm to another. In contrast, in decentralized networks, no single firm has architectural control, i.e. no-one has sufficient power and architectural knowledge to define a new architecture. The freedom and options to architecturally innovate are, however, externally limited to a certain extent (Chesbrough \& Teece, 1996; Orton \& Weick, 1990; Schilling \& Steensma, 2001). Firms that attempt to introduce interface standards, risk isolation if other firms choose not to follow (Langlois and Robertson, 1992). Therefore, the potential benefits of architectural innovations can only be realized if complementary innovations take place in other firms in the decentralized network (Chesbrough \& Teece, 1996). The type of network and the availability of dominant design rules pose unique challenges for modular and architectural innovation.

Based on the work of several authors, we derived a two-dimensional typology of innovation contexts as shown in Figure 4.1: the degree of centralization of architectural control and the availability of dominant design rules are framed in a two-by-two matrix. Microsoft Windows 3.0 is an example of a dominant design in a centralized business network. Software applications offered by other firms had to be Windows compatible to have any real chance of succeeding. Several observers have argued that Microsoft retained architectural control by providing only limited information to third-party application developers about the details that must be known to develop well functioning compatible applications (Schilling, 2000). In contrast, Langlois and Robertson (2006; 1992) describe how, in the automobile industry, centralized networks evolved around lead firms like Ford and Dodge who stuck to their own individual design rules rather than creating shared dominant design rules. Since no dominant design rules are available, modular innovation for non-leading firms is difficult since no shared design rules are available, and these firms will therefore often rely on lead firms coordinating architectural innovation. Non-leading vendors are therefore most likely to follow a defender strategy (Miles \& Snow, 1978) and invest only in internal process optimization. Staudenmayer et al. (2005) investigated seven firms from the computer hardware and software industries that operated in a decentralized network in which shared interface designs were present. They found some unique challenges and corresponding 
managerial solutions that this context imposed on firms. The availability of design rules allowed firms to differentiate within these rules. This decentralization, however, complicated architectural innovation since differentiation was limited given the need to accommodate common standards. A re-centralization of control across modular boundaries was required to optimize performance across the firm and module boundaries.

From these examples, we conclude that, in centralized networks, architectural innovation can be achieved by centralized coordination by the lead firm. Further, the availability of design rules enables the non-leading firms to innovate within their modules without requiring extensive coordination with other firms since interface standards make the modules from various suppliers non-specific as long as their modules adhere to the dominant design rules (Baldwin \& Clark, 1997; Sanchez \& Mahoney, 1996; Schilling, 2000). The four quadrants in Figure 4.1 identify four situations in which complexity influences modular and/or architectural innovation. In a decentralized business network where dominant design rules are not available (the bottom-right quadrant), firms have problems with both modular (MI) and architectural (AI) innovation, and product innovators can face unique challenges. Despite this, this context has not been extensively empirically investigated. We therefore focused our research on a setting within this quadrant: one with decentralized architectural control and no dominant design rules. 


\begin{tabular}{|c|c|c|}
\hline & Centralized & Decentralized \\
\hline Available & $\begin{array}{c}\text { Photolithography industry } \\
\text { (Henderson \& Clark, 1990); } \\
\text { Microsoft's Windows } 3.0 \text { and } \\
\text { compatible software } \\
\text { (Schilling, 2000) } \\
\text { Good conditions to realize MI } \\
\text { and Al. }\end{array}$ & $\begin{array}{c}\text { Mature computer industry } \\
\text { (Staudenmayer, Tripsas, \& } \\
\text { Tucci, 2005) } \\
\text { Moderate conditions to realize } \\
\text { MI and poor conditions to } \\
\text { realize Al. }\end{array}$ \\
\hline . & $\begin{array}{l}\text { Tire manufacturing industry } \\
\text { (Brusoni \& Prencipe, 2006); } \\
\text { Early computer industry, } \\
\text { System } 360 \text { (Baldwin \& Clark, } \\
\text { 2000); Automobile industry } \\
\text { (Langlois \& Robertson, 1992)* } \\
\text { Poor conditions to realize MI, } \\
\text { good conditions for 'lead firm' } \\
\text { to realize Al. }\end{array}$ & $\begin{array}{l}\text { Construction industry } \\
\text { This chapter: inertia and } \\
\text { compensation mechanisms to } \\
\text { realize architectural } \\
\text { innovation. } \\
\text { Poor conditions to realize MI } \\
\text { and Al. }\end{array}$ \\
\hline
\end{tabular}

* Langlois and Robertson (1992) also give an example of a consortium of equipment makers who lobby for an open control and interface protocol that will allow semiconductor producers to mix and match equipment from many suppliers. This consortium can be seen as a mechanism to gain architectural control in a decentralized context.

Figure 4.1. Conditions influencing modular innovation (MI) and architectural innovation (AI) 


\section{ARCHItectural inNovation IN LOOSELY COUPLED NETWORKS: CONCEPTUAL BACKGROUND}

To increase the success of product architectural innovation in loosely coupled networks it is important to know what causes inertia and the related failure to change. This will enable firms to adopt compensation mechanisms that are likely to increase success in architectural innovation.

\section{Inertia towards architectural innovation}

Factors that generate inertia can be internal and external to organizations. Internal factors include sunk costs in plant, equipment, and personnel (Tushman \& Anderson, 1986) as well as cognitive frames since a firm's inability to respond to architectural innovation is a function of a continued reliance on accumulated knowledge that reflects the architecture of the previous generation of products (Henderson \& Clark, 1990). The concept of a technology trajectory is closely related to that of cognitive frames. A technology trajectory represents the path of technological innovation and is based on the innovators' cognitive frames (Dosi, 1982). Orlikowski and Gash (1994) define it as that subset of members' organizational frames that concerns the assumptions, expectations, and knowledge they use to make sense of technology in organizations. Such technological beliefs are intertwined with strategic beliefs about how to align the organizational architecture to the new technology (Kaplan \& Tripsas, 2008). Firms benefit from a fit among strategy, technology, and organizational design features such as task structure, competences, culture, incentive structure, and the formal organization (Burton, Lauridsen, \& Obel, 2002; Chandler, 1962). However, technological innovation induces potential misfits with the other design features. Rigid strategic beliefs lead firms to adopt traditional solutions in legitimating technological innovation. Such solutions are associated with innovation failures (Dougherty \& Heller, 1994) since they do not really resolve misfits induced by the technological innovation. Various firms in a loosely coupled network may also hold incongruent strategic beliefs or interests. This is likely to lead to a set of incompatible solutions for resolving misfits. Therefore, firms with incongruent strategic beliefs often experience difficulties and conflicts around architectural innovation (Orlikowski \& Gash, 1994). This explains to an extent why innovating, especially in loosely coupled networks involving actors with inconsistent strategic beliefs, 
can be so difficult, and why purposeful reframing may be an important element of managing innovation. Rigid strategic beliefs can thus be seen as an important inertial factor in architectural innovation.

External inertial factors include the dynamics of the external environment such as investments in exchange relationships with other organizations and environmentally imposed legitimacy constraints (Hannan \& Freeman, 1984; Suchman, 1995). Hannan and Freeman (1984) explain that environmental turbulence can lead towards increased organizational inertia: "organizations have high inertia when the speed of reorganization is much lower than the rate at which environmental conditions change".

\section{Compensation mechanisms}

In the literature, loosely coupled systems are described as systems that are distinct but at the same time show responsiveness to each other. Loosely coupled firms may be formally independent and have different strategic beliefs, but they are responsive in the event of product architectural change. The theory of loosely coupled systems explains how compensation mechanisms can be applied to mitigate the impediments of loose coupling which can be viewed as an antecedent of inertia (Orton \& Weick, 1990). In restructuring systems, increased coupling is needed in some dimensions to compensate for the looseness in other dimensions.

Cognitive coupling. Shared values and aligned strategic beliefs are seen as enabling architectural innovation in networks (Tsai \& Ghoshal, 1998). Cognitive coupling is the act of creating trust, shared values, and shared strategic beliefs among dispersed firms. These cognitive frames must be free of inconsistencies not only within but also between firms. An internal inconsistency can arise when a firm aims to develop and exploit new technology but, due to excessive routinization, is unable to align their organization with this goal. Tripsas and Gavetti (2000) illustrated how this happened at Polaroid, which was able to develop digital technologies, but failed to align their business model to the new opportunity. However, innovation in loosely coupled networks depends on the collective action of many firms. For this reason, enhanced leadership that breeds trust and shared values and visions among firms appears to be an important compensatory mechanism (Orton \& Weick, 1990). Firms with aligned strategic beliefs about what to do and how to do it are more likely to 
collaborate and innovate successfully. It provides "the harmony of interests that erase[s] the possibility of opportunistic behavior" that makes it likely that a firm will get other firms' support for achieving goals (Tsai \& Ghoshal, 1998).

Structural coupling. Looseness in some dimensions can be compensated with couplings in other dimensions; firms, for example, can opt to integrate with other firms in order to achieve product modularization. Robertson and Langlois (1995) define two related but potentially separable dimensions of structural coupling: ownership integration and coordination integration. Ownership integration stems from the theory of property rights (Hart, 1989), and holds that adjoining production stages are integrated when the assets involved are under common ownership. Coordination integration refers to administrative arrangements and the extent of information exchange between two firms, for instance about sequential or reciprocal development or production tasks. Both forms of structural coupling influence the development and adoption of innovations, it helps to overcome important appropriation barriers for innovators (Teece, 1986). Increased structural coupling improves information flows between specialized firms about interdependencies such as those related to products. However, increased information exchange can also prevent firms from adopting innovations that are suboptimal for downstream stages in the value chain. Decentralized coordination entails local search processes which often fail to fully take these interdependencies into account (Levinthal \& Warglien, 1999). However, it has the potential to solve problems related to power relationships. An innovating firm might, for instance, face customer firms that are able to prevent the innovation being adopted. If the innovating firm does not share its profits, or firms perceive the distribution of costs and benefits to be unfair, customer firms will be inclined to prevent adoption of the innovation. 'Subtle leadership' in loosely coupled networks is therefore important to create the right pattern of structural couplings and related appropriation conditions (Orton \& Weick, 1990; Teece, 1986).

Figure 4.2 shows our conceptual model for studying architectural innovation in loosely coupled networks. Firms in loosely coupled networks face inertia when they attempt to architecturally innovate. Cognitive coupling achieved through enhanced leadership and the creation of trust, shared values, and shared strategic beliefs allows firms to structurally couple in a way that is aligned with the product architectural change. Together, cognitive 
and structural coupling are the 'compensation mechanisms' that moderate the detrimental effect of inertia on architectural innovation.

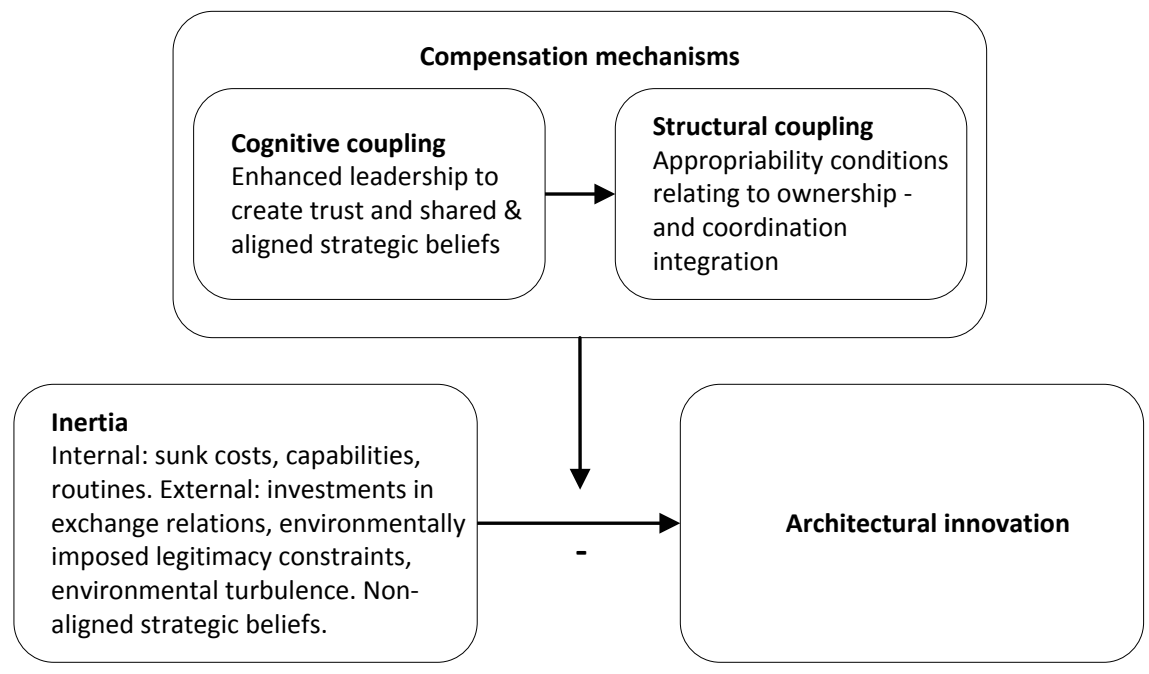

Figure 4.2. Conceptual model for studying architectural innovation

\section{RESEARCH QUESTIONS}

The conceptual model will be used to explore two research questions:

1. Why is architectural innovation difficult in decentralized business networks? To this end, we explore inertial factors that can explain why firms who are interdependent in architectural innovation and who have shared strategic beliefs about the technology trajectory still decide not to collaborate in developing and exploiting such systems.

2. We investigate what compensation mechanisms are available to overcome these impediments. If firms learn how to align product and organizational architectures, it is argued that they will be increasingly motivated to innovate architecturally.

\section{METHODS AND DATA}

The goal of this study is to advance our understanding of architectural innovations in decentralized business networks. To better understand the implications of this specific context for architectural innovation, an exploratory study involving twenty-six firms was 
conducted. Following Eisenhardt (1989a), we first specified what we saw as potentially important constructs and built the preliminary conceptual model shown in Figure 4.2. This model describes the inertial forces and compensating mechanisms in decentralized networks and has been derived on the basis of discussions with field experts and an extensive literature review.

We decided to focus on the construction industry because of its decentralized nature and the complexity of the products it produces (Thompson, 1967, pp 15-18; Hobday, 2000). The construction industry has some characteristics that make it substantially different from industrial manufacturing. It is a low-tech industry (Caerteling, Halman, \& Doree, 2008; Hagedoorn, 1993) that produces immobile, expensive highly-customized goods that are complex because of the large number of modules providing different functions, including mechanical and electrical ones (Eccles, 1981a; Gann, 1996). For this reason, various authors have classified buildings as belonging to the group of 'intensive technologies' (Thompson, 1967) or complex products and systems (Hobday, 2000). This uniqueness discourages the use of project-specific assets, unlike in manufacturing industries producing mass products (Gonzalez-Diaz, Arrunada, \& Fernandez, 2000). The result is an industry in which highly flexible organizational forms are the most common (Cacciatori and Jacobides 2005) and firms are tightly coupled within projects but only loosely coupled between projects (Dubois \& Gadde, 2002)

The study has an embedded design: those firms that were involved in a large architectural innovation form our unit of analysis. The firms involved come from the Netherlands, Belgium, and Germany. Firm level analysis is used to draw conclusions related to the dynamics at the firm, as well as at the network, level. Within this group of firms, various subgroups can be identified such as firms that decided to join, or not to join, the development team. Further, subgroups can be mapped onto the various product modules that were developed such as floor parts with integrated technical installations and prefabricated exterior walls. This allows a replication logic within the case study. The firms were treated as a series of experiments, each serving to confirm or reject the inferences drawn from the previous ones (Eisenhardt, 1989b; Yin, 1984).

All firms that were involved in this architectural innovation, as well as all the firms that decided not to join or to leave the development team, agreed to engage in this study. The 
decision to use this detailed approach allowed us to avoid potentially confounding effects of variations between architectural innovations. A major limitation of this research is that it cannot be statistically generalized beyond the sample of firms observed. Our purpose, however, was to focus on answering why and how questions. A significant event such as this, involving a major, identifiable attempt to shift toward increased product modularity, offered a natural experiment in which inertial forces and compensatory mechanisms could be examined in detail (Schilling and Steensma, 2001).

\section{Data sources}

We conducted in-depth interviews at 26 firms with the top management of the firms, typically including the CEO, and heads of major functions such as innovation, production, and sales. Table 4.1 summarizes the 26 firms in the study. The interview data were used to explain and explore firm and network dynamics in architectural innovations in decentralized networks. By analyzing the interview data we could increase our understanding of factors that impede architectural innovation and what compensation mechanisms are available to mitigate these impediments. The interviews typically took between one and three hours and often ended with a tour around the plant when we were allowed to take photos of some, if not all, parts of the production processes and products for later comparison of the plants we visited. With permission, the interviews were taped and most of them were transcribed within 24 hours of the interview.

We started our series of interviews by interviewing the systems architect of this architectural innovation project. He initiated and launched the project and had close-up experience with all the firms involved. Following this first interview, a semi-structured interview protocol was constructed. We began each interview by explaining the research goals, the independent role of the researcher, and guaranteeing confidentiality about all the reasons given for joining or not joining the development project. Each interviewee was asked to answer a set of structured, open-ended questions. These questions where supplemented with questions that arose during the interview. The interview started with a request to explain the firms' competitive strategy, their experiences with architectural innovation projects, how they got involved in this specific project, and what parts they were asked to jointly develop and produce. Interviewees explained the network in which they 
worked and the sometimes diverse nature of the relationships they have with suppliers and customers. Second, information was gathered about their familiarity with modular design principles and how they apply these in their own organization and products including, for example, a specification of the product interfaces and how these affect the coupling of their products to products supplied by other firms. Third, the interviewees were asked about potential inertia that prevented them from collaborating in this architectural innovation and in architectural innovations in general. Often, interviewees would immediately come up with potential compensating mechanisms for the inertia they mentioned; if not, we asked them questions such as "what solutions are available to confront the inertia you just mentioned?" or "what methods can overcome the relational network constraint you just mentioned?"

In addition to the interview data we also examined secondary sources such as industry reports, annual reports, the firms' websites, and technical documents that specify their products, production processes, and organization. We examined data on 17 patents related to the innovation that were publicly available through the European Patent Office. Finally, we visited two pilot projects: the first Mind Building home that had been erected close to the construction firm, and the second pilot home that was part of a larger traditional housing project. These documents and the site visits offered a way to cross-check the information given in the interviews and to control for retrospective bias.

\section{Research process}

The interview data were analyzed as follows. We began by highlighting recurring words and important issues and stories in the interview transcripts. We clustered these words and issues for each transcript and then compared the clusters across transcripts; finally, we labeled the clusters. We rearranged the data according to the new clusters and used made cross-firm comparisons. We then developed 'formally stated observations', which would be the basis for our hypotheses, based on an initial analysis of the data using methods appropriate for building theory from case studies (Eisenhardt, 1989a; Glaser \& Strauss, 1967; Yin, 2003). To increase external validity, we compared our findings with the literature on architectural innovations in decentralized 'loosely coupled' networks. From these analyses and field observations we developed a refined model with propositions that link inertia and compensation mechanisms to the success of architectural innovations. 


\section{CASE ANALYSIS AND FINDINGS}

In our case analysis, we successively analyzed the constructs and their relationships in our conceptual model as shown in Figure 4.2. First, we describe the architectural innovation: the development of a modular housing system labeled 'Mind Building'. Then, we elaborate on the factors that lead to inertia, and the compensatory mechanisms that increase the willingness of firms to commit themselves to the development and exploitation of this architectural innovation. Finally, we frame the inertial factors and compensation mechanisms in a full process model which helps to explain how architectural innovation in decentralized networks can be achieved.

\section{Research setting}

Our research setting, concerning housing supply in the Netherlands, consisted of a network of firms linked to an architectural innovation in housing systems. These firms provided different value adding activities within the housing supply chain and included professional clients, general contractors, specialized trade subcontractors, architects, engineers, and suppliers of various building elements. All of these firms had been approached by the architect who had initiated the system and asked to join in the development and exploitation of a modular housing system labeled 'Mind Building'. Table 4.1 outlines the twenty-six firms involved in this study. The firms are geographically spread across the Netherlands, Belgium, and Germany and range from small firms with six ftes and an annual turnover of $€ 4$ million up to large multinational firms with 90,000 ftes and an annual turnover of $€ 20$ billion.

The 'Mind Building' concept combines a modular housing system with a business model that is aligned with this innovation. It has a modular product architecture with new, standardized interface designs linking the modules. Figure 4.3 shows a simplified breakdown of the 'Mind Building' system, technical installations are excluded from this illustration but included in the overall system. The innovation was initiated by a systems architect who obtained the commitment of a lead customer, a contractor, and several suppliers of building elements to collaborate on the development and exploitation of the new housing system. Figures 4.4 and 4.5 illustrate the timeline of this architectural innovation. Figure 4.4 shows 
the major events: development started in January 2003, several pilot homes were built, and the timeline ends with the planned start of building the first sixty houses project which is scheduled for January 2009. The top part of Figure 4.5 presents those firms that are committed to the architectural innovation, and below the timeline the firms that were approached but did not commit themselves are shown.

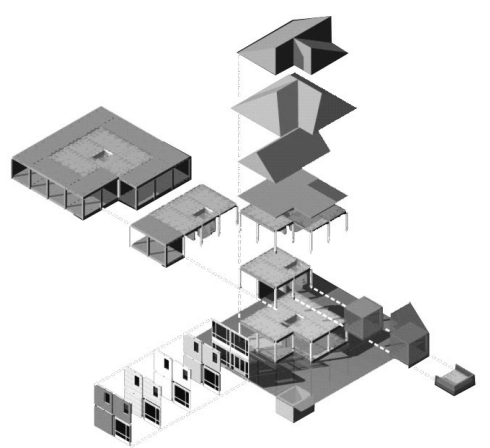

Figure 4. 3. Simplified breakdown of the 'Mind Building' system. Courtesy Jan Wind

Of the twenty-six firms involved, twenty-five commented that they see modularity in housing construction as the 'building principle of the future'. Only two firms argued that traditional construction principles are efficient and sufficiently flexible, and that modular housing construction will just be one of the future directions. Specifically considering the Mind Building system, twenty-four out of the twenty-six firms saw this system as a desirable innovation. The main motivations seen by the interviewees for modularity in housing design were its efficiency and flexibility in design and production. Further, it allows off-site production which is seen as a solution for an industry that is becoming increasingly reliant on a less skilled workforce. This collective image of 'industrial, modular housing systems' as the future is supported by a trend that is observed throughout Europe of increased use of industrial building elements (Bourn, 2001).

We have created three dummy variables representing three size divisions: large for firms with more than 500 employees; medium for firms with between 50 and 500 employees; and small for those with less than 50 employees. Among the firms included in this study are building companies and building materials suppliers listed in Forbes 2000 largest public companies in the world, including $\mathrm{CRH}$, the Royal BAM Group, and Hydro Building Systems. 


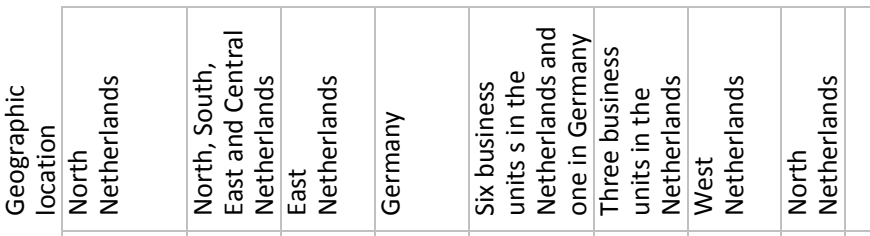

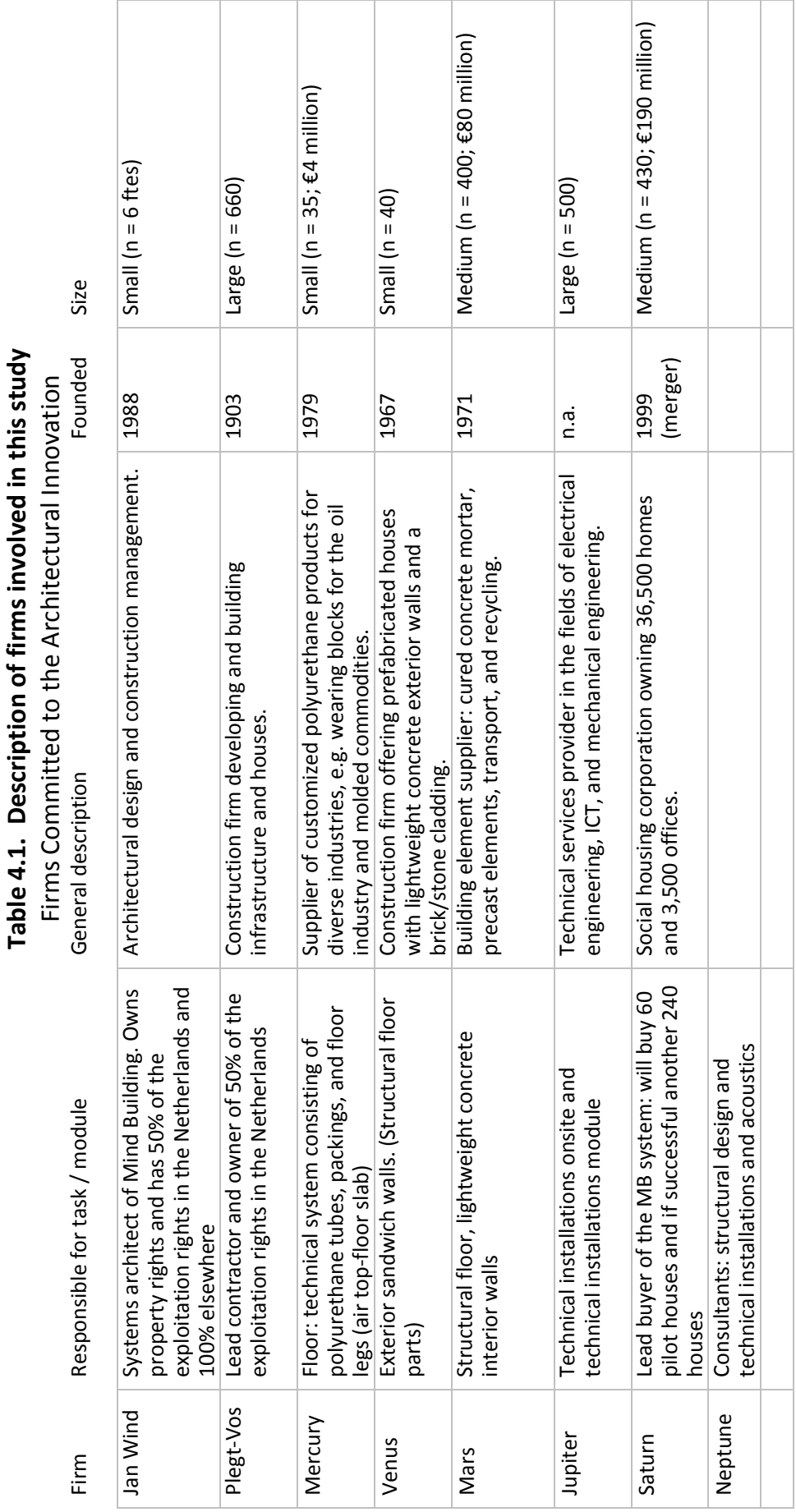



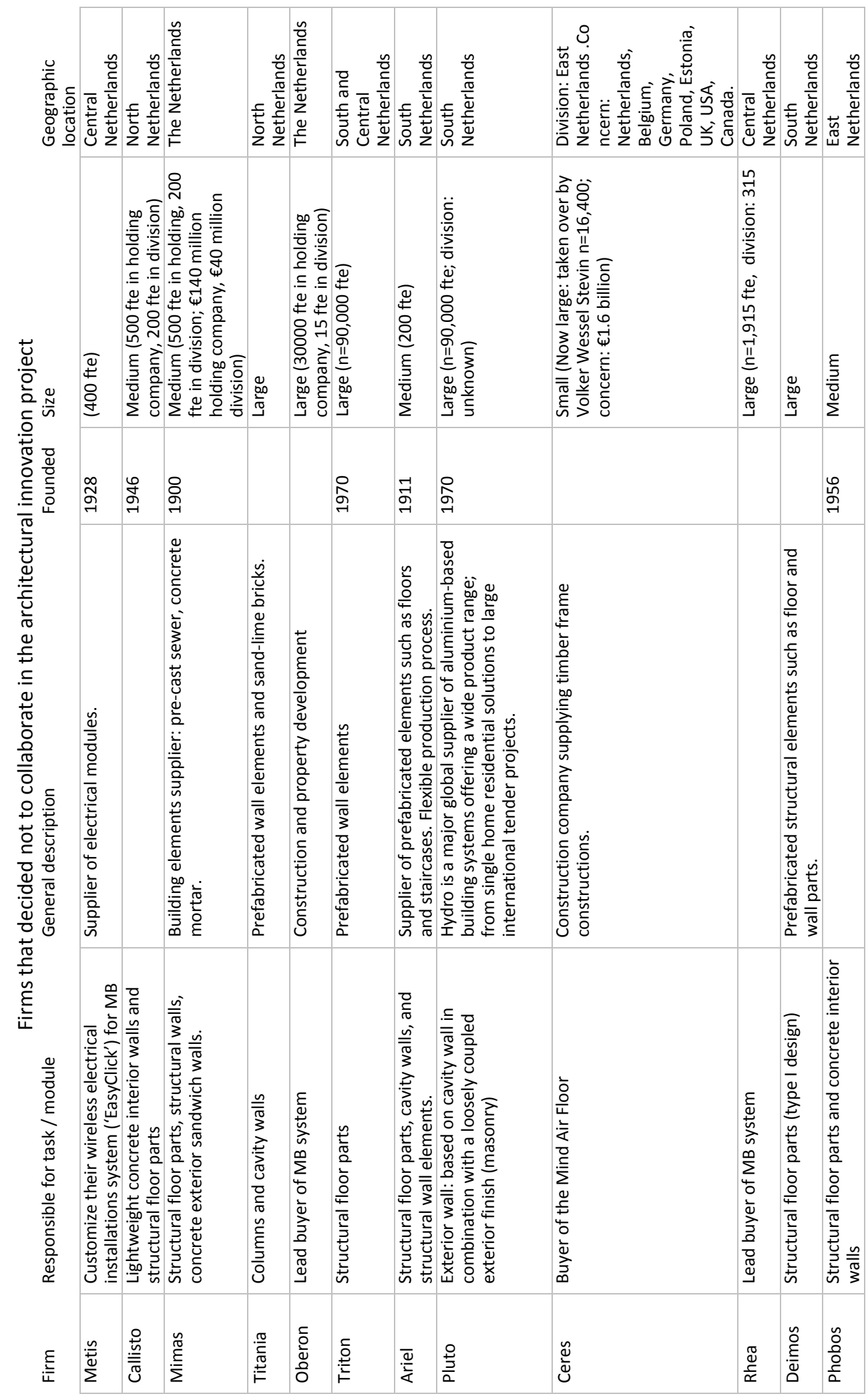


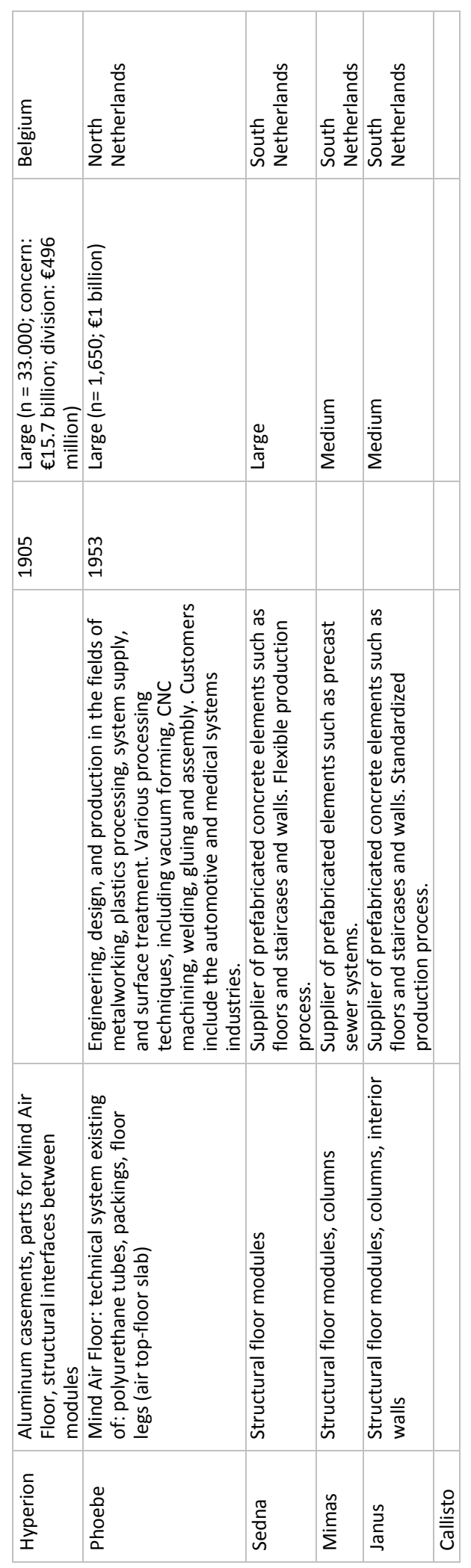




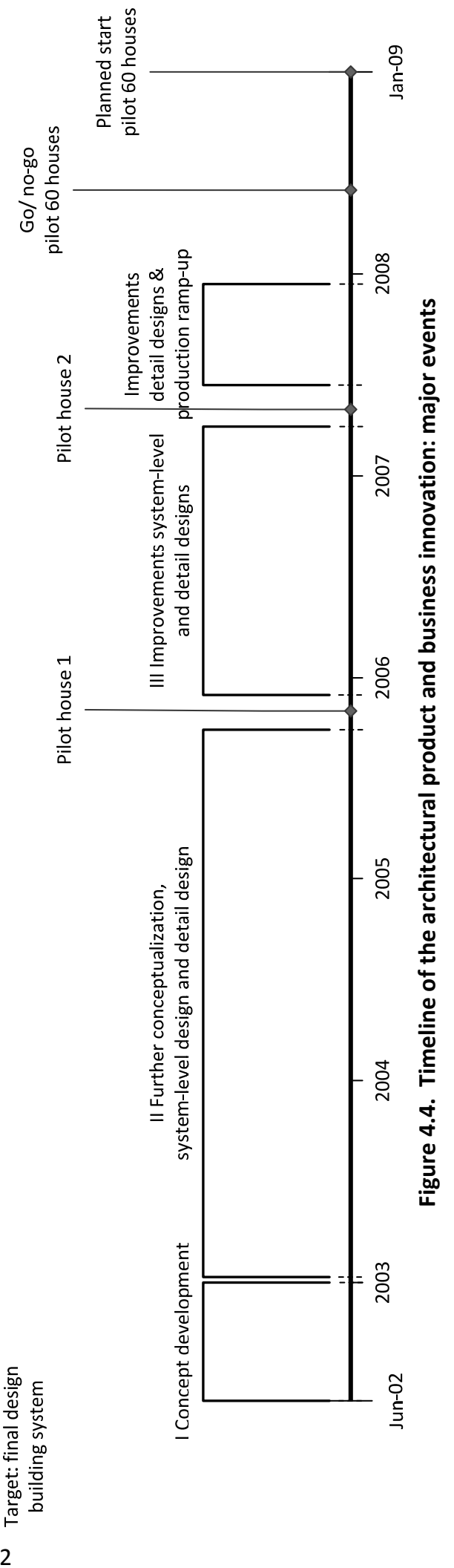




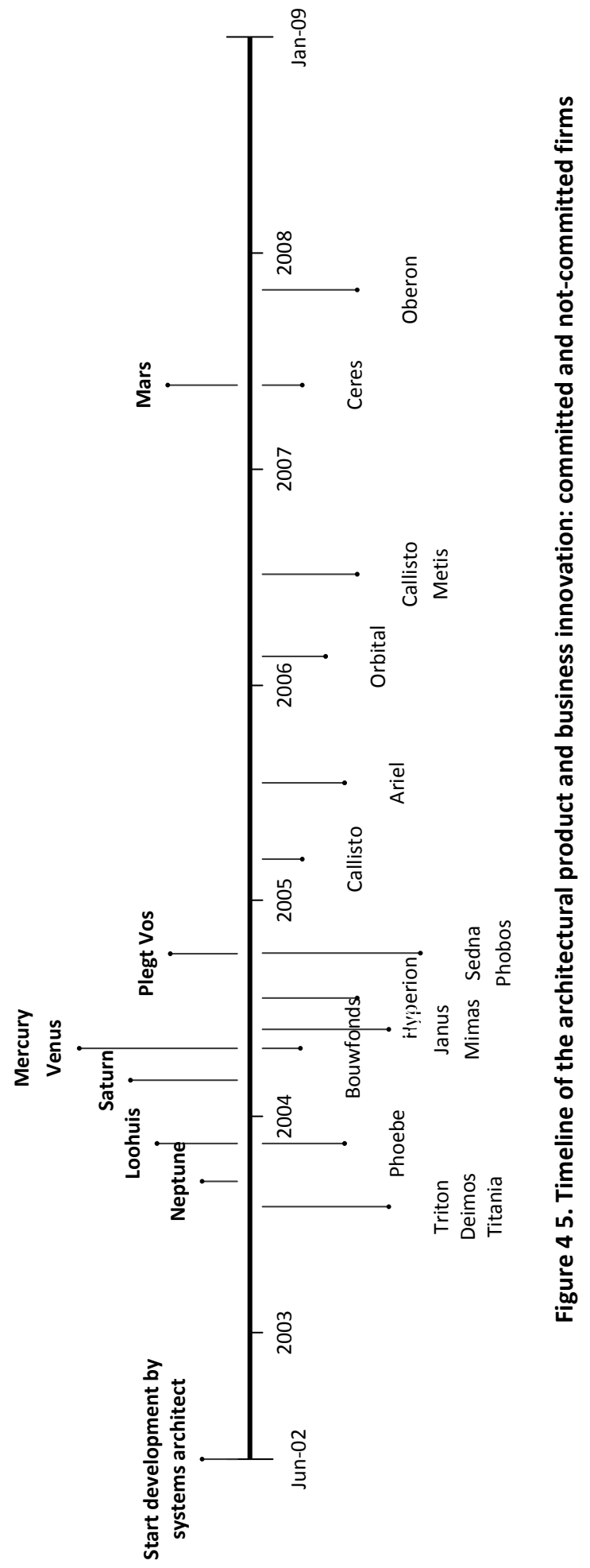




\section{Factors leading to increased inertia}

While we observe that the majority of the involved firms perceive the Mind Building concept to be desirable and technologically superior to current construction methods, it is striking that, even after careful preselection, twenty-six firms had to be approached to find eight firms that were willing to commit themselves to developing and producing the various modules. Given this situation, we searched for possible internal and external factors that caused firms to question, or even withhold their willingness to commit to developing the Mind Building concept.

Internal inertia. Several firms argued that the intended product modules were a misfit with their production facilities, and to achieve a fit would require large investments. Several interviewees explained that they were reluctant to make these investments because they had limited confidence in future sales.

Proposition 1: a misfit between the product innovation and the available production facilities decreases a firm's willingness to collaborate in architectural innovation.

External inertia. Four external inertial factors were identified that impeded architectural innovation. These concerned the high interface criticality between the modules, the high heterogeneity in demand, the routines of downstream firms, and the 'inability' to regain fit between the product innovation and the established organizational design. We will successively discuss these inertial factors supported by interview excerpts.

Interface criticality. Interface criticality reflects the potential impact of a dependency on the functioning of the interfacing modules. Tolerances are a way used to define permissible variations in dimensions, giving the designer, the contractor, and suppliers limits within which their work has to be performed. Traditionally, a contractor solves problems related to tolerance deviations on site but, in this new situation, this risk is to an extent partly passed back to the supplier. The Mind Building system requires all modules to be constructed within a product tolerance range of 1 to 2 millimeters. The modules have steel couplings that connect the elements and allow for potential deviations of this magnitude; that is, the steel couplings effectively function as a mechanism for handling tolerance discrepancies. Nevertheless, the functioning of the overall system and the final on-site assembly efficiency 
depends on two factors. First, the modules from the various suppliers have to be produced within the specified tolerances. Second, contractors must possess the assembly skills required to assemble the system on the site. Suppliers perceive this dependence on the capabilities of other firms as an impediment to collaboration in this architectural innovation.

Interviewees commented that they were not convinced that all the firms supplying modules were capable of producing to the tight tolerances, and that they also lacked confidence in the assembly capabilities of potential contractors. This increased the risks related to investing in the architectural innovation since the failure of any one of the collaborating firms to meet the required standards would likely result in a cascade of malfunctioning modules influencing the functioning of the overall system. The CEO of Phoebe noted:

Compared to traditional construction, the Mind Building system requires much smaller production tolerances. The functioning of our system depends on the accuracy of assembly and on whether the interfacing modules are produced with the same tight tolerances. An uneven surface or deviation in length of the structural floor modules causes leakage of our combined ventilation \& heating system. Unfortunately, we expect the suppliers to employ varying product tolerances, and that contractors do not possess the precise assembly capabilities that this system requires. We therefore cannot guarantee our system when its functioning depends heavily on the work of other firms.

This illustrates how the Mind Building system increases the mutual dependence and responsibility among firms. Another instance of high criticality between modules is explained by Metis, a supplier of wireless electrical systems:

The performance of our wireless electro system ('EasyClick') depends on the amount of iron in the surrounding structure. The 'interfacing' modules influence the quality of the information transfers throughout the building and thereby the functioning of our electro system. If the designs of the surrounding modules were to become fairly predictable, and we knew the amount of iron that is used, our willingness to collaborate in this innovation would certainly increase. 
Data further confirmed that suppliers of building elements have a range of capabilities. As a proxy for production capabilities, we investigated a firm's ability to produce their modules with a tight tolerance. Some firms explained that product tolerances typically ranged from 2 to 8 millimeters. Several firms argued that concrete is a heavyweight, natural material which makes it impossible to work according to the Mind Building tolerances. However, suppliers who produce elements for civil engineering projects, such as tunnels, stated that their elements would be within the product tolerance of 2 millimeters since they use steel molds and have strict quality control over their plant and production processes. To cross-check these findings, we consulted a building material scientist ${ }^{4}$. From this we learnt that the wide range of product tolerances found is most probably caused by differences in production capabilities and not by the natural properties of the basic material. The case evidence thus shows that the increased criticality between modules and the mixed production capabilities found within companies decreases a firm's willingness to collaborate in architectural innovation. Stated more formally:

Proposition 2: A firm's distrust in the competences of other firms with which they share an interdependency will be negatively related to their willingness to collaborate in architectural innovation.

Heterogeneity in demand. Each firm explained that they currently face a great variety in demand and that they could produce more efficiently if shared modular standards were more widely used. Interviewees went on to explain that they cope with this heterogeneity in demand by employing manufacturing flexibility rather than by investing in modular product architectures. Manufacturing flexibility is an alternative approach to achieving efficient production of a large variety of end-products (Ulrich, 1995). The interview data suggest that large heterogeneity in demand complicates the development and adoption of modular interface designs. A comment by the CEO of Ariel illustrates one result of the significant heterogeneity in demand:

\footnotetext{
${ }^{4}$ The thermal coefficient of concrete is typically $\alpha_{T}=10 \times 10^{-6} K^{-1}$ This means that a temperature change of 10 Kelvin causes a ten-meter concrete element to expand or shrink by 1 millimeter.
} 
You have to remember that all our projects are unique. Not because we think that's necessary, but each architect, end-customer, and contractor have their own standarddestroying demands, or they apply their own preferred interface details that do not correspond with ours. For us, it is just not worth investing in product standards. If I do invest, I will invest in flexible manufacturing systems, not in a modular product architecture with standard interface designs, that's simply too rigid in our business.

Similar statements were also made by firms who did commit themselves to the development team: they also experienced difficulties in trying to set standards. Jupiter, a technical installations supplier explained how varying interface specifications influenced their willingness to invest in standards setting:

Interfacing modules interact, and each time one or more interfacing modules are changed, our installation module needs to be adapted. Initially we were reluctant to invest in developing our standard module, and now we think we were wise not to start off too enthusiastically in investing time and money in developing our module since the systems architect kept on changing the design specifications of other modules. Unless all interfacing modules achieve a more-or-less stable design, investing in modular standardization remains very risky since it is unlikely we will get a return on our investment.

Our case data indicate that modular standards are perceived as too rigid given the high external variety in demand, and that firms prefer to stick to routine methods. In this case, the routine methods involve flexible manufacturing systems (FMS). In general, firms argued that the high demand heterogeneity, in a context where no shared standards are available, decreases the re-use potential of modules and this subsequently decreases the likelihood that investing in developing modular standards will produce a financial return through use in future projects. Contractors, architects, and customers all have conflicting interface demands which further decrease the potential of standard interface designs to find a large market. Stated more formally: 
Proposition 3: in loosely coupled networks, large heterogeneity in demand acts as a disincentive for firms considering investing in the creation of new interface standards and architectural innovation.

Routines at downstream firms. Our case findings show that if an architectural innovation changes the horizontal division of labor, suppliers are, in principle, interested if this increases the value they can add to their products. Most suppliers claimed to continuously consider integrating complementary products or services currently provided by other suppliers and that they are able to incorporate this sort of change. However, the interview results show that, in general, these suppliers were less enthusiastic about horizontal integration induced by architectural innovation. One major factor was that that they saw their customers' technology evaluation routines as impeding horizontal integration. A routine frequently involved the contractor's drive for minimizing costs. Two of the interviewed companies (Triton and Titania) gave the same example. They explained that they both produce lightweight floor systems made up of a biaxial reinforced load-carrying hollow slab filled with plastic or polystyrene balls that replace concrete that has no structural purpose. The main benefits are the easy integration of technical systems and a weight reduction of about $35 \%$ compared to traditional solid slabs with similar load bearing capacity. The modules further integrate several building elements and production tasks that were traditionally supplied by different suppliers. The CEO of Triton explained:

Contractors normally procure floors in parts. Since we add value to our integrated floor, the cost per square meter exceeds the cost of a traditional floor that lacks the integrated technical installations, and the achieved weight reduction. However, we experience difficulties in selling this innovative floor system because the contractor's norms for evaluation focus on minimizing costs per square meter. Therefore, as long as the contractor evaluates the parts instead of the whole, they will never choose our integrated floor system. If the contractor assessed our integration contributions, and took account of the fact that this saves a lot of work on site, and that the weight reduction would allow them to add more storeys to their building, our floor system would most probably outperform all other floors. They really should learn how to evaluate systems that differ from traditional systems. 
Furthermore, suppliers commented that the contractors' focus on cost-minimization at the project level discourages potentially good platforms that would save money if they were evaluated and applied at the multi-project level. The CEO of Jupiter Installations explained:

In the field of technical installations, there is a layout platform for walls. This platform is comparable with the dashboard of a car: it has slots and cables pre-installed which eases the addition of options like extra switches. Rather than this being an option, we could actually install them. Adopting this platform increases material costs a bit, but overall you would save money since it decreases production and coordination costs. However, in the construction industry, contractors still focus on optimization per project and per building element, which conflicts with standards that only pay-off on the multi-project level.

The case findings illustrate that suppliers have no objection to integrating the products and value-adding activities of other suppliers in their modules. There are no horizontal interdependencies that impede horizontal integration, but the routines followed by contractors appear to discourage such activities. Suppliers perceive the contractors' evaluation criteria as inappropriate for their proposed product innovations. The case evidence reveals that contractors are used to optimizing quality and prices for each building module at the project level, whereas a more holistic approach is needed to evaluate integrated modules. Contractors are used to optimizing on the project level, and this leads to suboptimal solutions at the multi-project level. This approach, reinforced by severe price competition, leads contractors to minimize prices of individual modules and projects. This form of constrained optimization hampers architectural innovation and makes it hard to develop modules that integrate traditionally fragmented tasks and components, such as the Mind Building concept calls for. In short, the routines of downstream firms have a significant impact on a firm's willingness to collaborate on architectural innovation, leading to the following hypothesis:

Proposition 4: The perception that downstream customers have rigid routines impedes architectural innovation by upstream firms. 
'Unsolvable' misfits. The case analysis, the pilot projects, and the consultations with experts reveal that, from a technical standpoint, the new system could be produced and that it would allow firms to make gains. Although suppliers were expected to make larger gains than the loses incurred by the building contractors, various suppliers explained that they were still reluctant to collaborate in the architectural innovation. The new technology changes the vertical division of labor, and requires the suppliers to integrate tasks traditionally performed by their main customer: the building contractors. The new product architecture would change the revenue structure of the value chain in a way that would harm their customers' businesses. According to one supplier (Metis):

Contractors will lose a lot of work with these industrial, modular systems; I cannot imagine why any contractor would be willing to commit to developing and exploiting a system like Mind Building. I actually don't understand why Plegt-Vos has.

Several suppliers could not imagine any contractor collaborating in this new business unless they were somehow able to appropriate part of the overall benefits. Interviewees suggested some ways of compensating the contractor but these later proved to be impossible to implement. One idea was full ownership integration or an equity alliance with the contractor to overcome complications related to the changing revenue structure. However, suppliers would than fulfill two incompatible roles in one firm: they would supply building elements to other contractors with whom they would then compete in other projects. These two roles have conflicting interests and threaten the integrity of suppliers, something that suppliers in the current climate are not willing to risk since it could lead to exclusion from other construction projects. For these reasons, suppliers expected contractors to resist collaboration as long as they have the power to reject adoption of the system. The CEO of Ariel explained:

The contractor, as a generalist, impedes other firms trying to set new product standards and integrate tasks that are traditionally integrated by the contractor since that would devalue the core coordinative capabilities of the contractor, which now forms the basis of their tasks. 
Other archival data also show evidence for there being this boundary in vertical integration. The 2006 Triton/Pluto annual report, for instance, explains: "we aim to be international market leaders in the production, sale, and distribution of primary materials and valueadded building products...but ... we stick to core businesses in building materials." Their reluctance to take on their customers' value adding activities acts as a strong inertial force against any architectural innovation that would overturn the old architecture and its corresponding labor divisions, even if the new system was technologically superior to the old one. Potential losses at one firm thus prevent a global optimization embracing all parts of the system and value chain. Stated more formally:

Proposition 5: in loosely coupled networks, an innovation that changes the prevailing revenue structure reduces a firm's willingness to collaborate in the architectural innovation.

\section{Compensation mechanisms}

Next, we analyzed whether and how the firms in this loosely coupled network employed compensatory mechanisms to overcome the inertial factors. The compensation mechanisms found to affect inertia concern cognitive and structural coupling. A process of cognitive coupling creates trust, shared values, and strategic beliefs among firms and this precedes structural coupling. To illustrate how compensation mechanisms help to overcome inertia, we contrast excerpts from interviews of collaborating and non-collaborating firms. Table 4.2 summarizes the inertia and related compensation mechanisms.

Cognitive coupling - screen and select, or reframe. In contrast to the firms which did collaborate, the firms that decided not to collaborate in the architectural innovation showed a lack of trust, or they had values and strategic beliefs that were misaligned and incompatible with those of the other firms. Cognitive coupling involved several managerial activities to overcome inertia. First, before accepting a potential collaborator, the systems architect and the contractor probed the firm's values, competences, and strategic beliefs. Some firms had strategic beliefs and competences that were good matches for their own and for the proposed innovation. For example, as the collaborating firm Mercury (a technical plastics manufacturer) explained: 
We share the values of the systems architect and contractor that the current methods of housing production are outdated. Efficient modular housing systems and design flexibility for the buyer is the future. And of course it is important that all firms produce their parts to small tolerances, that is already common in the other industries we supply.

Table 4.2. Inertia and related compensation mechanisms

\begin{tabular}{|c|c|c|}
\hline Compensations & $\begin{array}{l}\text { Cognitive coupling } \\
\text { Methods applied to align strategic } \\
\text { beliefs among firms }\end{array}$ & $\begin{array}{l}\text { Structural coupling } \\
\text { A pattern of structural couplings } \\
\text { that overcome inertia }\end{array}$ \\
\hline $\begin{array}{l}\text { Misfit between available } \\
\text { production facilities and } \\
\text { the innovation }\end{array}$ & $\begin{array}{l}\text { Inspirational communication to } \\
\text { increase trust in the potential } \\
\text { market success. }\end{array}$ & $\begin{array}{l}\text { Integrated coordination by } \\
\text { collaboration at the multi-project } \\
\text { level plus the commitment of a } \\
\text { lead customer. }\end{array}$ \\
\hline $\begin{array}{l}\text { High interface criticality } \\
\text { and low competence- } \\
\text { based trust }\end{array}$ & $\begin{array}{l}\text { Physical experimentation AND } \\
\text { communication about specialized } \\
\text { knowledge AND communication } \\
\text { about how to decrease variability } \\
\text { in production tolerances reframed } \\
\text { the firms' beliefs about what is } \\
\text { technologically possible and how } \\
\text { to align the organizational design. }\end{array}$ & $\begin{array}{l}\text { Integrated coordination through } \\
\text { multi-project collaboration } \\
\text { decreases the variability in } \\
\text { production capabilities among the } \\
\text { firms in the development team. }\end{array}$ \\
\hline Heterogeneity in demand & $\begin{array}{l}\text { Inspirational communication } \\
\text { reframed the firms' beliefs about } \\
\text { how to decrease heterogeneity in } \\
\text { demand by new forms of } \\
\text { integrated coordination to } \\
\text { increase the reuse potential. }\end{array}$ & $\begin{array}{l}\text { Centralized integrated } \\
\text { coordination of suppliers, } \\
\text { contractors, and the lead } \\
\text { customer. AND integrated } \\
\text { coordination by collaboration at } \\
\text { the multi-project level rather than } \\
\text { for single-projects. }\end{array}$ \\
\hline $\begin{array}{l}\text { Routines at downstream } \\
\text { firms }\end{array}$ & $\begin{array}{l}\text { Simulation showed differences } \\
\text { and commonalities between the } \\
\text { old and new technologies, this } \\
\text { reframed the contractor's beliefs } \\
\text { about how to evaluate the } \\
\text { innovation. }\end{array}$ & \\
\hline $\begin{array}{l}\text { 'Unsolvable' misfits } \\
\text { induced by the } \\
\text { technological innovation }\end{array}$ & $\begin{array}{l}\text { Inspirational communication } \\
\text { convinced firms to adopt new } \\
\text { forms of structural coupling to } \\
\text { solve misfits between the new } \\
\text { technology and the existing } \\
\text { organization design. }\end{array}$ & $\begin{array}{l}\text { New forms of integrated } \\
\text { coordination and ownership } \\
\text { integration. Ensuring the Mind } \\
\text { Building business is structurally } \\
\text { differentiated from that of the } \\
\text { contractor. }\end{array}$ \\
\hline
\end{tabular}


In contrast, firms who did not collaborate had incongruent values and strategic beliefs. For instance, the CEO of Ariel explained:

I don't believe in the market potential of the Mind Building system. Customers will only buy the Mind Building system if it is cheaper and of better quality than current housing construction, but I don't believe they will achieve this.

The systems architect selected Mercury to collaborate in the development and exploitation of the 'Mind Building' system because the company fitted with the product innovation in several ways. They had comparable values and strategic beliefs about the system, and about how to structurally couple with other firms to develop and exploit it. This example shows that sometimes it is enough for the systems architect and the contractor to screen the values and strategic beliefs of the firms they approach to see if 'cognitive coupling' already exists.

However, the cognitive coupling involved more than screening for compatibility and selection of firms. It also involved increased communication, experimentation, and simulation that helped to overcome inertia. For instance, two pilot houses and several pilot modules by various suppliers were built. This brought unforeseen critical interactions between the modules to light and it demonstrated to firms the importance of achieving the tight tolerances. As the contractor explained:

We expected that the assembly process of our first pilot house would go smoothly, after all the interfaces and tolerances were clearly standardized. The truth is that several modules did not connect well; it really showed us, and the firms involved, that we must stick to the small tolerances.

And, as the systems architect explained:

Experimentation showed the involved firms that there were major differences between the Mind Building system and the old technology. Furthermore, it showed us all how centralized coordination can help to decrease the variability in production tolerances of modules within the Mind Building team. 
Experimentation thus emphasized to firms the importance of producing the modules to tight tolerances, something that had never had any priority in the industry. Another example of cognitive coupling involved inappropriate evaluation routines used by the contractor that were resolved through a simulation exercise. A future sixty-house project was financially evaluated based on being built in the traditional way and then by using the Mind Building approach. This comparison highlighted the commonalities and differences between the old and new technologies and helped to reframe the existing inappropriate evaluation routines. Additionally, this exercise made clear that new and unusual forms of structural coupling would be required to enable the involved firms to earn a return on their investments through multi-project rather than single project arrangements. Experimentation and simulation thus both helped to improve the firms' beliefs about the technology and the importance of tighter production tolerances, and it helped to reframe inappropriate evaluation routines used by the contractor. In addition, increased communication made clear that the Mind Building system required new forms of structural coupling in order to overcome inertia. Thus, cognitive coupling helped to break down the mental frames of firms about 'how construction works and what can be achieved'. Expressing this more formally:

Proposition 6: in loosely coupled networks, cognitive coupling, achieved by screening and selecting firms with aligned strategic beliefs, or else by screening and then reframing inappropriate strategic beliefs (by physical experimentation, simulation, and communication) and selection, reduces the inertia that acts against collaboration in architectural innovation.

Structural coupling: patterns that worked. As we explained earlier, rigid strategic beliefs complicate the alignment of organizational architecture with architectural product innovation. We asked the firms involved how they resolved this issue, or what solutions they would propose for solving issues related to loose coupling and inertia. Further, we asked them what motivated them in selecting these solutions. It appeared that the firms that decided not to collaborate relied heavily on current practice, and tended to stress the potential exploitation of available product capabilities and organizational routines rather than the exploration of new, potentially better matched, solutions. These routine methods to solve misfits often conflicted with the requirements of the architectural innovation. 
Cognitive coupling convinced firms that structural coupling in novel ways was practical and would overcome the inertia. The firms who chose to collaborate adopted aligned and socalled 'reframed' solutions.

Ownership integration. The collaborating firms adopted reframed solutions in order to overcome inertia. In the new business, the systems architect owns the property rights to the modules and has equal shares with the contractor in the new venture that will exploit the system. This venture is structurally differentiated from the contractor's traditional activities. By allocating the commercial rights to the systems architect and to the contractor, the distribution of any surplus generated produces a positive benefit for these two organizations. Several of the suppliers viewed this reframed solution along the lines of the following quote:

...feels counter-intuitive since we are used to controlling our sales by selling our proprietary products externally.

Nevertheless, the collaborating firms shared a vision that this solution offered a way of compensating the contractor for the loss of its traditional value-adding activities, and that this decreased the potential resistance of the contractor to this innovation. This was seen as necessary since the contractor's collaboration was essential since it had the power to block adoption of the system. This solution thereby solved the 'unsolvable' by compensating the contractor for its potential losses due to a changed revenue structure. Non-collaborating firms had problems accepting this reframed solution, and did not offer alternative compensatory solutions for the issues related to the changing revenue structure. Instead, they stressed that they wanted to own the property rights for selling the system outside the Mind Building network. In short, collaborating firms were able to adopt reframed solutions while non-collaborating firms were unwilling to. Some suppliers were unwilling to become involved in the new venture since they thought they would lose integrity in the eyes of other contractors. To overcome this potential loss of business, collaborating firms were compensated for their investments by means of multi-project contracts with the new Mind Building venture. 
Coordination integration. Although ownership integration overcame inertia related to changing revenue structures, it did not supply suppliers with sufficient 'confidence in the future'. Firms argued that heterogeneity in demand had to be decreased in order to increase the reuse potential of standard modular components and so enable them to achieve a return on their investments. The firms we studied all tried to optimize individual sales: they invested time in controlling inbound orders, to a certain extent by 'selling' their products to the end-customer. In this way, contractors and suppliers both try to reduce heterogeneity in demand by coordinating downstream integration. One of the suppliers (Metis) explained their usual approach to this issue:

We always try to convince the end-customer to ask the contractor to use our products, whether the contractor likes it or not.

Contractors too tried to commit the end customer, and preferably at the multi-project level, in order to decrease the heterogeneity in demand. Unfortunately, this was often impossible due to decentralized and conflicting strategies. Jupiter, a specialized contractor, explained that it is the heterogeneity of inputs that increases the heterogeneity in demand:

It is difficult to stick to standards when our suppliers of technical components keep talking with our customers. Our customers often then ask us to use parts that don't match the interfaces of our installations module.

Thus upstream and downstream firms employed similar strategies, and these conflicted when they were simultaneously executed. These non-aligned strategies undermined the full reuse potential of products from firms offering modular components. In order to widen the reuse potential of modular standards, the non-collaborating firms wanted routine solutions and the property rights and associated benefits from selling the modules outside the network.

The systems architect proposed a reframed solution to compensate for the large heterogeneity in demand (and inputs) that involved collaboration at the multi-project level. For this purpose, early in the conceptual design phase, he obtained the commitment of 
Saturn, a large social housing corporation. Saturn agreed to order 300 houses before the modular platform design was finalized. This enabled the systems architect and the contractor to contract suppliers at the multi-project level. From the interviews it was clear that this was very unusual for firms in this project-based industry, and some firms could not believe that there was an order for so many houses. Nevertheless, the multi-project contracts and the commitment of the lead customer increased the other firms' beliefs in the potential for an ongoing relationship. This made these firms willing to invest in developing and exploiting the Mind Building system. In this way, a centralized integration of coordination mitigated the detrimental impacts of decentralized strategies, reduced heterogeneity in demand, and increased the reuse potential and the willingness of firms to collaborate in developing and exploiting the Mind Building system. Stated more formally:

Proposition 7: in loosely coupled networks, centralized coordination aligns the various firms' decentralized routine behaviors in a set of strategies that is more organizationally balanced towards product architectural innovation.

Proposition 8: in loosely coupled networks, increased stability achieved through collaboration at the multi-project level, rather than on the single engineer-to-order project level, increases a firm's willingness to collaborate in architectural innovation.

Further, integrated coordination also served another purpose; the tacit nature of the development task required increased integration of knowledge among the specialized firms. The systems architect and Plegt-Vos needed specialized knowledge that was available in other firms. Compared to systems integration firms as defined by (Brusoni et al., 2001), they knew 'a bit more than they produce' but certainly not enough to develop a fully working modular housing system on their own. The systems architect explained:

Close collaboration with suppliers to solve technical problems improved the module designs, the related manufacturability and product performance, and it decreased production costs. Inputs of supplier knowledge in the development phase also improved the quality of the design rules, which increased the suppliers' willingness to adopt these design rules. 
Although, in general, once developed these standard interface designs will function as a coordination mechanism reducing the need for mutual adjustment and communication, interviewees explained that increased knowledge exchange was required to develop these standard interfaces. The approach adopted of integrating suppliers in the development phase focused on learning and long-term benefits rather than the short-term expediency that most firms were used to. Stated more formally:

Proposition 9: in loosely coupled networks, an increase in informal personal and group modes of mutual adjustment is required to develop design rules.

\section{DISCUSSION OF FINDINGS}

This analysis of architectural innovation in a loosely coupled network with decentralized architectural control and no dominant design rules fills a significant gap in the literature regarding this important innovation context (see Figure 4.1). While earlier research had investigated inertia related to structural change (Hannan, 1984), academic research had not previously explicitly linked inertia to compensation mechanisms in one coherent conceptual model that could be used to study product architectural innovation. We used this conceptual model to study the challenges that a lack of architectural control and design rules pose on architectural innovation in loosely coupled networks. By looking closely at how firms dealt with these inertial factors we found a set of compensatory mechanisms that managers could employ to effectively meet these challenges.

\section{Inertial factors}

Our analysis uncovered five inertial factors that impede architectural innovation in this context. Although one factor was internal to the firm, the four most prevalent factors were imposed externally. Internal inertia was linked to the high cost of architectural innovation in combination with a limited trust in future sales. These costs reflected the investments in existing technological capabilities and production facilities that would become obsolete as well as those required in new capabilities and facilities. After evaluating the cost of the required changes against the future unknown rewards, many firms preferred to invest in 
internal process optimizations since incremental improvements were expected to deliver better returns. Existing literature explains this behavior and shows how firms often decide to invest in incremental innovation and local learning, even when this might lead to the adoption of suboptimal techniques. This effect is known as the competency trap (Levitt \& March, 1988; March, 1991).

However, our findings indicate that four external inertial factors, or 'network inertia', play a greater role in impeding firms from collaborating in architectural innovation than this internal factor. External inertia was found related to: high criticality among product modules, large heterogeneity in demand, rigid and inappropriate routines, and inappropriate strategic beliefs. We will now discuss these external factors in more detail.

First, research into engineering design distinguishes between weak and strong design dependencies; and the interface criticality then defines the potential impact of a dependency on the functioning of the interfacing modules (Pimmler \& Eppinger, 1994; Sosa et al., 2003, 2004). Due to only vague industry norms when it comes to production capabilities, firms had limited trust in other firms' production capabilities. Therefore, many firms expected problems with the high interface criticality combined with the limited performance of interfacing modules, and this decreased their willingness to collaborate and invest in the architectural innovation.

Second, we found that the large heterogeneity in demand made firms reluctant to collaborate because the consequent limited reuse potential of standard interfaces did not justify the costs related to standardization through developing and following modular design rules. Other research (Hannan \& Freeman, 1984) has also defined structural inertia relative to environmental change, and argued that structures have high inertia when the speed of reorganization is much lower than the rate at which environmental conditions change. However, this finding seems to contrast with the modularity literature which argues that wide heterogeneity in inputs and demands causes systems to shift toward increased modularity (Langlois \& Robertson, 1992; Schilling, 2000). These conflicting observations suggest that the phenomenon itself might be under-specified, and that a more complex set of determinants may resolve the confusion (Gilbert, 2005; Sitkin \& Pablo, 1992). In the next section, we elaborate on this apparent contradiction in the literature. 
Third, in the loosely coupled network that we studied, it was the routines of other firms that decreased a firms' willingness to collaborate in architectural innovation. This complements the findings of other academics who show how architectural innovation is complicated by embedded cognitive frames (Henderson \& Clark, 1990), for instance about what type of incentive regimes (Kaplan \& Henderson, 2005) or business models (Tripsas \& Gavetti, 2000) are suitable for developing and exploiting new technologies. This results in routines that deliver suboptimal performance when experience is transferred to inappropriate situations (Levitt \& March, 1988). However, these findings all concern routines at the firm level impeding action at the firm level. Our case evidence on the other hand shows how cognitive frames, embedded in individual firms, are reinforced by routines at the network level. Firms, for instance, prejudged the production capabilities of other firms and, having concluded that other firms were not able to produce modules with tight tolerances, decided not to invest in meeting tighter tolerances themselves. Another example is the inappropriate routines used by the contractor to evaluate integrated product modules which decreased the suppliers' willingness to add value to their modules. Here, the actions and reactions were not aligned with the architectural innovation: negative expectations of other firms' routines and strategic beliefs impeded architectural innovation. In line with the thesis of Cohen and Bacdayan (1994), we argue that, especially in loosely coupled networks, firms assume the routinized actions of other firms which then triggers behavior that possibly itself influences the actions of the other firms.

Fourth, a perception of there being 'unsolvable' misfits decreased the firms' willingness to collaborate in the architectural innovation. Firms benefit from a fit between strategy, technology, and organization design features such as task structure, competences, culture, incentive structure, and the formal organization (Burton et al., 2002; Chandler, 1962). However, several firms were not able to resolve misfits induced by the technological innovation. For example, $\mathrm{CRH}$ wanted to own the property rights and sell their module outside the project in order to increase its reuse potential and the return on investments. However, this conflicted with their formal strategy of not competing with the contractor. The proposed solution was therefore internally inconsistent. Further, this solution also conflicted with the strategic beliefs and solutions of the other firms' involved that, in some cases, preferred multi-project collaboration and the commitment of a lead customer to 
increase the reuse potential of modular standards. Strategic beliefs and related solutions were therefore also sometimes incongruent between firms. Our findings suggest that, in loosely coupled networks, external inconsistencies in strategic beliefs require at least as much attention as inappropriate and inconsistent internal strategic beliefs. Managerial actions to reframe inappropriate routines and strategic beliefs need to focus on creating a congruent set of internal and external strategic beliefs. With this conclusion, this research extends much of the recent work on managerial cognition in technological innovation (Henderson \& Clark, 1990; Kaplan, 2008; Tripsas \& Gavetti, 2000) from the firm level to the level of networks.

\section{Compensation mechanisms}

In practice, compensatory mechanisms were used to overcome inertia toward architectural product change. This involved a process of cognitive coupling preceding a pattern of structural couplings which, together, moderated the detrimental effect of inertia on architectural innovation.

In the Mind Building case study, firms with congruent values and similar strategic beliefs were specifically selected to collaborate in the innovation. However, despite this, often firms still needed to overcome rigid, inappropriate strategic beliefs that did not match the product innovation. Such beliefs were reframed through a process of cognitive coupling. This involved experimentation, simulation, and increased communication among the suppliers, the systems architect, the contractor, and the lead customer. This challenged conventional wisdom and highlighted the differences and commonalities between the new and the old technologies and the related organizational design. In this way, a process of cognitive coupling was used to reframe inconsistent strategic beliefs within and between firms, and to align them towards the product architectural innovation. Inappropriate product evaluation routines used by the contractor were, for instance, reframed through a simulation process, and the trials with pilot houses enabled firms to experience that the required production tolerances could be achieved, and were necessary, and this increased the firms' competence-based trust. Other research shows how previous technological choices and existing products and competences shape strategic beliefs that themselves guide future technological choices in the same direction (Cohen \& Levinthal, 1990; Garud \& Rappa, 1994). 
Consistent with research on cognitive processes, which suggests that significant learning should ideally precede change in such biases, our findings indicate that cognitive coupling can be used to purposefully reframe existing strategic beliefs and, as a consequence, it forms a powerful method to redirect a potentially suboptimal technology trajectory.

This research also suggests that cognitive coupling not only increased competence-based trust and reframed inappropriate evaluation routines; it also reframed strategic beliefs about how to structurally couple in ways that would overcome inertia related to appropriability conditions. As we explained earlier when discussing the conceptual background, appropriability conditions determine whether firms are able to capture part of the profits generated by an innovation (Teece, 1986). It appeared to be difficult in our case study for some firms to find new forms of structural coupling that would allow all the involved firms to appropriate part of the surplus. As we described earlier, the changing revenue balance was initially perceived as an 'unsolvable' misfit. However, new forms of ownership and coordination integration overcame these inertial factors: a 'counter-intuitive' method of ownership integration was found that resolved this issue. The systems architect and contractor established a new firm that owned the property rights and the rights to exploit the system, and each supplier has an ongoing contractual relationship with this new firm. Further, coordinated integration achieved through centralizing coordination in the hands of the systems architect aligned the decentralized and conflicting strategies initially proposed to appropriate a share of the profits from the Mind Building system. The integrated coordination achieved by committing a lead customer and by creating a stable Mind Building network through collaboration at the multi-project level, rather than for single projects, increased the firms' future expectations. Further, this mutual commitment decreased the potential variability in production capabilities within the Mind Building network, which reduced the risks related to high interface criticalities. 'Subtle leadership' (Orton \& Weick, 1990) is thus not only required for cognitive coupling, it is also essential if one is to develop a pattern of structural couplings that create the right appropriability conditions in loosely coupled networks in which 'relational ties are highly sensitive to the strength of the network's appropriability regime' (Dhanaraj \& Parkhe, 2006). The package of structural couplings developed by those involved increased their willingness to collaborate in 
an architectural innovation and share knowledge and other resources in developing new design rules.

\section{Toward a model of loose and tight cyclical couplings}

The modular systems theory explains that heterogeneity in demand and inputs motivate companies to adopt modular product design rules and loosely coupled organizational forms. This supplies companies with the flexibility and level of specialization they need to adapt and respond in fragmentized environments (Orton \& Weick, 1990; Schilling, 2000). For example modular products enable customers to specify products that match their unique tastes and needs (Baldwin and Clark, 1997) and it allows companies to cope with rapid technological change because changes within specific modules remain localized and have limited to no impact on tangent areas of the product system (Langlois \& Robertson, 1992; Ulrich, 1995).

Modular product standardization precedes and facilitates organizational specialization and loose coupling (Jacobides, 2005; Langlois \& Robertson, 1992; Schilling \& Steensma, 2001). This is explained by Ulrich (1995) and Sanchez and Mahoney (1996) who argue that fully specified component interfaces, codified in design rules, standardize the input and output requirements for the various product modules, and this allows the groups responsible for these modules to perform their development or production tasks autonomous and concurrently (Sanchez, 2000). Such differentiation allows companies to efficiently cope with the unique requirements of their sub-environments and allow companies to flexibly create and recreate organizational structures at little cost (Lawrence \& Lorsch, 1967; Orton \& Weick, 1990). Thus, fragmented, heterogeneous environments characterized by diverse and fast changing customer demands and technological inputs motivate companies to increase their responsiveness and innovativeness by adoption of modular design rules and loosely coupled organizational forms.

We illustrate the relationships between a fragmented environment, product design rules and organizational loose coupling in figure 4.6. Interestingly, our results indicate that the same variables associate with inertial forces and low architectural control which reduces a company's ability to re-modularize products in a later stadium. We summarize these relationships in figure 4.6 . 


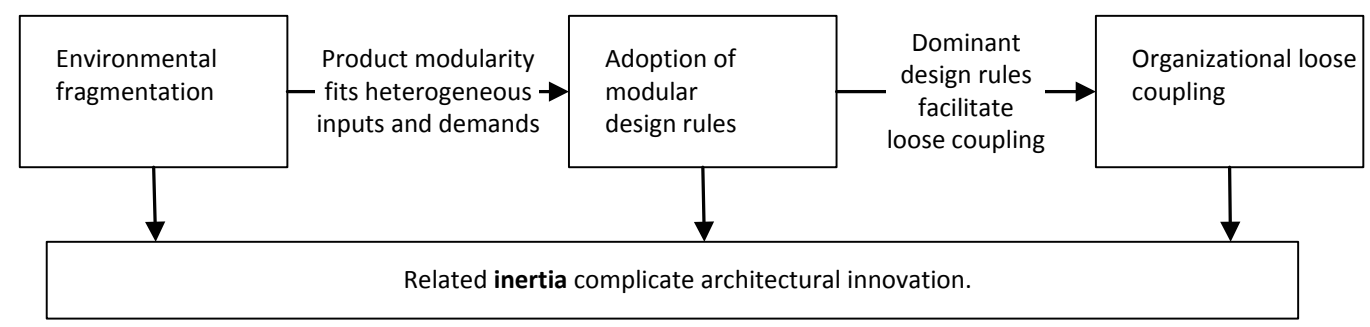

Figure 4.6. Relationships among the sources of 'innovation inertia'

A closer inspection of our case study and related literature helps to solve a controversy in the literature about a principle called the "mirroring hypothesis" (Baldwin, 2008). Proponents of this hypothesis argue that modularity in product design associates with modular organizational designs (Henderson \& Clark, 1990; Sanchez \& Mahoney, 1996). In Figure 4.7, this situation is illustrated as $\mathrm{t} 1$.

However, several studies found 'contradictory findings' and concluded that modular products may even lead to tightly coupled organizational forms e.g. (Brusoni \& Prencipe, 2006; Hoetker, 2006). Using our findings, we explain this as follows. To create new design rules in the loosely coupled organizational network we studied, structural coupling was required to increase the reuse potential of the new design rules. Brusoni and Prencipe's (2006) study of a radical innovation in the tire manufacturing industry corroborate these findings. They concluded that, for product modularization, structural coupling is required to effectively integrate specialized knowledge domains. In figure 4.7, this situation, one with design rules and a tightly coupled organization is depicted as $t 2$.

Over time, the heterogeneous inputs and demands will motivate companies to deintegrate their organization again (Langlois \& Robertson, 1992; Schilling, 2000). This allows them to reap the benefits of external economies of scale and/or scope (Jacobides, 2005). This process is now facilitated by the new product design rules which simplify the coordination and standardize the information between the companies involved (Jacobides, 2005). The result is a specialized, loosely coupled organizational form with decentralized architectural knowledge and power. This new situation is now depicted in Figure 4.7 by $t 2$. 


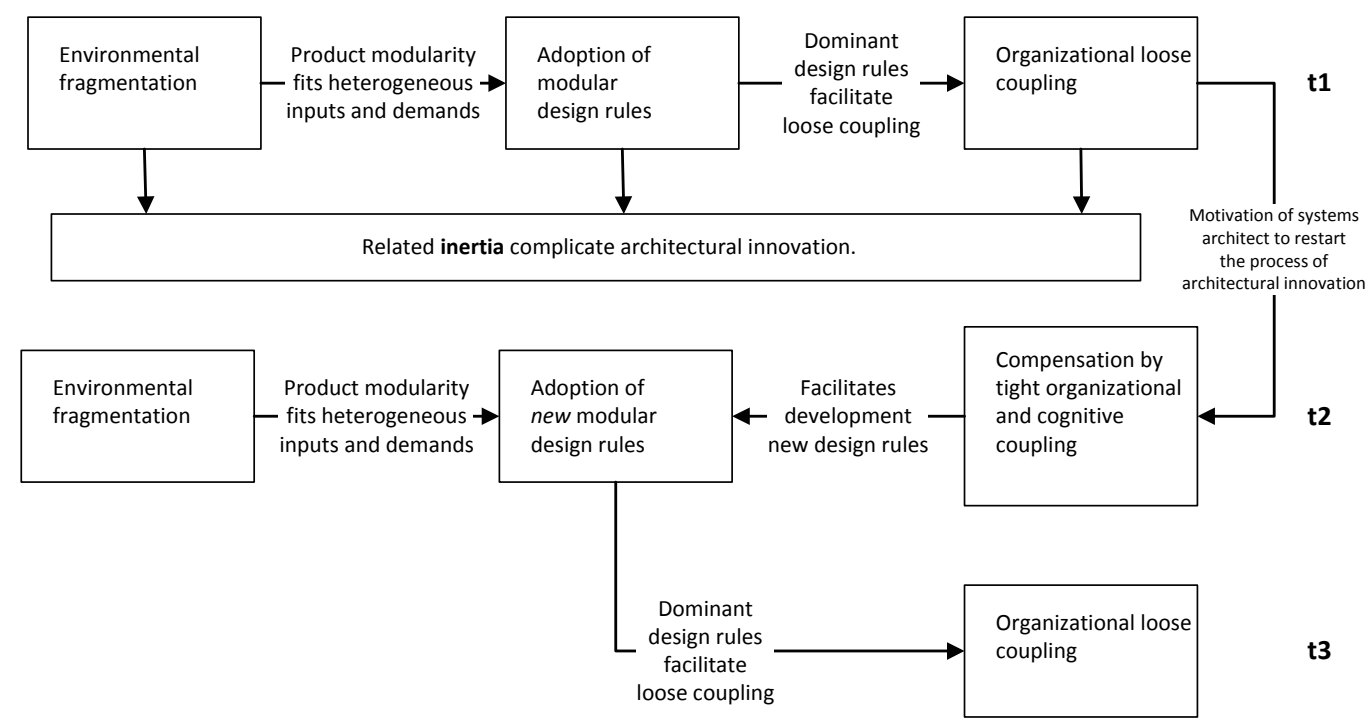

Figure 4.7. Relationships among the sources of 'innovation inertia'

The industry structure tends to remain loosely coupled until a system architect starts a new cycle of technological evolution. The systems architect will be motivated to overturn the existing design rules because of the potential gains to be achieved from product integration (Fixson \& Park, 2008) or, as in the Mind Building case, from the creation of new and better performing modular systems. As our case findings indicate, transitions to modular and integrated product and organizational designs are impeded by inertia that relate to the existing design standards and loose coupling. This explains the time lags between the adoption of modular products and related loose organizational forms. In the early phase of the technology life cycle, when new design rules are being created, organizations tend to be or to become integrated. Depending on the strength of the inertia and the motivating forces to modularize the organization, this pattern will persist for some time. However, once inertia is overcome, and when the motivations to modularize the organization increase, these design rules facilitate the creation of a loose organizational form, and this pattern may also persist for a period of time depending on the strength of the forces involved.

Thus, our findings and those in the modularity literature are not as inconsistent as they first appear. If one applies a dynamic view and focus on how patterns of coupling change 
over time, the findings become complementary. Our research combines types of loose coupling (modular organizations, products, and architectural controls) with compensation mechanisms (a pattern of cognitive and structural couplings) over time in a new theoretical model. It explains the changing patterns in product and organizational couplings over time. It retains a dialectical interpretation and shows how these 'variables shift as the cycle progresses' (Orton \& Weick, 1990).

\section{CONTRIBUTIONS, LIMITATIONS AND FUTURE RESEARCH DIRECTIONS}

This study is provides several important contributions. First, by combining perspectives from the concepts of inertia with those from the concept of loose coupling, it combines separate, but practically and theoretically complementary, views on innovation. By shifting the perspective on architectural innovation to the level of networks, this study has revealed inertial factors that have not been previously studied. These inertial factors inhibit architectural innovation in loosely coupled innovation networks.

Secondly, we discovered what compensation mechanisms can be used by managers to overcome inertia. Our case study illustrates the interactions between cognition and a pattern of structural couplings that arise during architectural innovation. This indicates that firms in loosely coupled networks benefit from cognitive coupling as a process that can create shared strategic beliefs about the technology trajectory, and lead to structural coupling as a solution to the inertia that impedes architectural innovation. In practical terms, the conceptual model provides a tool for managers who want to evaluate their plans for architectural innovation and, in this way, it can guide firms, in what is an increasingly common context of loosely coupled business networks, by providing robust insights for developing innovation strategies. The conceptual model we developed links inertia and compensation mechanisms and provides understanding how companies can succeed in architectural innovation.

Third, to differentiate our case study from other studies we have developed a new typology of innovation contexts. This typology is defined by the degree of architectural control on part of the innovation network leader (this is centralized versus decentralized networks) and the degree to which product design rules are available. Each innovation 
context has unique implications for different types of innovation including for example modular and architectural innovations or competence enhancing or destroying innovation.

Fourth, our case study findings and related literature helped solving a controversy in the literature about a principle called the "mirroring hypothesis" (Baldwin, 2008). Our model of loose and tight cyclical couplings shows that companies' can have modular products and be loosely coupled to their innovation partners. However, it also reveals that at a later moment in time, companies with modular products are more likely to be tightly coupled to their innovation partners.

Finally, the study results provide nine propositions; future research could focus on testing our propositions in a large-scale study. Future research could also beneficially address some of the other limitations of our study. First, a limited generality of one's research findings is often an inevitable trade-off of developing a more penetrating understanding (Sinha \& Van de Ven, 2005), and more research is required to generalize our findings. We focused on the construction industry, because of its loosely coupled structure, lack of dominant design rules and the decentralized architectural control. Since firms in this industry encounter strong inertial forces that complicate architectural innovation, it proved to be a good context for investigating inertia and compensatory mechanisms. Nevertheless, future research could usefully test our conceptual model in other industries and in other countries. This would allow account to be taken of technological, organizational, and institutional differences. Other industries could well reveal different or additional inertial factors and compensatory mechanisms. However, we would expect the found compensatory mechanisms to have a similar impact on inertia in architectural innovation.

Second, we focused on inertia that impeded firms in collaborating in architectural innovation. Although collaboration is seen as a mediator of successful architectural innovation in loosely coupled networks, we did not actually measure the commercial success of the investigated architectural innovation over time. Future research could therefore usefully investigate architectural innovations over a longer time horizon to determine the commercial success of architectural innovations.

Third, this investigation has shown how cognitive coupling precedes structural coupling, and it indicates those factors that play a role in the process of cognitive coupling. We do, 
however, recognize that more research is required to increase insight into the dynamics of such interpretive processes in networks of firms.

Finally, future research might further examine the cycle of technological and organizational evolution that we illustrated in Figure 4.7. Longitudinal qualitative and quantitative studies could strengthen the concept of patterns of cognitive and structural coupling and inertial factors over the technology life cycle. This could support our thesis of cyclical patterns of exploitation and innovation in which cognitive, structural, and product coupling alternate with decoupling among these dimensions. The actual pattern will depend on the stage of the technology life cycle and on purposeful architectural innovation. This recommendation is in line with Hannan et al. (2003) who suggest studying individual changes, and the subsequent cascading changes and their temporal dimensions.

Addressing these limitations would be an important contribution from both academic and managerial points of view. 


\section{CHAPTER 5}

\section{When to use loose or tightly coupled networks for product innovation? Empirical evidence ${ }^{5}$}

This study of collaborative innovation projects examines the impact of different innovation network configurations on innovation performance. Although the tradeoff between the potential benefits and drawbacks of loose and tight organizational couplings are discussed in the social network literature, their impact on the performance of modular and architectural innovations has not so far been studied. Using data from over 600 product innovation networks, from four different industries in the U.S., we found that modular innovation performance is greater in tightly coupled innovation networks but, more interestingly, that architectural innovation performance is highest when organized through loosely coupled innovation networks.

\footnotetext{
${ }^{5}$ This chapter has been submitted to an international refereed journal.
} 


\section{INTRODUCTION}

We have consistently observed that companies tend to rely on tightly coupled relationships for product innovation. The more radical or systemic that innovations are, the more likely it is that companies select partners with whom they share tight organizational links (Hoetker, 2006; Li, Eden, Hitt, \& Ireland, 2008). However, are strong ties really better than loose ties?

The general perception seems to be that companies benefit from tighter organizational coupling with their innovation partners. Coleman (Coleman, 1988) underpins this closure argument and explains that tightly coupled networks promote a normative environment that helps to overcome problems related to trust and cooperation (Ahuja, 2000; Granovetter, 1985). Yet, Burt's (1992) brokerage argument relies on the weak-tie theory and suggests that loose coupling provides firms with 'bridging ties' that give access to sources of novel information (Granovetter, 1973) whereas tight couplings tend to provide redundant paths to limited sources of knowledge but insulate firms from knowledge beyond their network (Uzzi 1997; Schilling and Phelps 2007). This suggests that weaker ties can provide certain benefits for product innovation.

For this study's purpose, we make a distinction between modular and architectural ${ }^{6}$ product innovation. Modular innovation takes place through changes within product modules that do not affect connecting modules (Sanchez \& Mahoney, 1996) whereas architectural innovations are more systemic in nature. Architectural innovations leave the design concepts of individual modules largely untouched, but do change the way in which subsystems are linked together (Henderson \& Clark, 1990). Some researchers have linked characteristics of product innovations to choosing particular innovation network configurations (Hoetker, 2006; Puranam, Singh, \& Chaudhuri, 2009). In several studies it is argued that because modular innovations are autonomous in nature they are more easily coordinated through loose innovation networks (Baldwin, 2008; Sanchez \& Mahoney, 1996; Schilling, 2000). In contrast, research in the semiconductor and computer industries has shown that systemic, architectural innovations require rich, bilateral, and intense

\footnotetext{
${ }^{6}$ Other scholars use the term 'systemic innovation' for what we call architectural innovation (cf. Chesbrough, $\mathrm{H}$. W. \& Teece, D. J. 1996: When is virtual virtuous? Organizing for innovation. Harvard Business Review, 74: 6573; Hoetker, G. 2006: Do modular products lead to modular organizations? Strategic Management Journal, 27 : 501-518).
} 
communication, so-called 'unstructured technical dialogue', and can therefore best be organized in tightly coupled or even integrated companies (Hoetker, 2006; Monteverde, 1995).

However, although these seminal studies are valuable, they do not show how different network configurations influence innovation performance, and whether this depends upon the type of innovation. Conventional wisdom suggests that companies benefit more from tight organizational coupling for architectural innovation than they do for modular innovation, but is this correct? Using a quantitative study among product innovation networks in four different industries in the United States, this research aims to definitively answer this question.

The results reported here challenge traditional views of innovation networks. Our empirical evidence reveals that, for architectural innovation, loose rather than tightly coupled innovation networks improve performance. On the other hand, consistent with the dominant view, tight coupling improves modular innovation performance. For architectural innovation, it is more effective for a company to work with partners that they have not yet established close and intensive relationships with through previous innovation projects. Furthermore having a long history of collaboration combined with the expectation that this will continue far into the future also decreases architectural innovation performance. In addition, companies can best chose to work with other companies that are easy to replace, i.e. their skills and resources are not unique, and where relation-specific investments are relatively low at the time of innovation network formation.

The paper is organized as follows. We first explain the anticipated main effects of loose and tight organizational coupling on collaborative innovation performance. Following this, we develop hypotheses about how this relationship differs for modular and architectural product innovation. After this, we explain our methods for studying the research questions. We then present the results of our study. Finally, we discuss the main theoretical and managerial implications of our findings, important limitations of our study, and avenues for future research. 


\section{THEORETICAL BACKGROUND AND HYPOTHESES}

Figure 5.1 presents a model that depicts the innovation network configuration as directly related to collaborative product innovation performance, and shows that this relationship is contingent upon the type of innovation. We begin this section by examining the potential benefits of loose and tight organizational coupling among innovation network partners for collaborative product innovation performance. Then, following ideas drawn from structural contingency theory, we explore the potentially moderating effects of different types of innovation (modular and architectural) on these relationships.

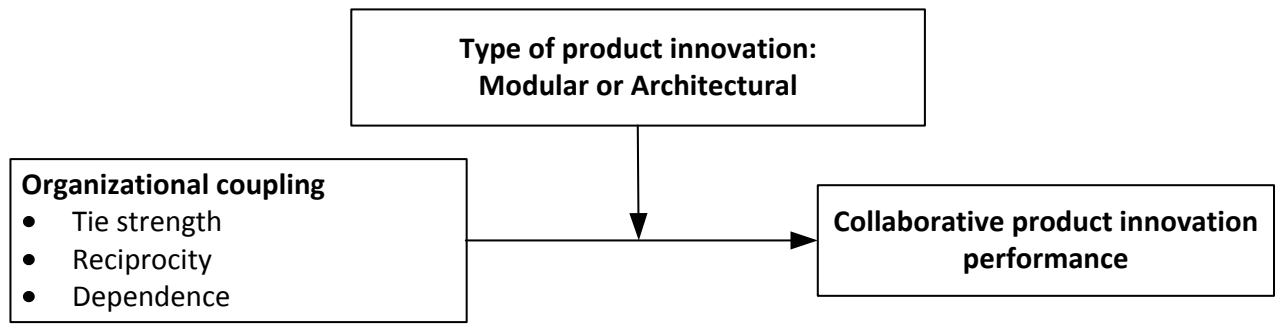

Figure 5.1. Contingency model for collaborative product innovation projects

Impact of loose and tightly coupled innovation networks on collaborative innovation performance

Nahapiet and Ghoshal (1998) argue that four organizational conditions shape social capital: interaction ties, time, interdependence, and network closure. Beekun and Glick (2001) adopted four very similar measures from the field of social network analysis to assess the degree of coupling among firms: tie strength, reciprocity, interdependence, and directness. Weick (1982) argues that these dimensions are all positively correlated, and that loosely coupled organizations score low on each of these dimensions.

In the social network literature, it is questioned whether it is tight or loose organizational coupling between people that improves collaborative innovation performance. Companies that innovate through tightly coupled, closed networks derive benefits from the ability provided by strong ties to effectively coordinate the exchange and integration of resources across loose organizational boundaries. Paradoxically, this comes with an opportunity loss related to accessing heterogeneous, useful resources and competences (Coleman, 1988; 
Granovetter, 1973). The opposite also holds true, a benefit of loose organizational coupling is that it provides an opportunity to access heterogeneous resources and competences, but this is often at the cost of a company's ability to effectively coordinate the exchange and integration of these resources across organizational boundaries (Burt, 1992; Granovetter, 1973). Obstfeld (2005) described this dilemma as the idea problem versus the action problem.

\section{The action problem: loose coupling decreases innovation performance.}

Many scholars argue that increased organizational coupling, which is characterized by high scores on the above-mentioned four dimensions, helps to overcome trust and cooperation problems (Ahuja, 2000; Granovetter, 1985; Krackhardt, 1992; Nowak, 2006; Parkhe, 1993). This view is endorsed by empirical studies that show how tighter organizational coupling shapes trustworthiness and aligns visions among innovation partners which then facilitates the exchange and combination of complementary resources that are located in distinct organizational units (Nahapiet \& Ghoshal, 1998; Tsai \& Ghoshal, 1998). Scholars that applied this view to inter-firm relationships came to similar results and showed that tight interorganizational coupling, for example having real teamwork in the past with partners that bring unique skills, and a high expectation that partners will be working together far into the future, reduces opportunism and increases relation-specific resource commitment in the direction of collaborative innovation (e.g.(Dyer \& Singh, 1998; Gulati, 1995; Kogut, 1989; Tiwana, 2008a; Wuyts \& Geyskens, 2005). In a recent study, Tortoriello and Krackhardt (2010) show that 'bridging ties' to non-redundant resources only improve innovation when the two companies are both strong and reciprocally tied to the same third party. This characteristic of tight coupling is a form of 'indirect reciprocity': when deciding to cooperate or compete, companies will take into account the possible consequences regarding the third party on their reputation (Nowak, 2006). Thus, tight coupling improves the willingness to cooperate in product innovation projects.

An argument from the knowledge-based view is that tight coupling improves collaborative innovation performance because it improves the ability to transfer heterogeneous knowledge among innovation partners. Knowledge that is used in technological innovation is often costly to acquire, transfer, and use in a new location (Vonhippel, 1994). Distant and infrequent relationships have little motivation to identify and 
share such knowledge or are unable to communicate it in such a way that it is readily understood and absorbed by the recipient (Levin \& Cross, 2004; Li, Poppo, \& Zhou, 2010). In contrast, tight organizational coupling enhances communication effectiveness (Dyer \& Singh, 1998) and especially over the transfer of tacit, non-codified information (Hansen, 1999).

To summarize, tight coupling is associated with increased willingness and ability to transfer complex knowledge (Hansen, 1999). Thus, other things being equal, tight organizational coupling is most likely to improve collaborative innovation performance, whereas loose organizational coupling is likely to decrease the performance of collaborative product innovation. This leads to our first hypothesis:

Hypothesis 1a: organizational loose coupling will be negatively related to the performance of collaborative product innovations.

\section{The action problem: tight coupling decreases innovation performance.}

For other reasons, tight organizational coupling can also decrease innovation performance. Strong relationships based on frequent and close working relationships can lead to overembeddedness (Hagedoorn \& Frankort, 2008). When companies are tied together by elaborate institutional, economic, and cultural relationships, technological change can be more difficult than in networks of independent organizations (Glasmeier, 1991; Greenwood \& Hinings, 1996; Uzzi, 1997). Tight coupling then becomes associated with deeply ingrained routines including fixed communication channels for discussing technological change (Henderson \& Clark, 1990). Such binding creates 'network inertia' that complicates the formation of new relationships that would be potentially better equipped for performing the task (Hansen, 1999; Kim, Oh, \& Swaminathan, 2006). In this way, tight coupling reduces the flexibility to adapt and to select the right partners (Weick, 1976); and this will result in lower innovation performance.

Thus, other things being equal, loose organizational coupling is most likely to improve collaborative innovation performance, whereas tight organizational coupling is likely to decrease performance in terms of collaborative product innovation. This leads to our second hypothesis: 
Hypothesis 1b: organizational loose coupling will be positively related with the performance of collaborative product innovations.

\section{Modular and architectural innovation}

Our analysis is organized around modular and architectural product innovations. Modular innovation takes the form of changes in the working concepts within product modules and so does not significantly affect connecting modules (Sanchez \& Mahoney, 1996). As such, modular innovations adhere to the existing modular product architecture. In contrast, architectural innovations leave the design concepts of individual modules largely untouched but overturn the existing product architecture by changing the way in which subsystems are linked together (Henderson \& Clark, 1990). Architectural innovation can also introduce previously unknown interdependencies between components. Compared to architectural innovation, which is systemic by nature, modular innovation is more autonomous and is associated with lower task interdependence among innovation partners. Modular product architectures allow 'information hiding' such that, for modular innovation, companies require information from only one organizational sub-unit (Baldwin \& Clark, 2000; Parnas, 1972). In the following two sections we explain why we expect the negative impact of loose coupling to be smaller for modular than for architectural product innovations, but we also argue that loose coupling may be beneficial for architectural innovation performance.

\section{Loose coupling decreases modular innovation performance}

A benefit of product modularity is that it facilitates suppliers of separate components to innovate their contribution to the end-product at their own chosen speeds (Langlois \& Robertson, 1992; Schilling, 2000). For example, advances made in rechargeable batteries led to Nickel-Cadmium batteries being replaced by batteries based on Nickel Metal Hydride technology. This innovation involved large changes within the battery, but it did not change the interfaces with components from other companies; both types of battery efficiently fit the devices they power in the same way. As in this example, modular product innovations involve improvements within sub-systems and leave the existing interfaces and interactions among subsystems largely unchanged (Henderson \& Clark, 1990). Therefore, modular innovations are more-or-less autonomous: they require only marginal coordination across 
the organizational boundaries of the companies producing the different modules. Consequently, the hypothesized negative impact of loose coupling will be low for modular innovation:

Hypothesis 2a: organizational loose coupling will have a negative impact on the performance of modular product innovation.

\section{Loose coupling decreases architectural innovation performance.}

It is often argued that loose organizational forms improve innovativeness because they give a company access to external resources that complement their own (Jacobides, 2005; Orton \& Weick, 1990; Schilling, 2000). However, the mixing and matching of complementary product modules that map one-to-one to chunks of specialized knowledge located in different companies is not architectural innovation. Only when changes are made in the way these modules interface and function together is it an architectural, system-wide change. Architectural innovation can only be realized if complementary innovations take place in separate firms: it involves systemic changes throughout a product system that includes interdependent changes to interfaces between modules. For example, if a building company decides to change the tolerances of a floor element from $0.6 "$ to $0.2^{\prime \prime}$ this requires a similar adaptation to components such as columns and walls that are all connected to this floor. If component suppliers do not adapt to the change, components will loose compatibility. In loose networks individual firms tend to emphasize local search processes for improving their modules and, because of this, they often fail to fully take account of the interdependencies associated with architectural innovation (Levinthal \& Warglien, 1999). Furthermore, companies that attempt to architecturally innovate and introduce new interface standards in loose networks risk isolation because other companies can simply choose not to follow (Langlois and Robertson, 1992). Therefore, a direct outcome of loose organizational coupling is persistence - or resistance to change - and, as a result, compared to tightly coupled organizations, loosely coupled organizations are less conducive to system-wide changes (Orton \& Weick, 1990). For similar reasons, Hoetker (2006) argues that "hierarchy is hypothesized to provide more valuable benefits for systemic designs". Thus, compared to modular innovation, architectural innovation depends more heavily on the cooperativeness 
of a group of companies, and firms would therefore gain a greater benefit from tighter organizational coupling (Chesbrough \& Teece, 1996; Orton \& Weick, 1990; Schilling \& Steensma, 2001).

A second argument as to why tight coupling has a greater positive impact on architectural than on modular innovation relates to the relatively large transfer of tacit design knowledge that is required for architectural innovation. When interfaces within the product architecture are not well specified, changing the specification of one component can require a cascade of unknown changes to other components; and managing these interdependencies requires 'unstructured technical dialogue' (Monteverde, 1995). Communication about changing interfaces requires the transfer of complex, non-codified and often 'sticky' design knowledge, and this is costly to transfer among innovation partners (Monteverde, 1995; Vonhippel, 1994). However, if companies have worked closely together on previous innovation projects, there is a good chance that they have developed a thorough, shared understanding of the product architecture, and a common language for discussing technical issues (Hoetker, 2006; Kogut, 1988). As such, architectural innovation is easier to accomplish in tightly coupled networks. Companies may even have translated this tacit knowledge into a comprehensible set of explicit design rules that clarifies how the different components interact, and this may further enhance the coordination of interdependencies in architectural innovation projects (Baldwin \& Clark, 2000). We therefore hypothesize the following:

Hypothesis 2b: the negative relationship between organizational loose coupling and the performance of collaborative product innovation will be stronger for architectural than for modular product innovations.

\section{Loose coupling improves architectural innovation performance}

The literature on the weak tie theory explains that loose relationships give rise to an opportunity to access useful resources by boundary spanning (Burt, 1992; Granovetter, 1973). If one neglects these 'search benefits', this will suppress the expected negative impact of loose coupling on collaborative innovation performance. Therefore, to be consistent with previous studies, we control for a suppressor mediator: 'bridging ties' that 
taps into the degree to which weak ties have linked innovation network partners that have useful, complementary resources and competences (Hansen, 1999; Levin \& Cross, 2004; Padula, 2008; Tiwana, 2008a). However, we argue that loose coupling has an additional positive effect on innovation performance that is not explained by these search benefits. We have two plausible explanations for why loose coupling potentially supplies a means for action rather than creates action problems.

First, we believe that strongly tied, reciprocal relationships are less likely to change existing network relationships because excluding a company from a project could have negative implications for the multiple other reciprocal commitments that exist between the companies. A strong focus on existing innovation network members will insulate companies from knowledge beyond their network (Uzzi 1997; Schilling and Phelps 2007). Thus, tight coupling creates network inertia that reduces flexibility and complicates the formation of new relationships that are potentially better equipped to perform the task, resulting in lower innovation performance (Hansen, 1999; Kim et al., 2006). In contrast, loose relationships escape this 'binding constraint' (Hansen, 1999).

Secondly, interaction processes produce shared interpretations that emerge gradually and incrementally (Ring \& Vandeven, 1994). A shared understanding about how the individual subsystems work together is likely to facilitate the coordination of interdependencies among subsystems (Puranam, Singh, \& Chaudhuri, 2009). This is also widely acknowledged in the literature on team mental models (e.g. Marks, Zaccaro, \& Mathieu, 2000; Rico, Sanchez-Manzanares, Gil, \& Gibson, 2008). However, Cohen and Bacdayan (1991) found that, in performing repetitive tasks, groups of people develop routines that are difficult to unlearn. Their experiments revealed that routines were used even when obvious and better alternatives were available and when wrong decisions were penalized. One can think of architectural innovation as this better alternative: and then companies, because they are likely to respond to each other and the technology in routine ways, may entirely overlook the changed interdependencies among the subsystems, and missing such crucial information is likely to reduce architectural innovation performance. This routinization of work is found in the companies' information channels and information filters, and this biases the information that is transferred between innovation partners (Henderson \& Clark, 1990). Shared technological frames guide future technological choices 
in a common direction (Cohen \& Levinthal, 1990; Garud \& Rappa, 1994). The ability to innovate will thus be limited given the inter-organizational routines becoming accommodated to the known architecture (Henderson \& Clark, 1990; Staudenmayer, Tripsas, \& Tucci, 2005). Thus, tight coupling will result in shared technical frames that improve the management of known interdependencies among subsystems, but will reduce the performance when it comes to architectural innovation because this depends upon an ability to coordinate non-repetitive, unknown interdependencies. As such, we expect loose relationships to be less biased by inter-organizational routines that are tuned to an existing product architecture, leading to the following hypothesis:

Hypothesis 2c: organizational loose coupling will have a positive impact on the performance of architectural product innovations.

\section{DATA AND METHODOLOGY}

\section{Research setting}

The objective of this study is to understand how firms can increase the success of collaborative product innovation projects conducted in innovation networks. We tested our hypotheses on a sample of innovation networks that consist of a lead company and one or more innovation partners responsible for different areas/subsystems of the end product. This nested product hierarchy allows companies to pursue both modular and architectural innovations, which are key variables in this study. Our unit of analysis is the product innovation project from the perspective of the lead firm. Innovation projects were selected from several industries in which we expected to find products that are composed of multiple subsystems (i.e., chunks, modules, or components).

\section{Survey development}

We developed the survey in several phases. First, we conducted a literature review to identify constructs that are commonly accepted in previous research. Whenever possible, we used existing multi-item scales to measure the constructs of interest in our questionnaire. We also conducted an in-depth case study involving 26 firms to advance our understanding 
of product innovation in loosely coupled innovation networks and to better understand the relationships among loose coupling, product design rules, and architectural and modular innovation performance. Next, we spoke to five academics to discuss the key theoretical relationships and to check the consistency and face validity of our constructs and we asked for their suggestions to develop items if precedents were missing. Finally, we pilot tested the revised survey using 20 project leaders from different industries to check if they interpreted the questions in the same way and to further refine wording. A final draft of the survey was completed and ready to pretest.

\section{Survey pretesting}

To pretest the survey, we selected four companies with two successful and two failure collaborative product innovation projects. In total the survey was pretested with a group of 31 people from these four companies. Several minor modifications were made to the original measures and the format of the survey was modified to improve readability. The results from the pretest indicated that the survey questions have high consistency and face validity. After pretesting was complete, a final version of the survey was constructed.

\section{Data collection}

This study reports the first empirical results of a large-scale empirical research study of collaborative product innovation projects in innovation networks. The original sample consisted of 3,000 companies randomly selected from the Dun \& Bradstreet business database in the following industries: construction, computer and software, machinery and equipment, and household appliances. To ensure that we included appropriate companies (with collaborative product innovation projects) in the final sample, we sent a presurvey letter to all 3,000 firms. The presurvey consisted of the following three questions: (1) "Did you partner with any companies in an innovation network to develop any product innovation projects in the past three years?" (2) "Was your company the lead company of the innovation network that includes your company and the innovation partner companies?" and (3) "Are you willing to participate in a study on the effect of innovation network on innovation success?" We received responses from 1,182 of the 3,000 companies (a 39.4\% response 
rate). Of the responding companies, only 924 met our criteria for inclusion in the final survey (i.e., the companies answered "yes" to all three presurvey questions).

The data were collected using a mail survey following Dillman's (1978) prescriptions as outlined in the Total Design Method for survey research. We mailed the first package to all 924 companies using priority mail. Following the procedures used by Song, Di Benedetto, and Song (2009), we included in the first package a business card, a personalized letter to our contact at the company, a copy of the questionnaire, a postage-paid envelope with an individually typed return-address label, and a list of research reports available to participants. We requested that each company select a most recent completed innovation project with the following characteristics: the project was completed in the last three years, the company partnered with one or several other companies that were responsible for different subsystems/areas of the end product, the company was the lead company of this innovation network, and the innovation project consists of multiple subsystems for which the different companies in the innovation network were responsible. The products could also be part of a larger product system and could be quite diverse: machines, buildings, equipment, consumer electronics, or software. For the sake of clarity we explained that synonyms for the word "subsystems" that may be used in the respondent's industry include components, modules, or chunks.

After three follow-up contacts with the companies, we received complete and usable data from 664 companies. The measurement scales and representative items are included in Appendix 5.A.

\section{Measure purification through confirmatory factor analysis}

The reliability of the measurement scales and representative items are included in Appendix 5.A. Table 5.1 reports the standardized coefficients, Z-statistics, reliability values and average extracted variances for the measurement model. Our sample was of sufficient size and had an adequate respondent-to-item ratio to use AMOS confirmatory factors analysis, and make maximum likelihood estimations to assess the psychometric properties of our measures. 
Table 5.1. Measurement model

\begin{tabular}{|c|c|c|c|c|}
\hline Variables & $\begin{array}{l}\text { Standardized } \\
\text { loadings }\end{array}$ & Z-score ${ }^{\mathrm{a}}$ & $\begin{array}{c}\text { Cronbach's alpha / Composite } \\
\text { reliability }\end{array}$ & AVE \\
\hline Performance & & & $0.97^{* *} / 0.97$ & 0.92 \\
\hline PERF01 & 1.00 & & & \\
\hline PERF02 & 0.94 & 66.21 & & \\
\hline PERF03 & 0.94 & 64.92 & & \\
\hline Tie strength & & & $0.87 * * / 0.87$ & 0.70 \\
\hline TIE01 & 0.82 & & & \\
\hline TIE02 & 0.82 & 23.21 & & \\
\hline TIEO3 & 0.86 & 24.28 & & \\
\hline Reciprocity & & & $0.85 * * / 0.85$ & 0.55 \\
\hline RECI01 & 0.77 & & & \\
\hline RECIO2 & 0.85 & 22.04 & & \\
\hline RECIO3 & 0.84 & 21.76 & & \\
\hline RECIO4 & 0.62 & 15.75 & & \\
\hline RECI05 & 0.58 & 14.52 & & \\
\hline Dependence & & & $0.87 * * / 0.86$ & 0.55 \\
\hline DEP01 & 0.81 & & & \\
\hline DEP02 & 0.76 & 20.25 & & \\
\hline DEP03 & 0.73 & 19.52 & & \\
\hline DEP04 & 0.71 & 18.31 & & \\
\hline DEP05 & 0.72 & 18.20 & & \\
\hline Bridging ties & & & $0.82 * * / 0.81$ & 0.52 \\
\hline ВT01 & 0.87 & & & \\
\hline ВT02 & 0.57 & 13.65 & & \\
\hline Вт03 & 0.64 & 15.45 & & \\
\hline BT04 & 0.76 & 17.76 & & \\
\hline Customer uncertainty & & & $0.70 * * / 0.73$ & 0.48 \\
\hline CU01 & 0.81 & & & \\
\hline CU02 & 0.68 & 11.76 & & \\
\hline CU03 & 0.55 & 10.87 & & \\
\hline $\begin{array}{l}\text { Technological } \\
\text { uncertainty }\end{array}$ & & & $0.71 * * / 0.72$ & 0.47 \\
\hline TU01 & 0.54 & & & \\
\hline TU02 & 0.84 & 11.60 & & \\
\hline TU03 & 0.63 & 11.20 & & \\
\hline
\end{tabular}

${ }^{a} Z$-scores for the leading indicator for each construct were set to 1.0 to establish a scale

${ }^{\text {b }}$ Cronbach's alpha

${ }^{\mathrm{C}}$ Composite reliability

$* * p<0.01$ 
For identification purposes, we set the path for each latent variable equal to 1.0 , and factor loadings were also set equal to 1.0 for non-latent variables (Kline, 2004). Following the recommendations of (Anderson \& Gerbing, 1988), we conducted a confirmatory factor analysis by specifying an 11 factor solution, and a satisfactory fit was achieved. $\left(\chi^{2}=923.0, \mathrm{df}\right.$ $=353, p<0.01)$. The chi-square per degree of freedom ratio is $2.62 ;$ where values lower than 3.0 indicate a good fit (Bentler \& Bonett, 1980). Further, fit indexes that are less prone to sample size effects also indicated a good fit. With a perfect fit between a measurement model and data from a sample population, the CFI, IFI, and TLI would have values of 1.0, and the RMSEA a value of zero. Cut-off values close to 0.95 for the $\mathrm{CFI}, \mathrm{IFI}$, and TLI, and a value of 0.08 or lower for the RMSEA are suggested as indicating an adequate fit (Hu \& Bentler, 1999). Comparing our model's fit indexes to these norms indicates that we have achieved a good model fit: $\mathrm{CFI}=0.94, \mathrm{IFI}=0.94, \mathrm{TLI}=0.93, \mathrm{RMSEA}=0.05$, plus the RMSEA confidence interval is $0.045-0.053$, which represents a good degree of precision (Byrne, 2001).

Having concluded that our overall CFA model is acceptable, we will move on to evaluate the convergent and discriminant validities of the constructs. Table 5.1 shows the standardized loadings, the related Z-scores (C.R. in AMOS), the average variance extracted estimate, and the constructs' composite reliabilities. The loadings of the individual indicators are statistically significant and the constructs composite reliability coefficients have an average value of 0.83 , both indicating a high internal consistency (Netemeyer, Bearden, \& Sharma, 2003). The average variance extracted (AVE) exceeded the benchmark of 0.5 for six of the eight constructs, with the other two control variables having an AVE of almost 0.5. An AVE value above 0.5 indicates good convergent validity (Fornell \& Larcker, 1981; Netemeyer et al., 2003).

We tested the discriminant validity of the constructs by comparing the average variance shared by each construct with its indicator (AVE), with the variance shared by each pair of constructs (squared correlation between constructs). We first computed the AVE for each construct (listed in Table 5.1). The finding that the squared correlation between each pair of constructs was less than the variance-extracted estimates for the individual constructs indicates that we have achieved discriminant validity (Fornell \& Larcker, 1981).

Finally, following the suggestions of Podsakoff and Organ (1986), we used Harman's onefactor test to check whether self-reporting led to common method variance. A factor 
analysis resulted in the expected number of factors, rather than a single common method factor accounting for the majority of the covariance among the items. These results indicate that the findings presented in this chapter are unlikely to be distorted by common method bias.

\section{Main variables}

Organizational coupling. Various social network scholars have argued that organizational coupling is best conceptualized as a multidimensional construct (e.g. Beekun \& Glick, 2001a, 2001b; Granovetter, 1973; Krackhardt, 1992; McEvily \& Zaheer, 1999; Nahapiet \& Ghoshal, 1998; Rindfleisch \& Moorman, 2001; Weick, 1982). To assess the degree of organizational coupling among innovation network partners, we have adopted the following three dimensions from Beekun and Glick's (2001) scale: tie strength, reciprocity, and interdependence. Weick (1982) argues that these dimensions are all positively correlated and that loosely coupled firms have a low score for each of these dimensions. We took a retrospective view on lead-firms' networks by asking the lead-firms about their relationships with their innovation partners prior to forming an innovation network in order to give us a measure of the looseness of the lead-firm's network prior to innovation network formation.

Loose coupling dimension 1: Tie strength. Traditionally, the tie strength construct is characterized by the closeness and interaction frequency of relationships between partners in an innovation network (Granovetter, 1973; Hansen, 1999). Marsden and Campbell's (1984) study indicates that a measure of 'closeness', or the emotional intensity of a relationship, is the best available indicator of the tie strength concept. Consequently, we adopted three items proposed by (Wuyts \& Geyskens, 2005) to measure the closeness of the lead-firm to the other innovation network members. The rating scale ranged from 1 "strongly disagree" to 7 "strongly agree", and the higher the score, the stronger the ties.

Loose coupling dimension 2: Reciprocity. We used five items drawn from three different studies that all contributed to our conceptualization of reciprocity between the lead-firm and its innovation partners. Three items were adopted from Rindfleisch and Moorman (2001) that were labeled as 'relational embeddedness' in the original study. We omitted one of their items because that item was already part of our tie strength construct. The fourth reciprocity item was adopted from (Kale, Singh, \& Perlmutter, 2000), and the fifth, based on 
(Kogut, 1989) definition of reciprocity, taps the multiplicity of the relationship. The higher the ratings, the greater the degree of reciprocity between the lead-firm and the other innovation network members. As before, the rating scale ranged from 1 "strongly disagree" to 7 "strongly agree".

Loose coupling dimension 3: Dependence. We adapted a reflective measure developed by (Robson, Katsikeas, \& Bello, 2008) which assesses well the reflective construct of dependence with their five items achieving an alpha coefficient of above 0.8 in their study. Apart from the fourth item (which is reversely stated) the higher the ratings, the larger the interdependence of the lead-firm and its innovation partners. The rating scale ranged from 1 "strongly disagree" to 7 "strongly agree".

Type of innovation. To assess the type of product innovation, we framed innovations using the two-dimensional typology developed by Henderson and Clark (1990). Using previous definitions of Baldwin and Clark (2000), Gatignon, Tushman, Smith, and Anderson (2002), and Henderson and Clark (1990) we provided clear definitions of modular and architectural product innovations, and asked each respondent to characterize the type of the innovation they had selected for the survey. Modular innovation was defined as innovations that involve significant improvements of sub-systems that leave the existing interface standards and interactions between the improved subsystems and other subsystems largely unchanged. Example: a notebook incorporating a higher resolution display. Architectural innovation was defined as innovations that involve (sometimes marginal) improvements of sub-systems that have a more significant impact on the existing interface standards and interactions with other subsystems. Example: a larger notebook display (=marginal improvement) draws more power (change in interaction) and requires simultaneous changes in other subsystems such as the battery, software and charging system in order to function. Type of innovation was a dummy variable coded 1 if the innovation was categorized as a modular innovation and 0 if it was categorized as an architectural innovation.

Innovation performance. The performance of the innovation is measured using three items adopted from (Gatignon et al., 2002) which measure the perceived commercial success of the product. The assessments are relative to the competition and to expectations within the industry, and this should remove industry-specific main effects (Gatignon \& 
Xuereb, 1997). The rating scale again ranged from 1 "strongly disagree" to 7 "strongly agree" and the higher the ratings, the higher the innovation performance.

\section{Control variables}

In our analyses we also included several variables to control for possible confounding effects: bridging ties, lead-firm size, project size, marketing resource input, environmental uncertainty, composition of the innovation network, contract structure, and industry effects.

Bridging ties: The 'brokerage argument', which builds on Grannovetter's (1973) weak-tie theory, suggests that weak ties allow 'bridging ties' that give access to external sources of non-redundant information (Burt, 1992; Tiwana, 2008a). In this way, weak ties give rise to an opportunity to access useful information which then improves collaborative innovation performance. Since this could suppress our hypothesized negative effects of loose coupling on collaborative innovation performance, we control for the 'bridging ties' suppressor mediator that reflects the degree to which weak ties have linked innovation network partners with useful, complementary resources and competences. We follow Tiwana (2008a) in measuring 'bridging ties' using items adopted from Campion, Medsker and Higgs (1993) that were labeled 'heterogeneity' in the original study. Influenced by Teece (1986), we added a fourth item to this scale which assesses the degree to which the innovation partners have complementary physical assets and resources. Again, the rating scale ranged from 1 "strongly disagree" to 7 "strongly agree".

Lead firm size. The relationship between firm size and innovation performance has been much debated (Schumpeter \& Opie, 1934). Large firms have more financial resources to fund innovation, and larger sales volumes speed up the return on investment which increases the willingness to invest in innovation (Cohen \& Klepper, 1996). Conversely, small firms may also have an advantage in being more flexible and faster to recognize opportunities (Bower \& Christensen, 1995). To control for both economies and diseconomies of scale, firm size was measured as the natural logarithm of the number of employees.

Project size. Previous research suggests that greater resource inputs, to serve the needs of the innovation project, by the innovation partners will boost the innovation's performance (Dyer, 1996; Parkhe, 1993; Teece, 1986). On this basis, several studies have controlled for financial cost of product innovation projects (e.g. Fang, 2008; Gatignon \& 
Xuereb, 1997). To make innovation projects comparable, we adopted Hansen's (1999) measure of innovation project size and controlled for the total estimated dollar cost of each product innovation project.

Marketing resource input. Besides the financial cost of an innovation, large marketing expenditures can also significantly influence product innovation success (Fang, Palmatier, \& Evans, 2008; Gatignon \& Xuereb, 1997). Accordingly, we developed a single-item measure to assess the relative marketing resource inputs that the innovation network devoted to the innovation project.

Environmental uncertainty: technical and customer uncertainty. Market characteristics that are often hypothesized as having an impact on the commercial performance of innovations come under the umbrella of external uncertainty (Gatignon \& Xuereb, 1997; Li \& Atuahene-Gima, 2001). Uncertainty is not a one-dimensional construct and is usually broken down into two key dimensions: technological (product) uncertainty, and customer (demand) uncertainty (Wolter \& Veloso, 2008). Technological uncertainty is defined as the probability of technological changes in the product and customer uncertainty refers to the rate of change of customer preferences. Technological uncertainty was measured using a two-item measure adopted from Walker and Weber (1984) plus one item taken from the technological uncertainty measure of Jaworski and Kohli (1993). Customer uncertainty was measured with a three-item measure adopted from Joshi and Sharma (2004). The higher the ratings, the greater the environmental uncertainty. The rating scale ranged from 1 "strongly disagree" to 7 "strongly agree".

Composition of the innovation network. Earlier research has suggested that innovation networks with a substantial number of horizontal alliances - collaborating competitors have a lower innovation performance (Rindfleisch \& Moorman, 2001). One company might gain inside knowledge of a partner's unique skills and expertise (Littler, Leverick, \& Bruce, 1995), and this associates with a higher potential for misappropriation than in an alliance with vertical partners (Katila, Rosenberger, \& Eisenhardt, 2008). To control for the degree of horizontal collaboration, we adapted Rindfleisch and Moorman's 'alliance composition' construct and asked how many companies in the innovation network could be classified as competitors. We calculated our 'network composition' measure by dividing the number of competitors by the total number of companies in the innovation network. 
Contract structure. In equity alliances, partners share or exchange equity, either by means of creating a new entity in which both partners share equity or by one partner taking an equity interest in the other (Gulati, 1995; Gulati \& Singh, 1998). Having an equity share provides companies with certain hierarchical control over other firms and may affect commitment and cooperation, thus influencing collaborative innovation performance (Krishnan, Martin, \& Noorderhaven, 2006; Luo, 2002; Poppo \& Zenger, 2002). We coded this alliance governance mode by a binary variable, assigning 1 to alliances that involved equity and 0 to non-equity alliances (e.g. Gulati, 1995; Robson et al., 2008).

Industry. Since collaborative innovations in some industries are known to perform better than in other industries, we controlled for industry effects (Krishnan, Martin, \& Noorderhaven, 2006). We used dummy variables, based on two-digit SIC codes, for the industries in our sample (construction industries, computer industries, machinery industries, household industries).

\section{ANALYSES AND RESULTS}

The means, standard deviations, and correlations among the variables are shown in Table 5.2. To test our hypotheses, we used hierarchical moderated multiple regression analysis to verify the individual effects on collaborative innovation performance of loose coupling and the type of innovation, and determine any interaction effects. As part of the analysis, we mean-centered all the terms of our interaction variables because this potentially facilitates the interpretation of regression coefficients (Echambadi \& Hess, 2007). Variance inflation factor scores are all less than the threshold of 10 and varied from 1.04 to 4.83 over the regressions, suggesting multicollinearity did not distort regression results. After creating dummy variables for the innovation type, we computed two-way-interaction terms for all our key variables: each of the three loose coupling dimensions (tie strength, reciprocity, and dependence) and innovation type. After this we compared two restricted plus one full regression models in which the following blocks of variables were successively introduced: control variables, individual main variables, and, finally, two-way interaction terms. 


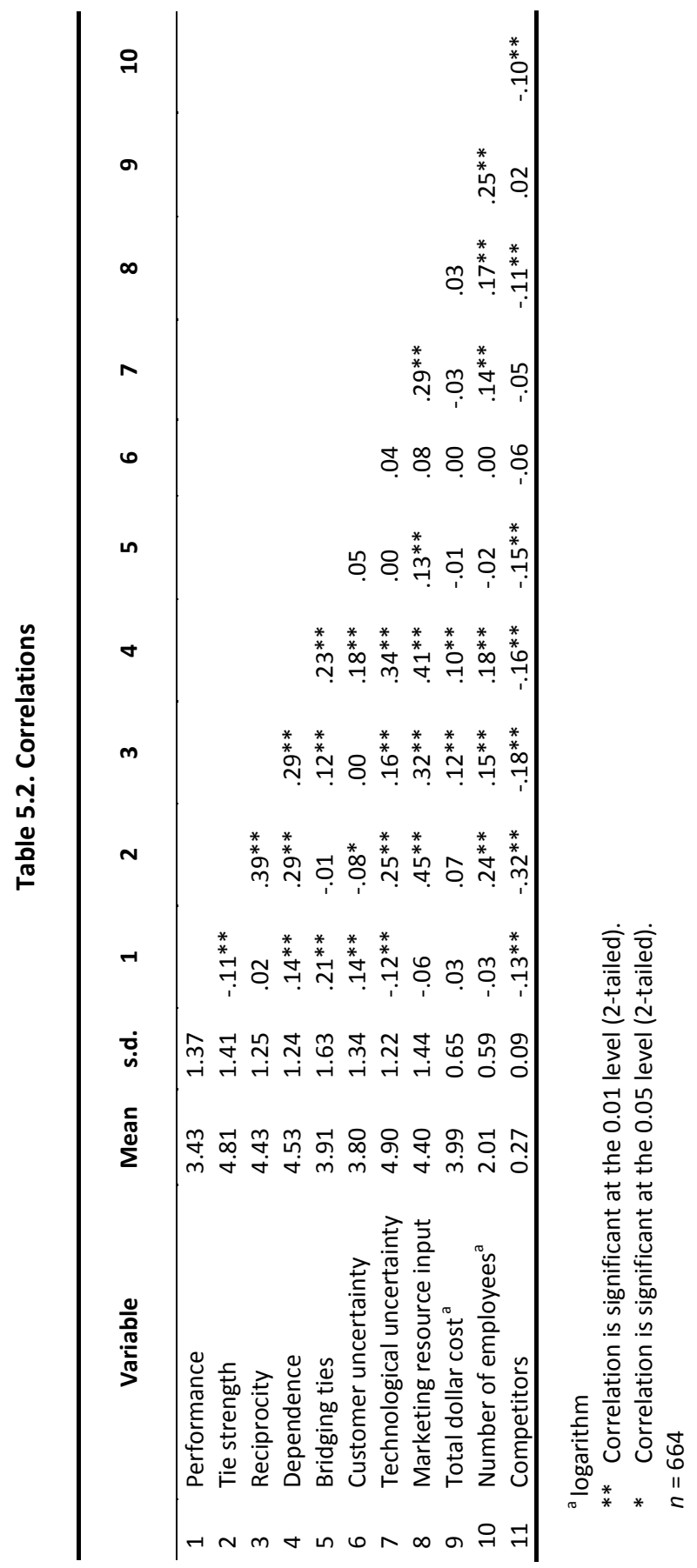




\section{Hypotheses testing with hierarchical regression analysis}

We begin by examining the improvement in model fit by introducing our main variables and interaction terms. In Table 5.3, the results from the regression models show that the main variables increase the overall model $R^{2}$ by 0.67 . Further, introducing the two-way interactions led to a significant improvement in the regression model, with an $R^{2}$ change of 0.07 , and therefore it is appropriate to explore the nature of these relationships.

TABLE 5.3. Results of Hierarchical Regression Models of Collaborative Innovation

\section{Performance $^{\mathrm{a}}$}

\begin{tabular}{|c|c|c|c|c|c|c|}
\hline \multirow[b]{2}{*}{ Variables } & \multicolumn{6}{|c|}{ Collaborative Innovation Performance } \\
\hline & Model 1 & & Model 2 & & Model 3 & \\
\hline Constant & 3.70 & $* *$ & 1.70 & $* *$ & 2.09 & $* *$ \\
\hline \multicolumn{7}{|l|}{ Control variables } \\
\hline Construction industry & 0.13 & & 0.01 & & -0.03 & \\
\hline Computer industry & 0.03 & & 0.01 & & 0.01 & \\
\hline Machinery industry & -0.04 & & -0.05 & & -0.08 & \\
\hline Household appliances industry & 0.08 & & -0.04 & & -0.10 & \\
\hline Bridging ties & 0.17 & $* *$ & 0.02 & & 0.04 & $* *$ \\
\hline Relative number of competitors in innovation network & -1.80 & $* *$ & 0.86 & $* *$ & -0.37 & \\
\hline Equity alliances & -0.46 & $* *$ & -0.01 & & -0.01 & \\
\hline Customer uncertainty & 0.11 & $* *$ & -0.03 & & 0.01 & \\
\hline Technological uncertainty & -0.11 & $*$ & 0.00 & & 0.01 & \\
\hline Marketing resource input & -0.06 & & 0.03 & & 0.02 & \\
\hline Total dollar cost innovation project & 0.06 & & -0.02 & & -0.01 & \\
\hline Number of employees lead firm & -0.06 & & -0.03 & & -0.03 & \\
\hline \multicolumn{7}{|l|}{ Main effects } \\
\hline Tie strength & & & 0.10 & $* *$ & -0.09 & $* *$ \\
\hline Reciprocity & & & 0.08 & $* *$ & -0.04 & \\
\hline Dependence & & & 0.20 & $* *$ & -0.07 & $*$ \\
\hline Type of innovation & & & 2.56 & $* *$ & 2.39 & $* *$ \\
\hline \multicolumn{7}{|l|}{ Two-way interactions } \\
\hline Tie strength X Type of innovation & & & & & 0.26 & $* *$ \\
\hline Reciprocity X Type of innovation & & & & & 0.18 & $* *$ \\
\hline Dependence X Type of innovation & & & & & 0.41 & $* *$ \\
\hline Model $F$ & 7.39 & & 150.38 & & 206.83 & \\
\hline$R^{2}$ & 0.12 & & 0.79 & & 0.86 & \\
\hline Adjusted $R^{2}$ & 0.10 & & 0.78 & & 0.86 & \\
\hline$\Delta R^{2}$ & & & 0.67 & & 0.07 & \\
\hline$F$ change & & & 509.98 & ** & 108.42 & $* *$ \\
\hline
\end{tabular}

anstandardized coefficients are shown. $n=664$.

${ }^{\dagger} p<.10 ;{ }^{*} p<.05 ; * * p<.01$ 
Model comparisons in the table were made using partial F-tests. Model 3 provides a significant improvement in explanatory power over model 2 (i.e., $F(3)(2)=108.42, p<0.01$ ).

To gain further insight into the interaction effects we used methods suggested by Aiken et al. (1991) to plot the two-way interaction effects and calculate the significance levels of the simple slopes. Further, we performed slope-difference tests using methods from Dawson and Richter (2006). The two-way interaction effects are plotted in Figure 5.2. The interaction effects for each of our loose coupling dimensions resulted in similar regression lines. For illustrative purposes we have plotted the regression lines at values \pm 2 standard deviations from the means of the independent and interaction variables. However, different conditional values of the moderator may correspond with different slopes of the regression lines being studied (Aiken et al., 1991). Another option would have been to select each value so that it lay within the observed range but, using the Johnson-Neyman technique as outlined in (Hayes \& Matthes, 2009), we have avoided the arbitrariness of this choice by computing the regions of significance. The two-way interactions are significant over all possible values of loose coupling found among the innovation network partners in our sample: this range running from -3.81 to 2.19 for tie-strength; from -3.43 to 2.57 for reciprocity, and from -3.53 to 2.47 for dependence. Further, in Figure 5.2, all the simple slopes differ significantly from 0 except the line that represents the impact of reciprocity on collaborative architectural innovation performance. Slope difference tests indicate that all paired slopes differ significantly from each other. 

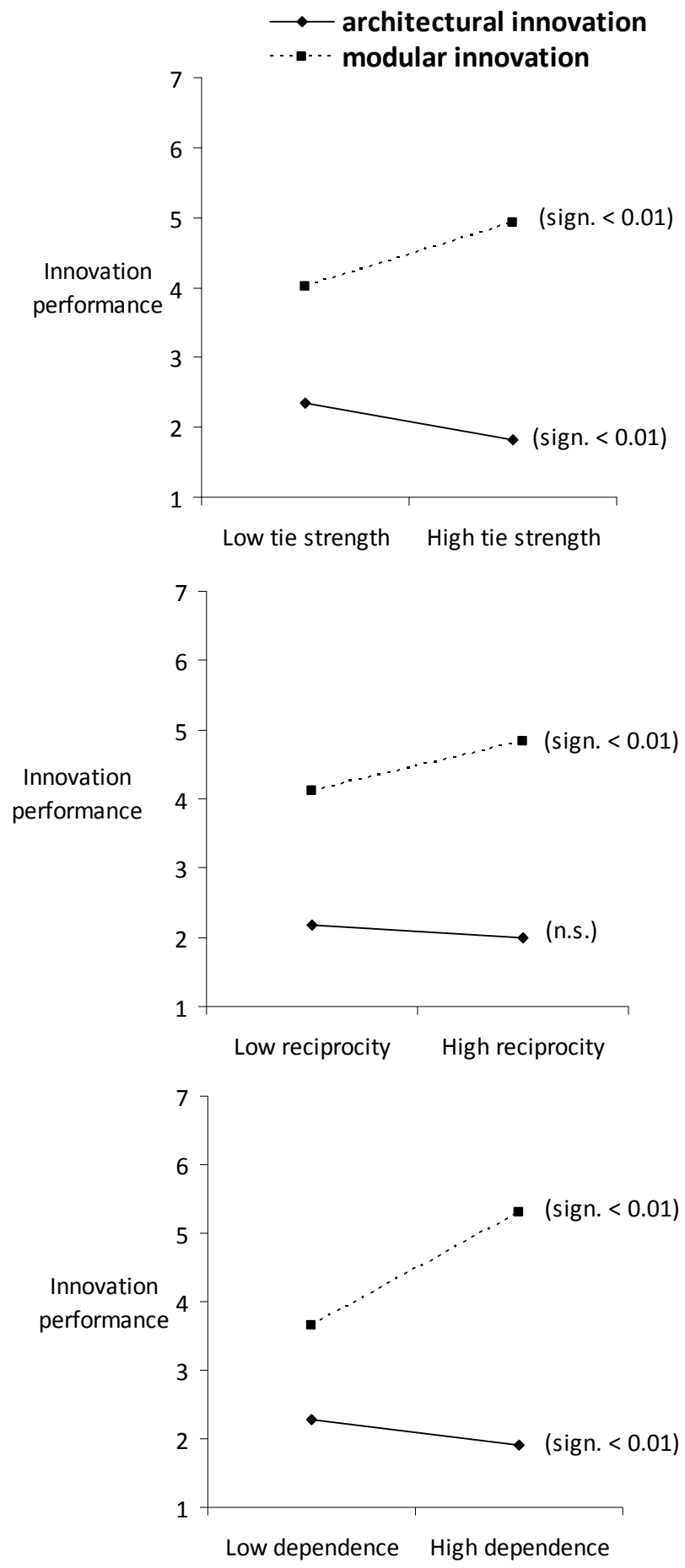

Figure 5.2. Interactions between Organizational coupling and Type of innovation 
Figure 5.2 shows that the highest innovation performance is achieved when companies pursue modular innovations in tightly coupled innovation networks. The poorest performance results from pursuing architectural innovations in strong innovation networks. Overall, modular innovations are associated with high collaborative innovation performance, while architectural innovations are associated with low collaborative innovation performance. We will now take a closer look at the positions of the lines (the intercepts), the directions of the regression lines, and the slope differences between the lines to interpret the research findings in more detail and assess the validity of our hypotheses.

Hypothesis 1a states that organizational loose coupling will be negatively related with the performance of collaborative product innovations. Further, Hypothesis $2 b$ states that this negative impact will be larger with architectural innovations than with modular ones. The regression coefficients of the variables in model 2 indeed indicate that loose coupling reduces the performance of collaborative innovations; however, the introduction of the interaction terms in model 3 overturns these premature conclusions. The resulting regression lines shown in Figure 5.2 indicate that loose coupling has a significant negative impact on modular innovation performance. However, contrary to conventional wisdom but confirming Hypothesis $2 \mathrm{c}$, our results show that loose coupling significantly improves the performance of architectural innovations. Thus, overall, Hypotheses $1 \mathrm{a}$ and $1 \mathrm{~b}$ are therefore only partly accepted, Hypothesis $2 \mathrm{a}$ is accepted, Hypothesis $2 \mathrm{~b}$ rejected, and Hypothesis $2 \mathrm{c}$ is accepted.

\section{Discussion}

\section{Managerial and theoretical contributions}

In this study, we set out to achieve a better understanding of how different configurations of innovation networks influence collaborative product innovation success. We found that the impact of different innovation network configurations on innovation performance is contingent upon the type of innovation that a company decides to aim at. The uncovered two-way interactions are plotted in Figure 5.2. These results have implications for management and theory, as discussed below. 
Overall, our study makes several contributions to the social network and modularity literature. First, we have extended the research on social networks by studying the impact of various degrees of organizational coupling among innovation network members on collaborative innovation performance. Second, we show how this relationship is contingent upon the type of innovation. We found that tighter coupling among innovation network members improves modular innovation performance in collaborative product innovation projects, but that looser coupling improves architectural innovation performance.

The social network literature argues that tighter coupling is likely to improve the coordination and exchange of critical resources and knowledge among innovation network members (e.g. Dhanaraj \& Parkhe, 2006; Hansen, 1999; Tiwana, 2008; Tsai \& Ghoshal, 1998). Scholars that draw on the knowledge-based view of the firm and transaction cost theory have also argued that, especially for systemic architectural innovations, tighter coupling would provide benefits over loose coupling among innovation partners (Wolter \& Veloso, 2008). In line with these arguments, Hoetker's empirical study (2006) showed that tighter coupling, i.e. working with internal suppliers, was favored by assemblers in organizing the production of large notebook displays, which can be seen as the equivalent of an architectural innovation because the innovation encompasses changes in many components within the display (Hoetker, 2006). However, our findings challenge Hoetker's (2006) generalization that tight organizational coupling is also beneficial for architectural innovation. There is strong internal support for this finding because the direction of this relationship is similar for different dimensions of organizational loose coupling. We now suggest two possible explanations for the finding that looser coupling improves architectural innovation performance.

First, Gargiulo and Benassi (2000) and Uzzi (1997) warn of the danger of cognitive 'lockin' as a result of tight coupling among innovation network members. Companies may become isolated from firms with novel ideas because these exist beyond the tightly coupled sub-network of existing partners on which the company focuses (Gargiulo \& Benassi, 2000; Hagedoorn \& Frankort, 2008). Even if better partners are known to be available beyond the existing sub-network, tight coupling may create 'network inertia', with multiplex, high reciprocity, long-lasting relationships likely to increase resistance to network partner change (Kim et al., 2006). Thus, the tighter the coupling among innovation network members, the 
lower the lead firm's ability to adapt the composition of their innovation network to match the coordination requirements of an architectural innovation. As such, the negative impact of tight coupling on architectural innovation performance may be the result of the lead firm's inability to exchange old partners for new ones that are better equipped for the task, and this is likely to outweigh the positive impact of tighter coupling on the ability to coordinate systemic interdependencies among the innovation network members. This finding fills an important gap in the modularity literature (Hoetker, Swaminathan, \& Mitchell, 2007).

An alternative plausible explanation comes from institutional and cognitive theories of technological change. Here, it has been argued that technological changes in decentralized networks of companies that are tied together by elaborate institutional, economic, and cultural relationships, are sometimes more difficult than technological change in more independent organizations (Uzzi, 1997). In stronger networks, companies often develop shared cognition (Levin \& Cross, 2004) and these shared technological frames then define the lens that people use when trying to make sense of innovations (Dougherty, 1992; Kaplan, 2008; Orlikowski \& Gash, 1994). However, a company's innovativeness can be restricted by a reliance on the accumulated knowledge that reflects the architecture of their previous generation of products (Henderson \& Clark, 1990; Leonard-Barton, 1992). As such, cognitive frames, which are more often shared among tightly coupled partners (Ring \& Vandeven, 1994), are likely to thwart collaborative, architectural innovation. In contrast, loose innovation networks are more often made up of companies that operate at the periphery of networks, or in non-related industries. These companies may be less biased by commitments to existing design standards. In addition, because loose ties are associated with limited competence-based trust (Levin \& Cross, 2004), loosely coupled firms may invest more time in carefully evaluating the changing interactions among the interfacing subsystems associated with architectural innovations, and whether companies are able to adhere to the new design rules. Given that technological frames develop over time, and strengthen to the extent that design standards become institutionalized, we would recommend that future studies explicitly take the dominancy of design standards into account, as a proxy of institutionalization, when studying the impact of loose coupling on collaborative innovation performance. 


\section{Implications for management}

Our findings can be used by innovation managers to direct their innovation strategies. Our results show that, overall, modular innovations perform better than architectural innovations. Yet, if companies align their innovation network to the innovation task, they can significantly enhance the collaborative innovation performance. Our study's results identify the type of innovation network that managers should configure in order to maximize the performance of their chosen type of innovation. For modular innovations, companies should collaborate with tightly coupled partners. However, for architectural innovation, managers can either best work with companies that are less committed to the old product architecture, or they should take this aspect into account and clearly explain the nature of the architectural innovation to their existing partners.

\section{Limitations and future research}

This study is not without limitations. First, we are in the process of also collecting objective performance data of the collaborative innovation projects that we studied. Unfortunately we were only able to collect objective performance data for $80 \%$ of the collaborative innovation projects in our full sample. Because we did not want to reduce the sample size with over 100 companies, we decided to use the subjective performance scales. The use of subjective performance data is very common in the innovation and marketing literature e.g. (Gatignon et al., 2002; Sobrero \& Roberts, 2001). It has also been shown that there are high correlations between subjective and objective performance measures (Dess \& Robinson, 1984; Song \& Parry, 1997). Therefore we expect that using subjective performance data did not reduce the reliability and validity of our empirical findings.

Secondly, we measured the degree of organizational coupling only at innovation network formation; we did not measure changes in organizational coupling during the innovation project, or in the exploitation phase. Although for architectural innovation the performance is maximized when the innovation network is composed of companies that were loosely coupled prior to forming the innovation network, it may well be the case that performance also increases if these companies become tightly coupled during the innovation project. For example, this could occur because tighter coupling (e.g. higher reciprocity and interdependence) provides some assurance to the individual companies that they will 
achieve a return on their innovation-specific investments in the commercialization phase. Future research should study this temporal element and pay attention to the pattern of organizational coupling over time in relation to collaborative innovation performance.

Third, we have studied innovation networks from the perspective of the lead firm. Although egocentric network analyses provide an efficient and effective network analysis method, they are less informative than full-network analysis (Marsden, 2002). Future studies could undertake a full network analysis and analyze a limited number of innovation networks in greater depth.

Fourth, the results of self-report surveys are potentially overestimated due to common method variance (Podsakoff, MacKenzie, Lee, \& Podsakoff, 2003). Although it is argued that such concerns may be overstated (Spector, 2006), we did statistically test for common method variance (Podsakoff \& Organ, 1986) and multicollinearity, but found no indications that our results are inflated. Furthermore, our hypotheses mainly pertain to interaction effects and, in relation to common methods, Evans' (1985) conclusion is clear-cut: "artifactual interactions cannot be created; true interactions can be attenuated". Thus, although future research could adopt different data collection methods, we do not believe the method adopted here is a serious concern.

Fifth, we found that architectural innovation performance is low compared to modular innovation performance, despite companies that have control over the evolution of a product's architecture being able to retain a competitive advantage in an industry (Morris \& Ferguson, 1993). As an example, Fixson and Park's (2008) investigation illustrates that architectural innovation - in their case the integration of previously modular product designs - was an important and successful competitive strategy in the bicycle industry. However, our study shows that, for many companies, architectural innovation is problematic and associated with low innovation performance. Therefore, it is critical to respond effectively to architectural innovation. As (Henderson \& Clark, 1990) vividly put it: "learning about changes in the architecture of the product is unlikely to occur naturally [...] changes in architecture new interactions across components (and often across functional boundaries) - may therefore require explicit management and attention". Nevertheless, only limited attention has been paid to how companies can actually succeed with architectural innovation. Therefore, future research should focus on developing an interpretive model that explores 
mechanisms for overcoming the detrimental impact of dominant design rules on architectural innovation. This will reveal how companies can succeed in collaborative architectural innovation. For this purpose, we propose a study on the behaviors of innovation network leaders that can actively compensate for the negative impact on architectural innovation of institutionalization through design rules. Enhanced leadership could compensate for organizational loose coupling in orchestrating collaborative architectural innovation (Dhanaraj \& Parkhe, 2006; Orton \& Weick, 1990). Soft power strategies (Katila et al., 2008) and transformational leadership behaviors that increase the willingness to experiment have the potential to moderate the negative impact of design rules on architectural innovation (Smith \& Tushman, 2005; Vera \& Crossan, 2004; Yukl, 2009). Thus, in addition to studying the role of institutionalized product 'design rules' on collaborative innovation, we also suggest studying the more-active leadership compensation mechanisms that could overcome the unique challenges facing companies in modular and architectural innovation.

\section{Conclusions}

Despite the limitations of this study, we have successfully addressed a gap in the literature on social networks configurations and collaborative innovation. Our results show that tight coupling is not unconditionally advantageous for companies pursuing innovations in networks of firms. This supports a contingency perspective on collaborative product innovation. The success of collaborative innovation is contingent upon the configuration of the innovation network and on the type of innovation. Finally, we speculate that a third variable, the dominancy of design rules, may play an important role and may well moderate the relationship between organizational coupling and collaborative innovation performance. Hopefully, this study will lead to further investigations into the complex set of interrelationships among variables related to modular and architectural innovation outcomes. 


\section{APPENDIX 5.A \\ Items measuring constructs}

For all items, where no other scale is indicated, the response scale was $1=$ "strongly disagree" to 7 "strongly agree". $(\mathrm{R})=$ reversed item.

\section{MAIN VARIABLES}

Loose coupling dimension 1, Tie strength:

Before our company selected companies for this product innovation project:

TIE 01 Our company worked very intensively with the innovation partners.

TIE 02 Our company had a very close relationship with the innovation partners.

TIE 03 Our company and the innovation partners had a very collaborative relationship, like a real team.

\section{Loose coupling dimension 2, Reciprocity:}

At the beginning of the product innovation project:

RECI01 This innovation network was characterized by high reciprocity among companies.

RECIO2 We were extensively tied to the innovation partners through other business ties in addition to this innovation project.

RECI03 We felt indebted to our innovation partners for what they have done for us in the past.

RECIO4 Our relationship with the innovation partners could be defined as "mutually gratifying".

RECI05 We expected that we would be working with the innovation partners far into the future.

\section{Loose coupling dimension 3, Dependence:}

At the beginning of the selected innovation project, we expected that:

DEP01 Each company would provide the innovation project with unique skills and resources.

DEP02 The operations of the innovation network would be severely disrupted if a partner were to withhold its skills and resources.

DEP03 My company and our partners would find it difficult to effectively perform the other companies' tasks and responsibilities in this product innovation project.

DEP04 The skills and resources that most partners brought to this product innovation project could easily have been replaced. ( $R$ )

DEP05 The total cost to the innovation network of losing a partner's assistance would be substantial.

\section{Type of innovation}

How would you characterize the type of innovation you have selected for this survey? (check one box)

$\square$ Modular innovation: These innovations involve significant $\square$ improvements of sub-systems that leave the existing interface standards and interactions between the improved subsystems and other subsystems largely unchanged. Example: a notebook incorporating a higher resolution display.

$\square$ Architectural innovation: These innovations involve (sometimes marginal) improvements of subsystems that have a more significant impact on the existing interface standards and interactions with other subsystems. Example: a larger notebook display (=marginal improvement) draws more power (change in interaction) and requires simultaneous changes in other subsystems such as the battery, software and charging system in order to function. 


\section{Performance:}

We are interested in your assessment of the product innovation's overall performance. Please indicate, using what you know today, how successful the innovation project was, by using the following criteria.

PERF01 Innovation was successfully implemented by the members of the innovation network.

PERF02 Innovation has been commercially successful for the members of the innovation network.

PERFO3 Innovation has met the innovation network members' expectations regarding the innovation's impact on sales.

CONTROL VARIABLES

Bridging ties:

BT01 Companies in this innovation network varied widely in their areas of expertise

BT02 Companies in this innovation network had a variety of different backgrounds and experiences

BT03 Companies in this innovation network had skills and abilities that complemented each others'

BT04 Companies in this innovation network had resources and assets that complemented each others'

\section{Competitive environment}

Please consider the following statements about possible market and technological uncertainties in your industry concerning the products you develop and produce.

\section{Customer uncertainty:}

For our end-products and/or subsystems we use and supply:

CU01 Customers' preferences for product features have changed quite a bit over time.

CU02 We are witnessing demand for our products from customers who never bought them before.

CU03 New customers tend to have product-related needs that are different from those of our existing customers.

\section{Technological uncertainty:}

For our end-products and/or subsystems we use and supply:

TU01 Specifications for products and subsystems change frequently.

TU02 Future technological improvements to products and subsystems are very likely.

TU03 The technologies used in our products are changing rapidly.

\section{Single item control variables:}

INPUT01 Relative to other product innovation projects, the marketing resources devoted to this innovation project by the innovation network partners are high.

SIZE01 What was approximately the total estimated dollar cost of this product innovation project? (___ dollars)

COMP01 How many companies in the innovation network could be classified as competitors? (__ companies)

SIZE01 How many employees does your company have approximately? ( employees)

EQ01 Can the relationships among companies in the innovation network be described as predominantly equity relationships? $\square$ (Yes) $\square$ (No) 


\section{CHAPTER 6}

\section{Product innovation networks, do design rules compensate or complicate innovation?} Empirical evidence ${ }^{7}$

This study of collaborative innovation projects examined the impact of different innovation contexts on collaborative innovation performance. We frame innovation contexts along two dimensions: the availability of product design rules and the degree of organizational coupling among innovation network partners. We found that each context has unique implications for modular and architectural innovation performance. Although the implications of loose versus tight organizational coupling and the availability of design rules are discussed in the social network and modularity literature, their simultaneous impact on the performance of modular and architectural innovation has not been studied to date. Using data from over 600 product innovation networks from four different industries in the U.S., we found that modular product design rules are incomplete substitutes for organizational loose coupling. Modular innovation performance is maximized in tightly coupled innovation networks where design rules are available. Furthermore, and against conventional wisdom, our findings reveal that architectural innovation performance is highest when organized in loosely coupled innovation networks where design rules are not available.

\footnotetext{
${ }^{7}$ Accepted and presented at: the Academy of management Conference, (2010); and the Tilburg Conference on Innovation, (2010). This chapter has been submitted to an international refereed journal.
} 


\section{INTRODUCTION}

Do product design rules compensate or complicate collaborative product innovations? Addressing this question, modular system theories explain that modular design rules facilitate product innovation in loose organizational networks (Baldwin \& Clark, 2000; Orton \& Weick, 1990; Schilling, 2000). The central argument is that if companies adhere to the prevailing modular product architecture and the subsystems' interface designs, integration protocols and testing standards, the inner workings of individual subsystems can be changed without the need to communicate these changes to other companies supplying connecting subsystems. In this way product design rules function as standards (1974) that compensate for organizational loose coupling among innovation partners in collaborative product innovation projects.

Yet, while the benefits of design rules and modular innovation are on the foreground of academic interest, many companies are more interested in how to re-modularize their products by means of architectural innovation ${ }^{8}$. Compared to modular innovation, architectural innovations are more systemic by nature because they leave the working concepts of individual subsystems largely untouched, but they change the way in which subsystems are linked together (Henderson \& Clark, 1990). This is an attractive alternative, especially when well-defined interfaces among subsystems are no longer compatible with customer needs or with technological opportunities provided by new materials, improved production technologies, or an higher expected quality of integrated subsystems e.g. (Cacciatori \& Jacobides, 2005). An interesting case is Shimano, by redesigning four components - shifter, derailleur, freewheel, and chain - and changing the linkages between them, it achieved superior product performance and has become by far the dominating firm supplying bicycle gear-shifting systems (Fixson \& Park, 2008).

Unfortunately, little is known about the conditions that facilitate architectural innovation. Previous studies indicate that the more radical or architectural innovations are, the more likely it is that companies select partners with who they share tight organizational links

\footnotetext{
${ }^{8}$ Other scholars use the term 'systemic innovation' for what we call architectural innovation cf. Chesbrough, $\mathrm{H}$. W. \& Teece, D. J. 1996. When is virtual virtuous? Organizing for innovation. Harvard Business Review, 74: 6573, Hoetker, G. 2006. Do modular products lead to modular organizations? Strategic Management Journal, 27 : 501-518.
} 
(Hoetker, 2006; Li, Eden, Hitt, \& Ireland, 2008; Wolter \& Veloso, 2008). Because modular innovations are autonomous by nature they are easily coordinated in loose innovation networks (Baldwin, 2008; Sanchez \& Mahoney, 1996; Schilling, 2000). But, research in the semiconductor and computer industry showed that architectural innovations require rich, bilateral and intense communication, so called 'unstructured technical dialogue', therefore they can best be organized in tightly coupled or even integrated companies (Hoetker, 2006; Monteverde, 1995).

From the engineering design literature we learn that product design rules also significantly influence collaborative product innovation. By defining the interactions among subsystems, explicitly codified designs rules easy the coordination of modular innovation among organizational subunits and allow component suppliers to keep their design activities disintegrated (Parnas, 1972; Sanchez \& Mahoney, 1996; Ulrich \& Ellison, 2005). In contrast, studies that applied a cognitive or institutional view to study architectural innovation argue that product design rules shape technological frames that guide technological choices in the same direction (Cohen \& Levinthal, 1990; Garud \& Rappa, 1994). Therefore the companies' ability to architecturally innovate will be limited given their routines to accommodate to the previous product and process architecture (Benner \& Tushman, 2002; Henderson \& Clark, 1990).

However, although these seminal studies are valuable, they do not show how different degrees of organizational coupling and the availability of design rules together influence the performance of modular and architectural innovations. The purpose of this chapter is to explore how collaborative innovation performance is affected by these two dimensions that together define the innovation context. Using a quantitative study among product innovation networks in four different industries in the United States, this research aims to definitively answer this question.

The results reported here challenge traditional views of innovation networks and modular product design rules. Our empirical evidence confirms that product design rules that describe how subsystems connect and communicate; and that inform designers how to assemble the system and provide standards that can be used to evaluate a subsystem's relative performance, improve the performance of modular innovation and decrease architectural innovation performance. However, in contrast to the intuitively appealing link 
between design rules and loose coupling, design rules do not compensate for the negative relationship between organizational loose coupling and collaborative innovation performance. Besides tight organizational coupling, design rules have an additive positive effect on modular innovation performance. Therefore, the best context for companies to pursue modular innovation is one with clear design rules and in which innovation network partners share close relationships that are difficult to replace with other partnerships. Our results for architectural innovation are even more striking. In contrast to conventional wisdom, tight organizational coupling does not improve architectural innovation performance, at least, not when product design rules are available. When design rules exist, for architectural innovation it is most effective for a company to work with partners that have not yet established a close and intensive relationship in previous innovation projects and companies can better chose to work with partners that are easy to replace, e.g. their skills and resources are not unique, and relation specific investments are relatively low at the moment of innovation network formation. In line with conventional wisdom, tighter coupling will improve architectural innovation performance when no common product design rules exist.

Surprisingly, a long history of collaboration combined with the expectation to be continuing working far into the future does not interact with the availability of design rules in explaining modular or architectural innovation performance.

The paper is organized as follows. We begin with examining the effect of loose and tightly coupled innovation networks on collaborative innovation performance. Next we explain how this relationship differs for modular and architectural innovation. We end the theoretical section by explaining the combined effect of organizational coupling and design rules on modular and architectural innovation performance. After this, we explicate our methods used to study our research questions. We then present the results of our study. Finally, we discuss the main theoretical and managerial implications of our findings, important limitations of our study and alternative avenues for future research. 


\section{THEORETICAL BACKGROUND AND HYPOTHESES}

Figure 6.1 summarizes this study's hypotheses. Our theoretical model depicts the innovation network configuration as directly related to collaborative product innovation performance and shows that this relationship is contingent upon the availability of product design rules and the type of innovation.

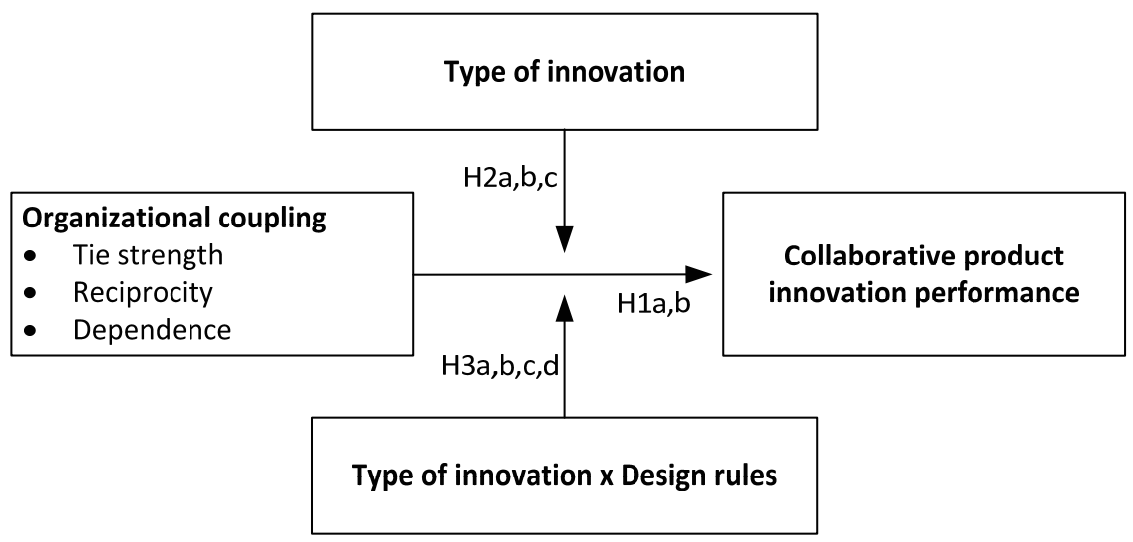

Figure 6.1. Contingency model for collaborative product innovation projects

Framework of innovation contexts: organizational coupling and compensation mechanisms

Early studies on organizational coupling suggested to identify social hierarchies, like innovation networks, by the members' interaction patterns within and between organizational subgroups (Moreno, 1943; Simon, 1962). Although these subgroups can be "visibly" differentiated in a larger organizational network, the interactions between them are often weak but not negligible (Simon, 1962). Drawing on this systems view Weick (1976) explains how 'loose coupling' suggests the idea of: "building blocks that can be grafted onto an organization or severed with relatively little disturbance to either the blocks or the organization". This supplies organizational parts with the autonomy to specialize and the ability to adapt to changing environmental conditions (Orton \& Weick, 1990; Schilling, 2000). Orton and Weick (1990) advocate a dialectical interpretation of loose coupling and argue that compensation mechanisms are required to achieve unity of effort of networks of loosely coupled organizations. A crucial determinant of organizational functioning over time is then 
the patterning of loose and tight couplings in different domains (Weick, 1976). We focus on two of such domains which together define innovation contexts: the degree of organizational coupling among innovation network members and the availability of product design rules and we investigate what patterns of both dimensions lead to successful collaborative innovation performance. To disentangle the complex relationship among both dimensions and its impact on innovation, we differentiate between modular and architectural innovation and study how both types of innovation are affected differently by different combinations (patterns) of organizational coupling and product design rules.

Impact loose and tight coupling on collaborative innovation performance. Nahapiet and Ghoshal (1998) argue that four organizational conditions shape social capital: interaction ties, time, interdependence, and network closure. Beekun and Glick (2001) adopted four very similar measures from the field of social network analysis to assess the degree of coupling among firms: tie strength, reciprocity, interdependence, and directness. Weick (1982) argues that these dimensions are all positively correlated and loosely coupled firms score low on each of these dimensions.

In the social network literature, it is questioned whether it is tight or loose coupling between people that improves collaborative innovation performance. Companies that innovate through tightly coupled, closed networks derive benefits from the ability provided by strong ties to effectively coordinate the exchange and integration of resources across loose organizational boundaries. Paradoxically, this comes with an opportunity loss related to accessing heterogeneous, useful resources and competences (Coleman, 1988; Granovetter, 1973). Conversely, a benefit of loose coupling is that it provides the opportunity to access heterogeneous resources and competences, but, this is often at the cost of a company's ability to effectively coordinate the exchange and integration of these resources across organizational boundaries (Burt, 1992; Granovetter, 1973). Obstfeld (2005) described this dilemma as the idea problem versus the action problem.

The action problem, loose coupling decreasing innovation performance. Many scholars argue that increased organizational coupling, which is characterized by high scores on the aforementioned four dimensions, helps to overcome trust and cooperation problems (Ahuja, 2000; Granovetter, 1985; Krackhardt, 1992; Nowak, 2006; Parkhe, 1993). This is endorsed by empirical studies that show how tighter organizational coupling shapes trustworthiness and 
aligns visions among innovation partners which facilitates the exchange and combination of complementary resources that are located in distinct organizational units (Nahapiet \& Ghoshal, 1998; Tsai \& Ghoshal, 1998). Scholars that extended this view to inter-firm relationships came to the same results and showed that tight inter-organizational coupling, for example real teamwork in the past with partners that bring in unique skills, and a high expectation that partners will be working far into the future, reduces opportunism and increases relation specific resource commitment in favor of collaborative innovation e.g. (Dyer \& Singh, 1998; Gulati, 1995; Kogut, 1989; Tiwana, 2008a; Wuyts \& Geyskens, 2005). In a recent study, Tortoriello and Krackhardt (2010) also show that 'bridging ties' to nonredundant resources only improve innovation when two companies are both strong and reciprocally tied to the same third party. This characteristic of tight coupling is a form of 'indirect reciprocity', when deciding to cooperate or defeat, companies will take into account the possible consequences for their reputation towards the third party (Nowak, 2006). Thus, tight coupling improves the willingness to cooperate in product innovation projects.

An argument from the knowledge based view explains that tight coupling improves collaborative innovation performance because it improves the ability to transfer heterogeneous knowledge among innovation partners. Knowledge that is used in technological innovation is often costly to acquire, transfer, and use in a new location (Vonhippel, 1994). Distant and infrequent relationships are less motivated to identify and share such knowledge or not able to communicate it in a way that it is readily understood and absorbed by the recipient (Levin \& Cross, 2004; Li, Poppo, \& Zhou, 2010). In contrast, tight organizational coupling enhances the communication effectiveness (Dyer \& Singh, 1998) especially for the transfer of tacit, non-codified information (Hansen, 1999).

To summarize, tight coupling associates with increased willingness and ability to transfer complex knowledge (Hansen, 1999). Thus, other things being equal, while tight organizational coupling most likely improves collaborative innovation performance, organizational loose coupling is likely to decrease the performance of collaborative product innovation. 
Hypothesis 1a: organizational loose coupling will be negatively related with the performance of collaborative product innovations.

The action problem: tight coupling decreasing innovation performance. For other reasons, we argue that tight organizational coupling can also decrease innovation performance. Strong relationships based on frequent and close working relationships can lead to over-embeddedness (Hagedoorn \& Frankort, 2008). When companies are tied together by elaborate institutional, economic and cultural relationships, change can be more difficult than technological change in networks of independent organizations (Glasmeier, 1991; Greenwood \& Hinings, 1996; Uzzi, 1997). Tight coupling than associates with deeply ingrained routines including fixed communication channels to discuss technological change (Henderson \& Clark, 1990). Furthermore, from functional theory it follows that reciprocity stabilizes human relationships because it involves a mutually gratifying pattern of exchanging goods and services (Gouldner, 1960). Such binding creates 'network inertia' that complicates the formation of new relationships that are potentially better equipped to perform the task (Hansen, 1999; Kim et al., 2006). In this way, tight coupling reduces the flexibility to adapt and select partners with the right abilities (Gouldner, 1960; Weick, 1976); this will result in lower innovation performance. Thus, other things being equal, while loose organizational coupling most likely improves collaborative innovation performance, organizational tight coupling is likely to decrease the performance of collaborative product innovation.

Hypothesis 1b: organizational loose coupling will be positively related with the performance of collaborative product innovations.

\section{Influence of loose coupling on the performance of modular and architectural innovations.}

We organize our analysis around modular and architectural product innovations. Modular innovation takes place through changes of the working concepts within product modules that do not significantly affect connecting modules (Sanchez \& Mahoney, 1996). Therefore modular innovations adhere to the existing modular product architecture. In contrast, architectural innovations leave the design concepts of individual modules largely untouched, 
but they overturn the existing product architecture by changing the way in which subsystems are linked together (Henderson \& Clark, 1990). Architectural innovation can also introduce previously unknown interdependencies between components. Compared to architectural innovation which is systemic by nature, modular innovation is more autonomous and associates with lower task interdependence among innovation partners. Modular product architectures allow so to say for 'information hiding' which implies that for modular innovation companies require information from only one organizational sub-unit (Baldwin \& Clark, 2000; Parnas, 1972). In following two paragraphs we explain why we expect that the negative impact of loose coupling is smaller for modular than for architectural product innovations, but we also develop plausible arguments why loose coupling may be beneficial for architectural innovation performance.

Loose coupling decreasing modular innovation performance. A benefit of product modularity is that it facilitates separate component-suppliers to innovate their components of the end-product at their own chosen speeds (Langlois \& Robertson, 1992; Schilling, 2000). For example advances made on rechargeable batteries involved substituting NickelCadmium batteries by batteries based on Nickel Metal Hydride technology. This innovation involved large changes within the battery, but it did not change the interfaces it has with components from other companies; both batteries efficiently fit the devices they power in the same way. Thus, modular product innovations involve improvements within sub-systems and leave the existing interfaces and interactions among subsystems largely unchanged (Henderson \& Clark, 1990). Therefore, modular innovations are more or less autonomous; they require only marginal coordination across organizational boundaries of the companies producing the different modules. Consequently, the negative impact of loose coupling will be low for modular innovation.

Hypothesis 2.a: organizational loose coupling will have a negative impact on the performance of modular product innovation.

Loose coupling decreasing architectural innovation performance. It is often argued that loose organizational forms improve innovativeness because it grants a company access to external resources that complement their own (Jacobides, 2005; Orton \& Weick, 1990; 
Schilling, 2000). However, mixing and matching of complementary product modules that map one-to-one to chunks of specialized knowledge located in different companies is not architectural innovation. Changing the way how those modules interface and function together is architectural, system-wide innovation. Architectural innovation can only be realized if complementary innovations take place in separate firms, it are systemic changes throughout a product system that involve interdependent changes of interfaces between modules. For example, when a building company decides to change the tolerances of a floorelement from 0.5 to 0.05 inch, it requires the same adaptation of connecting components like columns and walls that are all connected to this floor. If component suppliers don't adapt to this change, components will loose compatibility. Because in loose networks individual firms tend to emphasize local search processes for improving their modules, they often fail to fully take the interdependencies into account that go with architectural innovation (Levinthal \& Warglien, 1999). Furthermore, companies that attempt to architecturally innovate and introduce new interface standards in loose networks risk isolation because other companies can easily choose not to follow (Langlois and Robertson, 1992). Therefore, a direct outcome of organizational loose coupling is persistence resistance to change - as a result loosely coupled organizations are less conducive to system-wide changes than tightly coupled organizations (Orton \& Weick, 1990). For similar reasons, Hoetker (2006) argues that "hierarchy is hypothesized to provide more valuable benefits for systemic designs." Thus, compared to modular innovation, architectural innovation depends more heavily on the cooperativeness of a group of companies and firms would benefit more from tighter organizational coupling (Chesbrough \& Teece, 1996; Orton \& Weick, 1990; Schilling \& Steensma, 2001).

A second argument why tight coupling has a larger positive impact on architectural than modular innovation relate to the large transfer of tacit design knowledge that is required for architectural innovation, compared to the latter. When interfaces within the product architecture are not well specified, changing the specification of one component can create a cascade of unknown changes in other components, managing these interdependencies requires 'unstructured technical dialogue' (Monteverde, 1995). Communication about changing interfaces requires the transfer of complex, non-codified and often 'sticky' design knowledge which is costly to transfer among innovation partners (Monteverde, 1995; 
Vonhippel, 1994). When companies have closely worked together in previous innovation projects, there is a large chance they have developed a thorough, shared understanding of the product architecture, and a common language for discussing technical issues (Hoetker, 2006; Kogut, 1988); therefore architectural innovation is better accomplished in tightly coupled networks. Companies may even have translated this tacit knowledge in comprehensible set of explicit design rules that clarifies how the different components interact, this may further enhance the coordination of interdependencies in architectural innovation projects (Baldwin \& Clark, 2000). We therefore hypothesize the following:

Hypothesis 2.b: the negative relationship between organizational loose coupling and the performance of collaborative product innovation will be stronger for architectural than for modular product innovations.

Loose coupling improving architectural innovation performance. Literature on the weak tie theory explains that loose relationships give rise to the opportunity to access useful resources by boundary spanning (Burt, 1992; Granovetter, 1973). If one neglects these 'search benefits', this will suppress our expected negative impact of loose coupling on collaborative innovation performance. Therefore, to be consistent with previous studies, we control for a suppressor mediator: 'bridging ties' that taps into the degree to which weak ties have linked innovation network partners that have useful, complementary resources and competences (Hansen, 1999; Levin \& Cross, 2004; Padula, 2008; Tiwana, 2008a). However, we argue that loose coupling has an additional positive effect on innovation performance that is not explained by these search benefits. We have two plausible explanations for why loose coupling potentially supplies a means for action instead of creating action problems.

First, we believe that strongly tied, reciprocal relationships are less likely to change existing network relationships because excluding a company from a project could have negative implications for the multiple other reciprocal commitments that exist among the companies. A strong focus on existing innovation network members will insulate companies from knowledge beyond their network (Uzzi 1997; Schilling and Phelps 2007), loose relationships escape this 'binding constraint' (Hansen, 1999). Thus, tight coupling creates 
network inertia that reduces flexibility and complicates the formation of new relationships that are potentially better equipped to perform the task, resulting in lower innovation performance (Hansen, 1999; Kim et al., 2006).

Secondly, interaction processes produce shared interpretations that emerge gradually and incrementally (Ring \& Vandeven, 1994). A shared understanding about how the individual subsystems work together are likely to facilitate the coordination of interdependences among subsystems (Puranam et al., 2009). This is also widely acknowledged in the literature on team mental models cf (Marks, Zaccaro, \& Mathieu, 2000; Rico, Sanchez-Manzanares, Gil, \& Gibson, 2008). However, Cohen and Bacdayan (1991) found that in performing repetitive tasks groups of people develop routines that are difficult to unlearn. Their experiments reveal that routines were used even when obvious and better alternatives were available and when wrong decisions were penalized.

One can think of architectural innovation as this better alternative: and then companies, because they are likely to respond to each other and the technology in routine ways, may entirely overlook the changed interdependencies among the subsystems, and missing such crucial information is likely to reduce architectural innovation performance. This routinization of work is found in the companies' information channels and information filters, and this biases the information that is transferred between innovation partners (Henderson \& Clark, 1990). Shared technological frames guide future technological choices in a common direction (Cohen \& Levinthal, 1990; Garud \& Rappa, 1994). The ability to innovate will thus be limited given the inter-organizational routines becoming accommodated to the known architecture (Henderson \& Clark, 1990; Staudenmayer, Tripsas, \& Tucci, 2005). Thus, tight coupling will result in shared technical frames that improve the management of known interdependencies among subsystems, but will reduce the performance when it comes to architectural innovation because this depends upon an ability to coordinate non-repetitive, unknown interdependencies. As such, we expect loose relationships to be less biased by inter-organizational routines that are tuned to an existing product architecture, leading to the following hypothesis:

Hypothesis 2.c: organizational loose coupling will have a positive impact on the performance of architectural product innovation. 


\section{Product design rules}

In the process of creating modular products, the systems architect and its development team decide upon the following categories of design rules: product architecture, the interfaces and the testing standards that will be used (Baldwin and Clark, 2000). The product architecture comprises the specification of the modules that constitute the platform, their functions, the physical elements by which each module will fulfill its intended function and the layout of the modules. The interface specifications describe how modules will interact with other modules including how they are physically connected, how power or material is transferred and how they communicate (Sanchez, 2000). Finally, design rules comprise testing standards to evaluate the modules' relative performances, and these standards allow a designer to verify whether a module conforms to the design rules and make sure it will function in the end-system. In the following paragraphs we theorize why dominant design rules have a twofold effect on collaborative product innovation performance. We first discuss why the relationship between design rules and modular innovation performance is most positive in loose innovation networks. Next, we explain how dominant design rules moderate the relationship between loose and tight organizational coupling and architectural innovation performance. We have no univocal expectation about whether loose or tight coupling improves architectural innovation performance. Yet, we will argue that the relationship between organizational coupling (loose or tight) and architectural innovation performance is strongest when product design rules are available and weakest when no product design rules are available.

\section{Combined influence: design rules compensating for loose coupling during modular} innovation. The classic organizational research literature suggests that organizational units coordinate via impersonal task programming mechanisms (e.g., plans, rules and specifications) or by personal coordination modes (March and Simon 1958; Thompson 1967; VanDeVen et al. 1976). Design rules belong to the first group of coordination modes. They are industrial standards of compatibility that clarify the interactions across modules, and explain how they need to be handled by loosely coupled organizations (Baldwin \& Clark, 2000; Sanchez \& Mahoney, 1996; Tiwana, 2008b). Design rules that define the in- and output requirements of the different modules enable companies to divide their development and production organization into specialized groups with a narrow focus 
(Sanchez \& Mahoney, 1996; Ulrich, 1995). They decrease component specificity and provide a form of 'embedded control' that reduces the need to continuously overt hierarchical control over loosely coupled firms during concurrent improvements of individual subsystems (Henderson \& Clark, 1990; Sanchez \& Mahoney, 1996; Tiwana, 2008b; Vonhippel, 1990). Therefore, a benefit of design rules is that they allow for information hiding as long as companies' conform to the existing design rules. This means that companies don't need to communicate about changes that take place within modules when those changes do not affect interactions between modules (Baldwin \& Clark, 2000; Parnas, 1972).

Several scholars have studied how dominant design rules facilitate the coordination of collaborative innovation. For example Argyres (1999) explains how a shared 'technical grammar' facilitated communication and governance in development of the B-2 Stealth Bomber. Baldwin and Clark (2000) also provide evidence for this relation in their examination of the computer industry and the creation of IBM's System/360, a modular family of computer systems. IBM's design rules became shared at the industry level and horizontal sub-industries developed that nowadays supply for instance hard disk drives, central processing units and software that conform to shared, non-proprietary interface standards (Langlois \& Robertson, 1992). Schilling and Steensma (2001) extended this view to the supplier network of the firm and found evidence that increasing availability of shared standards such as shared 'groupware' platforms or process protocols like ISO 9000 facilitates the adoption of loose organizational forms and allows loosely coupled firms to function well. Thus, design rules provide a shared understanding and domain of consensus across companies about product architectures and compensate for organizational loose coupling during collaborative product innovation projects.

H3a: High dominancy of design rules improves the performance of modular innovations. $H 3 b$ : The negative relationship between loose coupling and modular innovation performance will be weaker under conditions of high dominancy of design rules.

Combined influence: design rules complicating loose coupling for architectural innovation. Research in cognitive science and organization studies underpins that due to routinization people tend to approach the new in terms of the old (Orlikowski \& Gash, 1994). 
Product innovation activities are often illegitimate since they violate prevailing norms and evaluation routines in and outside the firm, or no shared understanding exists to make them meaningful since it requires 'unthinkable' new ways of thinking and acting (Dougherty \& Heller, 1994). Technological frames, strategic beliefs or 'thought worlds' explain the lens that people apply when they make sense of innovations (Dougherty, 1992; Kaplan, 2008; Orlikowski \& Gash, 1994). Henderson and Clark (1990) argued that such cognitive frames often thwart architectural innovation. Therefore, once design rules have become dominant and shared among firms, a company's innovativeness is restricted by its reliance on the accumulated knowledge that reflects the design rules and architecture of their previous generation of products (Henderson \& Clark, 1990; Leonard Barton, 1992). Design standards thus trigger internal biases for certainty and predictable results (Benner \& Tushman, 2003) and reduce the performance of architectural innovations.

H3c: High dominancy of design rules decreases the performance of architectural innovations.

Because firms benefit from a fit between strategy, technology and organization design features (Burton, Lauridsen, \& Obel, 2002; Chandler, 1962) they tend to invest in achieving a congruent set of organizational features (Hannan et al., 2003). Although dominant design rules make component suppliers less specific to other suppliers - we believe that firms explicitly and implicitly make investments in organizational design features like competences (routines), culture, incentive structure and the formal organization that build upon this set of design rules. In other words, organizations become highly specific to product design rules. Once design rules are dominant within the innovation network or even at the industry level, they may even be viewed as what Hannan and Freeman (1984) name environmentally imposed legitimacy constraints. When organization design features and design rules are specific to each other, a change in technological design rules requires a cascade of changes in organizational design features to bring these features back in congruence. Longer cascades of change heighten the risk of failure (Hannan \& Freeman, 1984; Hannan et al., 2003). This detrimental effect is reinforced by loose coupling among firms. A 'benefit' of loose coupling is persistence or buffering, this means that it prevents the spread of problems within a sub-system across sub-systems (Glassman, 1973; Orton \& Weick, 1990). But, a 
cascade of change in the different firms supplying the sub-systems that together form the end-product may be required in case of architectural innovation. In this sense, persistence may complicate architectural innovation that challenges the prevailing design rules.

Recapitulating, dominant design rules function as a form of embedded coordination which allows companies to effectively achieve modular innovations in loosely coupled networks. But they have a detrimental effect on architectural innovations since this type of innovation conflicts with the firms' routine competences and other organizational design features. This requires coordinated action across the boundaries of firms; however, this is severely complicated by organizational loose coupling.

H3d. The relationship between loose coupling and architectural innovation performance is most negative when product design rules are available and (b) least positive when no product design rules are available.

Combined influence: design rules complicating tight coupling during architectural innovation. We also hypothesized a positive effect of loose coupling among innovation network partners on the performance of architectural innovation. When design rules are available, it is even more important for a company to select partners that are willing and able to change the existing design rules. For two reasons we expect that the positive impact of loose coupling on architectural innovation performance will be larger when design rules are available. First, because of reduced network inertia, companies that lack close, reciprocating relationships providing unique resources, can more easily switch innovation partners and select new partners with aligned goals and abilities (Kim et al., 2006). For example, companies that loose their investments when the design rules are changed will find it difficult to find consensus about developing new design rules and will be less inclined to collaborate. Loose coupling makes it easier to select companies that have not made too much design rule specific investments in for example competences and production facilities. Secondly, we expect that loose relationships are less biased by inter-organizational routines that are tuned to the old product architecture. Loose coupling will therefore have a larger positive impact on the performance of architectural innovations when clear design rules are available. 
H3e. The relationship between loose coupling and architectural innovation performance is most positive when product design rules are available and (b) least positive when no product design rules are available.

\section{DATA AND METHODOLOGY}

\section{Research setting}

The objective of this study is to understand how firms can increase the success of collaborative product innovation projects conducted in innovation networks. We tested our hypotheses on a sample of innovation networks that consist of a lead company and one or more innovation partners responsible for different areas/subsystems of the end product. This nested product hierarchy allows companies to pursue both modular and architectural innovations, which are key variables in this study. Our unit of analysis is the product innovation project from the perspective of the lead firm. Innovation projects were selected from several industries in which we expected to find products that are composed of multiple subsystems (i.e., chunks, modules, or components).

\section{Survey development}

We developed the survey in several phases. First, we conducted a literature review to identify constructs that are commonly accepted in previous research. Whenever possible, we used existing multi-item scales to measure the constructs of interest in our questionnaire. We also conducted an in-depth case study involving 26 firms to advance our understanding of product innovation in loosely coupled innovation networks and to better understand the relationships among loose coupling, product design rules, and architectural and modular innovation performance. Next, we spoke to five academics to discuss the key theoretical relationships and to check the consistency and face validity of our constructs and we asked for their suggestions to develop items if precedents were missing. Finally, we pilot tested the revised survey using 20 project leaders from different industries to check if they interpreted the questions in the same way and to further refine wording. A final draft of the survey was completed and ready to pretest. 


\section{Survey pretesting}

To pretest the survey, we selected four companies with two successful and two failure collaborative product innovation projects. In total the survey was pretested with a group of 31 people from these four companies. Several minor modifications were made to the original measures and the format of the survey was modified to improve readability. The results from the pretest indicated that the survey questions have high consistency and face validity. After pretesting was complete, a final version of the survey was constructed.

\section{Data collection}

This study reports the first empirical results of a large-scale empirical research study of collaborative product innovation projects in innovation networks. The original sample consisted of 3,000 companies randomly selected from the Dun \& Bradstreet business database in the following industries: construction, computer and software, machinery and equipment, and household appliances. To ensure that we included appropriate companies (with collaborative product innovation projects) in the final sample, we sent a presurvey letter to all 3,000 firms. The presurvey consisted of the following three questions: (1) "Did you partner with any companies in an innovation network to develop any product innovation projects in the past three years?" (2) "Was your company the lead company of the innovation network that includes your company and the innovation partner companies?" and (3) "Are you willing to participate in a study on the effect of innovation network on innovation success?" We received responses from 1,182 of the 3,000 companies (a $39.4 \%$ response rate). Of the responding companies, only 924 met our criteria for inclusion in the final survey (i.e., the companies answered "yes" to all three presurvey questions).

The data were collected using a mail survey following Dillman's (1978) prescriptions as outlined in the Total Design Method for survey research. We mailed the first package to all 924 companies using priority mail. Following the procedures used by Song, Di Benedetto, and Song (2009), we included in the first package a business card, a personalized letter to our contact at the company, a copy of the questionnaire, a postage-paid envelope with an individually typed return-address label, and a list of research reports available to participants. We requested that each company select a most recent completed innovation project with the following characteristics: the project was completed in the last three years, the company partnered with 
one or several other companies that were responsible for different subsystems/areas of the end product, the company was the lead company of this innovation network, and the innovation project consists of multiple subsystems for which the different companies in the innovation network were responsible. The products could also be part of a larger product system and could be quite diverse: machines, buildings, equipment, consumer electronics, or software. For the sake of clarity we explained that synonyms for the word "subsystems" that may be used in the respondent's industry include components, modules, or chunks.

After three follow-up contacts with the companies, we received complete and usable data from 664 companies. The measurement scales and representative items are included in Appendix 6.A.

\section{Measure purification using confirmatory factor analysis}

Table 6.1 reports the standardized coefficients, Z-statistics, reliability values and average extracted variances for the measurement model. Our sample was of sufficient size and had an adequate respondent-to-item ratio to use AMOS confirmatory factors analysis, and make maximum likelihood estimations to assess the psychometric properties of our measures. For identification purposes we set a path for each latent variable equal to 1.0 and factor loadings were also set equal to 1.0 for non-latent variables (Kline, 2004). Following the recommendations of (Anderson \& Gerbing, 1988), we conducted a confirmatory factor analysis by specifying a 12 factor solution, and a satisfactory fit was achieved $\left(\chi^{2}=1169.6\right.$, df $=460), p<0,000)$. The chi-square per degree of freedom is 2.54; where values lower than 3.0 indicate a good fit (Bentler \& Bonett, 1980). Further, fit indexes that are less prone to sample size effects also indicated a good fit. With a perfect fit between a measurement model and data from a sample population, the CFI, IFI, and TLI would have values of 1.0, and the RMSEA a value of zero. Cut-off values close to 0.95 for the $\mathrm{CFI}, \mathrm{IFI}$, and TLI, and a value of 0.08 or lower for the RMSEA are suggested as indicating an adequate fit (Hu \& Bentler, 1999). Comparing our model's fit indexes to these norms indicates that we have achieved a good model fit: $\mathrm{CFI}=0.94 ; \mathrm{IFI}=0.940, \mathrm{TLI}=0.94, \mathrm{RMSEA}=0.48$ and the RMSEA confidence interval $=0.045,0.052$, which represents a good degree of precision (Byrne, 2001) 
Table 6.1. Measurement model

\begin{tabular}{|c|c|c|c|c|}
\hline Variables & $\begin{array}{l}\text { Standardized } \\
\text { loadings }\end{array}$ & Z-score ${ }^{a}$ & $\begin{array}{c}\text { Cronbach's alpha / Composite } \\
\text { reliability }\end{array}$ & AVE \\
\hline Performance & & & $0.97^{* *} / 0.97$ & 0.92 \\
\hline PERF01 & 1.00 & & & \\
\hline PERF02 & 0.94 & 66.21 & & \\
\hline PERF03 & 0.94 & 64.92 & & \\
\hline Tie Strength & & & $0.87 * * / 0.87$ & 0.70 \\
\hline TIE01 & 0.82 & & & \\
\hline TIEO2 & 0.82 & 23.29 & & \\
\hline TIE03 & 0.86 & 24.24 & & \\
\hline Reciprocity & & & $0.85 * * / 0.85$ & 0.55 \\
\hline RECI01 & 0.77 & & & \\
\hline RECIO2 & 0.85 & 22.03 & & \\
\hline RECI03 & 0.84 & 21.78 & & \\
\hline RECIO4 & 0.62 & 15.74 & & \\
\hline RECI05 & 0.58 & 14.51 & & \\
\hline Dependence & & & $0.87^{* *} / 0.86$ & 0.56 \\
\hline DEP01 & 0.81 & & & \\
\hline DEP02 & 0.76 & 20.70 & & \\
\hline DEP03 & 0.73 & 19.48 & & \\
\hline DEP04 & 0.71 & 18.69 & & \\
\hline DEP05 & 0.72 & 18.69 & & \\
\hline Design rules & & & $0.88 * / 0.85$ & 0.59 \\
\hline DR01 & 0.74 & & & \\
\hline DR02 & 0.64 & 19.75 & & \\
\hline DR03 & 0.79 & 19.20 & & \\
\hline DR04 & 0.88 & 20.35 & & \\
\hline Bridging ties & & & $0.82 * * / 0.81$ & 0.52 \\
\hline ВT01 & 0.87 & & & \\
\hline ВT02 & 0.57 & 13.66 & & \\
\hline ВТ03 & 0.64 & 15.45 & & \\
\hline ВТ04 & 0.76 & 17.77 & & \\
\hline Customer uncertainty & & & $0.70 * * / 0.73$ & 0.48 \\
\hline PCU01 & 0.81 & & & \\
\hline PCU02 & 0.68 & 11.93 & & \\
\hline PCU03 & 0.55 & 10.96 & & \\
\hline $\begin{array}{l}\text { Technological } \\
\text { uncertainty }\end{array}$ & & & $0.71 * * * / 0.72$ & 0.47 \\
\hline PTU01 & 0.54 & & & \\
\hline PTU02 & 0.84 & 11.63 & & \\
\hline PTU03 & 0.63 & 11.21 & & \\
\hline
\end{tabular}

${ }^{a} Z$-scores for the leading indicator for each construct were set to 1.0 to establish scale

${ }^{\text {b }}$ Cronbach's alpha

${ }^{\mathrm{C}}$ Composite reliability

$* * p<0.01$ 
Having concluded that our overall CFA model is acceptable, we will move on to evaluate the convergent and discriminant validities of the constructs. Table 6.1 shows the standardized loadings, the related Z-scores (C.R. in AMOS), the average variance extracted estimate, and the constructs' composite reliabilities. The loadings of the individual indicators are statistically significant and the constructs composite reliability coefficients have an average value of 0.83 , both indicating a high internal consistency (Netemeyer et al., 2003). The average variance extracted (AVE) exceeded the benchmark of 0.5 for six of the eight constructs, two control variables had an AVE of almost 0.5; AVE values above 0.5 indicate good convergent validity (Fornell \& Larcker, 1981; Netemeyer et al., 2003).

We tested the discriminant validity of the constructs by comparing the average variance shared by each construct with its indicator (AVE), with the variance shared by each pair of constructs (squared correlation between constructs). We first computed the AVE for each construct (listed in Table 6.1). The finding that the squared correlation between each pair of constructs was less than the variance-extracted estimates for the individual constructs indicates that we have achieved discriminant validity (Fornell \& Larcker, 1981).

Finally, following the suggestions of Podsakoff and Organ (1986), we used Harman's onefactor test to check whether self-reporting led to common method variance. A factor analysis resulted in the expected number of factors, rather than a single common method factor accounting for the majority of the covariance among the items. These results indicate that the findings presented in this chapter are unlikely to be distorted by common method bias.

\section{Main variables}

Various social network scholars have argued that organizational coupling is best conceptualized as a multidimensional construct (e.g. Beekun \& Glick, 2001a, 2001b; Granovetter, 1973; Krackhardt, 1992; McEvily \& Zaheer, 1999; Nahapiet \& Ghoshal, 1998; Rindfleisch \& Moorman, 2001; Weick, 1982). To assess the degree of organizational coupling among innovation network partners, we have adopted the following three dimensions from Beekun and Glick's (2001) scale: tie strength, reciprocity, and interdependence. Weick (1982) argues that these dimensions are all positively correlated and that loosely coupled firms have a low score for each of these dimensions. We took a retrospective view on lead-firms' 
networks by asking the lead-firms about their relationships with their innovation partners prior to forming an innovation network in order to give us a measure of the looseness of the lead-firm's network prior to innovation network formation.

Loose coupling dimension 1: Tie strength. Traditionally the construct tie strength is characterized by the closeness and interaction frequency of relationships between partners in the innovation network (Granovetter, 1973; Hansen, 1999). Marsden and Campbell's (1984) study indicates that a measure of 'closeness', or the emotional intensity of a relationship, is the best available indicator of the tie strength concept. Consequently, we adopted three items proposed by (Wuyts \& Geyskens, 2005) to measure the closeness of the lead-firm to the other innovation network members. The rating scale ranged from 1 "strongly disagree" to 7 "strongly agree", and the higher the score, the stronger the ties.

Loose coupling dimension 2: Reciprocity. We used five items drawn from three different studies that all contributed to our conceptualization of reciprocity between the lead-firm and its innovation partners. Three items were adopted from Rindfleisch and Moorman (2001) that were labeled as 'relational embeddedness' in the original study. We omitted one of their items because that item was already part of our tie strength construct. The fourth reciprocity item was adopted from (Kale et al., 2000), and the fifth, based on (Kogut, 1989) definition of reciprocity, taps the multiplicity of the relationship. The higher the ratings, the greater the degree of reciprocity between the lead-firm and the other innovation network members. As before, the rating scale ranged from 1 "strongly disagree" to 7 "strongly agree".

Loose coupling dimension 3: Dependence. We adapted a reflective measure developed by (Robson et al., 2008) which assesses well the reflective construct of dependence with their five items achieving an alpha coefficient of above 0.8 in their study. Apart from the fourth item (which is reversely stated) the higher the ratings, the larger the interdependence of the lead-firm and its innovation partners. The rating scale ranged from 1 "strongly disagree" to 7 "strongly agree".

Type of innovation. To assess the type of product innovation, we framed innovations using the two-dimensional typology developed by Henderson and Clark (1990). Using previous definitions of Baldwin and Clark (2000), Gatignon, Tushman, Smith, and Anderson (2002), and Henderson and Clark (1990) we provided clear definitions of modular and architectural product innovations, and asked each respondent to characterize the type of 
the innovation they had selected for the survey. Modular innovation was defined as an innovation that involves significant improvements of sub-systems that leave the existing interface standards and interactions between the improved subsystems and other subsystems largely unchanged. Example: a notebook incorporating a higher resolution display. Architectural innovation was defined as an innovation that involve (sometimes marginal) improvements of sub-systems that have a more significant impact on the existing interface standards and interactions with other subsystems. Example: a larger notebook display (=marginal improvement) draws more power (change in interaction) and requires simultaneous changes in other subsystems such as the battery, software and charging system in order to function. Type of innovation was a dummy variable coded 1 if the innovation was categorized as a modular innovation and 0 if it was categorized as an architectural innovation.

Dominancy of design rules. To capture the dominancy of design rules in the industrial context of the innovation projects we adopted the categories of design information as defined by Baldwin and Clark on p.77 (2000). We translated these four categories in four items that together tap into a complete set of product design rules. The higher the rating, the more dominant design rules are in the industrial context in which the innovation project in embedded. The rating scale ranged from 1 "strongly disagree" to 7 "strongly agree."

Innovation performance. The performance of the innovation is measured using three items adopted from Gatignon et al. (2002) which measure the perceived commercial success of the product. The assessments are relative to the competition and to expectations within the industry, and this should remove industry-specific main effects (Gatignon \& Xuereb, 1997). The rating scale again ranged from 1 "strongly disagree" to 7 "strongly agree" and the higher the ratings, the higher the innovation performance.

\section{Control variables}

In our analysis we also included several variables to control for possible confounding effects: bridging ties, lead-firm size, project size, marketing resource input, environmental uncertainty, composition of the innovation network, contract structure, and industry effects.

Bridging ties. The 'brokerage argument', which builds on Grannovetter's (1973) weak-tie theory, suggests that weak ties allow 'bridging ties' that give access to external sources of 
non-redundant information (Burt, 1992; Tiwana, 2008a). In this way, weak ties give rise to an opportunity to access useful information which then improves collaborative innovation performance. Since this could suppress our hypothesized negative effects of loose coupling on collaborative innovation performance, we control for the 'bridging ties' suppressor mediator that reflects the degree to which weak ties have linked innovation network partners with useful, complementary resources and competences. We follow Tiwana (2008a) in measuring 'bridging ties' using items adopted from Campion, Medsker and Higgs (1993) that were labeled 'heterogeneity' in the original study. Influenced by Teece (1986), we added a fourth item to this scale which assesses the degree to which the innovation partners have complementary physical assets and resources. Again, the rating scale ranged from 1 "strongly disagree" to 7 "strongly agree".

Lead firm size. The relationship between firm size and innovation performance has been much debated (Schumpeter \& Opie, 1934). Large firms have more financial resources to fund innovation, and larger sales volumes speed up the return on investment which increases the willingness to invest in innovation (Cohen \& Klepper, 1996). Conversely, small firms may also have an advantage in being more flexible and faster to recognize opportunities (Bower \& Christensen, 1995). To control for both economies and diseconomies of scale, firm size was measured as the natural logarithm of the number of employees.

Project size. Previous research suggests that greater resource inputs, to serve the needs of the innovation project, by the innovation partners will boost the innovation's performance (Dyer, 1996; Parkhe, 1993; Teece, 1986). On this basis, several studies have controlled for financial cost of product innovation projects (e.g. Fang, 2008; Gatignon \& Xuereb, 1997). To make innovation projects comparable, we adopted Hansen's (1999) measure of innovation project size and controlled for the total estimated dollar cost of each product innovation project.

Marketing resource input. Besides the financial cost of an innovation, large marketing expenditures can also significantly influence product innovation success (Fang et al., 2008; Gatignon \& Xuereb, 1997). Accordingly, we developed a single-item measure to assess the relative marketing resource inputs that the innovation network devoted to the innovation project. 
Environmental uncertainty: technical and customer uncertainty. Market characteristics that are often hypothesized as having an impact on the commercial performance of innovations come under the umbrella of external uncertainty (Gatignon \& Xuereb, 1997; Li \& Atuahene-Gima, 2001). Uncertainty is not a one-dimensional construct and is usually broken down into two key dimensions: technological (product) uncertainty, and customer (demand) uncertainty (Wolter \& Veloso, 2008). Technological uncertainty is defined as the probability of technological changes in the product and customer uncertainty refers to the rate of change of customer preferences. Technological uncertainty was measured using a two-item measure adopted from Walker and Weber (1984) plus one item taken from the technological uncertainty measure of Jaworski and Kohli (1993). Customer uncertainty was measured with a three-item measure adopted from Joshi and Sharma (2004). The higher the ratings, the greater the environmental uncertainty. The rating scale ranged from 1 "strongly disagree" to 7 "strongly agree".

Composition of the innovation network. Earlier research has suggested that innovation networks with a substantial number of horizontal alliances - collaborating competitors have a lower innovation performance (Rindfleisch \& Moorman, 2001). One company might gain inside knowledge of a partner's unique skills and expertise (Littler et al., 1995), and this associates with a higher potential for misappropriation than in an alliance with vertical partners (Katila et al., 2008). To control for the degree of horizontal collaboration, we adapted Rindfleisch and Moorman's 'alliance composition' construct and asked how many companies in the innovation network could be classified as competitors. We calculated our 'network composition' measure by dividing the number of competitors by the total number of companies in the innovation network.

Contract structure. In equity alliances, partners share or exchange equity, either by means of creating a new entity in which both partners share equity or by one partner taking an equity interest in the other (Gulati, 1995; Gulati \& Singh, 1998). Having an equity share provides companies with certain hierarchical control over other firms and may affect commitment and cooperation, thus influencing collaborative innovation performance (Krishnan, Martin, \& Noorderhaven, 2006; Luo, 2002; Poppo \& Zenger, 2002). We coded this alliance governance mode by a binary variable, assigning 1 to alliances that involved equity and 0 to non-equity alliances (e.g. Gulati, 1995; Robson et al., 2008). 
Industry: Since collaborative innovations in some industries are known to perform better than in other industries, we controlled for industry effects (Krishnan et al., 2006). We used dummy variables, based on two-digit SIC codes, for the industries in our sample (construction industries, computer industries, machinery industries, household appliances industries).

\section{ANALYSES AND RESULTS}

The means, standard deviations, and correlations among the variables are shown in Table 6.2. To test our hypotheses we used hierarchical moderated multiple regression analysis to verify the individual effects on innovation performance of loose coupling, design rules and the type of innovation, and determine any interaction effects. As part of the analysis, we mean-centered all the terms of our interaction variables because this potentially facilitates the interpretation of our results (Echambadi \& Hess, 2007). Variance inflation factor scores are all less than the threshold of 10 and varied from 1.04 to 6.01 over the regressions, suggesting multicollinearity did not distort regression results. After creating dummy variables for the innovation type, we computed two and three-way-interaction terms for all our key variables: each of the three loose coupling dimensions (tie strength, reciprocity and dependence), design rules and innovation type. After this we compared three restricted and one full regression model in which the following blocks of variables were successively introduced: control variables, individual main variables, two-way-interaction terms and three-way-interaction terms.

\section{Hypotheses testing with hierarchical regression analysis}

We begin with examining the improvement in model fit of our main variables and interaction terms. In table 6.3, regression models show that the main variables increase the overall model $R^{2}$ by 0.70 the two-way interactions improve $R^{2}$ by 0.12 . Finally introduction of the three-way interactions led to a significant improvement in regression model with an $R^{2}$ change of 0.01 , and therefore it is appropriate to explore the nature of these relationships. 


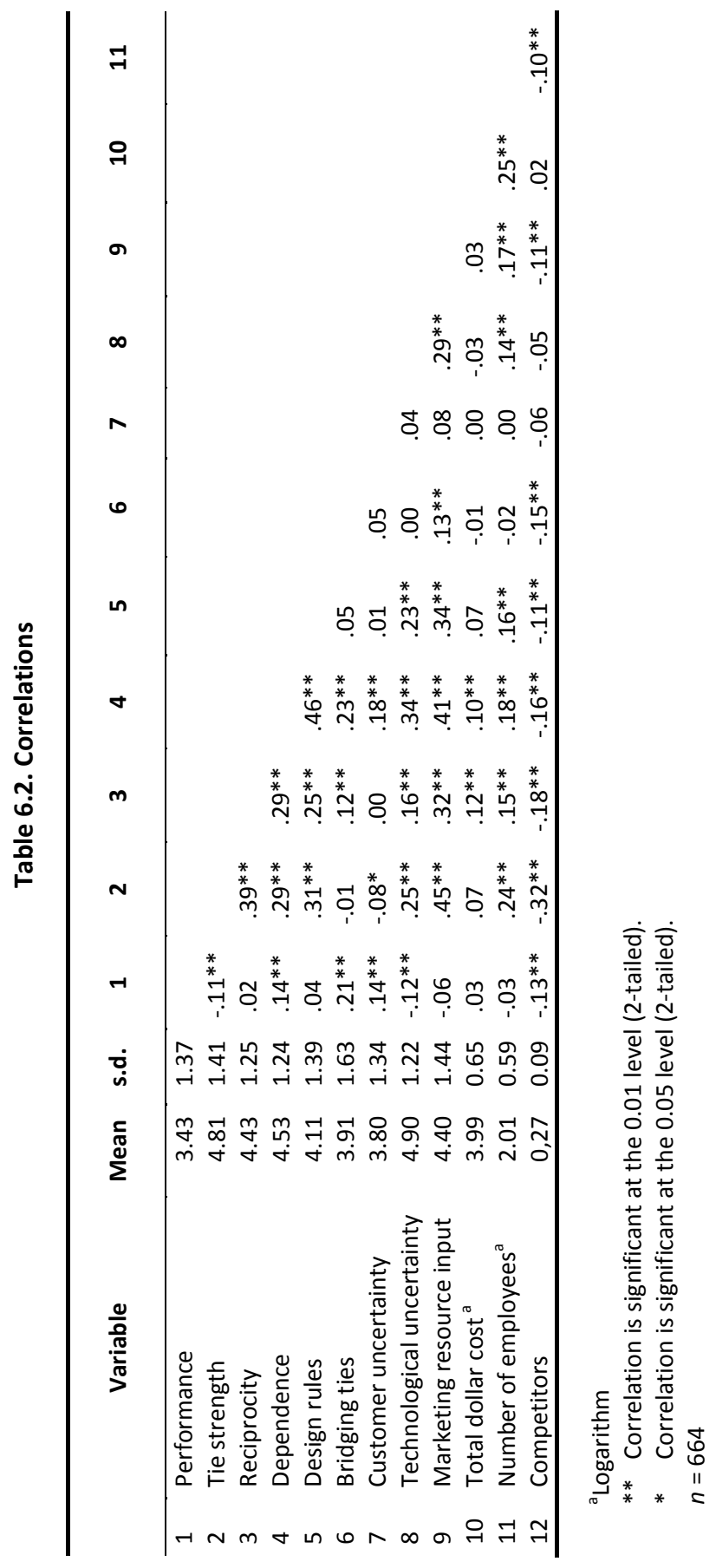


Table 6.3. Results of Hierarchical Regression Models of Collaborative Innovation Performance ${ }^{a}$

\begin{tabular}{|c|c|c|c|c|c|c|c|c|}
\hline \multirow[b]{2}{*}{ Variables } & \multicolumn{8}{|c|}{ Collaborative Innovation Performance } \\
\hline & Model 1 & & Model 2 & & Model 3 & & Model 4 & \\
\hline Constant & 3.70 & ** & 1.77 & $* *$ & 2.16 & $* *$ & 2.13 & $* * *$ \\
\hline \multicolumn{9}{|l|}{ Control variables } \\
\hline Construction industry & 0.13 & & 0.02 & & -0.04 & & -0.04 & \\
\hline Computer industry & 0.03 & & 0.01 & & 0.02 & & 0.03 & \\
\hline Machinery industry & -0.04 & & -0.06 & & 0.01 & & 0.01 & \\
\hline Household appliances industry & 0.08 & & -0.03 & & -0.02 & & 0.00 & \\
\hline Bridging ties & 0.17 & $* *$ & 0.03 & + & 0.01 & & 0.01 & \\
\hline $\begin{array}{l}\text { Relative number of competitors in the } \\
\text { innovation network }\end{array}$ & -1.80 & $* *$ & 0.90 & $* *$ & -0.35 & + & -0.09 & \\
\hline Equity alliances & -0.46 & $* *$ & -0.02 & & 0.01 & & 0.02 & \\
\hline Customer uncertainty & 0.11 & $* *$ & -0.02 & & 0.02 & & 0.02 & + \\
\hline Technological uncertainty & -0.11 & $*$ & -0.01 & & -0.02 & & -0.02 & + \\
\hline Marketing resource input & -0.06 & & 0.02 & & 0.01 & & 0.01 & \\
\hline Total dollar cost innovation project & 0.06 & & -0.02 & & 0.01 & & 0.01 & \\
\hline Number of employees lead firm & -0.06 & & -0.05 & & -0.01 & & -0.01 & \\
\hline \multicolumn{9}{|l|}{ Main effects } \\
\hline Tie strength & & & 0.09 & $* *$ & -0.06 & $* *$ & -0.05 & $*$ \\
\hline Reciprocity & & & 0.08 & $* *$ & -0.03 & & -0.02 & \\
\hline Dependence & & & 0.13 & $* *$ & -0.02 & & 0.01 & \\
\hline Design rules & & & 0.17 & $* *$ & -0.19 & $* *$ & -0.17 & $* *$ \\
\hline Type of innovation & & & 2.61 & $* *$ & 2.38 & $*$ & 2.33 & $* *$ \\
\hline \multicolumn{9}{|l|}{ Two-way interactions } \\
\hline Tie Strength $X$ Design rules & & & & & 0.01 & & -0.05 & $*$ \\
\hline Reciprocity X Design rules & & & & & 0.02 & $*$ & 0.03 & + \\
\hline Dependence $X$ Design rules & & & & & 0.01 & & -0.02 & \\
\hline Tie strength $X$ Type of innovation & & & & & 0.20 & $* *$ & 0.20 & $* *$ \\
\hline Reciprocity X Type of innovation & & & & & 0.17 & $* *$ & 0.16 & $* *$ \\
\hline Dependence X Type of innovation & & & & & 0.17 & $* *$ & 0.16 & $* *$ \\
\hline Design rules $X$ Type of innovation & & & & & 0.53 & $* *$ & 0.52 & $* *$ \\
\hline \multicolumn{9}{|l|}{ Three-way interactions } \\
\hline $\begin{array}{l}\text { Tie strength } X \text { Design rules } X \text { Type of } \\
\text { innovation }\end{array}$ & & & & & & & 0.07 & $* *$ \\
\hline $\begin{array}{l}\text { Reciprocity X Design rules X Type of } \\
\text { innovation }\end{array}$ & & & & & & & -0.01 & \\
\hline $\begin{array}{l}\text { Dependence } X \text { Design rules } X \text { Type of } \\
\text { innovation }\end{array}$ & & & & & & & 0.05 & $* *$ \\
\hline Model $F$ & 7.39 & & 160.08 & & 313.20 & & 289.48 & \\
\hline$R^{2}$ & 0.12 & & 0.81 & & 0.92 & & 0.93 & \\
\hline Adjusted $R^{2}$ & 0.10 & & 0.80 & & 0.92 & & 0.92 & \\
\hline$\Delta R^{2}$ & & & 0.70 & & 0.12 & & 0.01 & \\
\hline$F$ change & & & 465.77 & $* *$ & 131.38 & $* *$ & 8.73 & $* *$ \\
\hline
\end{tabular}

${ }^{a}$ unstandardized coefficients are shown. $n=664$.

${ }^{\dagger} p<.10 ;{ }^{*} p<.05 ;{ }^{* *} p<.01$ 
Model comparisons in the table were made using partial F-tests. Model 4 provides a significant improvement in explanatory power over model 3 (i.e., $F(4)(2)=8.73, p<0.000$ ).

To gain further insight into the interaction effects we used methods suggested by Aiken et al (1991) to plot the three-way-interaction effects and calculate the significance levels of the simple slopes. Furthermore we performed slope-difference tests using methods from Dawson and Richter (2006). We plotted the three-way interaction effects twice in figure 6.2 and 6.3 by interchanging the independent variable with the continuous interaction variable. In this chapter, we only show the interaction effects that include the loose coupling dimension tie strength. Interaction effects that include the loose coupling dimension dependence resulted in similar regression lines and are therefore redundant to illustrate. For illustrative purposes we have plotted the regression lines at values \pm 2 standard deviations from the means of the independent and interaction variables. However, different conditional values of the moderator may correspond with different slopes of the regression lines being studied (Aiken et al., 1991). Another option would have been to select each value so that it lay within the observed range but, using the Johnson-Neyman technique as outlined in (Hayes \& Matthes, 2009), we have avoided the arbitrariness of this choice by computing the regions of significance. The three-way-interactions shown in Figure 6.2 are significant over all possible values of loose coupling found among the innovation network partners in our sample; this range running from -3.50 to 2.19 for tie strength, and from -3.53 to 2.47 for dependence. The three-way-interaction effect shown on Figure 6.3 are significant over all possible values of design rules in the range from -1.60 to 2.89 , this means that regression slopes for conditional values of design rules below -1.60 are not significant, above this cutoff value they are.

When for the interactions shown in Figure 6.2, tie strength is replaced by dependence, the region of significance runs from: -3.53 to 2.47. This range comprises all observed values for dependence among innovation network partners in our sample. If in Figure 6.3 , tie strength is replaced by dependence, the region of significance runs from -1.55 to 2.89 , this region is slightly larger than the one that is shown in Figure 6.3. Slope difference tests indicate that all paired slopes in Figure 6.2 and 6.3 differ significantly from each other, except slope 2 and 3 in Figure 6.2. 


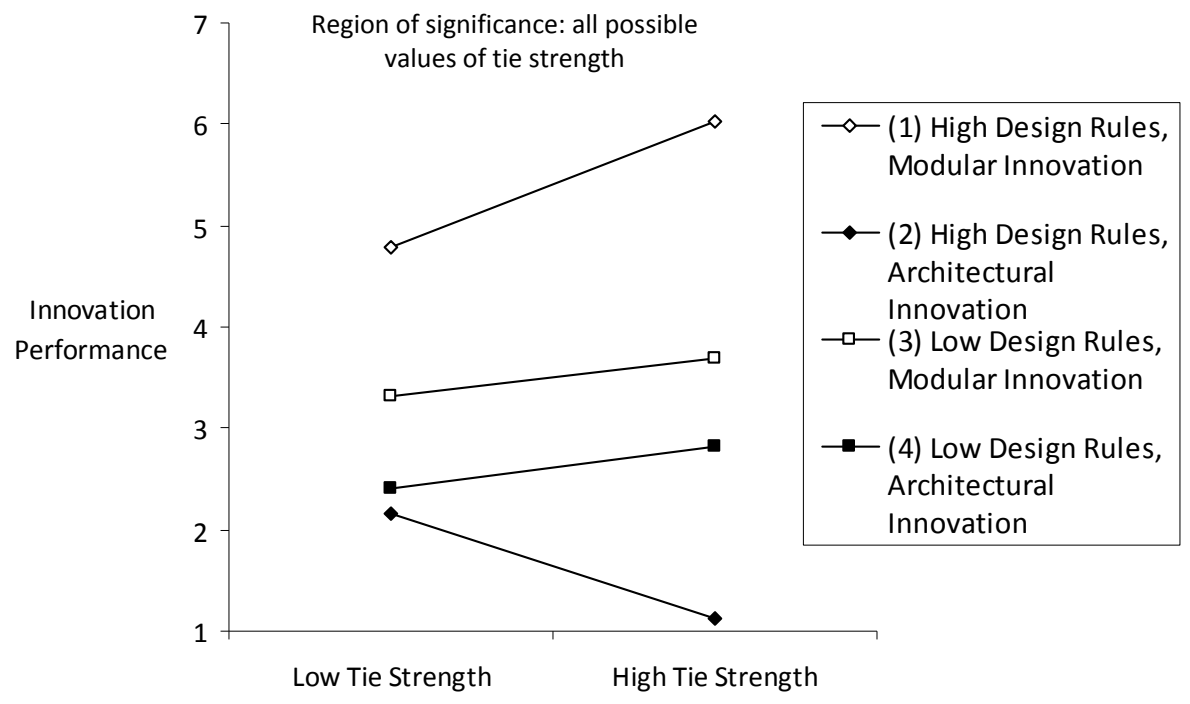

Figure 6.2. Three-way-interaction effect: coupling (tie strength) $x$ design rules $x$ type of innovation

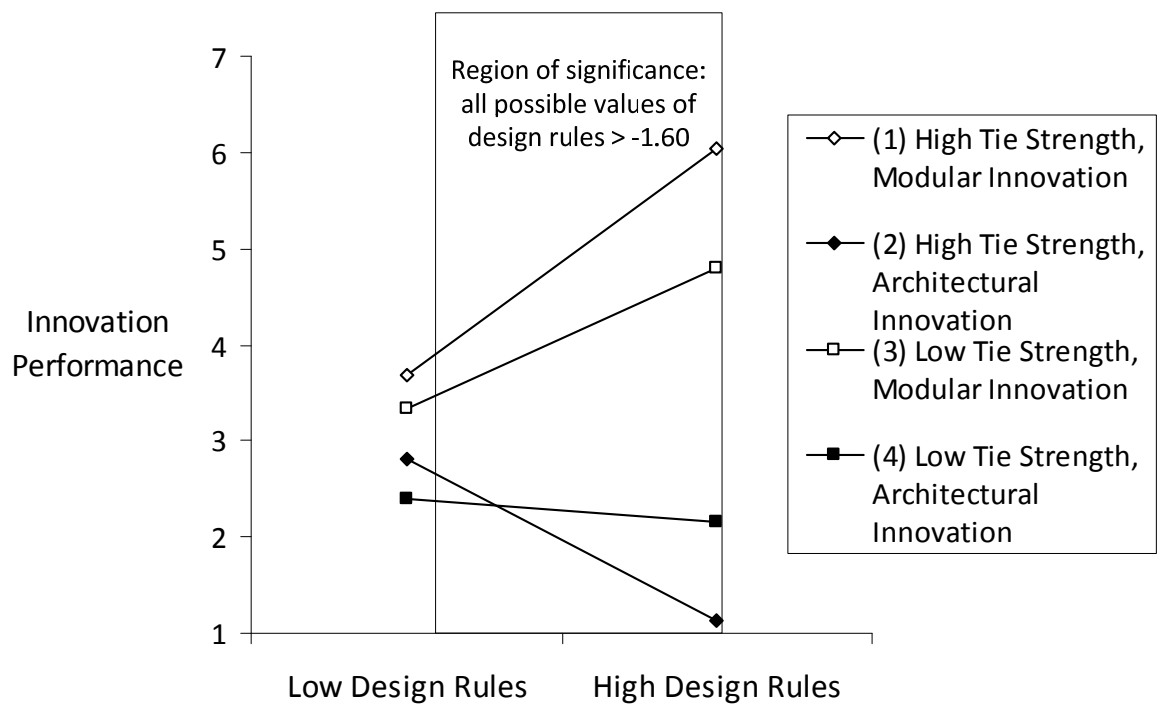

Figure 6.3. Three-way-interaction effect: design rules $x$ coupling (tie strength) $x$ type of innovation 
Replacing Tie strength for Dependence leads to similar regression plots. All slopes differ significantly from 0 . Figures 6.2 and 6.3 show that the highest innovation performance is achieved when companies pursue modular innovations in tightly coupled innovation networks where dominant design rules exist. The poorest performance results from pursuing architectural innovations in strong innovation networks where dominant design rules exist. Overall, modular innovations are associated with high collaborative innovation performance while architectural innovations are associated with low collaborative innovation performance. We will now take a closer look at the position of the lines (intercept), the directions of the regression lines, and the slope differences between the lines to interpret the research findings in more detail and assess the validity of our hypotheses.

Hypotheses $1 a$ and $1 \mathbf{b}$. Hypothesis 1a proposes that organizational loose coupling will be negatively related with the performance of collaborative product innovations. Further, Hypothesis $1 \mathrm{~b}$ proposes that organizational loose coupling will be positively related with the performance of collaborative innovation performance. The results displayed in Table 6.3 (model 2) reveal positive regression coefficients for all three dimensions of organizational coupling (tie strength, reciprocity and dependence). This suggests that loose coupling decreases the performance of collaborative innovations which leads us to accept Hypothesis $1 \mathrm{a}$ and reject Hypothesis $1 \mathrm{~b}$.

Hypotheses $2 \boldsymbol{a}, \boldsymbol{b}$ and $\boldsymbol{c}$. Hypothesis $2 \mathrm{a}$ and $2 \mathrm{~b}$ propose that organizational loose coupling will have a negative impact on the performance of modular and architectural product innovation, but that this negative relationship will be stronger for architectural then for modular innovations. Rivaling Hypothesis 2c suggests a positive impact of loose coupling on architectural innovation performance. Results displayed in Table 6.3 (model 3) reveal positive regression coefficients for all interactions between the three dimensions of organizational coupling and the type of innovation. Thus Hypothesis $2 a$ and $2 c$ were accepted and Hypothesis $2 \mathrm{~b}$ was rejected, the type of innovation moderates the relationship between loose coupling and innovation performance whereby the relationship is negative for modular innovation but positive for architectural innovation.

Hypotheses $3 a, b, c, d, e$. Hypothesis $3 a$ and $3 c$ proposes that the relationship between the type of innovation and innovation performance is contingent upon the availability of design rules, in such a way that high availability of design rules improve modular innovation 
performance, while they decrease architectural innovation performance. Both hypotheses are confirmed, this is best illustrated by the four regression lines in Figure 6.3. The slopes of the regression lines for modular innovations are significant and positive in sign while for architectural innovations the slopes are significant and negative in sign.

Hypothesis $3 b$ proposes a moderating effect of design rules whereby the relationship between organizational loose coupling and modular innovation performance is less negative for high availability of design rules than for low availability of design rules. Results displayed in Table 6.3 (model 4) reveal that for modular innovation, the interaction is significant for two of the three dimensions of loose coupling (tie strength and dependence). Hypothesis $3 \mathrm{~b}$ postulates a priori differences in the slopes of line 1 and 3 shown in Figure 6.2. To test this hypothesis accurately, we used the slope difference test (Dawson \& Richter, 2006). Table 6.3 shows that the slopes of line 1 and 2 significantly differ, however, this difference is not in the expected direction. Our results show that the negative impact of loose coupling on modular innovation performance is larger under high availability of design rules than when no design rules are available. Thus, Hypothesis $3 \mathrm{~b}$ was rejected.

Hypothesis $3 d$ proposes a moderating effect of design rules, whereby the relationship between organizational loose coupling and architectural innovation performance is less negative for high availability of design rules than for low availability. The rivaling Hypothesis 3e proposes a moderating effect of design rules, whereby the relationship between organizational loose coupling and architectural innovation performance is less positive for high availability of design rules than for low availability of design rules. Table 6.3 (model 4) shows that for two dimensions of organizational coupling (tie strength and dependence), the interactions with design rules have a significant impact on the performance of architectural innovation. Figure 6.2 and 6.3 illustrate that the impact of loose coupling on architectural innovation performance is positive under high availability of design rules and negative when no design rules are available. Thus, Hypotheses $3 \mathrm{~d}$ and $3 e$ are both rejected.

We summarize the impact of each innovation context, defined by the degree of organizational coupling among innovation partners and the availability of product design rules, on collaborative innovation performance in Figure 6.4. This Figure illustrates the collaborative innovation typology developed in this paper. 
MODULAR INNOVATION

Organizational coupling

Tie Strength and Dependence

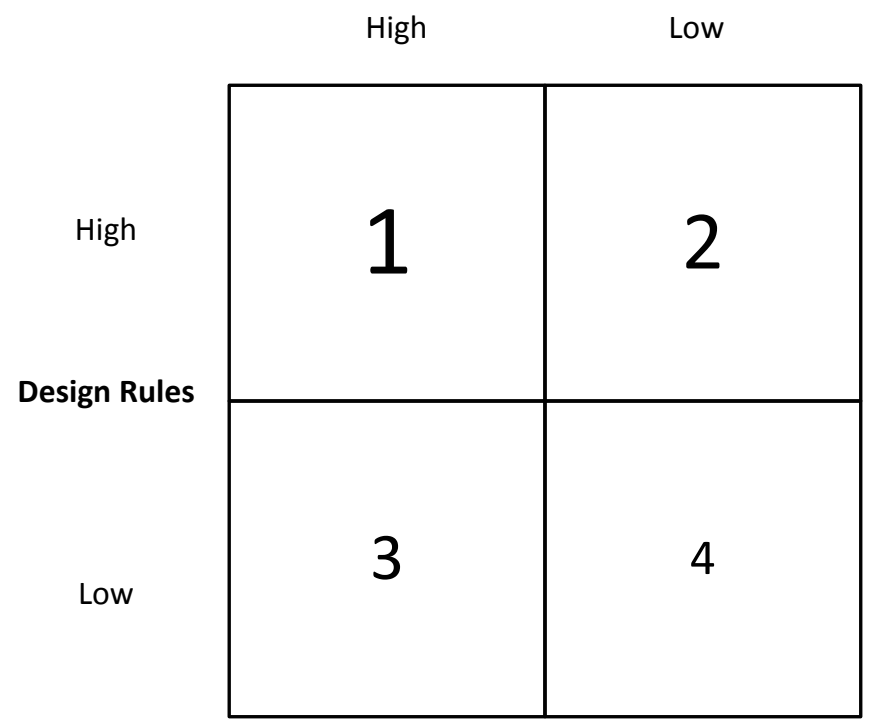

ARCHITECTURAL INNOVATION

Organizational coupling

Tie Strength and Dependence

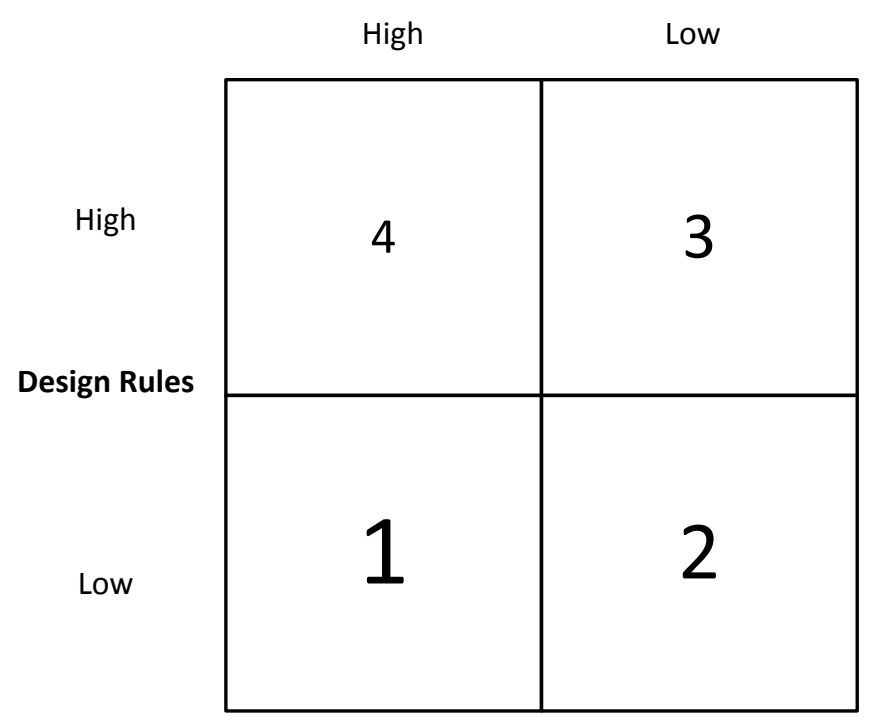

Figure 6.4. Performance ranking for innovation in different innovation contexts 
Performance differences among all quadrants except one are significant (two-tailed tests). For architectural innovation, the performance difference between quadrant 1 and 2 is also significant when we apply one-tailed difference tests. 1=high performance, $4=$ low performance.

\section{Discussion}

In this study, we set out to better understand how innovation contexts - described by the degree of organizational coupling among innovation network members and the availability of product design rules - influence collaborative product innovation success. We found that the impact of each context on collaborative innovation performance is contingent upon the type of innovation that any company can aim at. The uncovered three-way interactions are plotted in Figures 6.2 and 6.3. These results have implications for management and theory, as discussed below.

\section{Implications for management}

To provide a parsimonious framework, we summarize the three-way interaction effect in a typology shown in Figure 6.4. This typology describes four innovation contexts that explain the outcome of modular and architectural product innovations. Innovation managers can use the typology to direct their innovation strategies. It helps them to evaluate the expected profits of modular or architectural product innovations for their project specific innovation context. Furthermore, to maximize innovation performance and given a certain availability of design rules, the typology can also guide managers in configuring their innovation network.

Figure 6.4 shows that although design rules improve modular innovation, they are incomplete substitutes for organizational loose coupling. Therefore, for modular innovation, a company can best collaborate with tightly coupled partners, also when product design are available. For more radical, architectural innovations, companies most often collaborate with tightly coupled partners (Hoetker, 2006; Li et al., 2008). A practical implication that follows from our results is that companies can best first evaluate whether clear product design rules exist. In contrast to observed managerial behaviors, if design rules exist, for 
architectural innovation it is most effective for a company to work with partners that have not yet established a close and intensive relationship in previous innovation projects and companies can better chose to work with partners that are easy to replace, e.g. their skills and resources are not unique, and relation specific investments are relatively low at the moment of innovation network formation. If design rules do not yet exist and are created in the architectural innovation project, tightly coupled innovation networks leads to better innovation performance than when organized in loose innovation networks.

\section{Implications for theory}

We demonstrated that our two-dimensional framework describing innovation contexts is very powerful for predicting modular and architectural innovation performance. Overall, our study makes several contributions to the modularity and social network literature.

Our results show that in all possible innovation contexts defined by the degree of organizational coupling and dominancy of design rules, modular innovations perform better than architectural innovations, this confirms and extends research findings in the photolithography industry (Henderson \& Clark, 1990). Yet, the main findings of this study can be linked to the interaction among organizational coupling, design rules and type of innovation in explaining collaborative product innovation performance.

First, we argued that for modular innovation, dominant design rules compensate for the negative relationship between loose organizational couplings among innovation network partners and innovation performance. To our knowledge, this is the first study that provides empirical evidence that product design rules increase modular innovation performance irrespective of the degree of organizational coupling among innovation partners. Consistent with the dominant view, loose organizational coupling decreases modular innovation performance. In the modularity literature, it is claimed that product design rules compensate for loose coupling by reducing the need to overt hierarchical control during modular product innovation (Sanchez \& Mahoney, 1996). In line with this assumption, empirical studies show that design rules facilitate and lead towards the adoption of loose organizational forms (Jacobides, 2005; Schilling \& Steensma, 2001). However, our findings reveal that innovation contexts with clear design rules and loosely coupled innovation partners, results in suboptimal performance of modular innovations. Surprisingly, design rules have the 
strongest positive impact on modular innovation performance in tightly coupled innovation networks. Thus, design rules do not fully substitute for loose coupling during modular innovation. We find partial support for these observations in the findings of Tiwana (2008b) who tested the assumption that modular design rules substitute for different degrees of organizational control in collaborative software development projects. Tiwana's results corroborate our findings that suggest that design rules and organizational coupling are incomplete substitutes. Yet, our study adds understanding by showing that design rules and tight coupling both have an additive positive effect on modular innovation performance, and we also show that tighter coupling increases the value of product design rules in modular innovation projects.

Secondly, this is also the first study that provides empirical evidence that product design rules decrease architectural innovation performance irrespective of the degree of organizational coupling among innovation partners. However, the interaction among design rules and organizational coupling did not match our expectations. The evidence presented here shows that for architectural innovation, loose and tight coupling can both improve architectural innovation performance; this depends upon the availability of design rules. Consistent with the dominant view, when design rules are not available, for architectural innovation it is most effective for a company to work with tightly coupled partners. Yet, when design rules are available, companies can best choose to collaborate with partners that have not yet established a close and intensive relationship in previous innovation projects. In addition, companies can better chose to work with companies that are easy to replace, e.g. their skills and resources are not unique, and relation specific investments are relatively low at the moment of innovation network formation.

These findings have implications for the innovation literature as well as the social network literature. The social network literature argues that tighter coupling improves the coordination and exchange of critical resources and knowledge among innovation network members e.g. (Dhanaraj \& Parkhe, 2006; Hansen, 1999; Tiwana, 2008; Tsai \& Ghoshal, 1998). Innovation scholars drawing on the knowledge based view of the firm and transaction cost theory have also argued that especially for systemic, architectural innovations, tighter coupling would provide benefits over loose coupling among innovation partners (Wolter \& Veloso, 2008). In agreement with these arguments, Hoetker's empirical study (2006) 
showed that tighter coupling, i.e. working with internal suppliers, was favored by assemblers for organizing the production of larger notebook displays, the equivalent of an architectural innovation because the innovation encompasses changes in many components within the display p. 507 (Hoetker, 2006). However, our findings challenge Hoetker's (2006) generalization that tight organizational coupling is also beneficial for architectural innovation. This is only true for the innovation context in which Hoetker performed his study, one without design rules, see footnote on p.507 (Hoetker, 2006). We discovered the interesting result that architectural innovation in contexts with dominant design rules perform better when innovation partners are loosely coupled. There is strong internal support for this finding because the direction of this relationship is similar for two dimensions of organizational loose coupling, tie strength and dependence. We suggest two plausible explanations for the finding that looser coupling improves architectural innovation performance when clear design rules exist.

First, Gargiulo and Benassi (2000) and Uzzi (1997) warn of the danger of cognitive 'lockin' as a result of tight coupling among innovation network members. Companies may become isolated from firms with novel ideas that exist beyond the tightly coupled subnetwork of existing partners on which the company focuses (Gargiulo \& Benassi, 2000; Hagedoorn \& Frankort, 2008). Even if better partners are available, interdependent, multiplex, long-lasting relationships are likely to increase resistance to network partner change (Kim et al., 2006). Thus, tighter coupling among innovation network members lowers the lead firm's ability to adapt the composition of their innovation network to match the requirements of architectural innovation. Thus, the tighter the coupling among innovation network members, the lower the lead firm's ability to adapt the composition of their innovation network to match the coordination requirements of an architectural innovation. As such, the negative impact of tight coupling on architectural innovation performance may be the result of the lead firm's inability to exchange old partners for new ones that are better equipped for the task, and this is likely to outweigh the positive impact of tighter coupling on the ability to coordinate systemic interdependencies among the innovation network members. This finding fills an important gap in the modularity literature (Hoetker et al., 2007). 
An alternative plausible explanation comes from institutional and cognitive theories of technological change. Here, it has been argued that technological changes in networks of companies that are tied together by elaborate institutional, economic, and cultural relationships, are sometimes more difficult than technological change in more independent organizations (Glasmeier, 1991; Greenwood \& Hinings, 1996; Uzzi, 1997). In stronger networks, companies often develop shared cognition (Levin \& Cross, 2004) and these shared technological frames then define the lens that people use when trying to make sense of innovations (Dougherty, 1992; Kaplan, 2008; Orlikowski \& Gash, 1994). However, a company's innovativeness can be restricted by a reliance on the accumulated knowledge that reflects the architecture of their previous generation of products (Henderson \& Clark, 1990; Leonard-Barton, 1992). As such, cognitive frames, which are more often shared among tightly coupled partners (Ring \& Vandeven, 1994), are likely to thwart collaborative, architectural innovation. In contrast, loose innovation networks are often composed of companies that operate at the periphery of networks, and in non-related industries. These companies are less biased by commitments to existing design standards, this improves architectural innovation performance, and this effect outweighs the positive impact of tighter coupling on the ability to coordinate systemic interdependencies among the innovation network members. In addition, loose relationships also associate with limited competence-based trust (Levin \& Cross, 2004). Therefore loosely coupled companies invest more time in careful evaluation of the changed interactions among the interfacing subsystems that go with architectural innovations. Loosely coupled innovation partners will control whether each partner applies the correct 'architectural knowledge' and adheres to the new product design rules. This suggests that loose ties also improve architectural innovation, because lower levels of competence-based trust results in thorough inspection of sometime subtle changes in the interactions between subsystems. This attention is known to be crucial to the success of architectural innovation (Henderson \& Clark, 1990).

\section{Limitations and future research}

This study is not without limitations. First, we are in the process of also collecting objective performance data of the collaborative innovation projects that we studied. Unfortunately we were only able to collect objective performance data for $80 \%$ of the collaborative 
innovation projects in our full sample. Because we did not want to reduce the sample size with over 100 companies, we decided to use the subjective performance scales. The use of subjective performance data is very common in the innovation and marketing literature e.g. (Gatignon et al., 2002; Sobrero \& Roberts, 2001). It has also been shown that there are high correlations between subjective and objective performance measures (Dess \& Robinson, 1984; Song \& Parry, 1997). Therefore we expect that using subjective performance data did not reduce the reliability and validity of our empirical findings.

Second, we measured the degree of organizational coupling at innovation network formation; we did not measure changes in organizational coupling during the innovation project, or in the exploitation phase. Although for architectural innovation the performance is maximized when the innovation network is composed of companies that were loosely coupled prior to forming the innovation network, it may well be the case that performance also increases if these companies become tightly coupled during the innovation project. For example, this could occur because tighter coupling (e.g. higher reciprocity and interdependence) provides some assurance to the individual companies that they will achieve a return on their innovation-specific investments in the commercialization phase. Future research should study this temporal element and pay attention to the pattern of organizational coupling over time in relation to collaborative innovation performance.

Third, we have studied innovation networks from the perspective of the lead firm. Although ego-centric network analyses provide an efficient and effective network analysis method, they are less informative than full-network analysis (Marsden, 2002). Future studies could undertake a full network analysis and analyze a limited number of innovation networks in greater depth.

Fourth, the results of self-report surveys are potentially overestimated due to common method variance (Podsakoff et al., 2003). Although it is argued that such concerns may be overstated (Spector, 2006), we did statistically test for common method variance (Podsakoff \& Organ, 1986) and multicollinearity, but found no indications that our results are inflated. Furthermore, our hypotheses mainly pertain to interaction effects and, in relation to common methods, Evans' (1985) conclusion is clear-cut: "artifactual interactions cannot be created; true interactions can be attenuated". Thus, although future research could adopt 
different data collection methods, we do not believe the method adopted here is a serious concern.

Fifth, our study reveals that for many companies architectural innovation is problematic and associates with low innovation performance compared to modular innovations. However, companies that have control over the evolution of a product's architecture can retain competitive advantage in an industry (Morris \& Ferguson, 1993). For example, Fixson and Park's (2008) investigation illustrates that architectural innovation - in their case product integration of previously modular product designs - has also been an important and successful competitive strategy in the bicycle industry. Therefore, it is of critical importance that companies know how to respond effectively to architectural innovation, and as Henderson and Clark (1990) vividly explain: "learning about changes in the architecture of the product is unlikely to occur naturally [...] changes in architecture - new interactions across components (and often across functional boundaries) - may therefore require explicit management and attention." Still, limited attention has been paid to how companies can actually succeed in architectural innovation. Therefore, future research should focus on developing an interpretive model exploring mechanisms for overcoming the detrimental impact of dominant design rules on architectural innovation. This will reveal how companies can actually succeed in collaborative architectural innovation. For this purpose we propose to study what behaviors on part of the innovation network leaders actively compensate for the negative impact of design rules on architectural innovation. Enhanced leadership could compensate for organizational loose coupling in orchestrating collaborative architectural innovation (Dhanaraj \& Parkhe, 2006; Orton \& Weick, 1990). Soft power strategies (Katila et al., 2008) and transformational leadership behaviors for improving the willingness to experiment, potentially moderate the negative impact of design rules on architectural innovation (Smith \& Tushman, 2005; Vera \& Crossan, 2004; Yukl, 2009). Thus, besides the importance of studying the role of the passive compensation mechanism 'design rules', we now suggest to also study the more active compensation mechanisms of leadership to overcome the unique challenges for modular and architectural innovation, that companies face in each of the four innovation contexts shown in Figure 6.4. 


\section{CONCLUSION}

Despite the limitations of this study, our results suggest that innovation performance is contingent upon the type of innovation and the innovation context defined by the dominancy of design rules and degree of organizational coupling. As set out in our literature review, design rules, organizational coupling and the types of innovation cohere in a thematic way. Our typology ads understanding about the full set of interrelationships among these variables and provides support for a contingency perspective on collaborative product innovation. Hopefully this study leads to further investigation of the complex set of interrelationships among the variables related to modular and architectural innovation outcomes. 


\section{APPENDIX 6.A}

\section{Items measuring constructs}

For all items with no other scale indicated, the response scale was $1=$ "strongly disagree" to 7 "strongly agree". $(\mathrm{R})=$ reversed.

\section{MAIN VARIABLES}

Loose coupling dimension 1, Tie strength:

Before our company selected companies for this product innovation project:

TIE 01 Our company worked very intensively with the innovation partners.

TIE 02 Our company had a very close relationship with the innovation partners.

TIE 03 Our company and the innovation partners had a very collaborative relationship, like a real team.

\section{Loose coupling dimension 2, Reciprocity:}

At the beginning of the product innovation project:

RECI01 This innovation network was characterized by high reciprocity among companies.

RECIO2 We were extensively tied to the innovation partners through additional business ties in addition to this innovation project.

RECI03 We felt indebted to our innovation partners for what they have done for us in the past.

RECIO4 Our relationship with the innovation partners could be defined as "mutually gratifying."

RECI05 We expected that we would be working with the innovation partners far into the future.

\section{Loose coupling dimension 3, Dependence:}

At the beginning of the selected innovation project, we expected that:

DEP01 Each company would provide the innovation project with unique skills and resources.

DEP02 The operations of the innovation network would be severely disrupted if a partner were to withhold its skills and resources.

DEP03 My company and our partners would find it difficult to effectively perform the other companies' tasks and responsibilities in this product innovation project.

DEP04 The skills and resources that most partners brought to this product innovation project could easily have been replaced. (R)

DEP05 The total cost of the innovation network losing a partner's assistance would be substantial.

\section{Design rules:}

In our industry, there is a complete set of design rules that fully describe the following categories of design information:

DR01 The architecture (i.e., what subsystems will be part of the architecture system, and what the roles of the subsystems will be in the architecture system)

DR02 The interfaces among the subsystems of the architecture system (i.e., detailed descriptions of how the different subsystems will interact, including how they will fit together, connect, communicate, and so forth).

DR03 Integration protocols (i.e., procedures that will allow designers to assemble the architecture system).

DR04 Testing standards (i.e., standards that will allow designers to determine how well the architecture system works, whether a particular system conforms to the design rules, and how one version of a subsystem performs relative to another). 


\section{Type of innovation:}

How would you characterize the type of innovation you have selected for this survey? (check one box)

$\square$ Modular innovations: These innovations involve significant $\square$ improvements of sub-systems that leave the existing interface standards and interactions between the improved subsystems and other subsystems largely unchanged. Example: a notebook incorporating a higher resolution display.

$\square$ Architectural innovations: These innovations involve (sometimes marginal) improvements of subsystems that have a more significant impact on the existent interface standards and interactions with other subsystems. Example: a larger notebook display (=marginal improvement) draws more power (change in interaction) and requires simultaneous changes in other subsystems like the battery, software and charging system in order to function.

\section{Performance:}

We are interested in your assessment of the product innovation's overall performance. Please indicate, with what you know today, how successful the innovation project was, by using the following criteria. PERF01 Innovation was successfully implemented by the members of the innovation network.

PERF02 Innovation has been commercially successful for the members of the innovation network.

PERF03 Innovation has met the innovation network members' expectations regarding the innovation's impact on sales.

\section{CONTROL VARIABLES}

\section{Bridging ties:}

BT01 Companies in this innovation network varied widely in their areas of expertise

BT02 Companies in this innovation network had a variety of different backgrounds and experiences

BT03 Companies in this innovation network had skills and abilities that complemented each others'

BT04 Companies in this innovation network had resources and assets that complemented each others'

\section{Competitive environment}

Please consider the following statements about possible market and technological uncertainties in your industry concerning the products you develop and produce.

\section{Customer uncertainty:}

For our end-products and/or subsystems we use and supply:

CU01 Customers' preferences for product features have changed quite a bit over time.

CU02 We are witnessing demand for our products from customers who never bought them before.

CU03 New customers tend to have product-related needs that are different from those of our existing customers.

\section{Technological uncertainty:}

For our end-products and/or subsystems we use and supply:

TU01 Specifications for products and subsystems change frequently.

TU02 Future technological improvements of products and subsystems are very likely.

TU03 The technologies used in our products are changing rapidly. 


\section{Single item control variables:}

INPUT01 Relative to other product innovation projects the marketing resources devoted to this innovation project by the innovation network partners is high.

SIZE01 What was approximately the total estimated dollar cost of this product innovation project? (__ dollar)

COMP01 How many companies in the innovation network could be classified as competitors? (__ companies)

SIZE01 How many employees does your company approximately have? (__ employees)

EQ01 Can the relationship among companies in the innovation network predominantly be described as equity relationships? Yes $\square$ No 


\section{CHAPTER 7}

\section{General discussion, limitations, and conclusion}

This research was aimed at examining the relationships between customer variety needs, product architecture design and business network configurations. In this chapter we discuss the key findings, theoretical and managerial contributions from this research that can be linked to the original five research questions, explained in chapter 1. Finally, we discuss the limitations of our study, and avenues for future research. 


\section{General DisCusSiON}

\section{Discussion of chapter 2: Variation in housing design, identifying customer preferences ${ }^{9}$}

How do potential new home buyers in the Netherlands prioritize the different elements in a house design from the perspective of obtaining a variety of alternative solutions from which to select? And, what is the willingness-to-pay extra for a customized housing proposition? This chapter presents the findings of a vignette based survey about the variation needs among potential buyers of new houses in The Netherlands. The research findings indicate that customers evaluate the interior finish as the most important level of housing decomposition; it has a relative weight of $30 \%$. Floor plan and the volume and exterior of the home have a weight of respectively $23 \%$ and $26 \%$. The environment and technical systems are the least important levels with a weight of respectively $9 \%$ and $12 \%$. These five levels of housing decomposition were further decomposed into 35 housing attributes. Besides evaluating the proposed vignettes, respondents were also asked to score the relative importance of each housing attribute on their value of offering a customized solution. The priority listing derived from this study presents the 35 attributes sorted according to the relative importance for potential buyers of new homes of getting customized solutions. The attributes with the highest relative importance appear to be part of the level of housing decomposition "Interior finish" while the five least important attributes, except for the attribute roof finish, belong to the level "Environment". Respondents also had to rank each housing proposition under different price conditions. The results show that averagely a customer is willing to pay $€ 23.333$, or $10 \%$ of the sales price, extra for the perfect housing proposition compared to a house in which no variation is offered. From the Price - Customer Value trade off relationship one might deduce that the minimum value to satisfy a customer is $50 \%$. The points of intersection between the price-value curves of the respective housing propositions and the lower limit indicate the maximum price for which each proposition remains acceptable. The difference between this price and the maximum sum a customer is willing to pay for his "perfect package" forms the opportunity-sales for the supplier. The

\footnotetext{
${ }^{9}$ Published as: Hofman, E., Halman, J. I. M., \& Ion, R. A. 2006. Variation in housing design: Identifying customer preferences. Housing Studies, 21: 929-943.
} 
supplier can add options to the package up to the maximum amount of money the customer is willing to pay.

Contributions to theory. A main outcome of this study is the priority listing of housing attributes. The priority listing functions as primary input for an engineering design method called 'design for variety' (Veenstra et al., 2006). In this way, the research output has already proven its value in developing a modular housing architecture. A second principal contribution of this study has been the development of a model to deduce the trade off between customer value and price of housing proposition. The difference between customer value and price can be used to measure the incentive for the customer to buy. To outperform competitors, it is suggested that housing suppliers could follow a strategy of increasing this difference.

Contributions to management. First, we encourage housing suppliers to reconsider their traditional project-based way of product development and to consider platform-based housing solutions. Modular housing systems will allow housing suppliers to share components and production processes at the multi-project level. In this way housing suppliers could benefit from platform-based approaches to leverage investments in new product development, manufacturing, and marketing to develop differentiated products efficiently (Halman et al., 2003). From existing research it follows that for effective product modularization, companies should first determine what customer segments to enter and determine customer variety needs per segment, and secondly they should evaluate the commonality potential of the different parts across the products in these segments (Robertson \& Ulrich, 1998). Therefore we encourage housing suppliers to use our priority listing of customer variety needs in housing design as primary input in their product modularization efforts. This helps building developers in decision making about the right balance between the level of variety (such as different types of bathrooms, kitchens, roof types etc.) to be offered versus the need to standardize and produce economically. More specific engineering design methods such as Martin \& Ishii's (2002) design for variety method have already proven their usefulness for developing modular housing systems (Veenstra et al., 2006). To help decide about product modularization, companies can evaluate the required investments against the expected customers' willingness-to-pay-extra 
for a customized product, and the reduced product cost due to the reuse potential of product parts and design and production processes at the multi-project level.

Discussion of chapter 3: matching supply networks to a modular product architecture in the house-building industry ${ }^{10}$

What types of buyer-supplier relationships are needed to develop and produce a modular housing system that matches customer variety needs successfully? This case study has illustrated that, in a traditional, loosely coupled construction network, it can be hard to introduce and force adoption of new design rules. Based on the analysis of ten dyadic contractor-supplier relationships, this study shows that contractor-supplier relationships in modular house-building are moderated by both demand and supply aspects. The alignment between product modules and contractor-supplier relationships is found to be contingent on four drivers: the degree of variety in customer demand, the extent of the required supplier investment, the extent of dependence on supplier knowledge, and the intentions of both the supplier and the buyer in a relationship. In the case study company, the costs are closely related to the necessary financial investments in development and production, and the risks related to knowledge sharing. A positive return on an investment is dependent on the size of the investment and the reuse potential of modules related to that investment. Reuse potential is high when customer variety needs are low and, conversely, reuse potential is low when customer variety needs are high leading to partly standardized designs being unacceptable. In line with this argumentation, the research findings indicate that a decrease in the extent of customer variety demands combined with an increase in the companies' interdependence on innovation-specific investments and on each other's unique knowledge increased the degree of organizational integration among the parties involved. The business network that appeared to be appropriate for developing and implementing the new design rules involves three types of relationships: integrated, quasi-integrated, and nonintegrated. Parts with limited variety and which require supplier investment and supplier knowledge seem suited to cooperation at the multi-project level with full integration. For parts with a moderate to low demand for variety, and for which moderate supplier

\footnotetext{
${ }^{10}$ Hofman, E., Voordijk, H., \& Halman, J. 2009. Matching supply networks to a modular product architecture in the house-building industry. Building Research and Information, 37: 31-42.
} 
investments are needed but no specialized supplier knowledge required, quasi-vertical integration is sufficient. For parts for which it is hard to limit oneself to standard units at the multi-project level, one can still standardize to some extent for houses within a certain project and offer options per house. Conversely, for parts with a high demand for variety, such as type of kitchen, or type and colors of tiling, housing suppliers can best leave the choice to the buyer and procure these parts on a project-by project basis. These results suggest that one-size does not fit all, per product module; companies should evaluate the four antecedents before deciding about the level of organizational integration. We believe that this matching will not only facilitate the development of modular housing systems, but will also maximize business performance.

Contributions to theory. First we have developed a framework that can be used to evaluate the relationship between the modular product architecture that is being developed and the degree of organizational coupling among innovation partners. Second, this chapter has increased insight in how to cope with the dynamic limits of loosely coupled, specialized organizational forms (Cacciatori \& Jacobides, 2005). Although the project based nature of the construction industry provides short-term project flexibility, this inter-organizational structure impedes innovations that require collective investments that can only be returned over a longer time span. Our research findings show that for developing a modular product it is important for each part of the end-system to match supplier relationships that optimally balances short- and long-term interests.

Contributions to management. Because the managerial implications of chapter three and four are strongly related, we provide an integrated discussion on contributions to management for both chapters in the next section.

Discussion of chapter 4: architectural innovation in loosely coupled networks, how to compensate for loose coupling and inertia ${ }^{11}$

How can companies compensate for organizational loose coupling and inertia during collaborative architectural innovation? This work indicates that firms in loosely coupled networks benefit from cognitive coupling as a process that can create shared strategic beliefs about the technology trajectory, and lead to structural coupling as a solution to the

\footnotetext{
${ }^{11}$ Accepted and presented at $15^{\text {th }}$ EIASM international product development management conference (2008).
} 
inertia that impedes architectural innovation. In practical terms, this framework thus provides a tool for managers who want to evaluate their plans for architectural innovation and, in this way, it can guide firms, in what is an increasingly common context of loosely coupled business networks, by providing robust insights for developing innovation strategies.

Contributions to theory. In terms of research, by shifting the perspective on architectural innovation to the level of networks, this study has revealed inertial factors that have not been previously studied. Our case study illustrates the interactions between cognition and a pattern of structural couplings that arise during architectural innovation. By combining perspectives from the concepts of inertia and of cognitive and structural compensation mechanisms with those from the concept of loose coupling, it combines two separate, but practically and theoretically complementary, views on innovation.

Contributions to management. In the house-building industry companies are used to organize production and collaboration around projects. The tender system that is most often used favors the procurement of traditional, standard products because those are easy to compare and leave a single and simple criterion to select project partners: price (Dubois \& Gadde, 2002; Holmen, Pedersen, \& Torvatn, 2005). This is an important reason why traditionally, housing project organizations are highly instable at the multi-project level. The result is a loose and traditional innovation context that associates with several inertial forces that impede architectural innovation and include for example sunk cost commitments, misaligned capabilities, too much environmental turbulence, non-aligned strategic beliefs, and routines. However an effective means to overcome inertial forces and to achieve systemic, architectural innovation is aligning the degree of organizational coupling among the supply chain partners to the new requirements of the modular housing architecture. This not only requires a systems architect who knows how to modularize a product system from a customer and technical point of view (Ulrich, 1995). But, it also requires knowledge on how organizational coupling can best be achieved.

- The development of a modular product platform usually requires innovation specific investments on part of the innovation partners that cannot be returned in a single project. Therefore it is important that all companies involved in product modularization expect a positive return on investments. High heterogeneity in demand decreases the reuse potential of modules and this subsequently decreases the likelihood that 
investments in modular standards will produce a financial return through use in future projects. This is one of the reasons why compared to other industries, construction companies make relatively low idiosyncratic investments in technology development (Eccles, 1981b). We suggest that for high variety parts companies can best stick to flexible, project based procurement. But, for parts with moderate to low customer variety needs, and that require substantial innovation specific investments on part of the supplier, increased stability among contractor and supplier achieved through vertical integration and collaboration at the multi-project level, rather than on the single engineer-to-order project level, increases a firm's willingness to collaborate in architectural innovation. If possible, a lead customer can be committed; this will further increase the companies' beliefs in the potential for an ongoing relationship. This portfolio approach demands managers that know how to match supplier relationships with the new requirements of developing and exploiting modular product architectures, especially because a misfit between both is likely to lead to innovation failures.

- Next to structural coupling, cognitive coupling among innovation partners is also crucial to the success of architectural innovation. Traditional ways of organizing housing production reinforce rigid routines and lead to decreased willingness and ability to unlearn previous experiences (Dougherty, 1992). Given such bounded rationality, humans depend on suggestions, recommendations, persuasion, and information obtained through social channels as a major basis for choice (Simon, 1993). Because learning about changes in product architectures is unlikely to occur naturally, explicit management attention is required to new interactions across components and functional boundaries (Henderson \& Clark, 1990). Therefore, transformational leadership behaviors are required for improving the willingness to experiment and alleviate the negative impact of inertia on architectural innovation (Smith \& Tushman, 2005; Vera \& Crossan, 2004; Yukl, 2009). Leaders that apply transformational leadership know how to develop trust, a shared vision and sense of mission, intellectually stimulate, and inspire partners to transcend self-interests for collective innovation goals (Avolio, Bass, \& Jung, 1999; Bass, 1985). If management focuses on clarifying the contradictions and commonalities between the old and the new this will reduce people's cognitive commitments to past investments (Kaplan, 2008; Smith \& Tushman, 2005). Thus, transformative leadership is 
likely to improve organizational learning and innovation (Vera \& Crossan, 2004) since companies that have aligned strategic beliefs about what to do and how to do it are more likely to collaborate and innovate successfully. Thus, although organizational coupling and cognitive coupling by means of transformational leadership are distinct forces, they both influence the outcome of collaborative innovation projects through the same process. Accordingly we suggest using managers with a transformative leadership profile.

Discussion of chapter 5 . when to use loose or tightly coupled networks for innovation? Empirical evidence. ${ }^{12}$

Do companies benefit more from tight organizational coupling for architectural innovation than they do for modular innovation? The research findings from the third chapter relate to the propositions developed in chapter 4 . Table 7.1 shows the hypotheses we tested in this study. The findings indicate that for modular innovations, companies should collaborate with tightly coupled partners. However for architectural innovation, it is more effective for a company to work with partners that they have not yet established close and intensive relationships with through previous innovation projects. In addition, companies can best chose to work with other companies that are easy to replace, i.e. their skills and resources are not unique, and where relation-specific investments are relatively low at the time of innovation network formation. Furthermore working with partners that share a short history of collaboration also improves architectural innovation performance.

\footnotetext{
${ }^{12}$ This chapter has been submitted to an international refereed journal.
} 
Table 7.1: Main findings on the impact of organizational coupling on innovation performance

\begin{tabular}{|c|c|c|}
\hline $\mathrm{H} 1 \mathrm{a}$ & $\begin{array}{l}\text { Organizational loose coupling will be negatively related to the performance } \\
\text { of collaborative product innovations. }\end{array}$ & $\begin{array}{c}\text { Not } \\
\text { supported }\end{array}$ \\
\hline $\mathrm{H} 1 \mathrm{~b}$ & $\begin{array}{l}\text { Organizational loose coupling will be positively related with the } \\
\text { performance of collaborative product innovations. }\end{array}$ & $\begin{array}{c}\text { Not } \\
\text { supported }\end{array}$ \\
\hline $\mathrm{H} 2 \mathrm{a}$ & $\begin{array}{l}\text { Organizational loose coupling will have a negative impact on the } \\
\text { performance of modular product innovation. }\end{array}$ & Supported \\
\hline $\mathrm{H} 2 \mathrm{~b}$ & $\begin{array}{l}\text { The negative relationship between organizational loose coupling and the } \\
\text { performance of collaborative product innovation will be stronger for } \\
\text { architectural than for modular product innovations. }\end{array}$ & $\begin{array}{c}\text { Not } \\
\text { supported }\end{array}$ \\
\hline $\mathrm{H} 2 \mathrm{c}$ & $\begin{array}{l}\text { Organizational loose coupling will have a positive impact on the } \\
\text { performance of architectural product innovations. }\end{array}$ & Supported \\
\hline
\end{tabular}

Contributions to theory. We have successfully addressed a gap in the literature on social network configurations and collaborative innovation. The existing social network and innovation studies do not show how different network configurations influence innovation performance, and whether this depends upon the type of innovation. Our results add understanding by showing how different innovation network configurations influence the performance of modular and architectural innovation. Our results show that tight coupling is not unconditionally advantageous for companies pursuing innovations in networks of firms. The success of collaborative innovation is contingent upon the configuration of the innovation network and on the type of innovation. Although, the conventional wisdom suggests that companies benefit more from tight organizational coupling for architectural innovation than they do for modular innovation (Hoetker, 2006). Our empirical evidence challenge these traditional views of innovation networks and reveals that, for architectural innovation, loose rather than tightly coupled innovation networks improve performance. Thus, although loose coupling has traditionally been associated with an 'action problem' (Obstfeld, 2005), our empirical findings show that for architectural innovation loose coupling provides 'means for action'.

Contributions to management. Because the managerial implications of chapter 5 and 6 are strongly related, we provide an integrated discussion on contributions to management for both chapters in the next section. 
Discussion of chapter 6. Product innovation networks, do design rules compensate or complicate innovation? Empirical evidence ${ }^{13}$

Do product design rules compensate or complicate collaborative innovation? And, is this relationship contingent upon the type of innovation (i.e. modular or architectural innovation) and on the degree of organizational coupling among partners in the innovation network? In this chapter we expanded on our findings in chapter 5 and added a variable that is hypothesized to interact with the innovation network configuration in explaining collaborative innovation performance. An examination of 664 collaborative product innovation networks showed that design rules improve modular innovation performance and decrease architectural innovation performance. The interactions among design rules and organizational loose coupling in explaining modular and architectural innovation performance did not match our expectations. First, the results indicate that design rules compensate for the negative impact of organizational loose coupling on modular innovation performance. However, they are incomplete substitutes, meaning that modular innovation performance is highest in contexts where innovation partners are tightly coupled and product design rules are available. For architectural innovation, loose and tight coupling can both improve innovation performance; this depends upon the availability of design rules. Consistent with the dominant view, when design rules are not available, for architectural innovation it is most effective for a company to work with tightly coupled partners. Yet, when design rules are available, companies can best choose to collaborate with partners that have not yet established a close and intensive relationship in previous innovation projects. In addition, companies can better chose to work with companies that are easy to replace, e.g. their skills and resources are not unique, and relation specific investments are relatively low at the moment of innovation network formation. The main findings of this research are presented in Table 7.2.

\footnotetext{
${ }^{13}$ Accepted and presented at: the Academy of management Conference, (2010); and the Tilburg Conference on Innovation, (2010). This chapter has been submitted to an international refereed journal.
} 
Table 7.2. Main findings on the impact of organizational coupling on innovation performance

\begin{tabular}{|c|c|c|}
\hline $\mathrm{H} 1 \mathrm{a}$ & $\begin{array}{l}\text { Organizational loose coupling will be negatively related to the } \\
\text { performance of collaborative product innovations. }\end{array}$ & Not supported \\
\hline $\mathrm{H} 1 \mathrm{~b}$ & $\begin{array}{l}\text { Organizational loose coupling will be positively related with the } \\
\text { performance of collaborative product innovations. }\end{array}$ & Not supported \\
\hline $\mathrm{H} 2 \mathrm{a}$ & $\begin{array}{l}\text { Organizational loose coupling will have a negative impact on the } \\
\text { performance of modular product innovation. }\end{array}$ & Supported \\
\hline $\mathrm{H} 2 \mathrm{~b}$ & $\begin{array}{l}\text { The negative relationship between organizational loose coupling and the } \\
\text { performance of collaborative product innovation will be stronger for } \\
\text { architectural than for modular product innovations. }\end{array}$ & Not supported \\
\hline $\mathrm{H} 2 \mathrm{C}$ & $\begin{array}{l}\text { Organizational loose coupling will have a positive impact on the } \\
\text { performance of architectural product innovations. }\end{array}$ & Supported \\
\hline H3a & $\begin{array}{l}\text { High dominancy of design rules improves the performance of modular } \\
\text { innovations. }\end{array}$ & Supported \\
\hline $\mathrm{H} 3 \mathrm{~b}$ & $\begin{array}{l}\text { The negative relationship between loose coupling and modular } \\
\text { innovation performance will be weaker under conditions of high } \\
\text { dominancy of design rules. }\end{array}$ & Not supported \\
\hline $\mathrm{H} 3 \mathrm{c}$ & $\begin{array}{l}\text { High dominancy of design rules decreases the performance of } \\
\text { architectural innovations. }\end{array}$ & Supported \\
\hline$H 3 d$ & $\begin{array}{l}\text { The relationship between loose coupling and architectural innovation } \\
\text { performance is most negative when product design rules are available } \\
\text { and (b) least positive when no product design rules are available. }\end{array}$ & Not supported \\
\hline H3e & $\begin{array}{l}\text { The relationship between loose coupling and architectural innovation } \\
\text { performance is most positive when product design rules are available and } \\
\text { (b) least positive when no product design rules are available. }\end{array}$ & Supported \\
\hline
\end{tabular}

Contributions to theory. Overall, our study makes several contributions to the modularity and social network literature. First, our results show that modular innovations perform better than architectural innovations, this confirms and extends research findings in the photolithography industry (Henderson \& Clark, 1990). Secondly, to our knowledge, this is the first study that provides empirical evidence that product design rules increase modular innovation performance irrespective of the degree of organizational coupling among innovation partners. However, third, design rules do not fully substitute for loose coupling during modular innovation. This corroborates recent research findings of Tiwana (2008b). Yet, our study went to the bottom of this matter by showing that design rules and tight coupling not only have an additive positive effect on modular innovation performance, tighter coupling also increases the positive impact of design rules on modular innovation performance. Fifth, this is the first study that provides empirical evidence that product design rules decrease architectural innovation performance irrespective of the degree of 
organizational coupling among innovation partners. Sixth, the evidence presented here shows that for architectural innovation, loose and tight coupling can both improve architectural innovation performance; this depends upon the availability of design rules. Consistent with the dominant view, when design rules are not available, for architectural innovation it is most effective for a company to work with tightly coupled partners. Yet, when design rules are available, companies can best choose to collaborate with loosely coupled partners.

The social network and innovation literature argues that loose coupling associates with 'action problems' (Hansen, 1999; Obstfeld, 2005). However, we discovered that loose coupling also provides a 'means for action' for architectural innovation in contexts where design rules exist. We believe an important reason for this is that companies that are loosely coupled to their innovation partners are not handicapped by 'over-embeddedness' (Gargiulo \& Benassi, 2000; Hagedoorn \& Frankort, 2008; Uzzi, 1997). Reduced network inertia implies that companies can more easily change network partners (Kim et al., 2006).Thus, the looser the coupling among innovation network members, the higher the lead firm's ability to adapt the composition of the innovation network to match the coordination requirements of an architectural innovation. As such, the positive impact of loose coupling on architectural innovation performance is likely to be the result of the lead firm's ability to exchange old partners for new ones that are better equipped for the task. This finding fills an important gap in the modularity literature (Hoetker et al., 2007). An alterative explanation would contribute to the institutional and cognitive theories of technological change provide. In stronger networks, companies often develop shared cognition (Levin \& Cross, 2004) and these shared technological frames then define the lens that people use when trying to make sense of innovations (Dougherty, 1992; Kaplan, 2008; Orlikowski \& Gash, 1994). A company's innovativeness can be restricted by a reliance on the accumulated knowledge that reflects the design rules of their previous generation of products (Henderson \& Clark, 1990; LeonardBarton, 1992). As such, cognitive frames, which are more often shared among tightly coupled partners (Ring \& Vandeven, 1994), are likely to thwart collaborative, architectural innovation. Loose innovation networks are often composed of companies that operate at the periphery of networks, and in non-related industries. These companies are less cognitively biased by commitments to existing design standards, this improves architectural 
innovation performance, and this effect outweighs the positive impact of tighter coupling on the ability to coordinate systemic interdependencies among the innovation network members. Finally, loose relationships also associate with limited competence-based trust (Levin \& Cross, 2004). Therefore loosely coupled companies invest more time in careful evaluation of the changed interactions among the interfacing subsystems that go with architectural innovations. Loosely coupled innovation partners will control whether each partner applies the correct 'architectural knowledge' and adheres to the new product design rules. This suggests that loose ties also improve architectural innovation, because lower levels of competence-based trust results in thorough inspection of sometime subtle changes in the interactions between subsystems. This attention is known to be crucial to the success of architectural innovation (Henderson \& Clark, 1990).This final explanation contributes to the debate on the role of trust in innovation; we conclude that competence-based distrust also provides its benefits.

Contributions to management. Before deciding to collaborate with known or new partners, companies can best first evaluate whether they pursue modular or architectural innovation and if clear product design rules exist for the product that is being developed. In contrast to observed managerial behaviors (Hoetker, 2006; Li et al., 2008), if design rules exist, for architectural innovation it is most effective for a company to work with partners that have not yet established a close and intensive relationship in previous innovation projects and companies can better chose to work with partners that are easy to replace, e.g. their skills and resources are not unique, and relation specific investments are relatively low at the moment of innovation network formation. In all other situations, to maximize innovation performance, companies can best select partners they collaborated with before, and with whom they share close, reciprocal and interdependent relationships. The construction industry is a highly routine industry, and although one can argue about whether standard design rules exist for houses, we did find rigid routines that were misaligned with the architectural innovation under study. Accordingly, our study suggests that companies could escape these negative implications by collaborating with loose partners from for example related but more distant industries.

Finally, we caution people for drawing the wrong conclusion that companies should only pursue modular innovation because this results in higher performance than architectural 
innovation. Because architectural innovation is required to create a modular product platform it is a prerequisite for modular innovation. To support investments in architectural innovation we suggest that companies can best adopt a real options approach. Modular product architectures create an option space that provides opportunities to capitalize on modular innovations which can return investments made for developing the modular product architecture in the first place. This approach will reduce the likelihood that companies get stuck in the 'modularity trap', a situation in which companies stick to a suboptimal technology that is no longer competitive (Chesbrough, 2003).

\section{LIMITATIONS AND AGENDA FOR FUTURE RESEARCH}

In each chapter we have provided limitations or our research and directions for future research. We summarize the directions of future research in table 7.1. Some suggestions are already answered in this thesis. Below, we suggest some additional directions for future research.

Currently companies in the house-building industry run into many problems in implementing modular design principles. Overall, for developing a full set of modular design rules companies can choose from three strategies: 1 . they develop design rules that apply to their products only and if possible the intellectual property rights of the rules including interface designs are protected by patents, 2 . they develop a full set of modular design rules together with partners, the design rules are then used within this cluster of companies and are used to compete with other clusters that employ a set of non-compatible design rules, this reduces the opportunity to mix and match modules from companies of competing clusters, design rules are again protected by patents, 3. companies can develop design rules that are 'open' in a sense that they are not patented and can freely be used by other companies, including competitors. Each strategy will result in different industry dynamics. Different outcomes include that the modular interfaces will support exchangeability of building components at company, cluster or the industry level. Future research could evaluate these three scenarios against their business and societal benefits. 
Table 7.1. Directions for future research

\begin{tabular}{|c|c|}
\hline Chapter 2 & $\begin{array}{l}\text { - Repeat customer research outside The Netherlands to reveal to what extent } \\
\text { potential buyers of new houses in other countries differ in prioritizing attributes in } \\
\text { house design. } \\
\text { - In order to offer the right package of variation, we need to enlarge insights in the } \\
\text { way customers value possible packages of variation as a function of the matching } \\
\text { package-prices. }\end{array}$ \\
\hline Chapter 3 & $\begin{array}{l}\text { - Realizing multi-project modular housing in decentralized networks depends in } \\
\text { particular on the likelihood of supplier's investments being recovered from future } \\
\text { sales and the risks related to knowledge sharing. Further research is needed to test } \\
\text { the significance of the found relationships and costs and risks of different } \\
\text { contractor-supplier relationships. }\end{array}$ \\
\hline Chapter 4 & $\begin{array}{l}\text { Test the conceptual model in other industries and in other countries. This would } \\
\text { allow account to be taken of technological, organizational and institutionalization } \\
\text { differences. Other industries could well reveal different or additional inertial factors } \\
\text { and compensatory mechanism. } \\
\text { Examine the cycle of technological and organizational evolution. Longitudinal } \\
\text { qualitative and quantitative studies could strengthen the concept of pattern of } \\
\text { cognitive and structure coupling and inertial factors over the technology life cycle. } \\
\text { This could support our thesis of cycling patterns of exploitation and innovation in } \\
\text { which cognitive, structural, and product coupling alternate with coupling among } \\
\text { these dimensions. }\end{array}$ \\
\hline Chapter 5 & $\begin{array}{l}\text { - Architectural innovation performance is low compared to modular innovation } \\
\text { performance, therefore it is important to increase understanding how to respond } \\
\text { effectively to architectural innovation. } \\
\text { - Perform full network analyses and analyze a limited number of innovation networks } \\
\text { in greater depth. } \\
\text { - Study the pattern of organizational, cognitive and product architectural coupling } \\
\text { over time in relation to collaborative innovation performance. }\end{array}$ \\
\hline Chapter 6 & $\begin{array}{l}\text { - Developing an interpretive model that explores other mechanisms for overcoming } \\
\text { the detrimental impact of dominant design rules on architectural innovation. An } \\
\text { example is to study behaviors on part of the innovation network leaders that } \\
\text { actively compensate for the negative impact of design rules on architectural } \\
\text { innovation. }\end{array}$ \\
\hline
\end{tabular}

Related to the first suggestion for further investigation, our study shows that, for many companies, architectural innovation is problematic and was associated with low innovation performance. Controlling the evolution of a product's architecture should allow a company to retain a competitive advantage in an industry (Morris \& Ferguson, 1993). However, limited attention has been paid to how companies can actually succeed with architectural innovation. For this purpose, we propose two studies:

- on the behaviors of innovation network leaders that can actively compensate for the negative impact on architectural innovation of institutionalization through design rules. Enhanced leadership could compensate for organizational loose coupling in orchestrating 
collaborative architectural innovation (Dhanaraj \& Parkhe, 2006; Orton \& Weick, 1990). Soft power strategies (Katila et al., 2008) and transformational leadership behaviors that increase the willingness to experiment have the potential to moderate the negative impact of design rules on architectural innovation (Smith \& Tushman, 2005; Vera \& Crossan, 2004; Yukl, 2009). Thus, in addition to studying the role of institutionalized product 'design rules' on collaborative innovation, we also suggest studying the moreactive leadership compensation mechanisms that could overcome the unique challenges facing companies in modular and architectural innovation.

- on the role that business incubator (could) play in systemic, architectural innovations like currently occur in the modular house-building industry and the electric vehicle industry. The idea is that business incubators could manage the many interfaces between governmental and the private parties that are involved in systemic innovation. However, the existing research has mainly focused on the role of business incubators in new single venture creation and not on their potential role in architectural innovation.

\section{CONCLUSION}

In conclusion, our study revealed intriguing insights about how different business network configurations and the availability of product design rules together influence the performance of modular and architectural innovations. We acknowledge the wide spectrum of complexities companies challenge in pursuing architectural innovation. However, we are confident that our results, like for example the innovation typology in Figure 6.4, provide useful new insights for both researchers as well as practitioners. 


\section{REFERENCES}

Ahuja, G. 2000. Collaboration networks, structural holes, and innovation: A longitudinal study.

Administrative Science Quarterly, 45: 425-455.

Aiken, L. S., West, S. G., \& Reno, R. R. 1991. Multiple regression: Testing and interpreting

interactions: Sage Pubns.

Anderson, J. C. \& Gerbing, D. W. 1988. Structural Equation Modeling in Practice - a Review and Recommended 2-Step Approach. Psychological Bulletin, 103: 411-423.

Anderson, P. \& Tushman, M. L. 1990. Technological Discontinuities and Dominant Designs - a Cyclical Model of Technological-Change. Administrative Science Quarterly, 35: 604-633.

Armstrong, J. S. \& Overton, T. S. 1977. Estimating Nonresponse Bias in Mail Surveys. Journal of Marketing Research, 14: 396-402.

Avolio, B. J., Bass, B. M., \& Jung, D. I. 1999. Re-examining the components of transformational and transactional leadership using the Multifactor Leadership Questionnaire. Journal of Occupational and Organizational Psychology, 72: 441-462.

Axelrod, R. 1984. The Evolution of Cooperation [M]. New York: Basic book.

Baldwin, C. Y. 2008. Where do transactions come from? Modularity, transactions, and the boundaries of firms. Industrial and Corporate Change, 17: 155.

Baldwin, C. Y. \& Clark, K. B. 1997. Managing in an age of modularity. Harvard Business Review, 75 : 84-\&.

Baldwin, C. Y. \& Clark, K. B. 2000. Design Rules: Volume 1 The Power of Modularity. Cambridge, MA: MIT Press.

Ball, M. 1999. Chasing a snail: innovation and house building firms' strategies. . Housing Studies, 14: 9-22.

Barlow, J. \& Ozaki, R. 2003. Achieving 'customer focus' in private housebuilding: Current practice and lessons from other industries. Housing Studies, 18: 87-101.

Barlow, J. \& Ozaki, R. 2005. Building mass customised housing through innovation in the production system: lessons from Japan. Environment and Planning A, 37: 9-20.

Barlow, J., Childerhouse, P., Gann, D., Hong-Minh, S., Naim, M., \& Ozaki, R. 2003a. Choice and delivery in housebuilding, lessons from Japan for UK housebuilders. . Building Research and information, 31: 134-145.

Barlow, J., Childerhouse, P., Gann, D., Hong-Minh, S., Naim, M., \& Ozaki, R. 2003b. Choice and delivery in housebuilding: lessons from Japan for UK housebuilders. Building Research and Information, 31: 134-145.

Bass, B. M. 1985. Leadership and Performance Beyond Expectations: Free Press.

Beekun, R. I. \& Glick, W. H. 2001. Organization structure from a loose coupling perspective: A multidimensional approach. Decision Sciences, 32: 227-250.

Benner, M. J. \& Tushman, M. 2002. Process Management and Technological Innovation: A Longitudinal Study of the Photography and Paint Industries. Administrative Science Quarterly, 47: 676-706.

Benner, M. J. \& Tushman, M. L. 2003. Exploitation, exploration, and process management: The productivity dilemma revisited. Academy of Management Review, 28: 238-256.

Bensaou, M. 1999. Portfolios of buyer-supplier relationships. Sloan Management Review, 40: 35-+. Bentler, P. M. \& Bonett, D. G. 1980. Significance Tests and Goodness of Fit in the Analysis of Covariance-Structures. Psychological Bulletin, 88: 588-606.

Bourn, J. 2001. Modernising Construction. In N. A. Center (Ed.), Vol. HC 87.

Bower, J. L. \& Christensen, C. M. 1995. Disruptive Technologies - Catching the Wave. Harvard Business Review, 73: 43-53. 
Brusoni, S. \& Prencipe, A. 2006. Making design rules: A multidomain perspective. Organization Science, 17: 179-189.

Brusoni, S., Prencipe, A., \& Pavitt, K. 2001. Knowledge specialization, organizational coupling, and the boundaries of the firm: Why do firms know more than they make? Administrative Science Quarterly, 46: 597-621.

Burt, R. S. 1992. Structural holes: The social structure of competition: Harvard University Press.

Burton, R. M., Lauridsen, J., \& Obel, B. 2002. Return on assets loss from situational and contingency misfits. Management Science, 48: 1461-1485.

Byrne, B. M. 2001. Structural equation modeling with AMOS. New Jersey: Lawrence Erlbaum Associates, Inc., Publishers.

Cacciatori, E. \& Jacobides, M. G. 2005. The dynamic limits of specialization: Vertical integration reconsidered. Organization Studies, 26: 1851-1883.

Caerteling, J. S., Halman, J. I. M., \& Doree, A. G. 2008. Technology commercialization in road infrastructure: How government affects the variation and appropriability of technology. Journal of Product Innovation Management, 25: 143-161.

Campion, M. A., Medsker, G. J., \& Higgs, A. C. 1993. Relations between Work Group Characteristics and Effectiveness - Implications for Designing Effective Work Groups. Personnel Psychology, 46: 823850.

Chandler, A. D. 1962. Strategy and Structure: Chapters in the History of American Enterprise.

Cambridge, Massachusetts: Massachusetts Institute of Technology.

Chesbrough, H. W. 2003. Towards a dynamics of modularity: a cyclical model of technical advance.

The business of systems integration: 174-198.

Chesbrough, H. W. \& Teece, D. J. 1996. When is virtual virtuous? Organizing for innovation. Harvard Business Review, 74: 65-73.

Chesbrough, H. W. \& Kusunoki, K. 1999. The modularity trap: innovation, technology phase-shifts, and resulting limits of virtual organisations. Working paper.

Clark, K. B. \& Fujimoto, T. 1990. The Power of Product Integrity. Harvard Business Review, 68: 107118.

Cohen, M. D. \& Bacdayan, P. 1994. Organizational Routines Are Stored as Procedural Memory Evidence from a Laboratory Study. Organization Science, 5: 554-568.

Cohen, W. M. \& Levinthal, D. A. 1990. Absorptive-Capacity - a New Perspective on Learning and Innovation. Administrative Science Quarterly, 35: 128-152.

Cohen, W. M. \& Klepper, S. 1996. A reprise of size and R\&D. Economic Journal, 106: 925-951.

Coleman, J. S. 1988. Social capital in the creation of human capital. American Journal of Sociology, 94: 95.

Dawson, J. F. \& Richter, A. W. 2006. Probing three-way interactions in moderated multiple regression: Development and application of a slope difference test. Journal of Applied Psychology, 91: 917-926.

Dellaert, B. C. G. a. S., S. . 2005. Marketing Mass Customized Products: Striking the Balance between Utility and Complexity. Journal of Marketing Research, 42 219-227.

Dertouzos, M. L., Lester, R. K., \& Solow, R. M. 1989. Made in America: Regaining the productive edge. Dess, G. G. \& Robinson, R. B. 1984. Measuring Organizational Performance in the Absence of Objective Measures - the Case of the Privately-Held Firm and Conglomerate Business Unit. Strategic Management Journal, 5: 265-273.

Dhanaraj, C. \& Parkhe, A. 2006. Orchestrating innovation networks. Academy of Management Review, 31: 659-669.

Dillman, D. A. 1978. Mail and telephone surveys: The total design method. New York: NY: Wiley. Dosi, G. 1982. Technological Paradigms and Technological Trajectories - a Suggested Interpretation of the Determinants and Directions of Technical Change. Research Policy, 11: 147-162. 
Doty, D. H., Glick, W. H., \& Huber, G. P. 1993. Fit, Equifinality, and Organizational-Effectiveness - a Test of 2 Configurational Theories. Academy of Management Journal, 36: 1196-1250.

Dougherty, D. 1992. Interpretive Barriers to Successful Product Innovation in Large Firms.

Organization Science, 3: 179-202.

Dougherty, D. \& Heller, T. 1994. The Illegitimacy of Successful Product Innovation in Established

Firms. Organization Science, 5: 200-218.

Dubois, A. \& Gadde, L. E. 2000. Supply strategy and network effects-purchasing behaviour in the construction industry. European Journal of Purchasing and Supply Management, 6: 207-215.

Dubois, A. \& Gadde, L. E. 2002. The construction industry as a loosely coupled system: implications for productivity and innovation. Construction Management and Economics, 20: 621-631.

Dyer, J. H. \& Singh, H. 1998. The relational view: Cooperative strategy and sources of interorganizational competitive advantage. Academy of Management Review, 23: 660-679.

Eccles, R. G. 1981a. Bureaucratic versus Craft Administration: The Relationship of Market Structure to the Construction Firm. Administrative Science Quarterly, 26: 449-469.

Eccles, R. G. 1981b. The Quasi-Firm in the Construction-Industry. Journal of Economic Behavior \& Organization, 2: 335-357.

Echambadi, R. \& Hess, J. D. 2007. Mean-centering does not alleviate collinearity problems in moderated multiple regression models. Marketing Science, 26: 438-445.

Eisenhardt, K. M. 1989a. Building Theories from Case-Study Research. Academy of Management Review, 14: 532-550.

Eisenhardt, K. M. 1989b. Making Fast Strategic Decisions in High-Velocity Environments. Academy of Management Journal, 32: 543-576.

Evans, M. G. 1985. A Monte-Carlo Study of the Effects of Correlated Method Variance in Moderated Multiple-Regression Analysis. Organizational Behavior and Human Decision Processes, 36: 305-323. Fang, E., Palmatier, R. W., \& Evans, K. R. 2008. Influence of customer participation on creating and sharing of new product value. Journal of the Academy of Marketing Science, 36: 322-336.

Fixson, S. K. \& Park, J. K. 2008. The power of integrality: Linkages between product architecture, innovation, and industry structure. Research Policy.

Fornell, C. \& Larcker, D. F. 1981. Evaluating Structural Equation Models with Unobservable Variables and Measurement Error. Journal of Marketing Research, 18: 39-50.

Gadde, L. E. \& Snehota, I. 2000. Making the most of supplier relationships. Industrial Marketing Management, 29: 305-316.

Galbraith Jr., J. K. 1974. Organization Design - Information Processing View. Interfaces, 4: 28-36.

Gann, D. M. 1996. Construction as a manufacturing process? Similarities and differences between

industrialized housing and car production in Japan. . Construction Management and Economics, 14 437-450.

Gargiulo, M. \& Benassi, M. 2000. Trapped in your own net? Network cohesion structural holes, and the adaptation of social capital. Organization Science, 11: 183-196.

Garud, R. \& Rappa, M. A. 1994. A Sociocognitive Model of Technology Evolution - the Case of Cochlear Implants. Organization Science, 5: 344-362.

Gatignon, H. \& Xuereb, J. M. 1997. Strategic orientation of the firm and new product performance.

Journal of Marketing Research, 34: 77-90.

Gatignon, H., Tushman, M. L., Smith, W., \& Anderson, P. 2002. A structural approach to assessing innovation: Construct development of innovation locus, type, and characteristics. Management Science, 48: 1103-1122.

Gilbert, C. G. 2005. Unbundling the structure of inertia: Resource versus routine rigidity. Academy of Management Journal, 48: 741-763.

Glaser, B. G. \& Strauss, A. L. 1967. The Discovery of Grounded Theory: Strategies for Qualitative

Research: Aldine Transaction. 
Glasmeier, A. 1991. Technological Discontinuities and Flexible Production Networks - the Case of Switzerland and the World Watch Industry. Research Policy, 20: 469-485.

Glassman, R. B. 1973. Persistence and Loose Coupling in Living Systems. Behavioral Science, 18: 8398.

Gonzalez-Diaz, M., Arrunada, B., \& Fernandez, A. 2000. Causes of subcontracting: evidence from panel data on construction firms. Journal of Economic Behavior \& Organization, 42: 167-187. Gouldner, A. W. 1960. The Norm of Reciprocity - a Preliminary Statement. American Sociological Review, 25: 161-178.

Govers, C. P. M. 1993. Quality of Services Applicable to Production. International Journal of Production Economics, 30-1: 385-397.

Granovetter, M. 1985. Economic-Action and Social-Structure - the Problem of Embeddedness.

American Journal of Sociology, 91: 481-510.

Granovetter, M. S. 1973. Strength of Weak Ties. American Journal of Sociology, 78: 1360-1380.

Greenwood, R. \& Hinings, C. R. 1996. Understanding radical organizational change: Bringing together the old and the new institutionalism. Academy of Management Review, 21: 1022-1054.

Gulati, R. 1995. Does familiarity breed trust? The implications of repeated ties for contractual choice in alliances. Academy of Management Journal: 85-112.

Habraken, N. J. \& Teicher, J. 1998. The structure of the ordinary: MIT press.

Hagedoorn, J. 1993. Understanding the Rationale of Strategic Technology Partnering -

Interorganizational Modes of Cooperation and Sectoral Differences. Strategic Management Journal, 14: 371-385.

Hagedoorn, J. \& Frankort, H. T. W. 2008. The Gloomy Side of Embeddedness: The Effects of Overembeddedness on Inter-Firm Partnership Formation. Network Strategy, 25: 503-530.

Halman, J. I. M., Hofer, A. P., \& van Vuuren, W. 2003. Platform-driven development of product families: Linking theory with practice. Journal of Product Innovation Management, 20: 149-162. Hannan, M. T. \& Freeman, J. 1984. Structural Inertia and Organizational-Change. American Sociological Review, 49: 149-164.

Hannan, M. T., Polos, L., \& Carroll, G. R. 2003. Cascading organizational change. Organization Science, 14: 463-482.

Hansen, M. T. 1999. The search-transfer problem: The role of weak ties in sharing knowledge across organization subunits. Administrative Science Quarterly, 44: 82-111.

Harrigan, K. R. 1986. Matching Vertical Integration Strategies to Competitive Conditions. Strategic Management Journal, 7: 535-555.

Hayes, A. F. \& Matthes, J. 2009. Computational procedures for probing interactions in OLS and logistic regression: SPSS and SAS implementations. Behavior Research Methods, 41: 924-936.

Henderson, R. M. \& Clark, K. B. 1990. Architectural Innovation - the Reconfiguration of Existing Product Technologies and the Failure of Established Firms. Administrative Science Quarterly, 35: 930.

Hobday, M. 2000. The project-based organisation: an ideal form for managing complex products and systems? Research Policy, 29: 871-893.

Hoetker, G. 2006. Do modular products lead to modular organizations? Strategic Management Journal, 27: 501-518.

Hoetker, G., Swaminathan, A., \& Mitchell, W. 2007. Modularity and the impact of buyer-supplier relationships on the survival of suppliers. Management Science, 53: 178-191.

Hofman, E., Halman, J. I. M., \& Ion, R. A. 2006. Variation in housing design: Identifying customer preferences. Housing Studies, 21: 929-943.

Hofman, E., Voordijk, H., \& Halman, J. 2009. Matching supply networks to a modular product architecture in the house-building industry. Building Research and Information, 37: 31-42.

Holmen, E., Pedersen, A. C., \& Torvatn, T. 2005. Building relationships for technological innovation. Journal of Business Research, 58: 1240-1250. 
Howell, J. M. \& Avolio, B. J. 1993. Transformational Leadership, Transactional Leadership, Locus of Control, and Support for Innovation - Key Predictors of Consolidated-Business-Unit Performance. Journal of Applied Psychology, 78: 891-902.

Jacobides, M. G. 2005. Industry change through vertical disintegration: How and why markets emerged in mortgage banking. Academy of Management Journal, 48: 465-498.

Jaworski, B. J. \& Kohli, A. K. 1993. Market Orientation - Antecedents and Consequences. Journal of Marketing, 57: 53-70.

Jick, T. D. 1979. Mixing Qualitative and Quantitative Methods - Triangulation in Action.

Administrative Science Quarterly, 24: 602-611.

Joshi, A. W. \& Sharma, S. 2004. Customer knowledge development: Antecedents and impact on new product performance. Journal of Marketing, 68: 47-59.

Kahn, B. E. 1998. Dynamic relationships with customers: High-variety strategies. Journal of the Academy of Marketing Science, 26: 45-53.

Kale, P., Singh, H., \& Perlmutter, H. 2000. Learning and protection of proprietary assets in strategic alliances: Building relational capital. Strategic Management Journal, 21: 217-237.

Kaplan, S. 2008. Cognition, Capabilities \& Incentives: Assessing Firm Response to the Fiber-Optic Revolution. Academy of Management Journal, 51.

Kaplan, S. \& Henderson, R. 2005. Inertia and incentives: Bridging organizational economics and organizational theory. Organization Science, 16: 509-521.

Kaplan, S. \& Tripsas, M. 2008. Thinking about technology: Applying a cognitive lens to technical change. Research Policy, 37: 790-805.

Karlsson, C., Nellore, R., \& Soderquist, K. 1998. Black box engineering: Redefining the role of product specifications. Journal of Product Innovation Management, 15: 534-549.

Katila, R., Rosenberger, J. D., \& Eisenhardt, K. M. 2008. Swimming with Sharks: Technology Ventures, Defense Mechanisms and Corporate Relationships. Administrative Science Quarterly, 53: 295-332. Kendall, S. \& Teicher, J. 2000. Residential open building: Taylor \& Francis.

Kim, T. Y., Oh, H., \& Swaminathan, A. 2006. Framing interorganizational network change: A network inertia perspective. Academy of Management Review, 31: 704-720.

Kline, R. B. 2004. Principles and practice of structural equation modeling (2nd ed.). New York: The Guilford Press.

Kogut, B. 1988. Joint Ventures - Theoretical and Empirical-Perspectives. Strategic Management Journal, 9: 319-332.

Kogut, B. 1989. The Stability of Joint Ventures - Reciprocity and Competitive Rivalry. Journal of Industrial Economics, 38: 183-198.

Krishnan, R., Martin, X., \& Noorderhaven, N. G. 2006. When does trust matter to alliance performance? Academy of Management Journal, 49: 894-917.

Krishnan, V. \& Ulrich, K. T. 2001. Product development decisions: A review of the literature.

Management Science, 47: 1-21.

Langlois, R. N. 2002. Modularity in technology and organization. Journal of Economic Behavior \& Organization, 49: 19-37.

Langlois, R. N. 2003. The vanishing hand: the changing dynamics of industrial capitalism. Industrial Corporate Change, 12: 351-385.

Langlois, R. N. \& Robertson, P. L. 1992. Networks and Innovation in a Modular System - Lessons from the Microcomputer and Stereo Component Industries. Research Policy, 21: 297-313.

Lawrence, P. R. \& Lorsch, J. W. 1967. Differentiation and Integration in Complex Organizations.

Administrative Science Quarterly, 12: 1-47.

Leonard-Barton, D. 1992. Core Capabilities and Core Rigidities - a Paradox in Managing New Product Development. Strategic Management Journal, 13: 111-125.

Levin, D. Z. \& Cross, R. 2004. The strength of weak ties you can trust: The mediating role of trust in effective knowledge transfer. Management Science, 50: 1477-1490. 
Levinthal, D. A. \& Warglien, M. 1999. Landscape design: Designing for local action in complex worlds. Organization Science, 10: 342-357.

Levitt, B. \& March, J. G. 1988. Organizational Learning. Annual Review of Sociology, 14: 319-340.

Li, D., Eden, L., Hitt, M. A., \& Ireland, R. D. 2008. Friends, acquaintances, or strangers? Partner selection in R\&D alliances. Academy of Management Journal, 51: 315-334.

Li, H. Y. \& Atuahene-Gima, K. 2001. Product innovation strategy and the performance of new technology ventures in China. Academy of Management Journal, 44: 1123-1134.

Littler, D., Leverick, F., \& Bruce, M. 1995. Factors Affecting the Process of Collaborative Product

Development - a Study of Uk Manufacturers of Information and Communications Technology

Products. Journal of Product Innovation Management, 12: 16-32.

London, K. A. \& Kenley, R. 2001. Industrial organisation of supply chains in a small isolated

construction market. Construction Management and Economics, 19: 777-788.

MacDuffie, J. P., Sethuraman, K., \& Fisher, M. L. 1996. Product variety and manufacturing performance: evidence from the international automotive assembly plant study. Management Science, 42: 350-369.

March, J. G. 1991. Exploration and Exploitation in Organizational Learning. Organization Science, 2. Marsden, P. V. 1990. Network Data and Measurement. Annual Review of Sociology, 16: 435-463.

Marsden, P. V. 2002. Egocentric and sociocentric measures of network centrality. Social Networks, 24: 407-422.

Marsden, P. V. \& Campbell, K. E. 1984. Measuring Tie Strength. Social Forces, 63: 482-501.

Martin, M. V. \& Ishii, K. 2002. Design for variety: developing standardized and modularized product platform architectures. Research in Engineering Design-Theory Applications and Concurrent

Engineering, 13: 213-235.

Meyer, M. H. \& Utterback, J. M. 1993. The Product Family and the Dynamics of Core Capability. Sloan Management Review, 34: 29-47.

Meyer, M. H. \& Lehnerd, A. P. 1997. The power of product platforms: building value and cost leadership: Free Pr.

Meyer, M. H., Tertzakian, P., \& Utterback, J. M. 1997. Metrics for managing research and development in the context of the product family. Management Science, 43: 88-111.

Miles, R. E. \& Snow, C. 1978. Organizational strategy, structure and process: New York: McGraw-Hill. Monteverde, K. 1995. Technical dialog as an incentive for vertical integration in the semiconductor industry. Management Science, 41: 1624-1638.

Moreno, J. L. 1943. Sociometry and the Cultural Order: Beacon House.

Morris, C. R. \& Ferguson, C. H. 1993. How Architecture Wins Technology Wars. Harvard Business

Review, 71: 86-96.

Muffato, M. \& Roveda, M. 2000. Developing product platforms: analysis of the development process. Technovation, 20: 617-630.

Nahapiet, J. \& Ghoshal, S. 1998. Social capital, intellectual capital, and the organizational advantage. Academy of Management Review, 23: 242-266.

Netemeyer, R. G., Bearden, W. O., \& Sharma, S. 2003. Scaling Procedures: Issues and Applications Sage Publications, Inc.

Noguchi, M. 2003. The effect of the quality-oriented production approach on the delivery of prefabricated homes in Japan. Journal of Housing and the Built Environment, 18: 353-364. Novak, S. \& Eppinger, S. D. 2001. Sourcing by design: Product complexity and the supply chain. Management Science, 47: 189-204.

Nowak, M. A. 2006. Five rules for the evolution of cooperation. Science, 314: 1560-1563. Obstfeld, D. 2005. Social networks, the Tertius lungens and orientation involvement in innovation. Administrative Science Quarterly, 50: 100-130.

Orlikowski, W. J. \& Gash, D. C. 1994. Technological Frames - Making Sense of Information Technology in Organizations. Acm Transactions on Information Systems, 12: 174-207. 
Orton, J. D. \& Weick, K. E. 1990. Loosely Coupled Systems - a Reconceptualization. Academy of Management Review, 15: 203-223.

Ozaki, R. 2003. Customer-focused approaches to innovation in house building. Construction Management \& Economics, 21: 557-564.

Padula, G. 2008. Enhancing the innovation performance of firms by balancing cohesiveness and bridging ties. Long Range Planning, 41: 395-419.

Parnas, D. L. 1972. Criteria to Be Used in Decomposing Systems into Modules. Communications of the Acm, 15: 1053-\&.

Pimmler, T. U. \& Eppinger, S. D. 1994. Integration Analysis of Product Decompositions. Paper presented at the Design Theory and Methodology - DTM

Podsakoff, P. M. \& Organ, D. W. 1986. Self-Reports in Organizational Research - Problems and Prospects. Journal of Management, 12: 531-544.

Podsakoff, P. M., MacKenzie, S. B., Lee, J. Y., \& Podsakoff, N. P. 2003. Common method biases in behavioral research: A critical review of the literature and recommended remedies. Journal of Applied Psychology, 88: 879-903.

Porter, M. E. 1985. Competitive advantage: Free Press New York.

Puranam, P., Singh, H., \& Chaudhuri, S. 2009. Integrating Acquired Capabilities: When Structural Integration is (Un) Necessary, Organization Science, Vol. 20: 313-328.

Randall, T. \& Ulrich, K. 2001. Product variety, supply chain structure, and firm performance: Analysis of the US bicycle industry. Management Science, 47: 1588-1604.

Remkes, J. W. \& Pronk, J. P. 2000. Nota Wonen. Mensen, wensen, wonen. In VROM (Ed.). Den Haag. Rindfleisch, A. \& Moorman, C. 2001. The acquisition and utilization of information in new product alliances: A strength-of-ties perspective. Journal of Marketing, 65: 1-18.

Ring, P. S. \& Vandeven, A. H. 1994. Developmental Processes of Cooperative Interorganizational Relationships. Academy of Management Review, 19: 90-118.

Ro, Y. K., Liker, J. K., \& Fixson, S. K. 2007. Modularity as a strategy for supply chain coordination: The case of US auto. leee Transactions on Engineering Management, 54: 172-189.

Robertson, D. \& Ulrich, K. 1998. Planning for product platforms. Sloan Management Review, 39: 19+ .

Robertson, P. L. \& Langlois, R. N. 1995. Innovation, Networks, and Vertical Integration. Research

Policy, 24: 543-562.

Robson, M. J., Katsikeas, C. S., \& Bello, D. C. 2008. Drivers and performance outcomes of trust in international strategic alliances: The role of organizational complexity. Organization Science, 19: 647-665.

Rossi, P. H. \& Nock, S. L. 1982. Measuring social judgments: The factorial survey approach: Sage Publications, Inc.

Saaty, T. L. \& Vargas, L. G. 1982. The Logic of Priorities, Applications in Business, Energy, Health, and Transportation. Boston: Kluwer Nijhof Publishing.

Salvador, F., Forza, C., \& Rungtusanatham, M. 2002. Modularity, product variety, production volume, and component sourcing: theorizing beyond generic prescriptions. Journal of Operations

Management, 20: 549-575.

Sanchez, R. 2000. Modular architectures, knowledge assets and organizational learning: new management processes for product creation. International Journal of Technology Management, 19: 610-629.

Sanchez, R. \& Mahoney, J. T. 1996. Modularity, flexibility, and knowledge management in product and organization design. Strategic Management Journal, 17: 63-76.

Sanderson, S. \& Uzumeri, M. 1995. Managing Product Families - the Case of the Sony-Walkman.

Research Policy, 24: 761-782.

Schilling, M. A. 2000. Toward a general modular systems theory and its application to interfirm product modularity. Academy of Management Review, 25: 312-334. 
Schilling, M. A. \& Steensma, H. K. 2001. The use of modular organizational forms: An industry-level analysis. Academy of Management Journal, 44: 1149-1168.

Schumpeter, J. A. \& Opie, R. 1934. The theory of economic development: Springer.

Simon, H. A. 1962. The architecture of complexity. Proceedings of the American Philosophical

Society: 467-482.

Simon, H. A. 1993. Altruism and Economics. American Economic Review, 83: 156-161.

Simpson, T. W., Siddique, Z., \& Jiao, J. 2006. Platform-based product family development,

introduction and overview. New York: Springer Science + Business Media.

Sinha, K. K. \& Van de Ven, A. H. 2005. Designing work within and between organizations.

Organization Science, 16: 389-408.

Sitkin, S. B. \& Pablo, A. L. 1992. Reconceptualizing the Determinants of Risk Behavior. Academy of Management Review, 17: 9-38.

Smith, W. K. \& Tushman, M. L. 2005. Managing strategic contradictions: A top management model for managing innovation streams. Organization Science, 16: 522-536.

Sobrero, M. \& Roberts, E. B. 2001. The trade-off between efficiency and learning in interorganizational relationships for product development. Management Science, 47: 493-511.

Song, L. Z., Song, M., \& Di Benedetto, C. A. 2009. A Staged Service Innovation Model. Decision Sciences, 40: 571-599.

Song, X. M. \& Parry, M. E. 1997. The determinants of Japanese new product successes. Journal of Marketing Research, 34: 64-76.

Sosa, M. E., Eppinger, S. D., \& Rowles, C. M. 2003. Identifying modular and integrative systems and their impact on design team interactions. Journal of Mechanical Design, 125: 240-252.

Sosa, M. E., Eppinger, S. D., \& Rowles, C. M. 2004. The misalignment of product architecture and organizational structure in complex product development. Management Science, 50: 1674-1689. Spector, P. E. 2006. Method variance in organizational research - Truth or urban legend? Organizational Research Methods, 9: 221-232.

Staudenmayer, N., Tripsas, M., \& Tucci, C. L. 2005. Interfirm modularity and its implications for product development. Journal of Product Innovation Management, 22: 303-321.

Storer, C. E., Holmen, E., \& Pedersen, A. C. 2003. Exploration of customer horizons to measure understanding of netchains. Supply Chain Management-an International Journal, 8: 455-466.

Sturgeon, T. J. 2002. Modular production networks: a new American model of industrial organization. Industrial and Corporate Change, 11: 451-496.

Suchman, M. C. 1995. Managing Legitimacy - Strategic and Institutional Approaches. Academy of Management Review, 20: 571-610.

Teece, D. J. 1986. Profiting from Technological Innovation - Implications for Integration, Collaboration, Licensing and Public-Policy. Research Policy, 15: 285-305.

Thompson, J. D. 1967. Organizations in action. New York: McGrawhill.

Tiwana, A. 2008a. Do bridging ties complement strong ties? An empirical examination of alliance ambidexterity. Strategic Management Journal, 29: 251-272.

Tiwana, A. 2008b. Does technological modularity substitute for control? A study of alliance performance in software outsourcing. Strategic Management Journal, 29: 769-780.

Tortoriello, M. \& Krackhardt, D. 2010. Activating Cross-Boundary Knowledge: The Role of Simmelian Ties in the Generation of Innovations. Academy of Management Journal, 53: 167-181.

Tripsas, M. \& Gavetti, G. 2000. Capabilities, cognition, and inertia: Evidence from digital imaging.

Strategic Management Journal, 21: 1147-1161.

Tsai, W. P. \& Ghoshal, S. 1998. Social capital and value creation: The role of intrafirm networks.

Academy of Management Journal, 41: 464-476.

Tseng, M. M. \& Piller, F. T. 2003. The customer centric enterprise: advances in mass customization and personalizaton: Springer Verlag. 
Tushman, M. L. \& Anderson, P. 1986. Technological Discontinuities and Organizational Environments. Administrative Science Quarterly, 31: 439-465.

Ulrich, K. T. 1995. The Role of Product Architecture in the Manufacturing Firm. Research Policy, 24: 419-440.

Ulrich, K. T. \& Ellison, D. J. 2005. Beyond make-buy: Internalization and integration of design and production. Production and Operations Management, 14: 315-330.

Uzzi, B. 1997. Social structure and competition in interfirm networks: The paradox of embeddedness.

Administrative Science Quarterly, 42: 35-67.

Van den Thillart, C. C. A. M. 2004. Customised Industrialisation in the Residential Sector. Amsterdam SUN Publishers.

Veenstra, V., Halman, J. I. M., \& Voordijk, J. T. 2006. A Methodology for Developing Product

Platforms in the Specific Setting of the Housing Industry. . Research in Engineering Design, 7: 157173.

Vera, D. \& Crossan, M. 2004. Strategic leadership and organizational learning. Academy of

Management Review, 29: 222-240.

Vonhippel, E. 1990. Task Partitioning - an Innovation Process Variable. Research Policy, 19: 407-418.

Vonhippel, E. 1994. Sticky Information and the Locus of Problem-Solving - Implications for Innovation. Management Science, 40: 429-439.

Voordijk, H., Meijboom, B., \& De Haan, J. 2006. Modularity in supply chains: a multiple case study in the construction industry. . International Journal of Operations and Production Management, 26 : 600-618.

VROM. 2005. Nota Ruimte.

Walker, G. \& Weber, D. 1984. A Transaction Cost Approach to Make-or-Buy Decisions. Administrative Science Quarterly, 29: 373-391.

Wason, K. D., Polonsky, M. J., \& Hyman, M. R. 2002. Designing vignette studies in marketing.

Australasian Marketing Journal, 10: 41-58.

Weick, K. E. 1976. Educational Organizations as Loosely Coupled Systems. Administrative Science Quarterly, 21: 1-19.

Wolter, C. \& Veloso, F. M. 2008. The effects of innovation on vertical structure: Perspectives on transaction costs and competences. Academy of Management Review, 33: 586-605.

Wolters, M. J. J. 2001. The business of modularity and the modularity of business. Erasmus University Rotterdam.

Wuyts, S. \& Geyskens, I. 2005. The Formation of Buyer-Supplier Relationships: Detailed Contract Drafting and Close Partner Selection. Journal of Marketing, 69: 103-117.

Yin, R. K. 1984. Case study research: Design and methods (Vol. 5). Beverly Hills: Sage.

Yin, R. K. 2003. Case Study Research: Design and Methods: Sage Publications Inc.

Yukl, G. 2009. Leading organizational learning: Reflections on theory and research. Leadership Quarterly, 20: 49-53.

Zollo, M., Reuer, J. J., \& Singh, H. 2002. Interorganizational routines and performance in strategic alliances. Organization Science, 13: 701-713. 


\section{SUMMARY}

To cope with shortening product life cycles due to rapid technological change and fast changing customer demands companies have become increasingly interested in modularizing their products, production processes, and organizational structures (Baldwin \& Clark, 2000; Salvador et al., 2002; Schilling, 2000). The concept of modularity is seen as a key success factor in many markets because it allows a family of differentiated products to be quickly developed and produced at a decreased cost (Ro et al., 2007; Ulrich, 1995). Success stories of modular product platforms include for example Black \& Decker power tools (Meyer \& Utterback, 1993), and Microsoft's Windows (Schilling, 2000). But also low-tech industries, such as the house-building industry, are challenged to more efficiently serve their increasingly dynamic markets. However, to achieve product modularization in such specialized, loosely coupled innovation contexts is an arduous task due to low architectural control on part of the companies involved (Langlois \& Robertson, 1992; Orton \& Weick, 1990). In this research we study the challenges that companies face in the process of developing and adopting modular systems in loosely coupled innovation contexts. We started our research in the house-building industry and we generalized our findings to other industries, including the computer and software, machinery and equipment, and household appliances industries.

The general research problem is formulated as: How to create modular product design rules in the context of loosely coupled organizational networks?

More specifically this research addresses five important questions for companies that plan to architecturally innovate (i.e. modularize their products). Qualitative and quantitative research methods were used in this study. Below we briefly summarize the answers this research provides to the five research questions. 


\section{Chapter 2}

How do potential new home buyers in the Netherlands prioritize the different elements in a house design from the perspective of obtaining a variety of alternative solutions from which to select? And, what is the willingness-to-pay extra for a customized housing proposition? For effective product modularization, companies should first choose their target market and determine customer variety needs per segment (Robertson \& Ulrich, 1998). Our research findings include a priority listing of customer variety needs in housing design. These findings help building developers in decision making about the right balance between the level of variety to be offered versus the need to standardize and produce economically. We found that averagely a customer is willing to pay $€ 23.333$, or $10 \%$ of the sales price, extra for the perfect housing proposition compared to a house that cannot be customized. Additionally we have illustrated the trade-off relationship between customer value and price of a housing proposition. The difference between customer value and price can be used to measure the incentive for the customer to buy. To outperform competitors, it is suggested that housing suppliers could follow a strategy of increasing this difference.

\section{Chapter 3}

What types of supplier relationships are needed to develop and produce a modular housing system successfully? Although the project based nature of the construction industry provides short-term project flexibility, this loose inter-organizational structure impedes innovations that require collective investments that can only be returned over a longer time span. An indepth case study examines a Dutch house-building company that is developing a modular housing system in collaboration with several suppliers. Based on the analysis of ten dyadic contractor-supplier relationships, the alignment between product modules and contractorsupplier relationships is found to be contingent on four drivers: the degree of variety in customer demand, the extent of the required supplier investment, the extent of dependence on supplier knowledge, and the intentions of both the supplier and the buyer in a relationship. The network that appeared to be appropriate for developing and implementing new modular product design rules involves three types of relationships: integrated, quasiintegrated, and non-integrated. Parts with limited variety and which require supplier investment and supplier knowledge seem suited to cooperation at the multi-project level 
with full integration. For parts with a moderate to low demand for variety, and for which moderate supplier investments are needed but no specialized supplier knowledge required, quasi-vertical integration is sufficient. For parts for which it is hard to limit oneself to standard units at the multi-project level, one can still standardize to some extent for houses within a certain project and offer options per house. For parts with a high demand for variety, such as type of kitchen, housing suppliers can best leave the choice to the buyer and procure these parts on a project-by project basis. These results suggest that one-size does not fit all, per product module; companies should evaluate the four antecedents before deciding about the level of organizational integration. We believe that this matching will not only facilitate the development of modular housing systems, but will also maximize business performance.

\section{Chapter 4}

How can companies compensate for organizational loose coupling and inertia during collaborative architectural innovation? Our study of an architectural innovation process provides rich details that highlight (1) the multitude of inertial factors that inhibit innovation and (2) the necessity for managers to apply compensation mechanisms to overcome inertia. For example, we found that traditional ways of organizing housing production reinforce rigid routines that lead to decreased willingness and ability to unlearn previous technology (Dougherty, 1992). Secondly, large heterogeneity in demand decreases the re-use potential of modules. This acted as a disincentive for companies considering investing in the creation of modular interface standards. To compensate for rigid routines, explicit management attention was required to the new interactions across components and functional boundaries (Henderson \& Clark, 1990). Transformational leadership behaviors and experimentation improved the willingness and ability to challenge routines (Smith \& Tushman, 2005; Vera \& Crossan, 2004; Yukl, 2009). Subsequently, this opened people's mind for organizational coupling which was required to solve the issue with heterogeneous customer demands. Thus, in loosely coupled networks companies benefit from cognitive coupling to develop shared beliefs about the technology trajectory, and this precedes organizational coupling (e.g. cooperation at the multi-project level) to solve other inertial factors. We also discuss a model of loose and tight cyclical couplings; this indicates that it is 
important to differentiate between four possible innovation contexts. Chapter 5 and 6 we elaborate on the unique challenges that results from each context for companies that pursue collaborative product innovation.

\section{Chapters 5 and 6}

Do product design rules compensate or complicate collaborative innovation? And, is this relationship contingent upon the type of innovation (i.e. modular or architectural innovation) and on the degree of organizational coupling among partners in the innovation network? Using data from 664 product innovation networks from four different industries in the U.S., these studies examined the impact of different innovation contexts on collaborative innovation performance. The main result presented in chapter 5 and 6 is a typology of innovation contexts. In this typology we frame innovation contexts along two dimensions: the availability of product design rules and the degree of organizational coupling among innovation network partners. We found that each innovation context has unique implications for modular and architectural innovation performance.

Although the implications of loose versus tight organizational coupling and the availability of design rules are discussed in the social network and modularity literature, their simultaneous impact on the performance of modular and architectural innovation has not been studied to date. Our findings show that loose coupling decreases modular innovation performance and design rules improve modular innovation performance. However, surprisingly our findings show that design rules are incomplete substitutes for organizational loose coupling. Modular innovation performance is maximized in tightly coupled innovation networks where design rules are available.

The conventional wisdom suggests that companies benefit more from tight organizational coupling for architectural innovation than they do for modular innovation (Hoetker, 2006). However, against conventional wisdom, our empirical findings reveal that architectural innovation performance is highest when organized in loosely coupled innovation networks where design rules are not available. For architectural innovation in contexts with design rules, it is more effective for a company to work with partners that they have not yet established close and intensive relationships with through previous innovation projects. In addition, companies can best chose to work with other companies that are easy 
to replace, i.e. their skills and resources are not unique, and where relation-specific investments are relatively low at the time of innovation network formation. Furthermore working with partners that share a short history of collaboration also improves architectural innovation performance. Thus, although loose coupling has traditionally been associated with an 'action problem' (Hansen, 1999; Obstfeld, 2005), our empirical findings show that for architectural innovation in contexts with design rules, loose coupling also provides a 'means for action'.

The final chapter provides an overview of the answers we found to our five research questions. Together these answers explain how companies can create modular product design rules in the context of loosely coupled organizational networks. This study shows that for the development and adoption of modular products, companies can best first evaluate the variety needs and willingness to pay extra for a customized solution of customers in their target markets. This helps in determining how to modularize a product system. Next, to overcome the inertial factors that impede architectural innovation (i.e. product modularization), companies depend upon cognitive coupling and organizational coupling. For collaborative product innovation, companies should also carefully evaluate the innovation context in which their innovation project is embedded. Each innovation context, defined by the degree of organizational coupling among innovation network members and the availability of product design rules, has a unique impact on the performance of modular and architectural innovations. Therefore our findings suggest that these key variables should not be studied in isolation. 


\section{ACADEMIC OUTPUT PER CHAPTER}

Each chapter included in this thesis was peer-reviewed. All chapters have been presented at scientific conferences and to practitioners. Final versions of chapter 2 and chapter 3 are published in international refereed journals. Chapter 4,5 and 6 have been submitted to international refereed journals. Below, we provide a brief overview of the exposure our work received per chapter.

Chapter 2 in its final version appeared as Hofman, E., Halman, J. I. M., \& Ion, R. A. 2006. Variation in housing design: Identifying customer preferences. Housing Studies, 21: 929-943. An earlier version was accepted for presentation at the following conferences:

- 6th International Postgraduate Research Conference, Salford University \& TU Delft, International Built \& Human Environment research week, 6-7 april 2006. The relevant reference to the proceeding is Hofman, E., \& Halman, J. I. M. (2006). Variation in housing design: Identifying customer preferences. Proceedings of the 6th International Postgraduate Research Conference, Salford University \& TU Delft, International Built \& Human Environment research week, 6-7 april 2006. In D. Amaratunga, R. Haigh, R. Vrijhoef, M. Hamblett, \& C. van den Broek (Eds.),. (pp. 351-368). Salford, UK: SCRI (ISBN 0 90289662).

- The first Concept House conference. The relevant reference to the proceeding is Hofman, E. and Halman, J.I.M. Identifying Customer Preferences for Housing Projects. In: Eekhout, M. (ed.), Proceedings of Concept House, towards customized industrial housing (2005), Delft University of Technology, Delft, 22 June 2005, pp 111, 125.

Chapter 3 in its final version appeared as Hofman, E., Voordijk, H., \& Halman, J. 2009. Matching supply networks to a modular product architecture in the house-building industry. Building Research and Information, 37: 31-42. An earlier version was accepted for presentation at the following conferences:

- Hofman, E. Halman, J.I.M. and Voordijk J.T. (2007). Proceedings of the 2007 ASCE/CIB Construction Research Congress, Grand Bahama Island, 6-8 May 2007. In Garvin, M. 
Edum-Fotwe, F. Chinowsky, P. (Ed.) Design by sourcing, how to create variety economically (ISBN 0-9707869-1-3). And Hofman, E., Halman, J.I.M. and Voordijk, J.T. Aligning product architecture design and sourcing decisions in the house building industry. Proceedings of ManuBuild $1^{\text {st }}$ International Conference, The transformation of the Industry: Open Building manufacturing, 25-26 April 2007, Rotterdam, the Netherlands.

- Hofman, E., Halman, J.I.M., Voordijk, J.T. (2007) Aligning Product Architecture Design and Sourcing Decisions in the House Building Industry. Proceedings of the 16th annual IPSERA conference - practice makes perfect 1-4 April 2007, Hilton Bath City, Bath, United Kingdom.

Chapter 4 in its earlier version was presented as Hofman, E., Halman, J.I.M. \& Voordijk, J.T. (2008). Architectural innovation in a loosely coupled network, how to compensate for loosecoupling and inertia. In H. Koller, C. Herstatt \& T. Teichert (Eds.), $15^{\text {th }}$ EIASM international product development management conference, 30 June - 1 July 2008, Hamburg, Germany Vol. 2008. EIASM international product development management conference, (ISSN 19987374). A revised version of this article is part of this thesis and is ready to be submitted to an international journal.

Chapter 5 and 6 in their earlier versions were presented at the following conferences:

- The Academy of management Conference, august 9- 10 2010. The relevant reference is: Hofman, E., Halman, J.I.M., X.M. Song (2010). Innovation in loosely coupled networks, design rules as compensations or complications?

- Tilburg Conference on Innovation, (2010). The relevant reference is: Hofman, E., Halman, J.I.M., X.M. Song (2010). Product innovation networks, do design rules compensate or complicate innovation? Revised versions of chapters 5 and 6 are submitted to international refereed journals.

\section{Award}

Best scientific paper Award (2006) at $6^{\text {th }}$ international research conference in the built and human environment, 6-7 April 2006, Delft, The Netherlands, $1^{\text {st }}$ prize. 


\section{ABOUT THE AUTHOR}

Erwin Hofman (Utrecht, 1980) received his M.Sc. degree in Industrial Engineering and Management from the University of Twente, Enschede, The Netherlands. Currently Erwin holds a position as assistant professor at the School of Management and Governance at the same university. His research interests are in the areas of: managing collaborative innovation, strategic management, and the concept of modular products, services and organizations as a new method for organizing development and production within and between companies. His research is theoretical and empirical alike and he prefers to combine qualitative and quantitative research methods. During his $\mathrm{PhD}$ research Erwin focused on understanding architectural and modular innovation in loosely coupled innovation networks. His early research findings have been published in several international journals, including Housing studies and Building research and Information. His later work that has been presented at diverse international conferences such as the Academy of Management, the International Product Development Management Conference and the Tilburg Conference on Innovation and has been submitted to international management journals. The research findings are used by companies who are in the process of developing modular products or services that will allow them to efficiently produce highly customized products or services. For this purpose, Erwin also often give talks at major industry events, and helps business people in areas such as product or service modularization and new business development. At the University of Twente Erwin is responsible for teaching the subject of organization theory and design, and he teaches innovation management to an executive MBA audience.

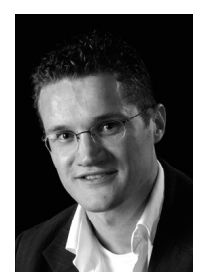

